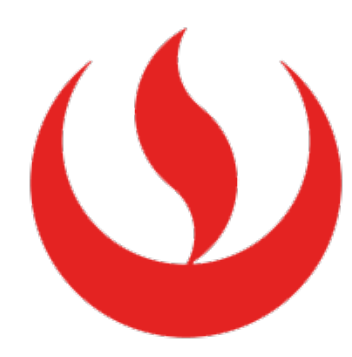

UNIVERSIDAD PERUANA DE CIENCIAS APLICADAS

Facultad de Negocios

CARRERA DE ADMINISTRACIÓN DE EMPRESAS

\title{
¡ÑAM! BUSCADOR DE FOOD TRUCKS
}

\author{
TRABAJO DE INVESTIGACIÓN \\ Para optar el grado académico de bachiller en Administración de empresas
}

Autores:

Erika Ivette Morales Benites - Orcid Id 0000-0003-0472-8624

Andrea Patricia Portal Laguna - Orcid Id 0000-0003-0641-6034

Aurelio Silvion Ramirez Franco - Orcid Id 0000-0002-9456-9403

Lizbeth Rivera Salhuana - Orcid Id 0000-0002-8701-088X

Asesor:

Lorena Verónica Alfaro Coronel - 0000-0002-6867-9297

Lima, 10 de julio del 2018 
A nuestras familias quienes han sido parte fundamental para desarrollar esta tesis, ellos nos dieron grandes enseñanzas. A nuestras amistades que nos apoyaron durante el desarrollo de esta tesis. A nuestra asesora y profesora Lorena que nos brindó su apoyo y conocimientos. 


\section{RESUMEN}

El proyecto ¡ÑAM! Buscador de Food Trucks se ha mostrado viable de acuerdo a la investigación que el equipo de trabajo realizó a través de un estudio de mercado centrado en consumidores de alimentos como comida rápida y de aquellos que la ofrecen bajo la modalidad de Food Truck.

El servicio de Food Trucks está en crecimiento e incluso algunas municipalidades han destinado zonas en las cuales varias categorías se reúnen y los comenzales pueden encontrar una especie de patio de comidas.

¡Ñam! Buscador de Food Trucks será un aplicativo que reunirá información de todos los Food Trucks disponbiles en la ciudad e indicará al usuario cuál es el más cercano a su ubicación y el tipo de comida que podrá encontrar, incluso si el Food Truck se ha movido de lugar.

¡Ñam! Buscador de Food Trucks requiere una inversión inicial de S/ 142 761, la cual se finaciará el $28 \%$ con aporte de los cuatro socios iniciales y el saldo de $72 \%$ será financiado mediante un instrumento de renta fija tal como un bono a largo plazo, el cual se pagará en cinco años.

\section{Palabras clave:}

Food Trucks, crecimiento, ubicación, cercano, reunirá. 


\begin{abstract}
¡ÑAM! Finding Food Trucks project has been shown achiviable according to the research that the team carried out through a market study focused on food consumers such as fast food and those who offer it under the Food Truck modality.

The Food Trucks service is growing and even some municipalities have allocated areas in which several categories meet and users can find a kind of food court.

¡ÑAM! Finding Food Trucks will be an application that will gather information on all available Food Trucks in the city and will indicate to users which is the closest to their location and the type of food they can find, even if the Food Truck has moved.

¡ÑAM! Finding Food Trucks search engine requires an initial investment of S / 142 761, which will be financed $28 \%$ with the contribution of the four initial partners and the balance of $72 \%$ will be financed through a fixed income instrument such as a long-term bond, which will be paid in five years
\end{abstract}

\title{
Key Words:
}

Food Trucks, growing, location, near, will gather. 
TABLA DE CONTENIDO

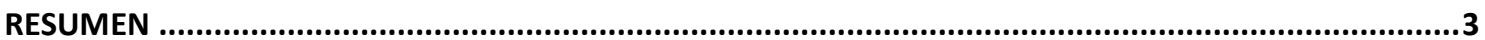

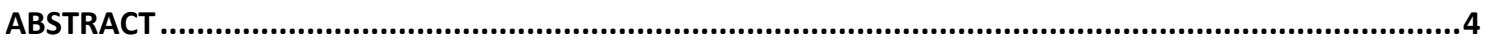

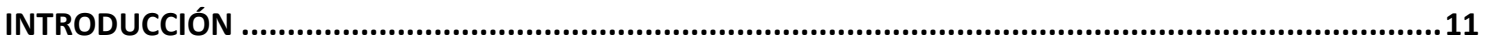

CÁPITULO 1: ASPECTOS GENERALES DEL NEGOCIO ................................................................ 12

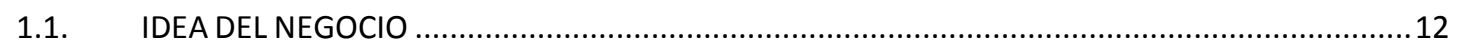

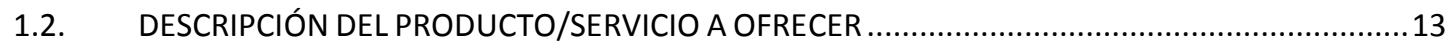

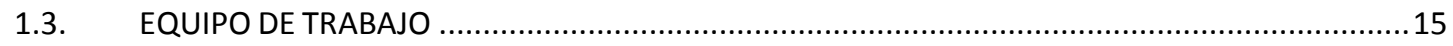

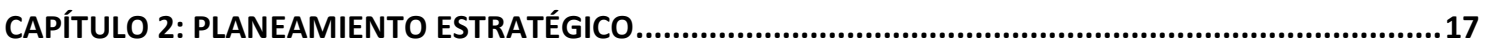

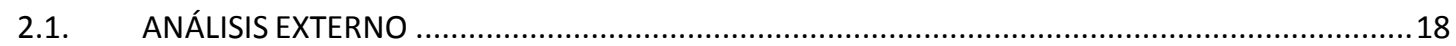

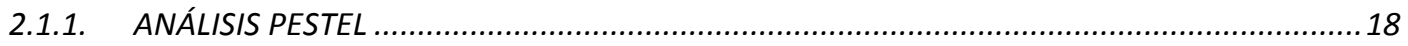

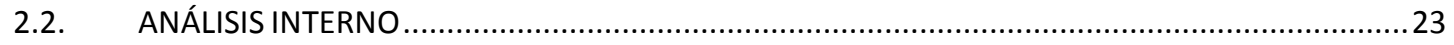

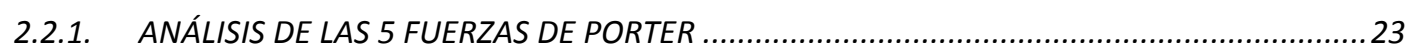

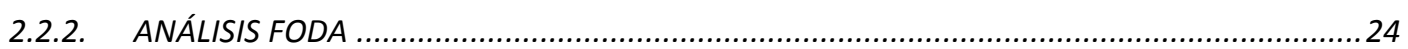

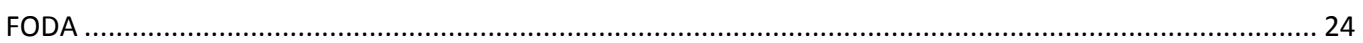

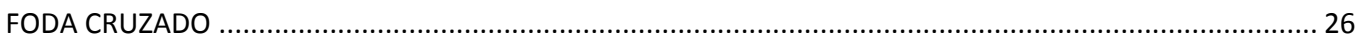

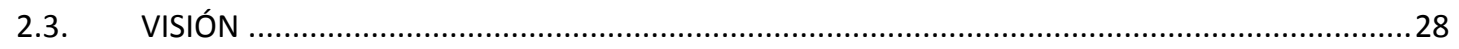

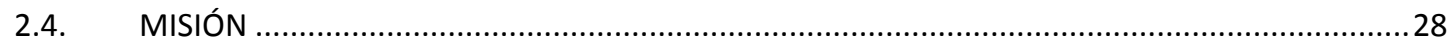

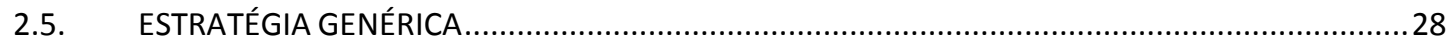

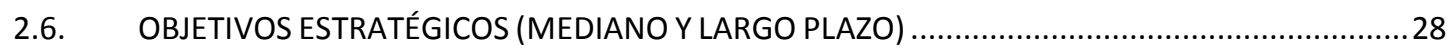

CAPÍTULO 3: INVESTIGACIÓN/CONVALIDACIÓN DE MERCADO .........................................................30

3.1. DISEÑO METODOLÓGICO DE LA INVESTIGACION / METODOLOGIA DE VALIDACION DE

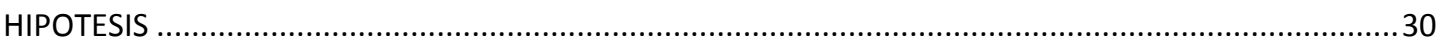

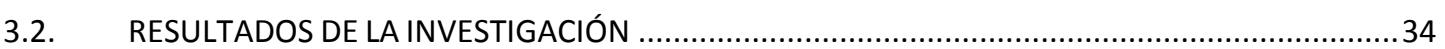

3.3. INFORME FINAL: ELABORACIÓN DE TENDENCIAS, PATRONES Y CONCLUSIONES....................51

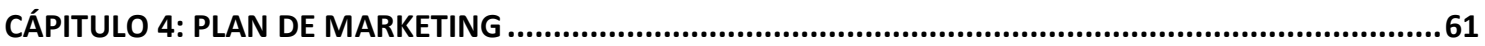

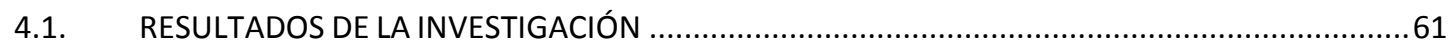

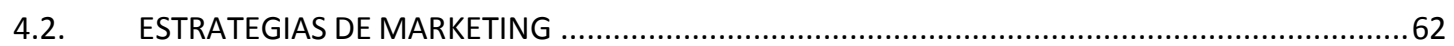

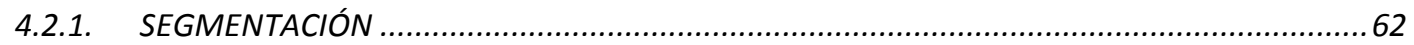

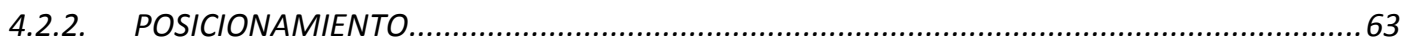

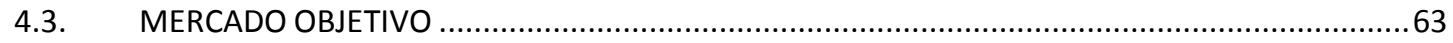

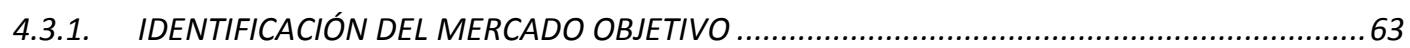

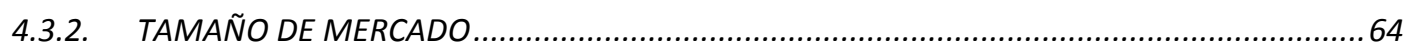

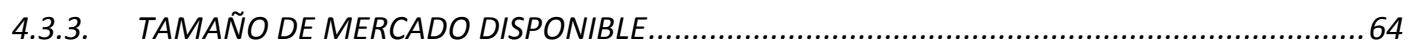

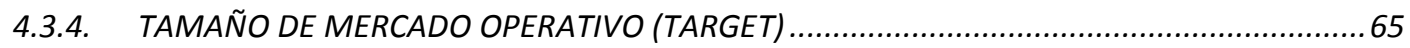




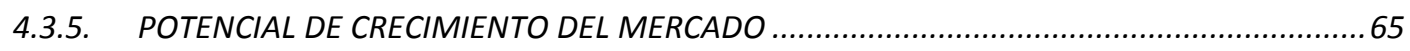

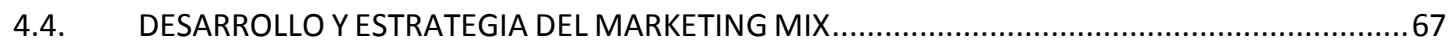

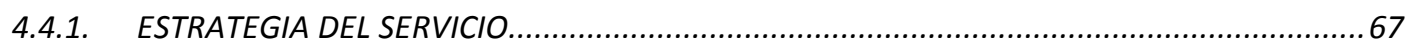

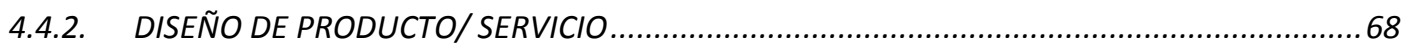

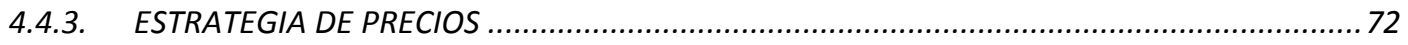

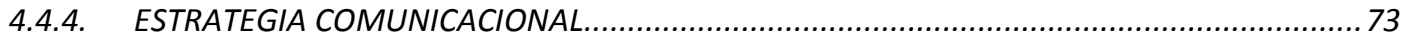

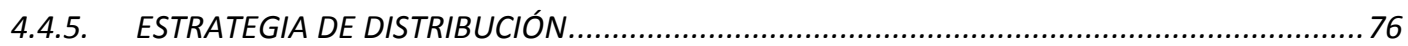

4.5. PLAN DE VENTAS Y PROYECCIÓN DE LA DEMANDA ........................................................... 76

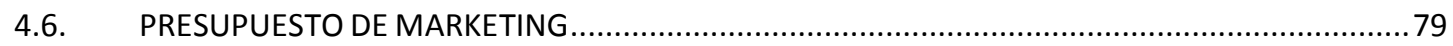

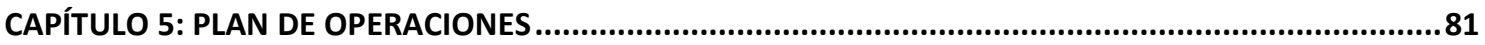

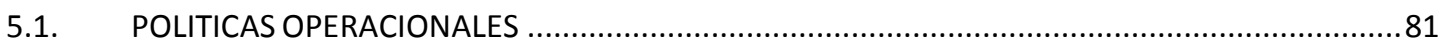

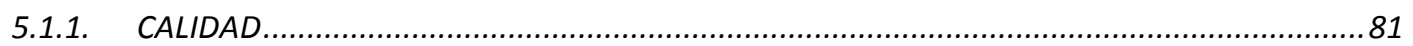

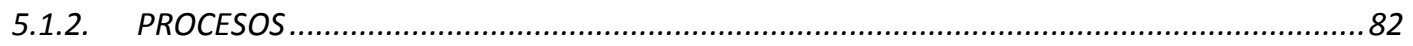

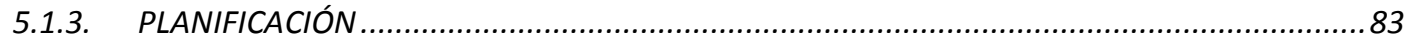

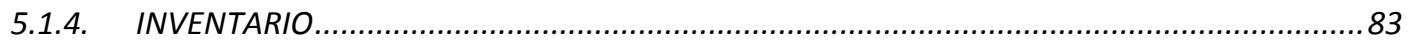

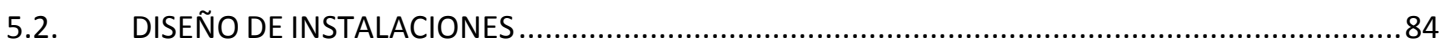

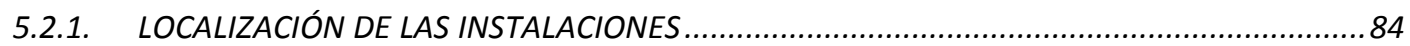

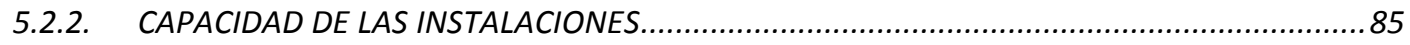

5.2.3. DISTRIBUCIÓN DE LAS INSTALACIONES .............................................................. 86

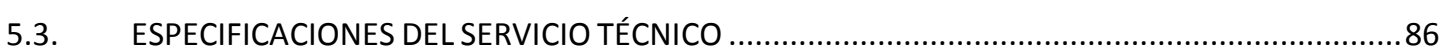

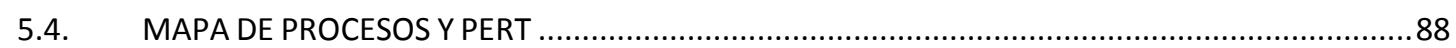

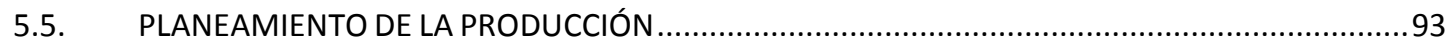

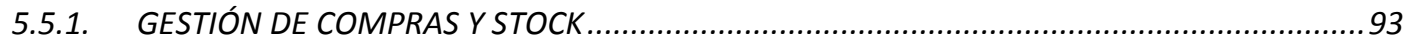

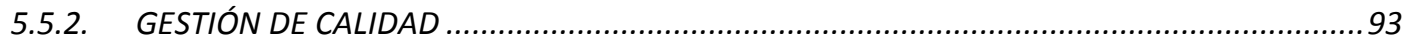

5.6. INVERSIÓN DE ACTIVOS FIJOS VINCULADOS AL PROCESO PRODUCTIVO ..............................95

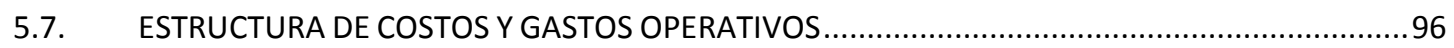

CAPÍTULO 6: ESTRUCTURA ORGANIZACIONAL Y RECURSOS HUMANOS ........................................98

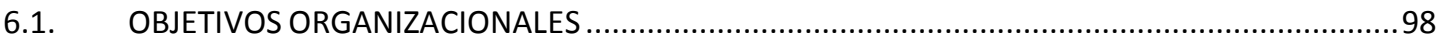

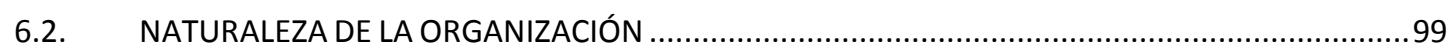

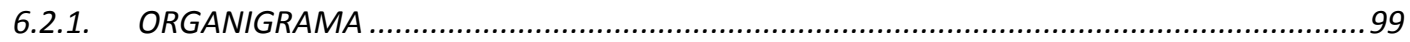

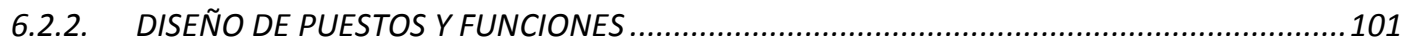

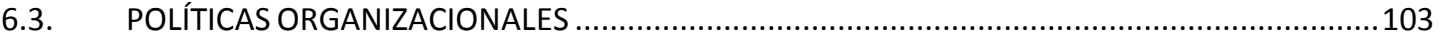

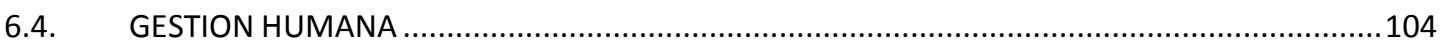

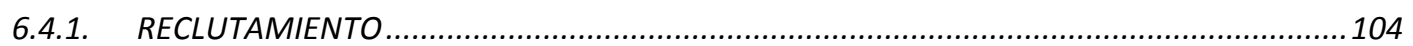

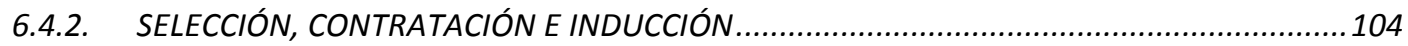

6.4.3. CAPACITACIONES. DESEMPEÑO Y EVALUACIÓN DE DESEMPEÑO................................ 105

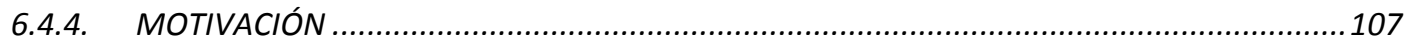


6.4.5. SISTEMA DE REMUNERACIÓN ............................................................................. 107

6.5. ESTRUCTURA DE GASTOS DE RECURSOS HUMANOS .................................................110

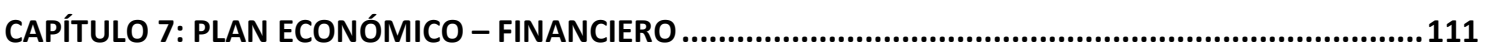

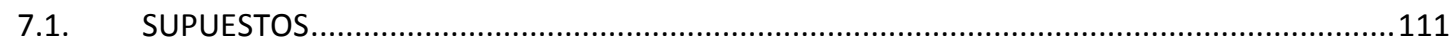

7.2. INVERSIÓN EN ACTIVOS (FIJOS E INTANGIBLE) Y DEPRECIACIÓN.........................................113

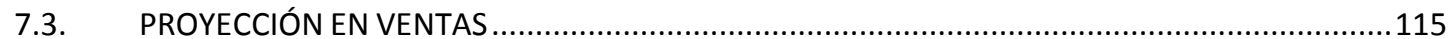

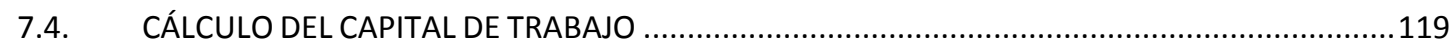

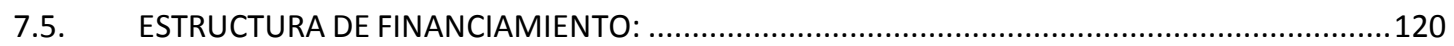

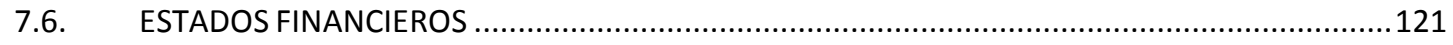

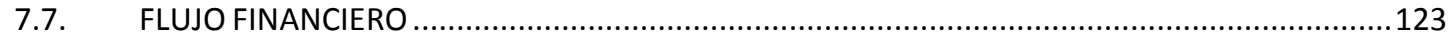

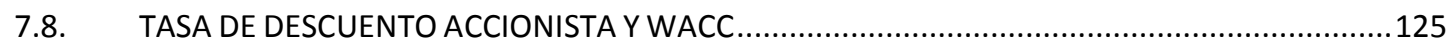

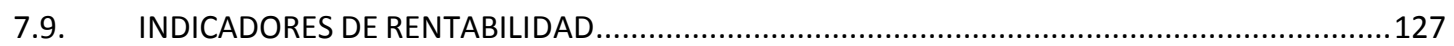

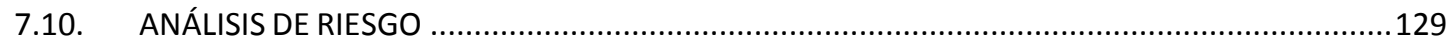

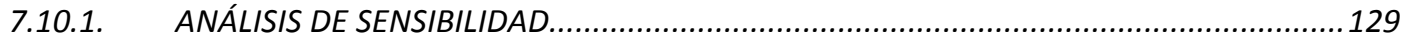

7.10.2. ANALISIS POR ESCENARIOS (POR VARIABLES) ..................................................... 131

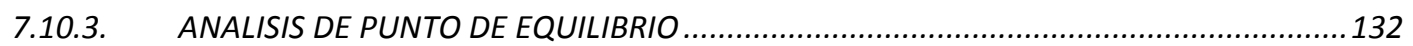

7.10.4. PRINCIPALES RIESGOS DEL PROYECTO (CUALITATIVOS) ........................................... 134

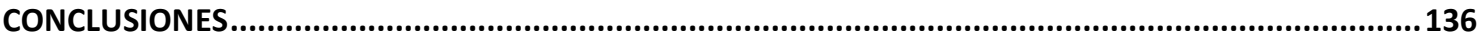

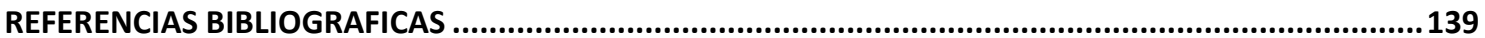

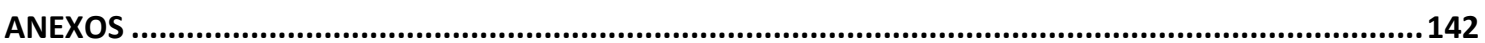

\section{Índice de ilustraciones}

Ilustración 1: Modelo de Negocios ¡Ñam! Buscador de Food Trucks ............................ 17

Ilustración 2: Entrevista Camiones de Venta de Comida al Paso en Lima ..................... 34

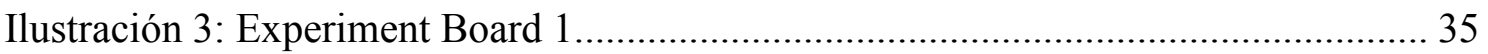

Ilustración 4: Entrevista Consumidores de Comida Rápida en Lima y Provincia .......... 36

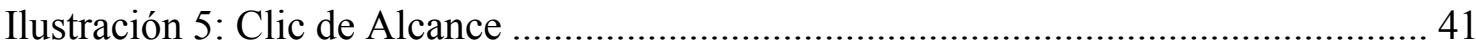

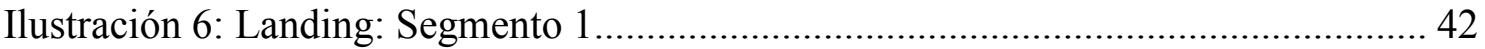

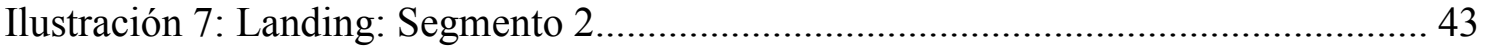

Ilustración 8: Captación De Prospectos............................................................................... 43

Ilustración 9: Camiones de venta de comida al paso - Métricas ..................................... 44

Ilustración 10: Camiones de venta de comida al paso - Métricas .................................. 44

Ilustración 11: Camiones de venta de comida al paso - Métricas ................................. 45

Ilustración 12: Camiones de venta de comida al paso - Métricas .................................. 45 
Ilustración 13: Consumidores de comida rápida en Lima y provincias ......................... 46

Ilustración 14: Consumidores de comida rápida en Lima y provincias ......................... 46

Ilustración 15: Consumidores de comida rápida en Lima y provincias ......................... 47

Ilustración 16: Clientes Y Food Trucks Que Ingresaron Y Dieron Clic ........................ 47

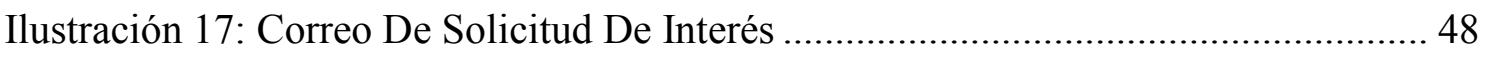

Ilustración 18: Camiones de venta de comida al paso ................................................... 49

Ilustración 19: Consumidores de comida rápida en Lima y provincias. ..........................50

Ilustración 20: Mapa De Empatía - Food Trucks ……................................................... 52

Ilustración 21: Mapa De Empatía - Clientes.................................................................. 52

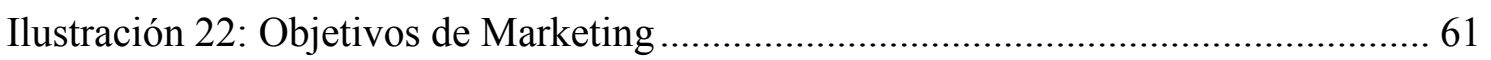

Ilustración 23 : Población por Edad y Según Nivel Socioeconómico 2017.................... 64

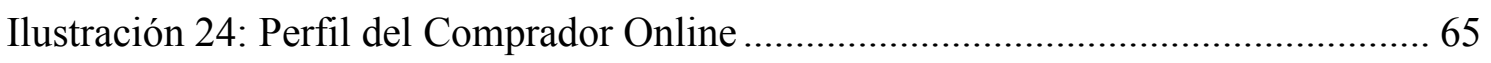

Ilustración 25: Participación de Servicios del E-Commerce en el 2017 ......................... 66

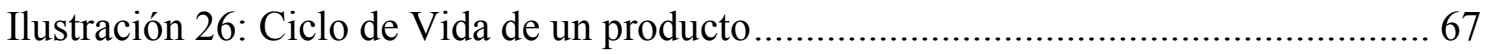

Ilustración 27: Matriz Ansoff ¡Ñam! Buscador de Food Trucks...................................... 68

Ilustración 28: Propuesta Visualización APP - Móvil...................................................... 69

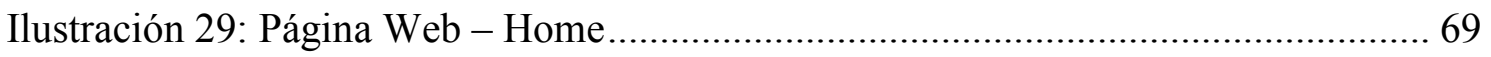

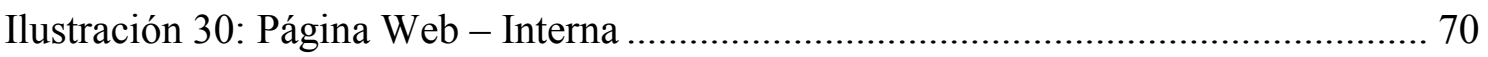

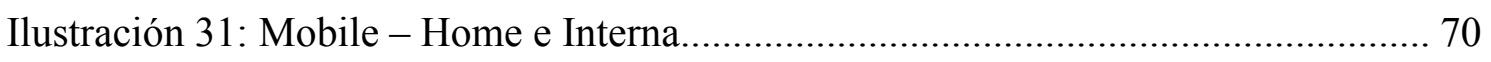

Ilustración 32: Logo ¡Ñam! Buscador de Food Trucks .................................................. 71

Ilustración 33: Publicidad en redes sociales .................................................................. 74

Ilustración 34: Rollscreen en patios de Food Trucks ...................................................... 74

Ilustración 35: Publicidad-afiches y volantes en el patio de comidas Food Trucks....... 75

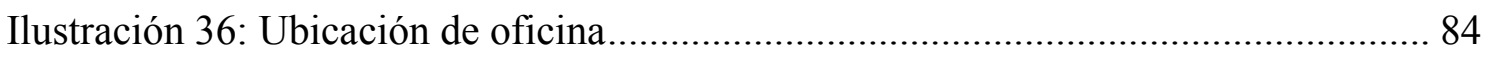

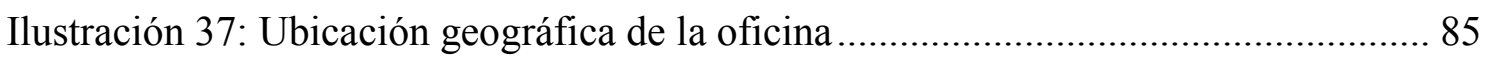

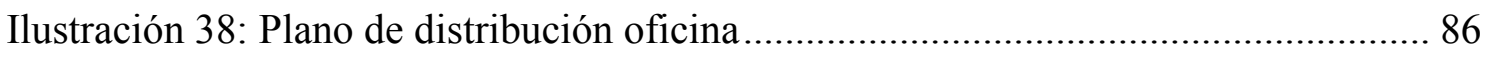

Ilustración 39: Navegación del usuario en la aplicación. ............................................... 88

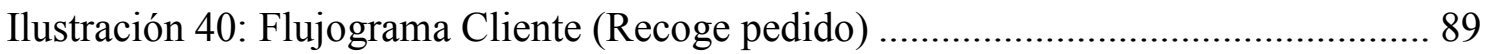

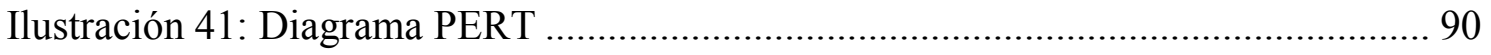

Ilustración 42: Paso 1 Registro Usuario y Contraseña................................................ 91

Ilustración 43: Paso 2 Ingresa detalle y lugar de la búsqueda...................................... 91

Ilustración 44: Paso 3 Resultado de búsqueda y elección de local ............................... 91

Ilustración 45: Paso 4 Información del Producto y confirmación del pedido ................. 92

Ilustración 46: Paso 5 Solicitud de tarjeta, cálculo de tarifa y pago.............................. 92 


\section{Índice de tablas}

Tabla 1: Desarrollo de Análisis Pestel - ¡Ñam! Buscador de Food Trucks..................... 18

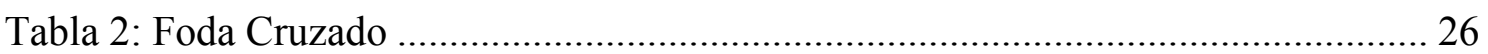

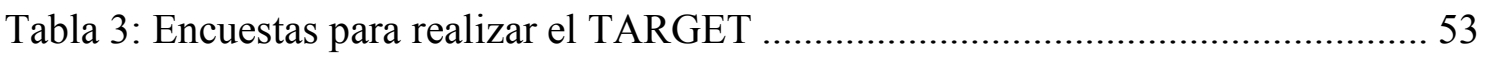

Tabla 4: Análisis de los resultados de la encuesta......................................................... 54

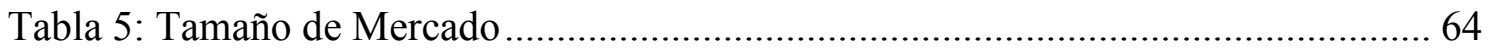

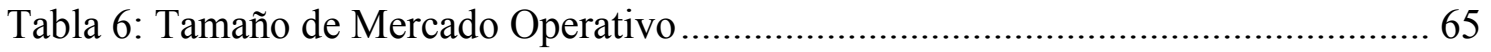

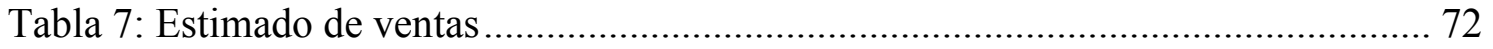

Tabla 8: Cantidad de unidades vendidas. .................................................................. 76

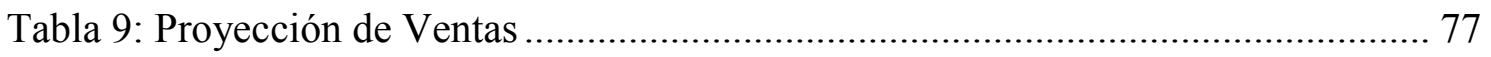

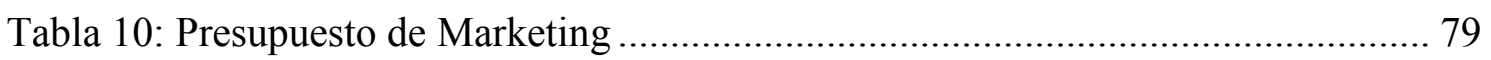

Tabla 11: Actividades del Proyecto para el Diagrama PERT ….................................. 90

Tabla 12: Inversión en Activos Fijos vinculados al Costo ............................................. 95

Tabla 13: Gastos vinculados al Costo y Gastos Operativos .......................................... 96

Tabla 14: Ficha de evaluación de desempeño ............................................................. 106

Tabla 15: Sistema Tributario Microempresas ............................................................... 107

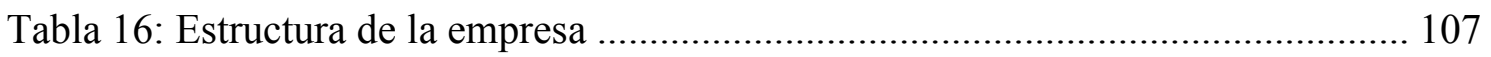

Tabla 17: Régimen Laboral para una Microempresa ................................................ 108

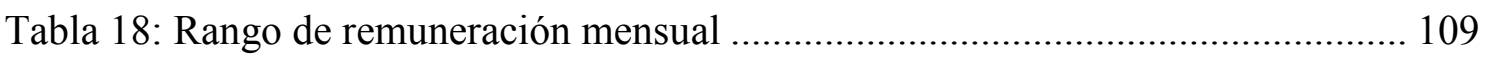

Tabla 19: Planilla Correspondiente Al Primer Año ..................................................... 110

Tabla 20: Inversión en Activos Fijos Vinculados al Costo ......................................... 113

Tabla 21: Inversión en Activos Fijos vinculados ........................................................ 114

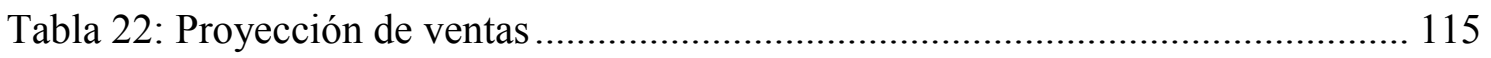

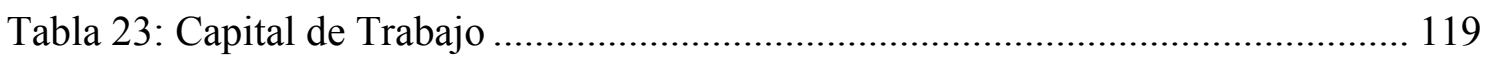

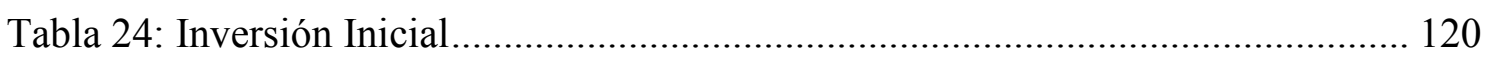

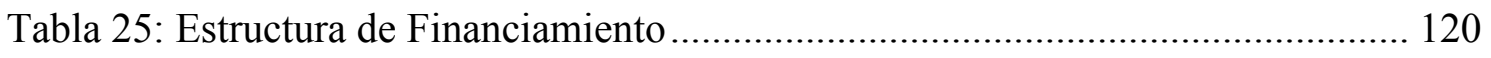

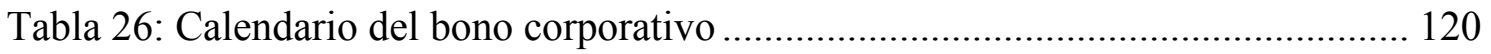

Tabla 27: Estados Financieros Anuales (En nuevos soles) ....................................... 121

Tabla 28: Estado de Situación Financiera .................................................................... 122

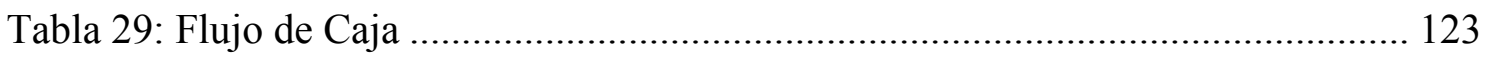

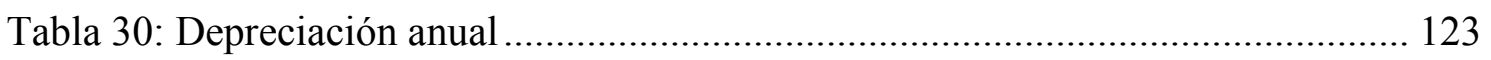




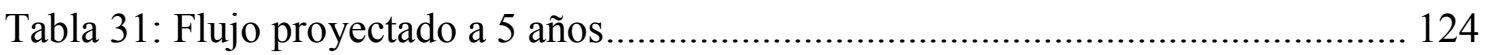

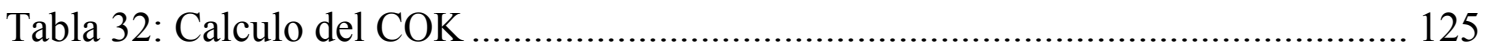

Tabla 33: Estructura de Financiamiento ...................................................................... 125

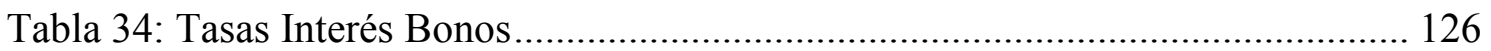

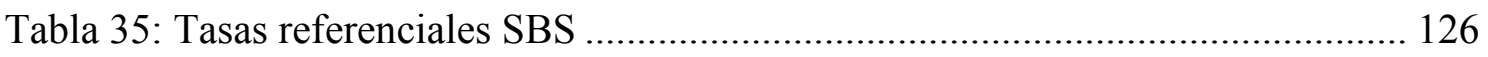

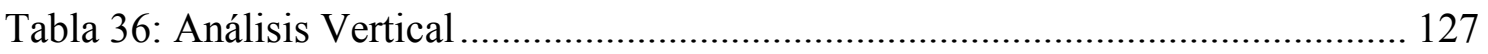

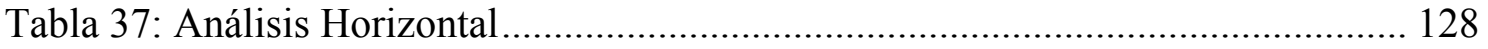

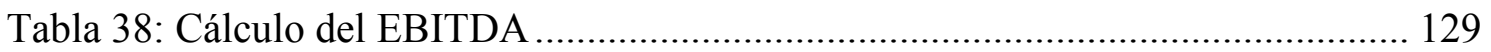

Tabla 39: Pbi Y Sector Alimentos: Valor Agregado Bruto Por Años ........................... 130

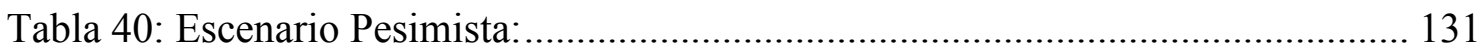

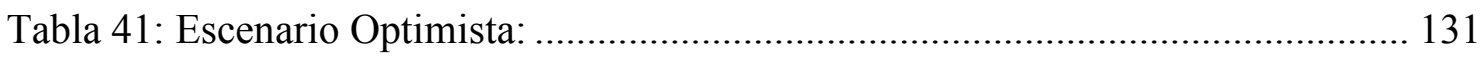

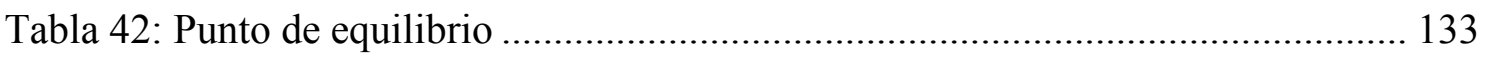




\section{INTRODUCCIÓN}

El presente Plan de Negocios identifica la necesidad de contar con una herramienta (APP), que permita a los usuarios consumidores de alimentos en Food Trucks ganar tiempo y satisfacer los diferentes deseos de comida que puedan tener en el momento.

El análisis del negocio nos muestra un gran potencial de inversión y crecimiento, ya que en los últimos años se ha observado crecimiento en este tipo de oferta de comida. El gasto per cápita en alimentación fuera del hogar ha aumentado, así como la recuperación en el crecimiento del PBI y la aparición de Food Trucks como puntos de venta de comida rápida generan la idea de negocio de ¡Ñam! Buscador de Food Trucks. Este aplicativo permite unir los clientes que buscan nuevas opciones y conceptos de comida, con los lugares asociados que ofrecen comida en los Foods Trucks de la capital, este app brinda la facilidad de ubicar locales de Food Trucks cercanos a la ubicación del cliente, realizar el pedido y pagar vía online, llegar al lugar donde se encuentre el Food Trucks, recoger el pedido y disfrutar un nuevo concepto de comida que ofrece el ambiente. La forma de ser rentable con la aplicación se da por parte del Food Trucks ya que ellos pagarían un 5\% por volumen de ventas y se estima un $2 \%$ por ventas de publicidad en la app.

Nuestra comunicación será a través de las redes sociales, pagina web y aplicativo. Nos situaremos en la estrategia de Diferenciación, ya que nos enfocaremos en atraer clientes potenciales con publicidad y promoción por redes sociales, de igual forma atraer clientes de la competencia presentándoles una marca fresca, diferente, que ofrece una característica distinta, la ubicación de food trucks cercanos a la localización de la persona en la capital.

Cubriremos necesidades para nuestros clientes y los dueños de los Food Trucks que podrán incrementar sus clientes, generar más ingresos y hacerse más conocidos; y de los usuarios o consumidores de Food Trucks que es ahorrar tiempo, satisfacer la necesidad de alimentarse y la rápida ubicación de puestos de comida. 


\section{CÁPITULO 1: ASPECTOS GENERALES DEL NEGOCIO}

Este capítulo comprende los aspectos generales del proyecto en donde describimos nuestra idea de negocio, descripción del producto/servicio que vamos a ofrecer y el equipo de trabajo.

\subsection{IDEA DEL NEGOCIO}

El peruano promedio se mantiene en constante actividad laboral, ello no le permite elaborar comida para su día a día (desayuno, almuerzo, cena) por esta razón, el peruano opta por gastar un tercio de su sueldo en alimentos que encuentra fuera de casa, tomando como opción restaurantes, fast foods, o lo que encuentre cerca al lugar donde labora. Asimismo, también se observa que el peruano está dispuesto a probar nuevas opciones de comida que ofrezca un ambiente diferente al que usualmente visita, pero, por falta de conocimiento de nuevas propuestas de comida, opta por regresar a los lugares de siempre. Al mismo tiempo se conoce que el negocio de Food Trucks es un negocio que se encuentra en tendencia y aumento por el boom gastronómico que atraviesa el Perú.

Existen diversas organizaciones de Foods Trucks en la capital que ofrecen variedad de opciones de comida, entre ellas tenemos comida árabe, comida mexicana, comida vegetariana, comida marina, comida criolla, comida japonesa, y carnes, también se encuentra variedad de bebidas y postres para el gusto del cliente.

Éstas organizaciones logran publicitarse por medio de redes sociales, si bien se ha obtenido una buena respuesta por parte del público, se considera que la demanda de comida en los Foods Trucks tiene la oportunidad de ganar un aumento diferenciable, al ver éstas fortalezas se decide crear una aplicación llamada "¡Ñam! Buscador de Food Trucks en el que permite unir los clientes que buscan nuevas opciones y conceptos de comida, con los lugares asociados que ofrecen comida en los Foods Trucks de la capital, este app brinda la facilidad de ubicar locales de Food Trucks cercanos a la ubicación del cliente, realizar el pedido y pagar vía online, llegar al lugar donde se encuentre el Food Trucks, recoger el pedido y disfrutar un nuevo concepto de comida que ofrece el 
ambiente. La forma de ser rentable con la aplicación se da por parte del Food Truck ya que ellos pagarían una comisión por pedido del cliente.

\subsection{DESCRIPCIÓN DEL PRODUCTO/SERVICIO A OFRECER}

¡Ñam! Buscador de Food Trucks es una aplicativo móvil con el que podrás localizar mediante GPS, los Food Trucks más cercanos a tu localización.

Con ¡Ñam! Buscador de Food Trucks podrás realizar tu pedido, pagar vía online, recogerlo o comer en el lugar; como tú gustes.

Para empezar, debes realizar un rápido inicio de sesión y colocar en el buscador donde te gustaría encontrar un Food Trucks, eliges el distrito y el aplicativo te dará un resultado de Food Trucks del lugar elegido con el tiempo que te tomará en llegar.

¡Ñam! Buscador de Food Trucks te brinda diversas soluciones:

\section{Compra Online}

¡Ñam! Buscador de Food Trucks Te muestra diversas opciones para compra online. Te brinda la facilidad de pagar con tarjeta de crédito o débito, asimismo te da la opción de elegir entre los precios más baratos y caros.

\section{Recojo}

Para ir al lugar de recojo, solo debes activar el filtro de ubicación, así el aplicativo te dirá en cuanto tiempo llegarás a tu destino, según sea tu movilidad.

\section{Otros - ¡Comparte tus comidas!}

Una vez en el lugar del recojo, podrás degustar tus comidas, tomarle foto y compartirlas en el aplicativo, para que otras personas se animen a elegir tu plato, podrás rankear tu Food Trucks favorito, asimismo comentar que te pareció la atención y el lugar.

\section{4. ¿Cómo uso el aplicativo?}

Para un mejor uso del aplicativo debes ingresar a www.ñam.com.pe allí entrarás al home e donde podrás descargar el APP, los instalas y con el buscador es donde tendrás que colocar que comida deseas encontrar y el lugar, automáticamente el buscador te arrojará las opciones solicitadas. 
Una vez dentro, irás a la opción filtros, para elegir algunas características de tu pedido, tales como: cuanto tiempo demoraré en llegar, comidas con variedad de precios, pago con tarjeta de crédito y débito, los lugares más visitados, horarios de atención.

Eliges las opciones y dejas que el buscador arroje resultados, una vez ubicado el plato y la ubicación del lugar, procedes a realizar el pedido, cancelando con tarjeta de crédito o visa vía online. El aplicativo te brinda la información del tiempo que te tomará llegar al lugar.

Una vez en el lugar indicado, recoges el plato elegido y tú decides si llevarlo o comerlo en el mismo lugar ya que existen variedad de patios de Food Trucks en la capital.

Inicialmente nuestras operaciones serán en los distritos de Surco y Miraflores pero nuestra proyección contempla extenderse a nivel nacional.

Un poco de información adicional sobre nuestro proceso de negocio:

El usuario: Al descargar e ingresar al aplicativo deberá loguearse de manera gratuita, esto le permite acceso al buscador de Food Trucks, ya que el aplicativo está conectado con Facebook puedes compartir tus platos mediante esa red social, asimismo su localización ayudará mucho en la búsqueda de Food Trucks cercanos.

Pago: El pago será el 5\% por el volumen de ventas pagado por los dueños de los food trucks.

Con respecto al usuario la descarga del aplicativo es totalmente gratuita, el pago se realiza con tarjeta de crédito o débito.

Crecimiento futuro: ¡Ñam! Buscador de FoodTrucks decidió unir 2 necesidades ya existentes, el peruano siempre se encuentra en búsqueda de nuevas opciones de comida en Lima Metropolitana y los Food Trucks tienen interés de aumentar el número de clientes.

El éxito del aplicativo será por la búsqueda y presentación de nuevos lugares para degustar platos.

Con las ganancias se pretende que el aplicativo sea usado a nivel nacional, aprovechando la rica cultura y diversidad de nuestra comida con una nueva forma de presentación. 


\subsection{EQUIPO DE TRABAJO}

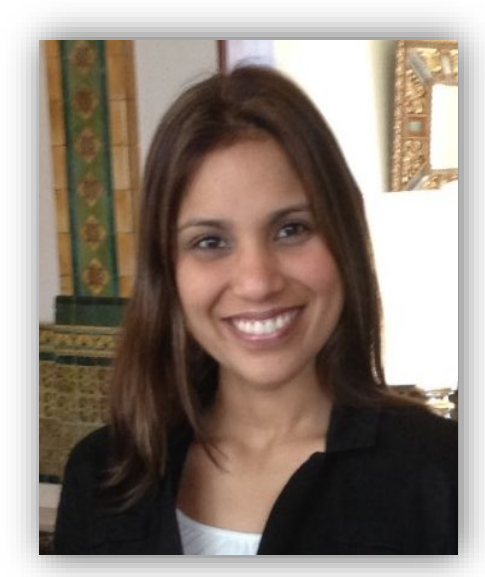

Mi nombre es Erika Morales Benites, curso el 10moCiclo de la carrera de Administración de Empresas en UPC. Me desempeñe por 11 años en el sector Hotelero, ocupando diversos puestos siendo el último la gerencia de operaciones y administración de un hotel boutique. Mis habilidades son: toma de decisiones, trabajo en equipo, resolución de conflictos laborales, gestión del tiempo, gestión del stress, escucha activa, capacidad de análisis, comunicación, motivación y liderazgo.

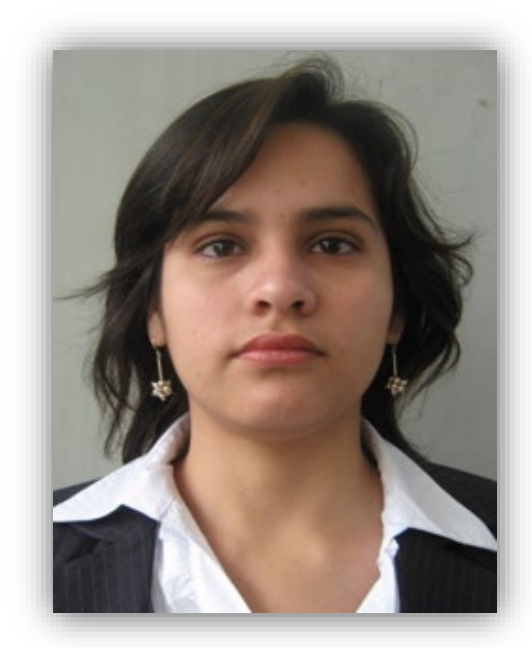

Mi nombre es Andrea Patricia Portal Laguna, estoy cursando el 10mo ciclo de Administración de Empresas en la Universidad de Ciencias Aplicadas -UPC. Mi experiencia laboral es en el área de Riesgos aprobando créditos para pequeñas y medianas empresas. Mis habilidades directivas son: Escucha activa, responsable, enfocada hacia objetivos y demostrada capacidad de análisis.

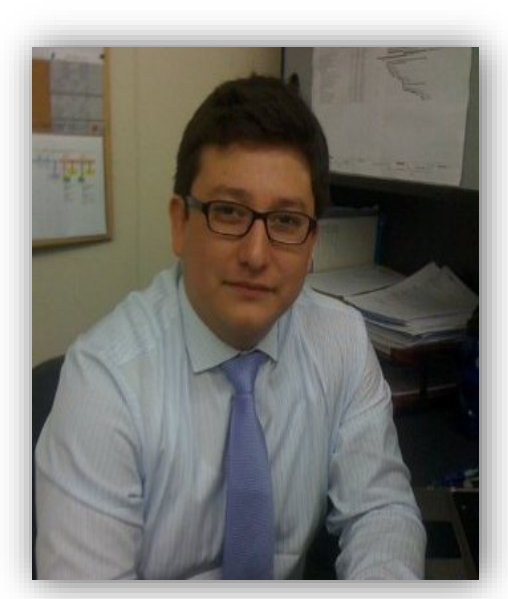

Mi nombre es Aurelio Ramírez Franco, estoy cursando el 10mo ciclo de Administración de Empresas en la Universidad Peruana de Ciencias Aplicadas - UPC. Mi experiencia laboral es en el área de Planeamiento Estratégico y Financiero, el cual realizo evaluaciones financieras que están acordes a los planes de la empresa. Mis habilidades directivas son: Comunicación, resiliente, capacidad de organización, planificación y reacción. 
Lizbeth Nataly Rivera Salhuana, curso el 9no ciclo de la

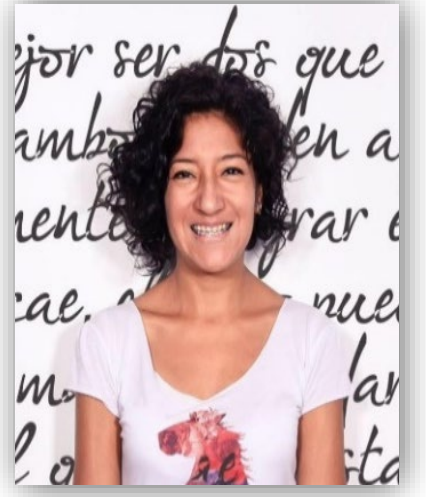
carrera de marketing en UPC. Me desempeño como diseñadora y fotógrafa en el Estado desde hace 3 años. Tengo experiencia como arte finalista en servicios de impresión, Directora de Arte en agencias de publicidad y fotógrafa en bodas. Mis habilidades son empatía, creatividad y buena gestión del tiempo. 


\section{CAPÍTULO 2: PLANEAMIENTO ESTRATÉGICO}

Ilustración 1: Modelo de Negocios ¡Ñam! Buscador de Food Trucks

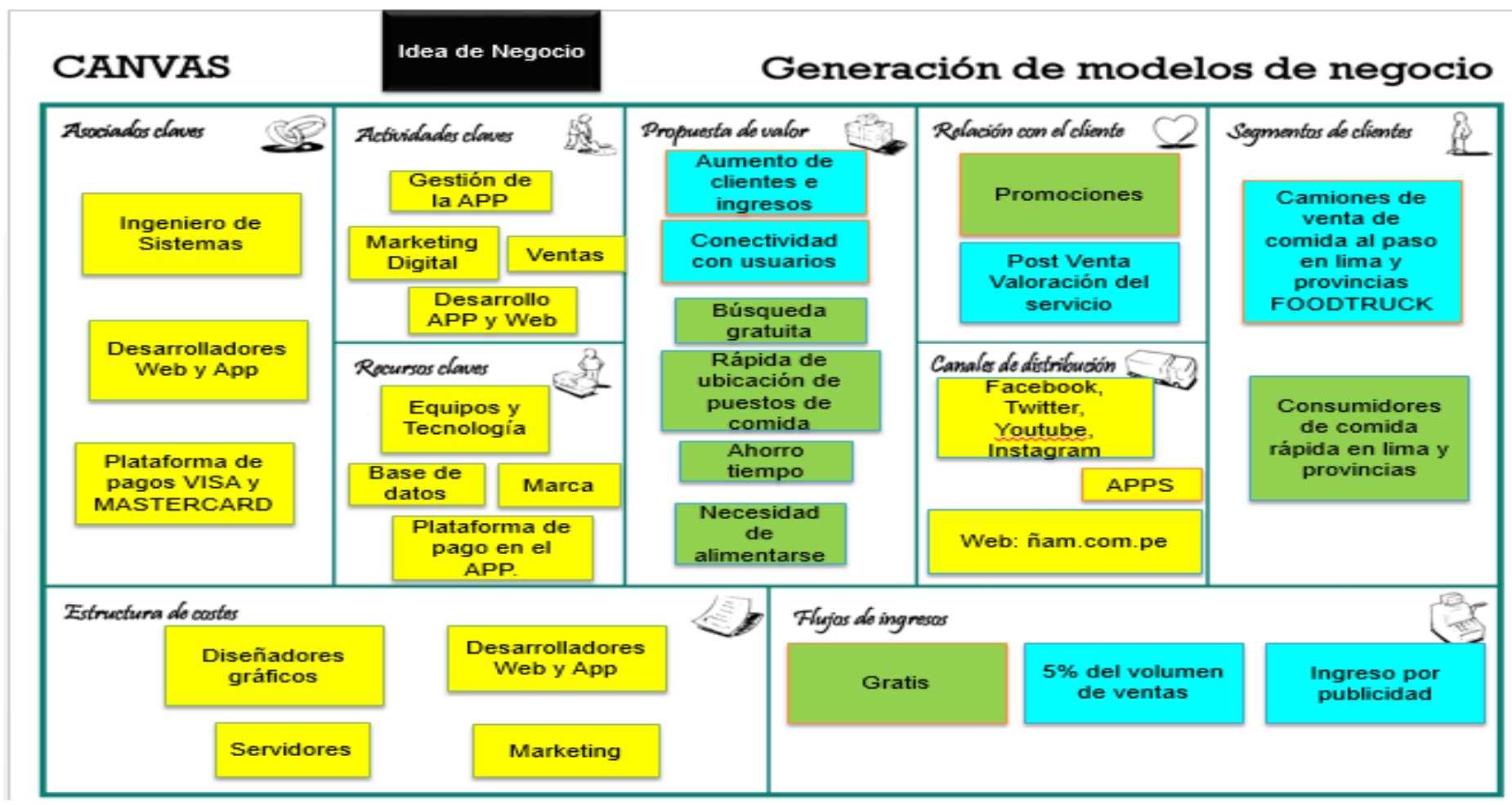

Fuente: Elaboración Propia 


\subsection{ANÁLISIS EXTERNO}

\subsubsection{ANÁLISIS PESTEL}

Tabla 1: Desarrollo de Análisis Pestel - ¡Ñam! Buscador de Food Trucks

\begin{tabular}{|c|c|c|c|c|}
\hline & TENDENCIA & CLIENTES & NEGOCIO & FUENTE \\
\hline \multirow{3}{*}{ 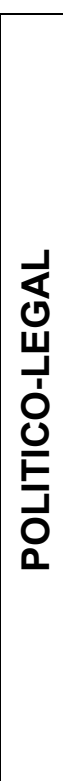 } & $\begin{array}{l}\text { Con la vacancia del Expresidente } \\
\text { Pedro Pablo Kuczynski, el cual genero } \\
\text { una incertidumbre económica en el } \\
\text { país. Con el actual Presidente Martin } \\
\text { Vizcarra, se espera que se logre } \\
\text { mejorar la gubernalidad del país asi } \\
\text { como el mejoramiento de las } \\
\text { inversiones. }\end{array}$ & $\begin{array}{l}\text { Por el momento sigue la confianza en la } \\
\text { capacidad del presidente lo cual fortalece } \\
\text { la credibilidad en un mejor futuro para el } \\
\text { país }\end{array}$ & $\begin{array}{l}\text { OPORTUNIDAD: Los Food trucks } \\
\text { aún están apostando por la } \\
\text { inversión. Por ello, el crecimiento } \\
\text { de esos nuevos modelos de } \\
\text { negocio. }\end{array}$ & \\
\hline & $\begin{array}{l}\text { Los recientes acontecimientos de } \\
\text { corrupción que existe en el país, } \\
\text { causan una inestabilidad política, el } \\
\text { cual genera desconfianza por parte de } \\
\text { las empresas inversoras. }\end{array}$ & $\begin{array}{l}\text { Las empresas no pensarían en la } \\
\text { formalización, porque creerían que sus } \\
\text { impuestos no serían destinados para } \\
\text { obras del estado. }\end{array}$ & $\begin{array}{l}\text { AMENAZA: Algunas empresas se } \\
\text { mantendrian en la informalidad, el } \\
\text { cual no estarían dispuesta asumir } \\
\text { el costo de nuestro servicio. }\end{array}$ & \\
\hline & $\begin{array}{l}\text { No existe una regulación legal en caso } \\
\text { un cliente tenga un problema con el } \\
\text { servicio. Por lo cual, se tendría que } \\
\text { establecer políticas y normas. }\end{array}$ & $\begin{array}{l}\text { Podrían verse afectados si no se } \\
\text { establece unas políticas y normas para el } \\
\text { consumidor, con el fin de no perjudicar el } \\
\text { servicio que ofrecen }\end{array}$ & $\begin{array}{l}\text { AMENAZA: Podríamos perder } \\
\text { clientes, por tener como seriedad } \\
\text { en el servicio que brindamos. }\end{array}$ & \\
\hline
\end{tabular}




\begin{tabular}{|c|c|c|c|c|}
\hline \multirow{3}{*}{ 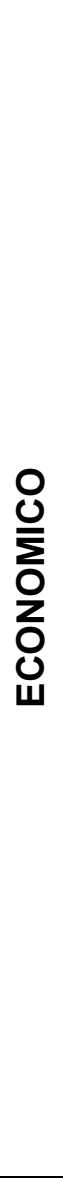 } & $\begin{array}{l}\text { A inicios del } 2018 \text { se indicaba un } \\
\text { crecimiento del } 4 \% \text { a } 4.5 \% \text { de } \\
\text { crecimiento. Hoy en día se espera un } \\
\text { crecimiento del } 3.5 \% \text { con tendencia a } \\
\text { bajar, si } 1 \text {. Se incrementa el ruido } \\
\text { político, } 2 \text {. Se produce una sub- } \\
\text { ejecución en la inversión pública } \\
\text { destinada en la reconstrucción del Niño } \\
\text { Costero o } 3 \text {. Si se genera una abrupta } \\
\text { reversión de los flujos de capitales } \\
\text { hacia economías emergentes }\end{array}$ & $\begin{array}{l}\text { Al tener una visión clara de la economía, } \\
\text { las empresas no podrán crear un buen } \\
\text { Planeamiento Estratégico de a dónde } \\
\text { quieren dirigirse. Por ello, es importante } \\
\text { que el estado defina cuál sería su } \\
\text { participación dentro del proceso. }\end{array}$ & $\begin{array}{l}\text { AMENAZA: Al no tener un buen } \\
\text { crecimiento económico, ciertos } \\
\text { productos aumentarían el precio. } \\
\text { Por lo cual, disminuirá las ventas } \\
\text { de nuestros clientes. }\end{array}$ & $\begin{array}{l}\frac{\text { https://gestion.p }}{\text { e/economia/bcp- }} \\
\text { recorta- } \\
\frac{\text { estimado- }}{\text { recimiento- }} \\
\frac{\text { crecimomico-peru- }}{\text { econominas- }} \\
\frac{\text { 4-2-hasta-3-5- }}{\underline{2018-226008}}\end{array}$ \\
\hline & $\begin{array}{l}\text { Hoy en día el "Boom de la } \\
\text { Gastronomía" está pasando de un } \\
\text { estado crecimiento a un estado de } \\
\text { madurez. Por lo cual, mantener un } \\
\text { estándar en la calidad, es importante } \\
\text { para mantener el crecimiento } \\
\text { económico que ha tenido en estos } \\
\text { últimos años. }\end{array}$ & $\begin{array}{l}\text { Las empresas están creando nuevos } \\
\text { modelos económicos, el cual les generan } \\
\text { rentabilidad, ya que su propuesta de } \\
\text { valor es estar más cerca y más rápido al } \\
\text { consumidor. }\end{array}$ & $\begin{array}{l}\text { OPORTUNIDAD: Los clientes } \\
\text { están creando un nuevo modelo de } \\
\text { negocio, el cual son nuestra } \\
\text { aplicación los podría conectar de } \\
\text { manera más rápida con los } \\
\text { consumidores. }\end{array}$ & 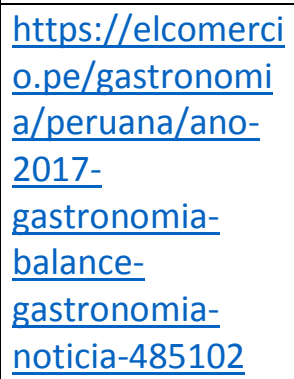 \\
\hline & $\begin{array}{l}\text { Según el estudio del Instituto Nacional } \\
\text { de Estadística e Informática - INEI, } \\
\text { indica que la tasa de desempleo se ha } \\
\text { incrementado a } 7.3 \% \text { en Enero, el cual } \\
\text { se da por esta incertidumbre política, } \\
\text { en que las empresas no quieren } \\
\text { invertir. }\end{array}$ & $\begin{array}{l}\text { Podrían generar nuevas oportunidades } \\
\text { de negocio como son los Food trucks, } \\
\text { como nueva oportunidad de ingresos. }\end{array}$ & $\begin{array}{l}\text { OPORTUNIDAD: Nuevos clientes } \\
\text { potenciales, con el fin de generar } \\
\text { nuevos ingresos. Por lo cual, } \\
\text { nuestra aplicación les servirá para } \\
\text { hacerse conocido en el mercado. }\end{array}$ & $\begin{array}{l}\frac{\text { https://peru21.p }}{\text { e/economia/dese }} \\
\frac{\text { mpleo-lima-tasa- }}{\text { sube-7-3-enero- }} \\
\underline{\text { 2018-395983 }}\end{array}$ \\
\hline $\begin{array}{l}\frac{1}{4} \\
\\
0\end{array}$ & $\begin{array}{l}\text { En el informe técnico de la INEI sobre } \\
\text { "Evolución de la Pobreza Monetaria } \\
2007-2016 " \text {, indica que los últimos } 10 \\
\text { años la pobreza se ha reducido en } 28.4 \\
\text { puntos porcentuales }\end{array}$ & $\begin{array}{l}\text { Crecimiento en ventas de sus productos, } \\
\text { ya hoy en día existe un consumidor con } \\
\text { una nueva tendencia de consumo y de } \\
\text { liquidez para adquirir nuevos servicios. } \\
\text { Los Food Trucks son una estrategia de } \\
\text { venta de alimentos, el cual reduce el }\end{array}$ & $\begin{array}{l}\text { OPORTUNIDAD: Existe una } \\
\text { disminución en la pobreza, el cual } \\
\text { permite que tengas más usuarios } \\
\text { en la aplicación. }\end{array}$ & $\begin{array}{l}\frac{\text { https://www.tele }}{\text { surtv.net/news/S }} \\
\text { ituacion- } \\
\text { economica-y- } \\
\begin{array}{l}\text { social-de-Peru-a- } \\
\text { un-ano-de- }\end{array} \\
\end{array}$ \\
\hline
\end{tabular}




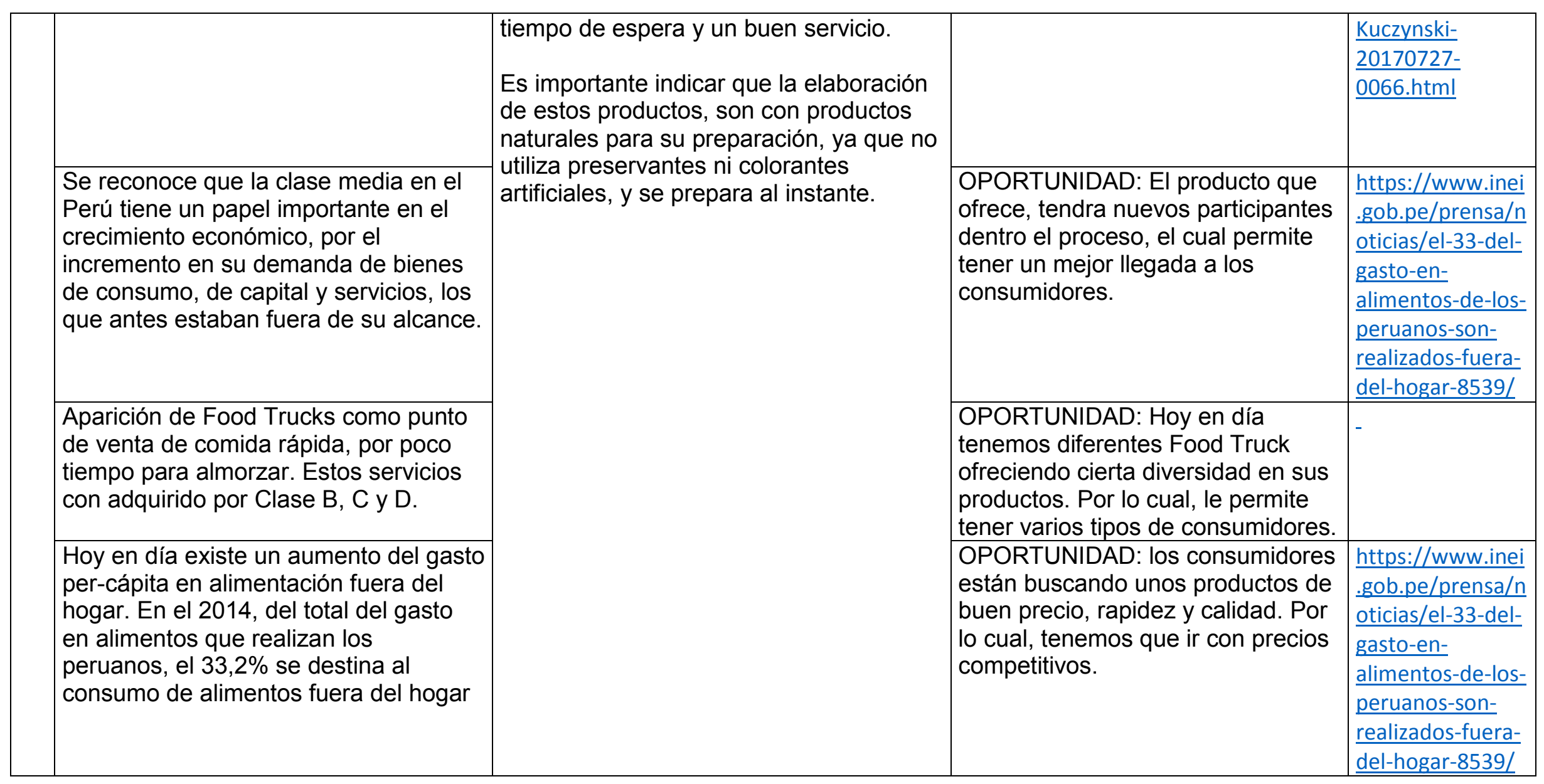




\begin{tabular}{|c|c|c|c|c|}
\hline & $\begin{array}{l}\text { Los negocios de Food Trucks en } \\
\text { algunas zonas de Lima tienen un } \\
\text { potencial rechazo, ya que trae consigo } \\
\text { insalubridad y contaminación. }\end{array}$ & $\begin{array}{l}\text { Hoy en día existe una Asociación } \\
\text { Peruana de Food Trucks, el cual } \\
\text { coordinan con la Municipalidad en donde } \\
\text { se ubiquen, a fin de evitar este tipo de } \\
\text { quejas. }\end{array}$ & $\begin{array}{l}\text { OPORTUNIDAD: Como el Food } \\
\text { Trucks se ha convertido en un } \\
\text { negocio formal. Nuestra aplicación } \\
\text { sería un buen medio de ubicación } \\
\text { para los consumidores. }\end{array}$ & 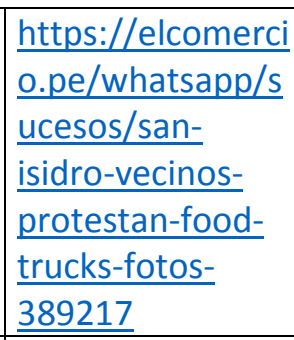 \\
\hline & $\begin{array}{l}\text { Hoy en día existe una tendencia en la } \\
\text { alimentación saludable. Por el cual, las } \\
\text { empresas deben de rediseñar sus } \\
\text { productos. }\end{array}$ & $\begin{array}{l}\text { Crear nuevos modelos de productos, con } \\
\text { el fin de estar preparado frente a posibles } \\
\text { cambios de consumo. }\end{array}$ & $\begin{array}{l}\text { AMENAZA: Si las empresas, no } \\
\text { acomodan su modelo de negocios, } \\
\text { el consumo de sus productos } \\
\text { podrían disminuir y nuestras ventas } \\
\text { se reducirían. }\end{array}$ & $\begin{array}{l}\text { http://larepublic } \\
\text { a.pe/marketing/8 } \\
\text { 60310- } \\
\text { tendencias-del- } \\
\text { mercado-de-lo- } \\
\text { natural }\end{array}$ \\
\hline \multirow{3}{*}{ 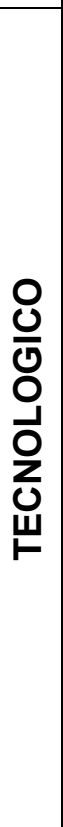 } & $\begin{array}{l}\text { Aparición de nuevas tecnologías y } \\
\text { software más efectivos. }\end{array}$ & $\begin{array}{l}\text { Las empresas han llegado a ser } \\
\text { conocida por el boca a boca, el cual les } \\
\text { ha permitida generar más clientes en su } \\
\text { cartera. }\end{array}$ & $\begin{array}{l}\text { OPORTUNIDAD: Con nuestra } \\
\text { aplicación, los clientes podrían } \\
\text { obtener un mayor número de } \\
\text { consumidores, en el cual conozcan } \\
\text { su ubicación y gama de productos } \\
\text { que ofrece. }\end{array}$ & \\
\hline & $\begin{array}{l}\text { Consumidores más exigentes con el } \\
\text { desarrollo de gadgets. }\end{array}$ & $\begin{array}{l}\text { Buscan un sistema sencillo de fácil } \\
\text { acceso, el cual esté conectado con cada } \\
\text { Food Truck. }\end{array}$ & $\begin{array}{l}\text { OPORTUNIDAD: Tenemos que } \\
\text { generar un sistema sencillo y fácil } \\
\text { acceso, para que el consumidor } \\
\text { tome una decisión de compra } \\
\text { rápida y económica. }\end{array}$ & \\
\hline & $\begin{array}{l}\text { En la actualidad } 4 \text { de cada } 10 \\
\text { peruanos utiliza un Smartphone. Por lo } \\
\text { cual, en los últimos cuatro años se ha } \\
\text { triplicado el acceso a dicho dispositivo. }\end{array}$ & $\begin{array}{l}\text { Pueden tener un mayor acceso a la } \\
\text { ubicación en donde se encuentran y } \\
\text { saber que productos son los que ofrecen. }\end{array}$ & $\begin{array}{l}\text { OPORTUNIDAD: Con nuestra } \\
\text { aplicación, los consumidores } \\
\text { podrían conocer la ubicación de } \\
\text { nuestros clientes y que productos } \\
\text { ofrecen. }\end{array}$ & $\begin{array}{l}\frac{\text { https://gestion.p }}{\text { e/economia/emp }} \\
\text { resas/penetracio } \\
\text { n-smartphones- } \\
\text { peru-triplico- } \\
\text { ultimos-cuatro- } \\
\text { anos-225607 }\end{array}$ \\
\hline
\end{tabular}




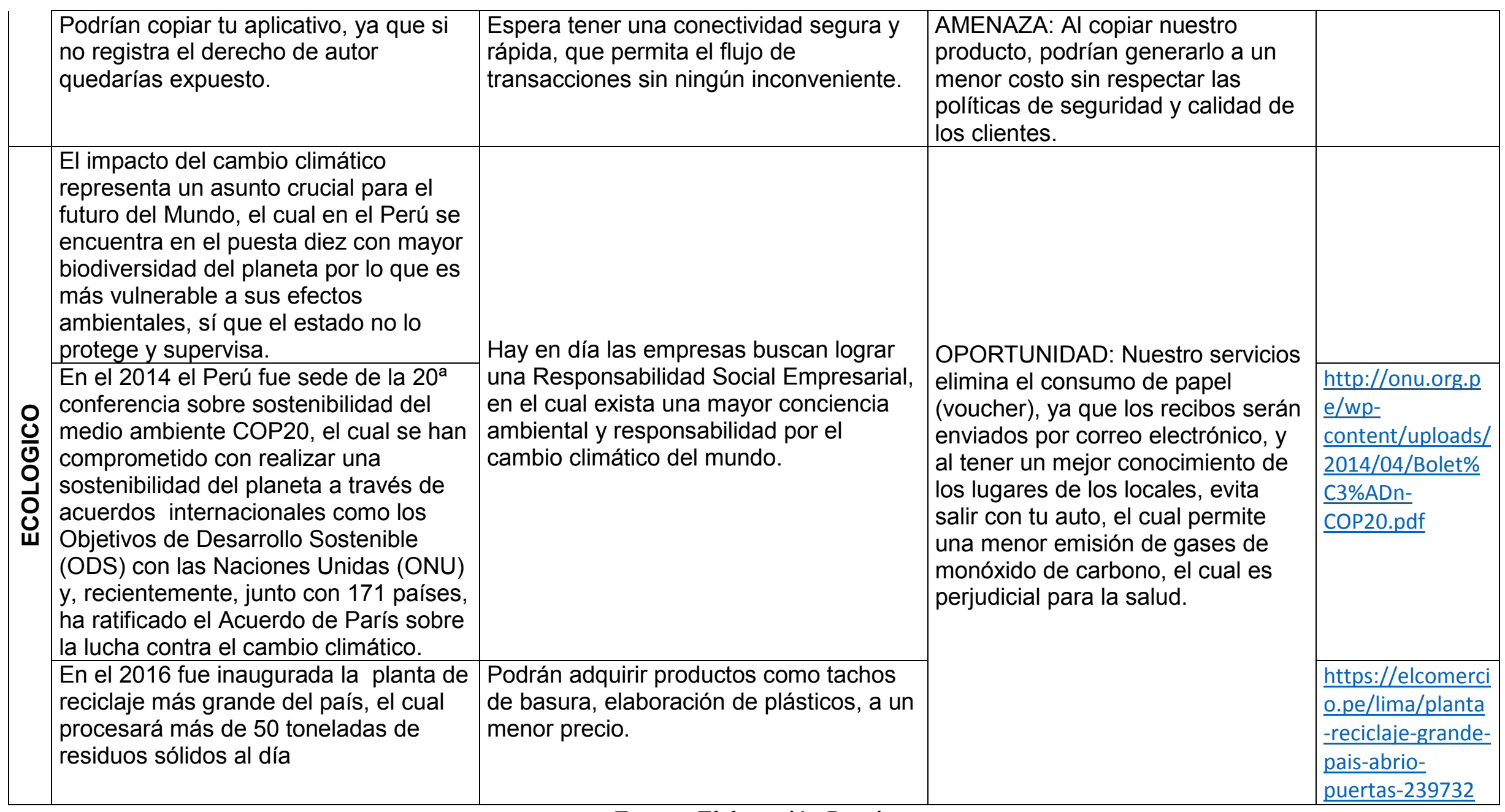

Fuente: Elaboración Propia 


\subsection{ANÁLISIS INTERNO}

\subsubsection{ANÁLISIS DE LAS 5 FUERZAS DE PORTER}

Poder de negociación de compradores o clientes: ¡Ñam! Buscador de Food Trucks tiene como clientes a los dueños de los Food Trucks de Lima, el poder de negociación es medio si bien los food trucks desean mayor exposición en el mercado para poder captar más clientes, a los dueños de los food trucks se les cobrara el 5\% del volumen de ventas, lo cual, podría ser considerado una afectación en sus ingresos. Muchas veces la representación de un pago podría ser una barrera para acceder al servicio.

Poder de negociación de los proveedores o vendedores: ¡Ñam! Buscador de Food Trucks actúa como intermediario del servicio, socios y puede ser considerado como proveedor. Es por esto que su poder de negociación es alto, ellos pueden buscar las alternativas para que la alianza con los Food Trucks sea positiva para ambas partes. En este momento la falta de conocimiento de los clientes de los Food trucks es la problemática más importante del modelo. Si bien la industria está en crecimiento estos no llegan a abarcar la cantidad de mercado que desean. Existe muchos Food Trucks que deseen captar más clientes y hacerse conocidos para ello ¡Ñam! Buscador de Food Trucks los ayudara.

Amenaza de nuevos competidores entrantes: ¡Ñam! Buscador de Food Trucks no cuenta con competidores directos debido a que no existe un servicio abocado a los Food Trucks lo que sí es una competencia indirecta son los restaurantes que cuentan con una página virtual y realizan delivery de comida. Satisfacen la necesidad de comer del cliente más no de variedad y experiencia diferentes que busca el cliente final. Las barreras de los competidores entrantes son medias si bien no hay una competencia directa, la idea de negocio podría ser copiada y ofrecida al mercado a un costo menor sin respetar las políticas de seguridad y calidad.

Amenaza de productos sustitutos: Al no existir una oferta que reúna las mismas características de ¡Ñam! Buscador de Food Trucks, los negocios que podría brindar alternativas parecidas son los restaurantes con delivery y los restaurantes de comida rápida que realizan órdenes mediante la página web, pero con un costo agregado por el 
envío del pedido solicitado. La barrera para esta amenaza es media si bien el producto es dirigido a una clientela exclusiva (Food Trucks) la elección del consumidor podría variar y dirigirse a los restaurantes con delivery si prevalece la comodidad de estar en casa a la elección de la comida que se desea.

Rivalidad entre los competidores: Mientras menos competidores tengamos en el sector se beneficiará el negocio, los competidores son indirectos, pero puede surgir la rivalidad si aumentan los clientes de los Food Trucks y si estos logran la notoriedad que se desea, pudiendo estos competidores buscar alternativas para satisfacer la demanda del cliente con costos más bajos.

\subsubsection{ANÁLISIS FODA}

\section{FODA}

\section{FORTALEZA}

1. Descargar el aplicativo de cualquier sistema operativo (Android y IOS).

2. Contaremos con un diseño del aplicativo que será rápido y fácil de usar.

3. Contar con una alianza directa con la Asociación de los FOOD TRUCKS.

4. Excelente equipo de trabajo que cuenta con experiencia en Administración de Empresas, Marketing y Finanzas.

\section{OPORTUNIDADES}

1. El aplicativo servirá para que los FOOD TRUCKS se hagan más conocidos en el mercado.

2. Obtener diferentes tipos de consumidores.

3. Crecimiento tecnológico en el país.

4. Crecimiento de los FOOD TRUCKS en el mercado.

\section{$\underline{\text { DEBILIDADES }}$}

1. No tenemos capital suficiente para realizar el APP.

2. Desconocimiento de desarrollo Web.

3. No contar con un determinado mínimo de descargar para obtener los beneficios de estar dentro del top ten. 
4. Limitarse a los distritos donde están los FOOD TRUCKS.

\section{$\underline{\text { AMENAZAS }}$}

1. Desconocimiento del marco legal de un APP.

2. Los FOOD TRUCKS no acepten pagar la comisión por venta que se realice por el APP.

3. Dificultad de sacar licencia de funcionamiento y por ello aumentan los informales.

4. Copiar el producto, generando un menor costo sin respetar las políticas de seguridad y calidad de los clientes. 
FODA CRUZADO

Tabla 2: Foda Cruzado

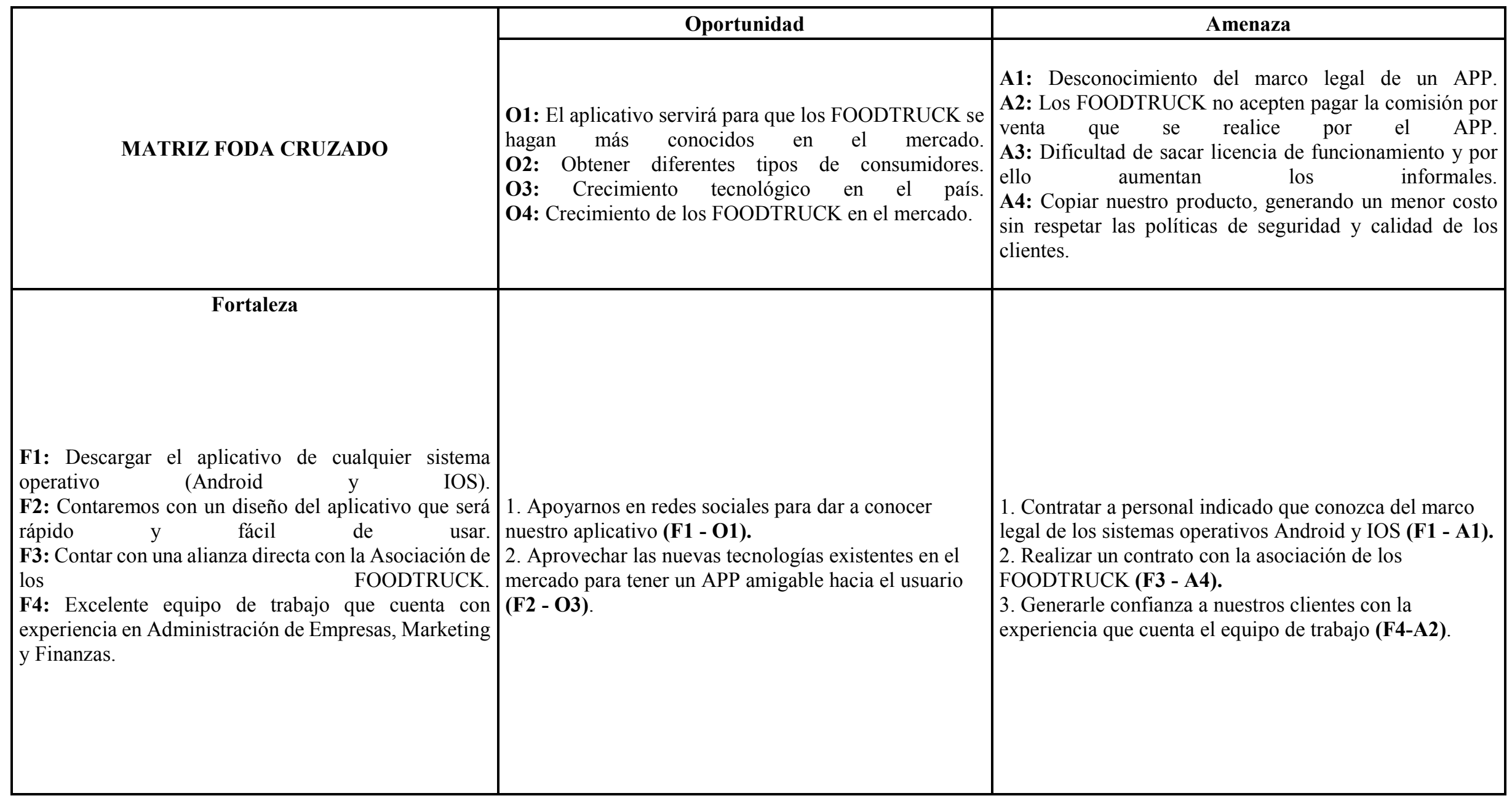




\begin{tabular}{|c|c|c|}
\hline Debilidad & & \\
\hline 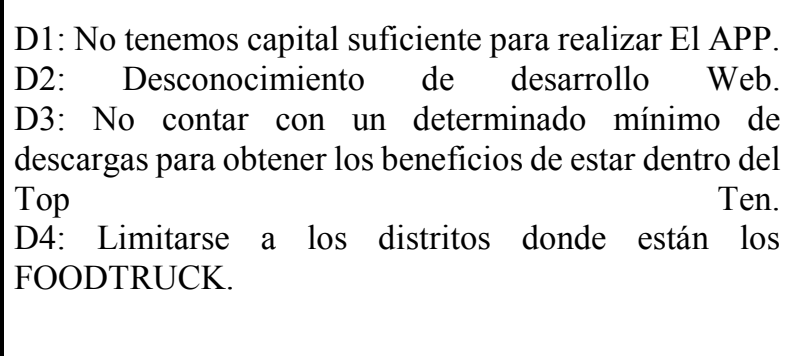 & $\begin{array}{l}\text { 1. Contratar a un desarrollador web para que Realizar } \\
\text { El APP y sea sencillo y de fácil acceso (D2 - O3). } \\
\text { 2. Realizar campañas para hacernos conocidos con el } \\
\text { APP de los FOODTRUCK y por ende obtener un } \\
\text { beneficio por el número de descargas realizadas y estar } \\
\text { dentro de las Top Ten (D3 - O4). } \\
\text { 3. Aprovechando el crecimiento de los FOODTRUCK } \\
\text { en los últimos años y apoyándonos con la aparición de } \\
\text { las START UP (D1 - O4). }\end{array}$ & $\begin{array}{l}\text { 1. Contratar profesionales con conocimiento en marco } \\
\text { legal y tecnológico (A1 - D2). } \\
\text { 2. Realizar reuniones con cada dueño de los } \\
\text { FOODTRUCK y presentarles el modelo de negocio (A2 - } \\
\text { D3). } \\
\text { 3. Plantear a la asociación que amplíen el universo de } \\
\text { distritos de atención de los FOODTRUCK (A3-D4). }\end{array}$ \\
\hline
\end{tabular}

Fuente: Elaboración Propia 


\subsection{VISIÓN}

Ser el aplicativo de búsqueda de comida de food trucks más utilizado en Lima y expandirse a todo el Perú.

\subsection{MISIÓN}

Cambiar la forma de solicitar comida por aplicación, al reducir el tiempo de espera en los Food Trucks. Conectar a los usuarios con los Food trucks por medio de la aplicación. Agilizar la ubicación de los locales de Food Trucks, para aumentar la demanda del servicio de Food Trucks en Lima.

\subsection{ESTRATÉGIA GENÉRICA}

La estrategia general de Porter, ha llevado a que el nicho de mercado este enfocado en “Diferenciación”, la propuesta de valor es utilizar una herramienta tecnológica (App) que una a los Food Trucks con los consumidores. Por ello, se ha identificado que no existe una propuesta competitiva, esto es favorable para la empresa.

\subsection{OBJETIVOS ESTRATÉGICOS (MEDIANO Y LARGO PLAZO)}

- Formar parte de la asociación de Food Trucks en Lima, ya que con ellos se le permitirá a la empresa tener una mejor red de contactos, a los que se les podrá ofrecer el producto.

- Desarrollar un App de fácil acceso, que permita a los usuarios identificar donde ubicar a los Food Trucks, los diferentes tipos de Food Trucks y los precios de sus productos.

- Tener un personal altamente calificado, que permita resolver cualquier inconveniente de manera rápida y eficiente y además ser innovadores en crear nuevas formas de incrementar los usuarios.

- Contar con la tecnología más moderna, amigable y eficiente del mercado.

- Crear programa de fidelización de los clientes. 
- Mantener la estrategia de segmentación orientada a la diferenciación lo que permitirá a la empresa generar un LOVEMARK.

- Incrementar los canales de comunicación de la marca. 


\section{CAPÍTULO 3:}

\section{INVESTIGACIÓN/CONVALIDACIÓN DE}

MERCADO

\subsection{DISEÑO METODOLÓGICO DE LA INVESTIGACION / METODOLOGIA DE VALIDACION DE HIPOTESIS}

El objetivo de la siguiente exploración es la validación la hipótesis cliente/problema que dio origen a la propuesta de solución.

Debido al boom gastronómico que viene representando al país, los food trucks han encontrado una oportunidad de negocio que ha tomado forma en estos últimos años. Esta industria está en crecimiento la cual facturó 2.7 mil millones de dólares en el 2017, lo cual superaría en un $11 \%$ a la industria tradicional. El crecimiento ha sido en escalas mayores ya que, en 2012 sólo movía unos 650 millones de dólares. ${ }^{1}$

Los consumidores buscan precios más accesibles, pero con comida destacada. El paladar del consumidor se ha vuelto más exquisito y ha escalado peldaños a una comida al paso. Como podría ser unas salchipapas o hamburguesas corrientes a una comida más sofisticada, que contenga más detalle y gastronomía. Tanto los millennials como las nuevas generaciones son las más inquietas, quienes buscan novedades y satisfacer sus nuevas necesidades. Esto es lo que ha llevado a que el mercado de los Food Trucks crezca exponencialmente y se multipliquen con varias opciones de comida, desde ceviches hasta comida vegetariana. El abanico de posibilidades y de opciones son las que surgen de estas necesidades y nosotros sabemos que, desde hace un tiempo, las personas buscan cómo mantener esa unión y esa conectividad con estos camiones de comida, los cuales no sólo buscan ser reconocidos como una comida al paso sino toda una experiencia. ${ }^{2}$

HIPÓTESIS DEL PROBLEMA:

1 Redactor del Diario Gestion (2018). Una tendencia que crece sobre ruedas. 04/045/2018. Sitio web : https://gestion.pe/especial/50ideas-de-negocios/noticias/food-trucks-tendencia-sobre-ruedas-noticia-1992335

2 Redactora de la BBC Lucy Burton (2012). Food trucks rev-up fast food. 04/04/2018. Sitio web: http://www.bbc.com/news/av/business-20094042/food-trucks-rev-up-fast-food 
SEGMENTO 1: Camiones de venta de comida al paso en Lima y provincias Food Trucks

\section{PROBLEMA 1: NO SON CONOCIDOS (MARCA O FOOD TRUCK):}

Los FOOD TRUCKS ven esta industria en crecimiento y quieren tener una parte de ella, por ello, ellos quieren hacerse conocido porque saben que mientras más conocidos sean ya sea por el boca a boca o por publicidad, podrán abarcar a más clientes y poder inclusive tener más de estos camiones.

\section{PROBLEMA 2: FALTA DE CLIENTES:}

Si bien, es una industria en crecimiento, esta se está saturando, muchos nuevos camiones de comida han aparecido satisfaciendo las necesidades de los clientes. El ser un camión más significa que a pesar de tener clientela hay productos sustitutos u otros camiones que pueden darte lo mismo, es por ello que los Food Trucks ven como un problema la falta de clientes para este mercado que se comienza a saturar.

\section{PROBLEMA 3: DIFICULTAD PARA OBTENER PERMISOS:}

Los Food Trucks de por sí ya tienen difícil obtener permisos para colocarse en las calles, muchas municipalidades ven con malos ojos que estén parqueados ofreciendo comida y ponen muchas dificultades para obtener permisos, a esto hay que sumarle la corrupción que se puede encontrar en ciertas municipalidades. Es por ello, que estos camiones se terminan yendo a estacionamientos adaptados para este tipo de establecimientos como lo es Truck Park (https://www.facebook.com/truckpark.pe/) en el cual podemos encontrar variedad en comida y en tipos de camiones.

\section{Hipótesis Clave del Problema:}

Se escogió QUE NO SON CONOCIDOS porque es un punto de partida importante para los Food Trucks, ya que haciéndose conocidos muchos de sus problemas podrían solucionarse. Ver que el problema de ser uno más del montón significa que es como cualquier otro establecimiento y saben que deben entregar un valor añadido $\mathrm{y}$ diferenciarse del resto, además, de tener una comida con lo que los clientes se sientan satisfechos. 
SEGMENTO 2: Consumidores de comida rápida en Lima y provincias.

PROBLEMA 1: ESTA ABURRIDO DE IR A COMER A LOS MISMOS

\section{LUGARES}

El cliente quiere tener nuevas experiencias de lugares de comida, se encuentra aburrido de comer en los mismos lugares clásicos (restaurantes, patio de comida).

\section{PROBLEMA 2: QUIERE COMER ALGO RICO SIN GASTAR MUCHO}

El cliente siempre está en la búsqueda no solo de nuevas opciones de comida, busca nuevas experiencias y lo más importante que sea agradable no solo a la vista sino también a los sabores; busca economizar en lo que gasta.

\section{PROBLEMA 3: NO TIENE TIEMPO}

El cliente objetivo de nuestro proyecto es aquel que no cuenta con tiempo para esperar a que lo atiendan, hacer largas colas, desplazarse más lejos del punto que se encuentra ya sea por trabajo o estudios; por eso desea algo más cerca y que no tenga los inconvenientes de las largas colas o la espera en la atención a la mesa.

Hipótesis Clave del Problema:

Se escogió ESTÁ ABURRIDO DE IR A COMER A LOS MISMOS LUGARES como Problema 1, pues los clientes, siempre se encuentran en búsqueda de lugares que les ofrezcan nuevas experiencias, vivencias, o sensaciones donde el degustar un plato favorito esté acompañado de un lugar que le permita vivir un momento agradable y diferente.

\section{CUESTIONARIO PARA VALIDACION DE HIPOTESIS}




\section{¿POR QUÉ DEBEMOS HACER ENTREVISTAS A PROFUNDIDAD EN VEZ DE FOCUS GROUP?}

Para una validación, el mejor método es realizar las entrevistas a profundidad porque es más personalizado, y ambos segmentos son públicos diferentes y tienen diferentes problemas.

Las encuestas nos permiten estar en contacto con el usuario y el proveedor de manera directa e íntima para identificar rápidamente su problema

SEGMENTO 1: Camiones de venta de comida al paso en Lima y provincias Food Trucks

FOOD TRUCKS PREGUNTAS:

¿Cuéntame la historia de cómo sueles promocionarte para hacerte más conocido?

¿Cuéntame a que problemas sueles enfrentarte en esa situación?

¿Qué tan seguido te ocurre este problema el que más le molesta?

¿Cómo es que actualmente resuelves este problema?

¿Qué es lo más crítico para ti entorno a este problema?

\section{SEGMENTO 2: Consumidores de comida rápida en Lima y provincias.}

\section{CLIENTE PREGUNTAS:}

¿Cuéntame la historia de que haces o como decides que comer en la calle?

¿Cuéntame a que problemas sueles enfrentarte en esa situación?

¿Qué tan seguido te ocurre este problema el que más le molesta?

¿Cómo es que actualmente resuelves este problema?

¿Qué es lo más crítico para ti entorno a este problema? 


\subsection{RESULTADOS DE LA INVESTIGACIÓN}

La empresa realizo entrevistas de profundidad a 22 personas, 11 para cada segmento al que va dirigido el modelo de negocio.

1er. Segmento: Camiones de venta de comida al paso en Lima y provincias Food Trucks.

Ilustración 2: Entrevista Camiones de Venta de Comida al Paso en Lima

Fuente: Elaboración Propia

\begin{tabular}{|c|c|}
\hline \multicolumn{2}{|c|}{$\begin{array}{l}\text { ENTREVISTA CAMIONES DE VENTA DE COMIDA AL PASO EN LIMA Y } \\
\text { PROVINCIA (FOODTRUCK): }\end{array}$} \\
\hline \multicolumn{2}{|r|}{ PROBLEMA } \\
\hline & DESCRIPCION DEL PROBLEMA \\
\hline FOODTRUCK 1 & DESEARIA MAYOR PROMOCION Y PUBLICIDAD \\
\hline FOODTRUCK 2 & TRABAJA MAYORMENTE EN EVENTOS PRIVADOS PERO NO PUEDE ATENDER AL PUBLICO EN \\
\hline FOODTRUCK 3 & PROBLEMA CON LICENCIA DE FUNCIONAMIENTO Y LO BOTAN DE DONDE SE UBICA \\
\hline FOODTRUCK 4 & PROBLEMA CON LICENCIA DE FUNCIONAMIENTO Y LO BOTAN DE DONDE SE UBICA \\
\hline FOODTRUCK 5 & PROBLEMA CON LICENCIA DE FUNCIONAMIENTO Y LO BOTAN DE DONDE SE UBICA \\
\hline FOODTRUCK 6 & PROBLEMA CON LICENCIA DE FUNCIONAMIENTO Y LO BOTAN DE DONDE SE UBICA \\
\hline FOODTRUCK 7 & TIENE LOCAL PROPIO PERO HAN TENIDO QUE INVERTIR EN FOODTRUCK PARA CAPTAR MAS CLIENTES \\
\hline FOODTRUCK 8 & TIENE LOCAL PROPIO PERO HAN TENIDO QUE INVERTIR EN FOODTRUCK PARA CAPTAR MAS CLIENTES \\
\hline FOODTRUCK 9 & PROBLEMA CON LICENCIA DE FUNCIONAMIENTO Y LO BOTAN DE DONDE SE UBICA \\
\hline FOODTRUCK 10 & PROBLEMA CON LICENCIA DE FUNCIONAMIENTO Y LO BOTAN DE DONDE SE UBICA \\
\hline FOODTRUCK 11 & PROBLEMA CON LICENCIA DE FUNCIONAMIENTO Y LO BOTAN DE DONDE SE UBICA \\
\hline
\end{tabular}




\section{Experiment Board :}

Ilustración 3: Experiment Board 1

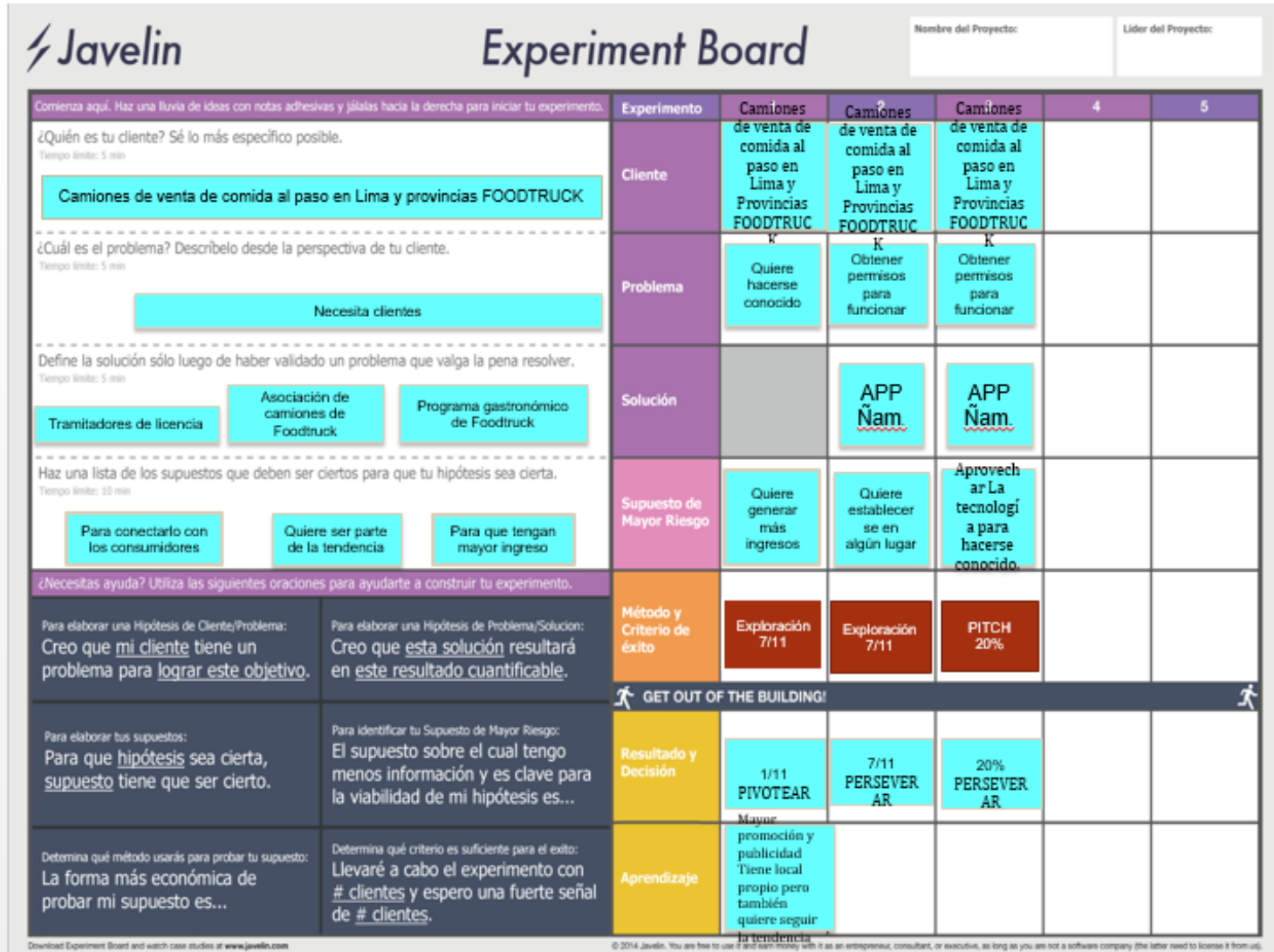

Fuente: Elaboración Propia

\section{PIVOTEAR}

Siguiendo el proceso del tablero de experimentación nos indica que siendo el resultado 7/11 la empresa debe Perseverar. 


\section{2do. Segmento: Consumidores de comida rápida en Lima y provincias.}

De acuerdo a las entrevistas realizadas al primer segmento que son los consumidores de comida rápida en Lima y provincia, se ha identificado que el problema no era que "esta aburrido de ir a comer a los mismos lugares"; sino el mayor problema es la falta de tiempo y el supuesto es que no le gusta esperar.

Ilustración 4: Entrevista Consumidores de Comida Rápida en Lima y Provincia

\begin{tabular}{|l|l|}
\hline \multicolumn{1}{|c|}{ ENTREVISTA : CONSUMIDORES DE COMIDA RÁPIDA EN LIMA Y } \\
\multicolumn{1}{|c|}{ PROVINCIA } \\
\hline \multicolumn{1}{|c|}{ PROBLEMA } \\
\hline & \multicolumn{1}{|c|}{ DESCRIPCION DEL PROBLEMA } \\
\hline CLIENTES 1 & \multicolumn{1}{|c|}{ NO TIENE TIEMPO PARA ESPERAR } \\
CLIENTE 2 & NO ENCUENTRA INFORMACION DE DONDE COMER \\
CLIENTE 3 & NO TIENE TIEMPO PARA ESPERAR \\
CLIENTE 4 & LE GUSTARIA ENCONTRAR BUENAS RECOMENDACIONES \\
CLIENTE 5 & NO TIENE TIEMPO PARA ESPERAR \\
CLIENTE 6 & NO TIENE TIEMPO PARA ESPERAR \\
CLIENTE 7 & BUSCA NUEVAS EXPERIENCIAS \\
CLIENTE 8 & NO ENCUENTRA MUCHOS LUGARES PARA COMER CON OPCIONES DE JUEGOS PARA NIÑOS \\
CLIENTE 9 & BUSCA NUEVAS EXPERIENCIAS \\
CLIENTE 10 & NO TIENE TIEMPO PARA ESPERAR \\
CLIENTE 11 & NO TIENE TIEMPO PARA ESPERAR \\
\hline
\end{tabular}

Fuente: Elaboración Propia 


\section{Experiment Board:}

Ilustración 4: Experiment Board 2

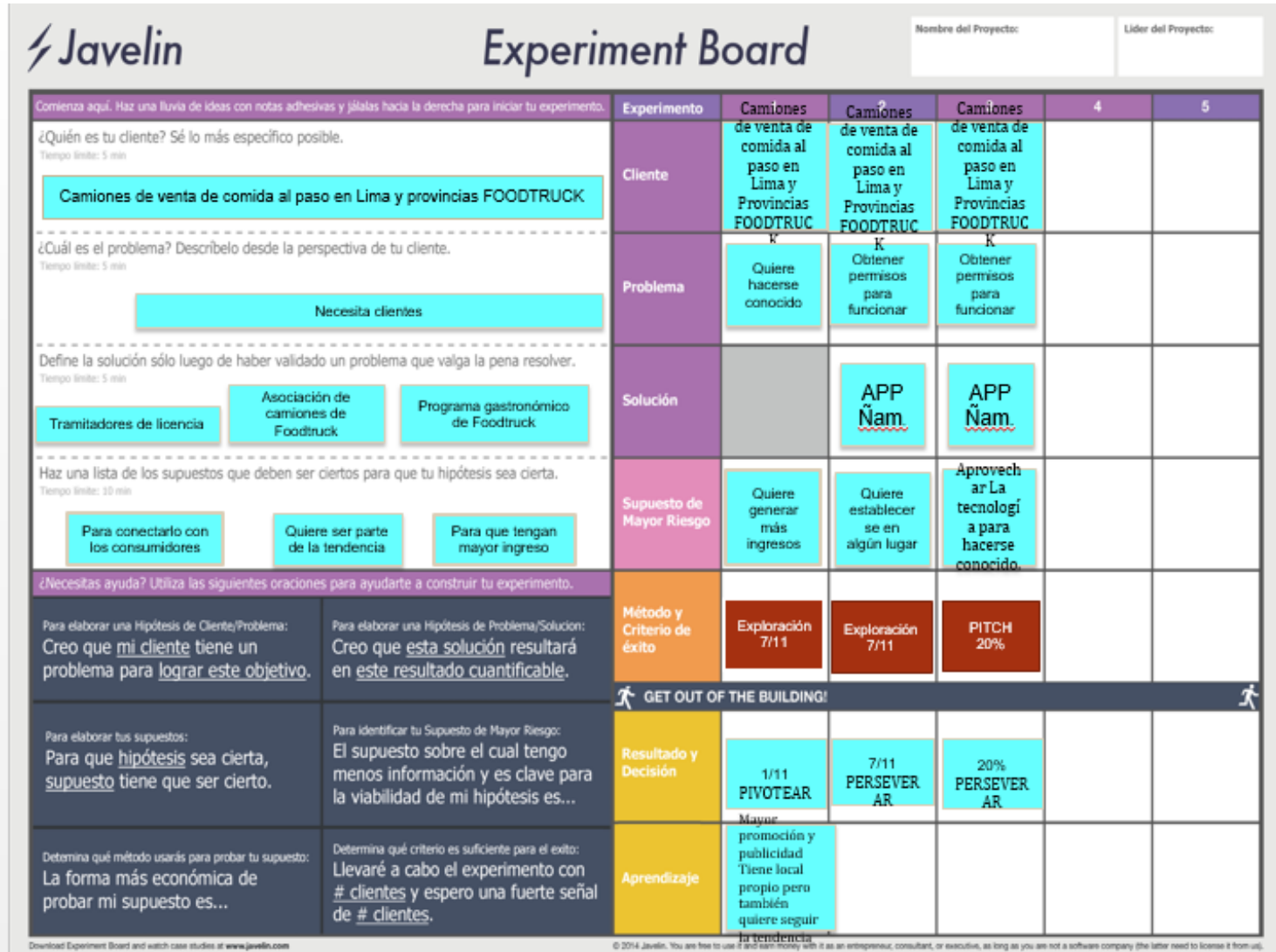

Fuente: Elaboración Propia

\section{PIVOTEAR}

Siguiendo el proceso del tablero de experimentación nos indica que siendo el resultado 7/11 la empresa debe Perseverar.

Siguiendo el proceso del tablero de experimentación nos indica que siendo el resultado 6/11 debemos Perseverar. 


\section{HIPOTESIS DE LA SOLUCION:}

De acuerdo a los problemas encontrados se proponen diferentes soluciones:

Soluciones para el 1er. Segmento: Camiones de venta de comida al paso en Lima y provincias Food Trucks.

TRAMITES DE LICENCIA: Esta posible solución permite que el dueño del camión de Food Trucks este más estable y con ello tenga mayor tranquilidad para crear sus recetas y atender a su público, así podrá pensar en cómo atraer más clientes.

APP (¡ÑAM!): Es una propuesta de un aplicativo que brinde información acerca de la ubicación de los food trucks, así los clientes podrán ubicar el más cercano. Además, podrán tener información de cada especialidad de los food trucks y poder hacer su solicitud y pagar con tarjeta de crédito, así cuando llegue su orden estará lista.

ASOCIACION DE CAMIONES DE FOOD TRUCKS: Pertenecer a una asociación organizada es muy conveniente porque pueden tener mayor presencia y fuerza en grupo. Además de contar con información de eventos para participar como en ferias o conciertos. PROGRAMA GASTRONOMICO DE FOOD TRUCKS: Un programa de televisión que visite y difunda los camiones food trucks podría atraer a muchos clientes, podrían presentar sus productos y ser una vitrina de exhibición y recomendación.

\section{SOLUCIÓN ESCOGIDA}

Se escogió elaborar un APP, cuyo nombre será ¡Ñam! Buscador de FOOD TRUCKS, porque la empresa cree que es una buena solución para conectar a los camiones de comida con muchos consumidores de comida rápida, que desean comer algo al paso y no les gusta esperar mucho.

También es una manera de promocionar esta tendencia que puede hacer vivir a muchas personas experiencias agradables y salir de la monotonía.

Soluciones para el 2do. Segmento: Consumidores de comida rápida en Lima y provincias. 
DELIVERY DE COMIDAS: Opción de entrega de comida que el consumidor elija desde la comodidad de su hogar, contando siempre con las mismas opciones de lugares de comida.

\section{SEÑORAS QUE SE ESPECIALICEN EN PREPARAR COMIDA PARA TODA}

LA SEMANA: Contratar a personas para que realicen la preparación de comida, de acuerdo al gusto del consumidor o lo que tengan en su carta de comidas, generándoles la comodidad de la preparación.

\section{EMPRESAS QUE OFREZCAN MEMBRESIAS DE ALMUERZOS PARA}

OFICINA: Pagar a estas empresas para que envíen a las oficinas los almuerzos y así evitarse cocinar a diario y tenga mayor tiempo al momento de alistarse. Además de enviarles su almuerzo a su oficina sin que el consumidor salga de ella y así pueda tener mayor tiempo en su hora de almuerzo.

APP (¡ÑAM!): con este aplicativo el consumidor se podrá contactar con los FOODTRUCKS para que su pedido esté listo al momento de ir a recogerlo en el lugar donde se encuentre. Además de salir a un lugar cómodo y bonito, podrá degustar de su comida apenas llegue donde se encuentren los FOOD TRUCKS.

\section{SOLUCION ESCOGIDA}

Se escogió elaborar el aplicativo ¡Ñam! buscador de FOOD TRUCKS, ya que el consumidor podrá solicitar su pedido por medio del aplicativo y además podrá visitar un lugar cómodo y bonito, pasará un momento tranquilo con amigos, familiares o porque no solo. Con ello evitará de realizar colas y no perderá tiempo.

\section{SUPUESTO MÁS RIESGOSO}

SEGMENTO 1: Camiones de venta de comida al paso en Lima y provincias Food Trucks.

\section{SUPUESTO 1: QUIERE GENERAR MÁS INGRESOS:}

Al hacerse más conocidos en el mundo culinario los FOOD TRUCKS generaran mayores ingresos lo cual debe ser aprovechado al máximo, esto les permitirá expandirse en varios distritos de Lima o provincias.

SUPUESTO 2: QUIERE SER PARTE DE LA TENDENCIA: 
La tendencia culinaria que existe de los FOOD TRUCKS ha ido creciendo rápidamente, por ello queremos que sea aprovechado al máximo para poder cumplir con las expectativas que hay en el país por esta tendencia.

\section{SUPUESTO 3: QUIERE ESTABLECERSE EN ALGUN LUGAR:}

Los camiones de venta de comida rápida al paso en Lima provincias FOOD TRUCKS desean que sus clientes o posibles consumidores los puedan ubicar rápidamente y de fácil acceso para poder brindarles propuestas diversas de comida.

\section{¿POR QUÉ SE ELIGIÓ EL SUPUESTO 1?}

Se escogió a QUIERE GENERAR MAS INGRESOS, porque con ello podrán implementar su negocio de FOOD TRUCKS, además de generarle rentabilidad y ganancias en el negocio, pudiendo expandirse en otras provincias que aún no han llegado y distritos de Lima.

\section{SEGMENTO 2: Consumidores de comida rápida en Lima y provincias.}

\section{SUPUESTO 1: BUSCA NUEVAS EXPERIENCIAS}

Los clientes siempre buscan un servicio que les brinde innovación, vivencias, mejor aún si se presenta en lugares no comunes y su estadía sea agradable.

\section{SUPUESTO 2: QUIERE ECONOMIZAR}

Los clientes prefieren los productos o servicios que ofrezcan las $3 \mathrm{~B}$ (bueno, bonito y barato), si bien son exigentes al buscar lo que desean, genera un placer adicional al generarse un ahorro sin previo aviso.

\section{SUPUESTO 3: TIENE HAMBRE}

Las exigencias del día a día, permite que los clientes busquen lugares donde el almorzar, cenar, no les tome mucha parte del tiempo, durante el transcurso de la semana, buscan lugares, que se adapten a su estilo de vida y puedan encontrar rápidamente lo que buscan. ¿POR QUÉ SE ELIGIÓ EL SUPUESTO 1?

Se escogió BUSCAN NUEVAS EXPERIENCIAS como supuesto 1, ya que es la opción que mejor se generaliza a las exigencias del cliente. Creemos que es el principal motivo por el que el cliente esté dispuesto a consumir el servicio.

METODO Y CRITERIO DE ÉXITO: OBJETIVO MÍNIMO DEL PRODUCT PITCH 
El método que se está utilizando es el PITCH MVP; Ya que aún no se tiene un proyecto tangible ni que vender, se usara el Landing page; creando anuncios donde se ofrezcan nuestros productos (supuestos) a los clientes y proveedores que en este caso serán los negocios de comida rápida sobre ruedas también llamados FOOD TRUCKS. Este Landing page, será anunciado en redes sociales (Facebook) con lo cual, se buscará que el público objetivo encuentre llamativo el anuncio y deje su correo electrónico.

Al dejar su correo electrónico, estarán brindando información necesaria para cubrir su necesidad de falta de tiempo a la hora de buscar que comer ya que no le gusta esperar; De la misma forma intercambiaran información con los señores de los Food Trucks para saber cuáles son sus necesidades para obtener mayores ingresos.

Así se intercambiará información tanto a los usuarios de los Food Trucks y los dueños de estos negocios, es decir se realizará una preventa del producto; con el fin no solo de solucionar las necesidades de ambos sectores, sino también obtener ingresos por este servicio.

Ilustración 5: Clic de Alcance

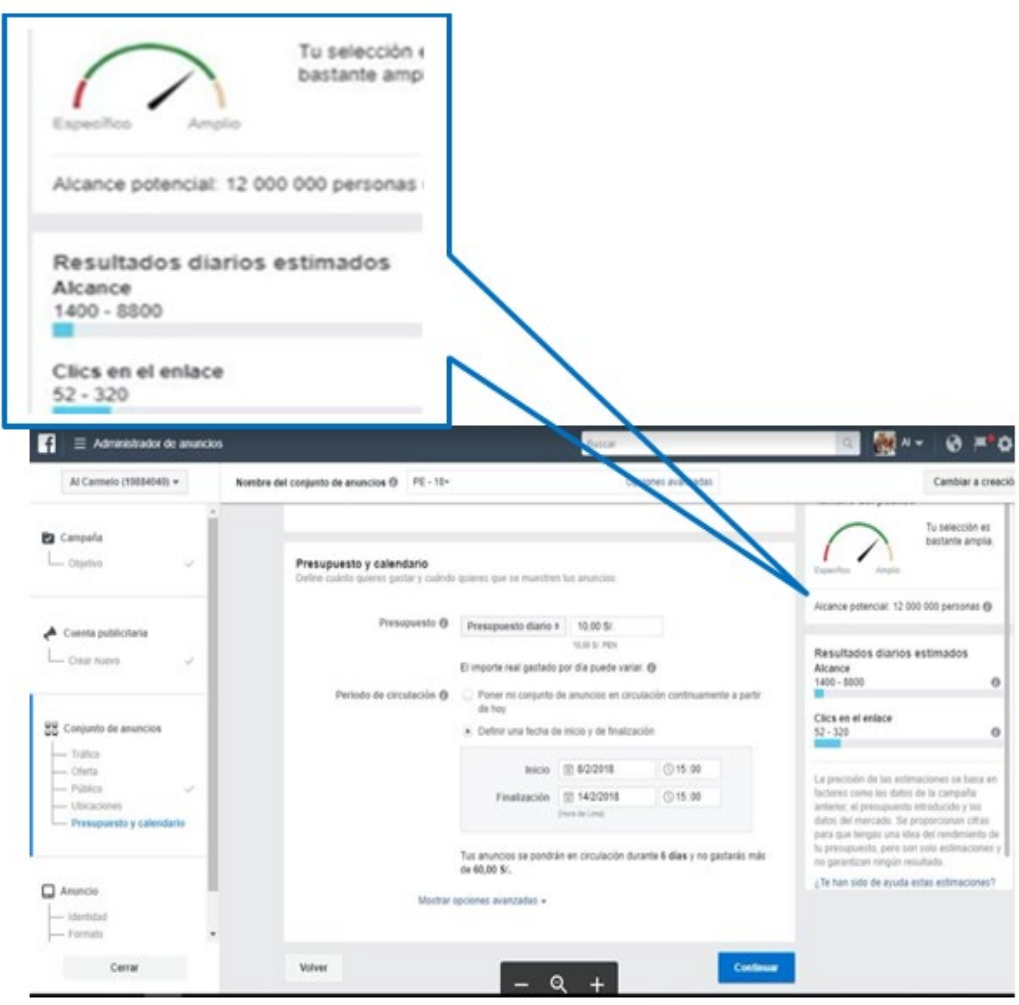

Fuente: Elaboración Propia

Por antes mencionado, esta etapa del método PITCH MVP se buscará mínimamente que los clientes y proveedores; brinden su correo electrónico e información concerniente a la 
idea de negocio que se ofrece; para esto luego de lanzar el anuncio se revisaran los resultados de las métricas para obtener mayor información de cómo les fue en el testeo de las redes sociales, lo que permitirá validar la solución.

El segmento escogido está orientado a las personas que se encuentran en la búsqueda de comida por las diversas redes sociales entre 18 a 65 años de edad. La publicación del Landing page nos refleja un alcance potencial del universo de 12000 000; el Facebook nos da un universo de 52 impresiones de los cuales en un primer momento de publicación ya 16 personas le dieron clic aún nos falta la información que nos otorga el Landing mediante los correos que nos dejen los usuarios; la métrica de éxito esperada será de $20 \%$.

Ilustración 6: Landing: Segmento 1

Camiones de venta de comida al paso en Lima y Provincias

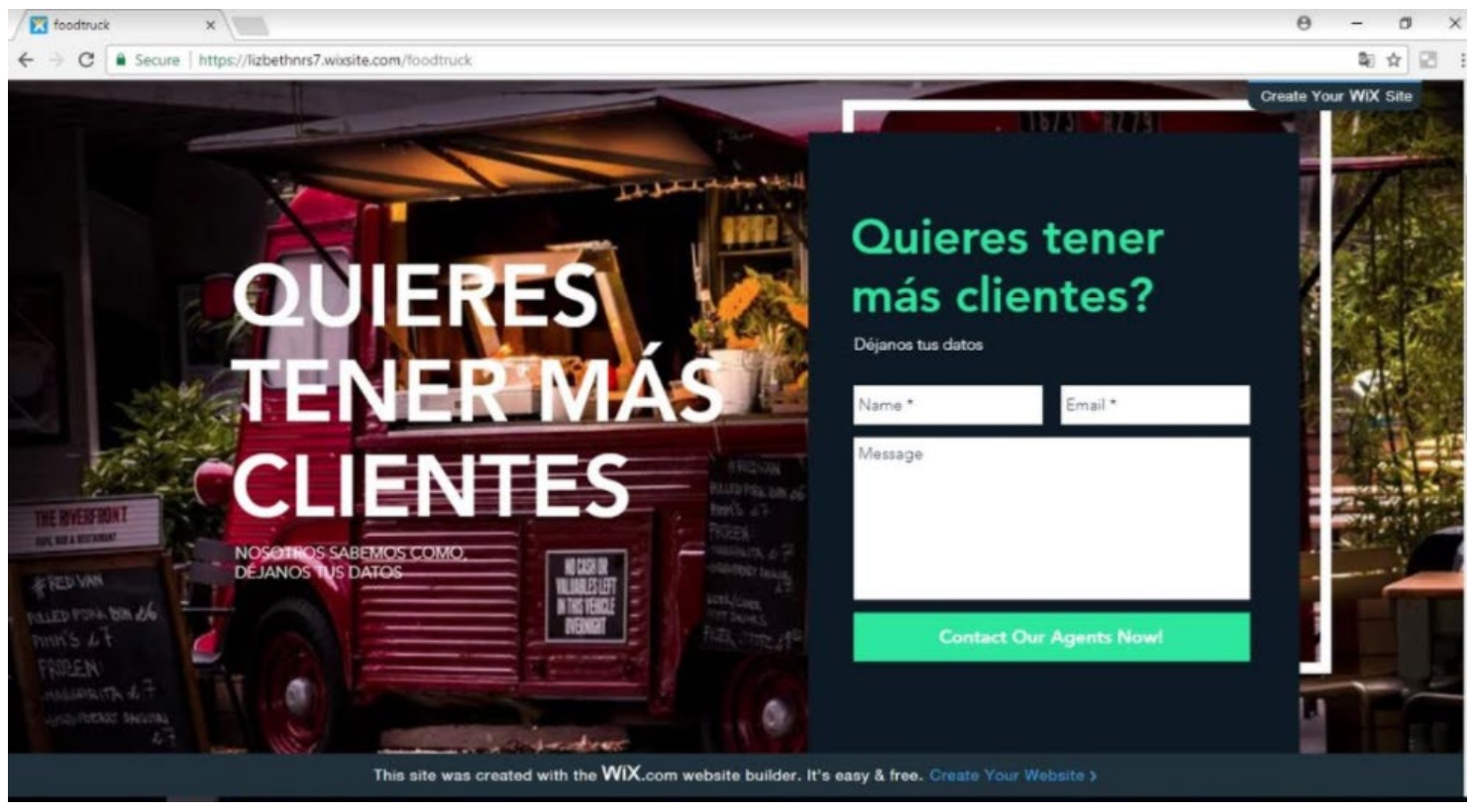

Fuente: Elaboración Propia 
Ilustración 7: Landing: Segmento 2

Consumidores de comida rápida en Lima y provincias CONSUMIDORES DE

\section{COMIDA RAPIDA}

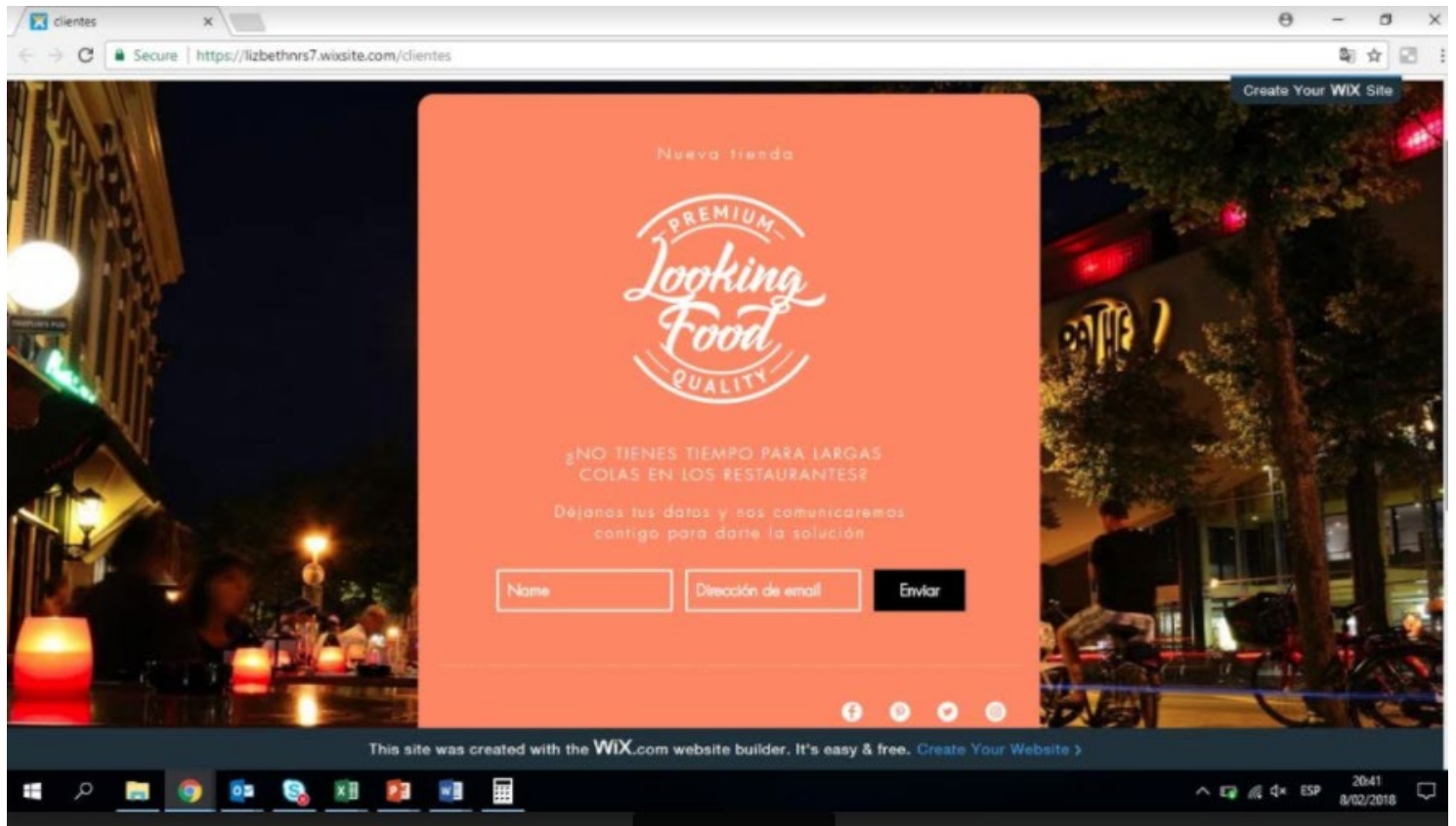

Fuente: Propia

Ilustración 8: Captación De Prospectos

POR EJEMPLO, PANTALLAZOS DE FACEBOOK Y MÉTRICAS

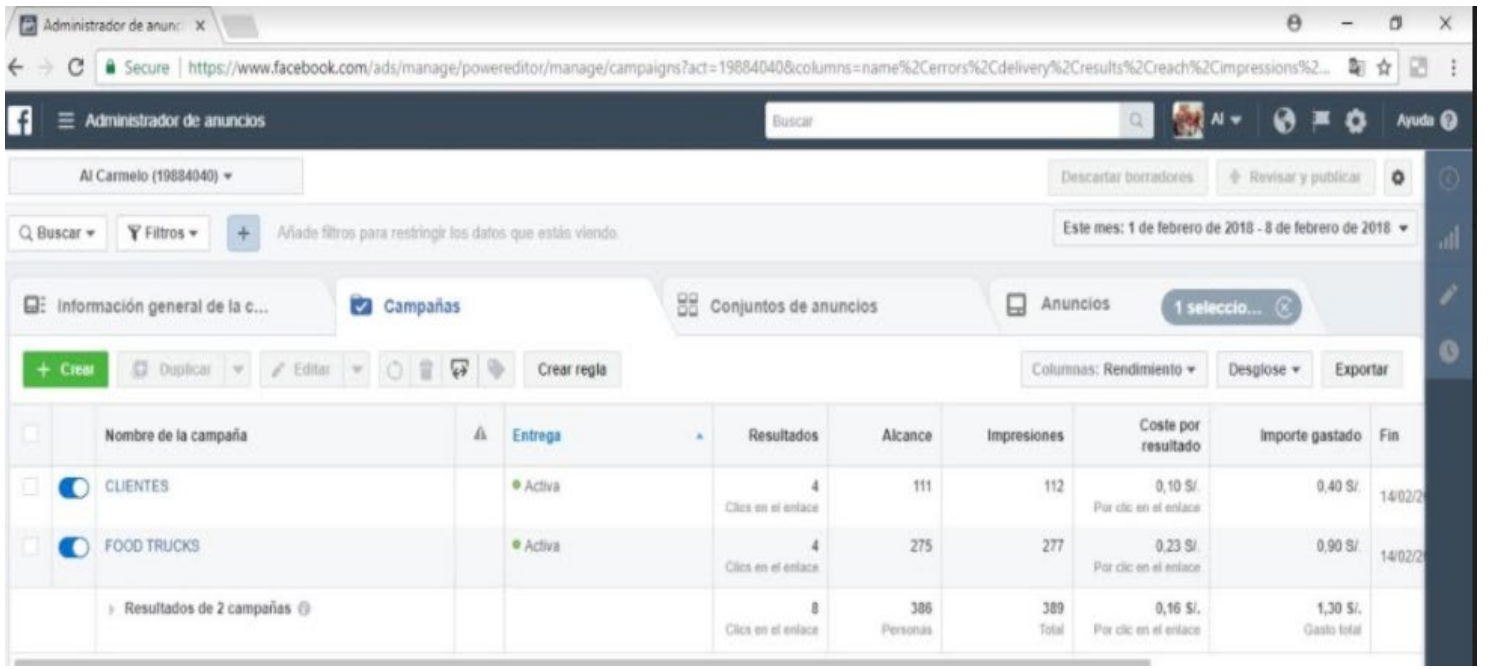

Fuente: Elaboración Propia 


\section{RESULTADO, DECISIÓN Y APRENDIZAJE: PERSEVERAR O PIVOTAR.}

Ilustración 9: Camiones de venta de comida al paso - Métricas

SEGMENTO 1: Lima y provincias Food Trucks

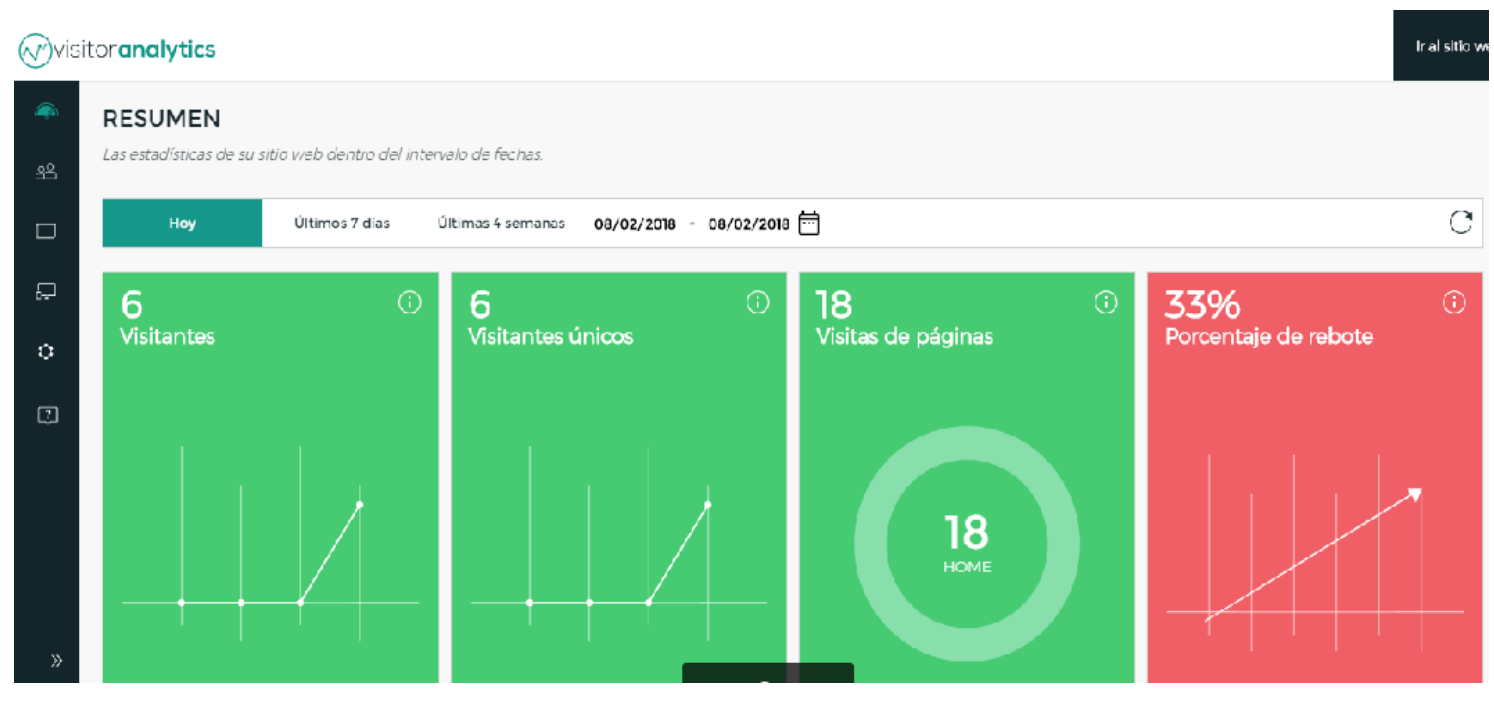

Fuente: Elaboración Propia

Ilustración 10: Camiones de venta de comida al paso - Métricas

SEGMENTO 1: Lima y provincias Food Trucks
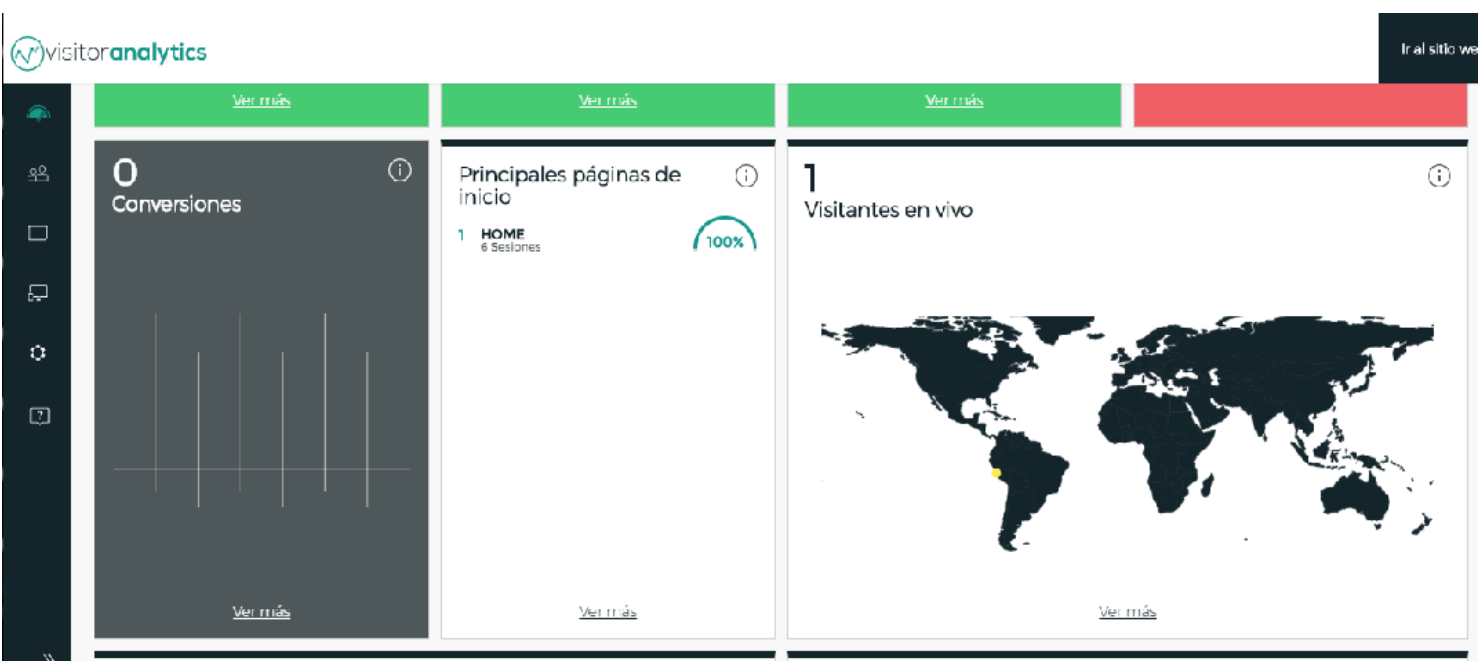

Fuente: Elaboración Propia 
Ilustración 11: Camiones de venta de comida al paso - Métricas

SEGMENTO 1: Lima y provincias Food Trucks

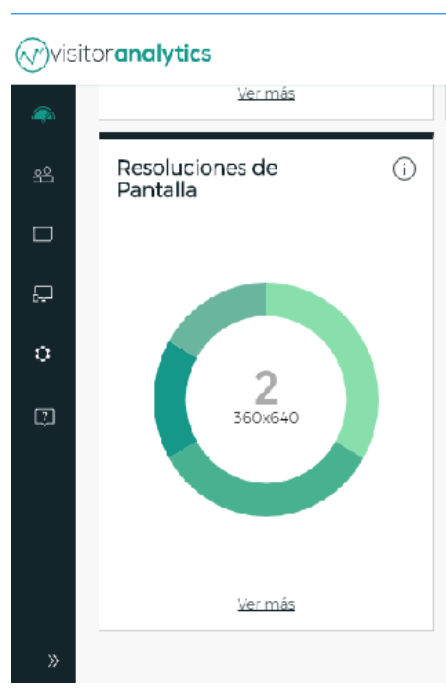

Fuente: Elaboración Propia

Ilustración 12: Camiones de venta de comida al paso - Métricas

SEGMENTO 1: Lima y provincias Food Trucks

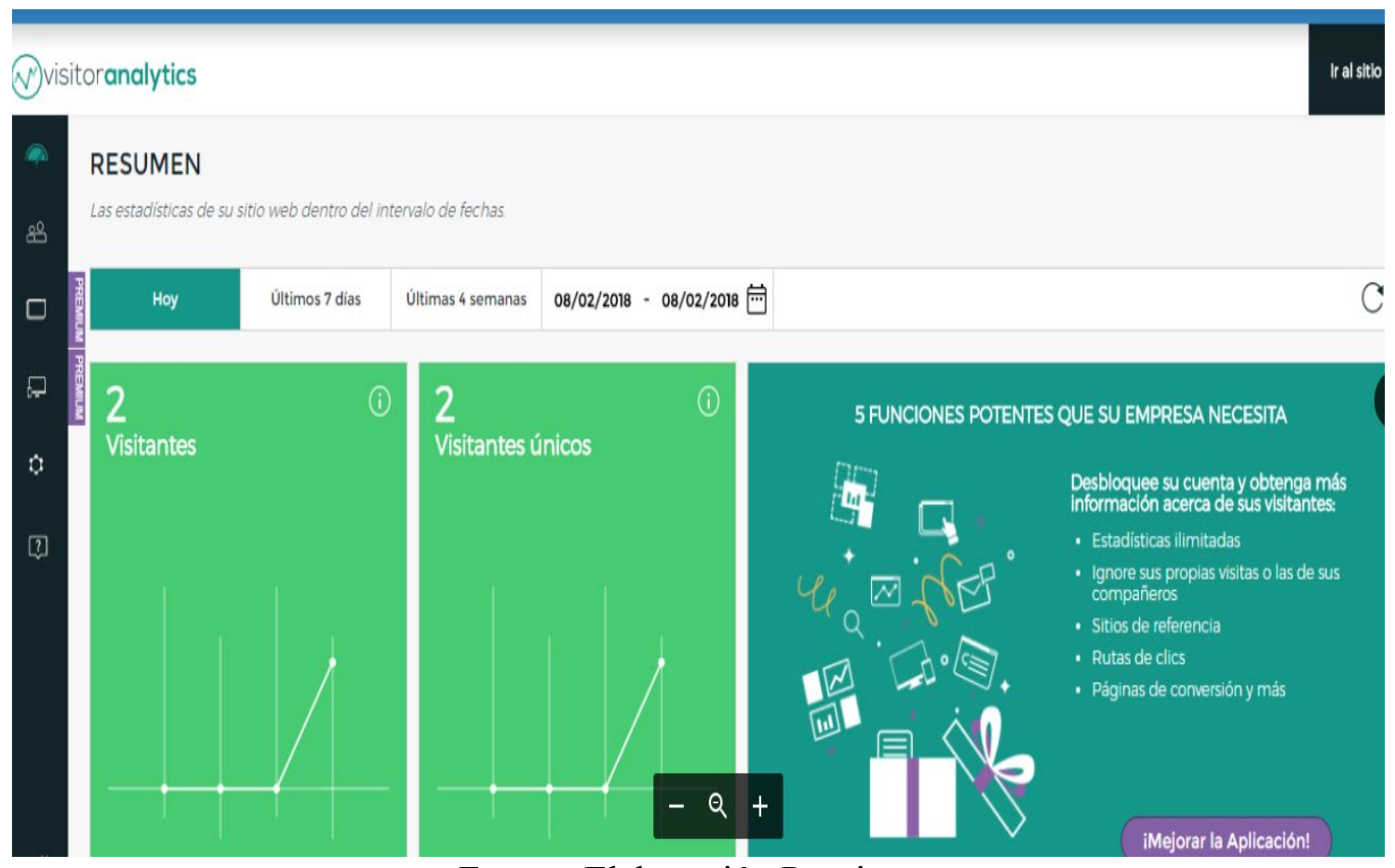

Fuente: Elaboración Propia 
Ilustración 13: Consumidores de comida rápida en Lima y provincias

SEGMENTO 2: CONSUMIDORES DE COMIDA RAPIDA

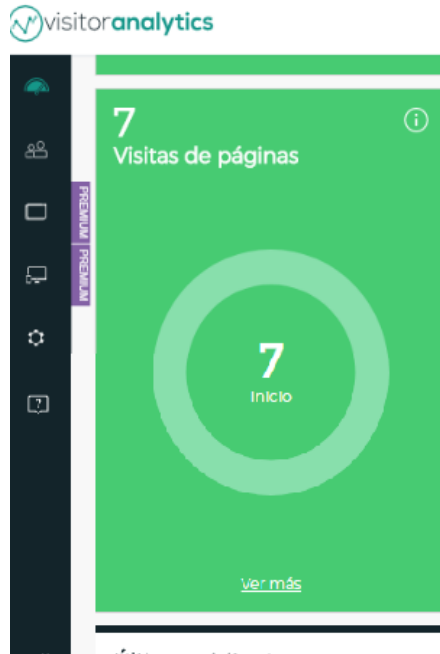

I'lltimne vicitantes
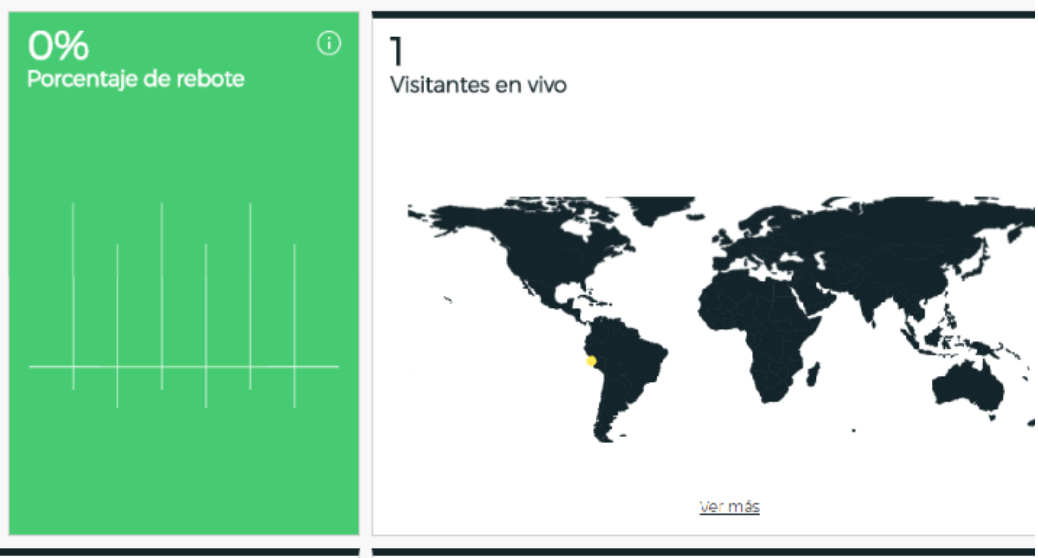

Fuente: Elaboración Propia

Ilustración 14: Consumidores de comida rápida en Lima y provincias

SEGMENTO 2: Países

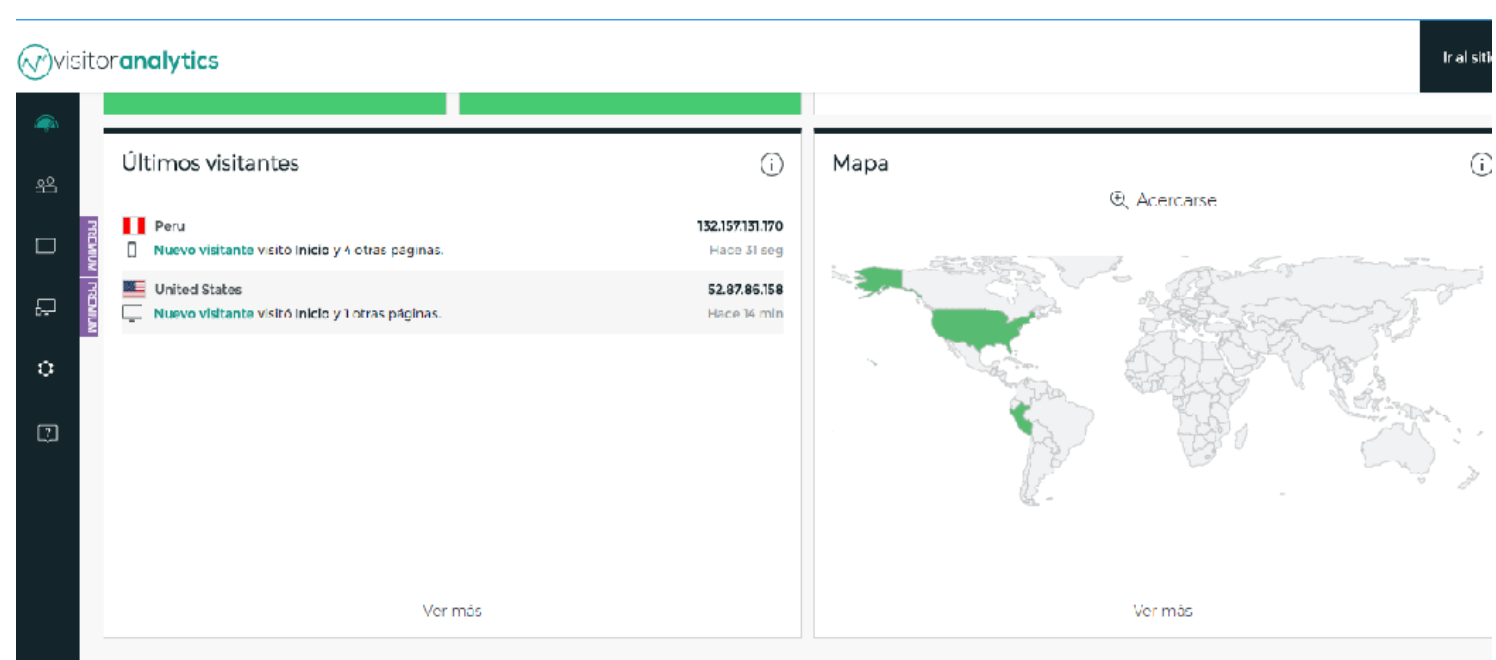

Fuente: Elaboración Propia 
Ilustración 15: Consumidores de comida rápida en Lima y provincias

SEGMENTO 2: Últimos visitantes

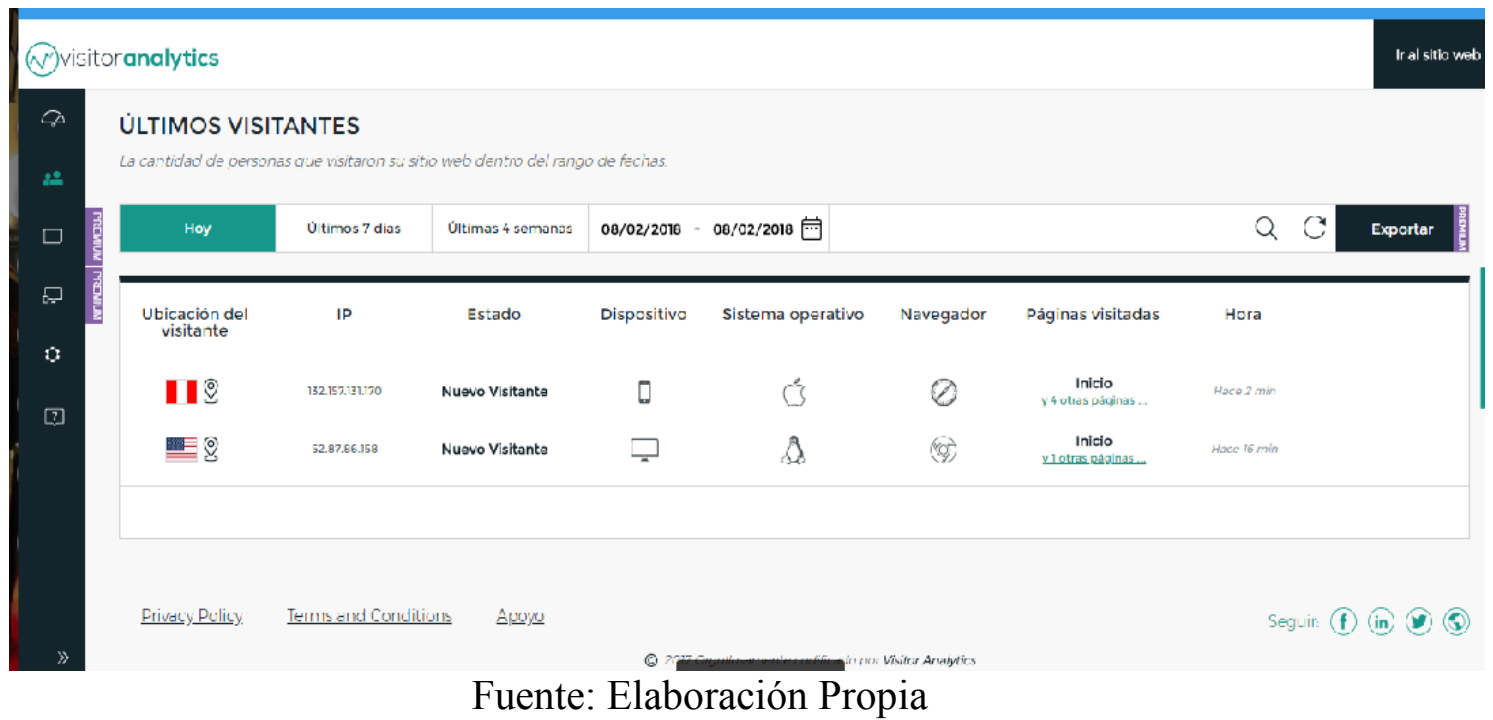

Ilustración 16: Clientes Y Food Trucks Que Ingresaron Y Dieron Clic

\begin{tabular}{|c|c|c|c|c|c|c|c|c|c|c|c|c|c|c|c|}
\hline ff & $\equiv \mathrm{Ad}$ & Iministrador de an & ndios & & & & & & Buscar & & & Q 5 & -0 & 0 & Ayuda \\
\hline & & Carmelo (19884040) & & & & & & & & & & iscartar borradores & + Revisary & ublicar & 0 \\
\hline Q Bus & iscar v & P Filtros V & + & Ariade filtr & os para restringir los & datos & que estas viendo & & & & & ste mes: 1 de febrero & 2018 - 8 de fet & ero de 2 & 18 . \\
\hline Q: & Informs & lación general de & la c... & & D Campañas & & & 용 & :onjuntos de an & & 日 Anur & eios & & & \\
\hline & Crear & (1) Duplicar & $\nabla$ & 1 Editar & $=0=\pi$ & $\theta$ & Crear regla & & & & Colum & las: Rendimiento & Desglose - & Expor & \\
\hline & & Nombre de la camp & & & & $\Delta$ & Entrega & . & Resultados & Alcance & Impresiones & $\begin{array}{l}\text { Coste por } \\
\text { resultado }\end{array}$ & Importe & astado & Fin \\
\hline & 0 & CLIENTES & & & & & - Activa & & $\begin{array}{r}10 \\
\text { Clics en el endace }\end{array}$ & 409 & 411 & $\begin{array}{l}0,17 \mathrm{SI} \text {. } \\
\text { Por tilic en el eniace }\end{array}$ & & $1.70 \mathrm{si}$. & $140:$ \\
\hline & O & FOOD TRUCKS & & & & & - Acliva & & $\begin{array}{r}5 \\
\text { Clics en el enace }\end{array}$ & 481 & 486 & $\begin{array}{l}0,27 \mathrm{~s} \text {. } \\
\text { Por dic en di enilase }\end{array}$ & & $1.37 \mathrm{Sl}$ & $140:$ \\
\hline & & , Resultados de 2 & campa & nắas 0 & & & & & $\begin{array}{r}15 \\
\text { Clics en el enlisce }\end{array}$ & $\begin{array}{r}838 \\
\text { Personas }\end{array}$ & $\begin{array}{l}897 \\
\text { Total }\end{array}$ & $\begin{array}{r}0,20 \mathrm{~S} / . \\
\text { Por clice en el enlace }\end{array}$ & & 3,07 Si. & \\
\hline
\end{tabular}

Fuente: Elaboración Propia 
Ilustración 17: Correo De Solicitud De Interés

SEGMENTO 1: Camiones de venta de comida al paso en Lima y provincias Food Trucks

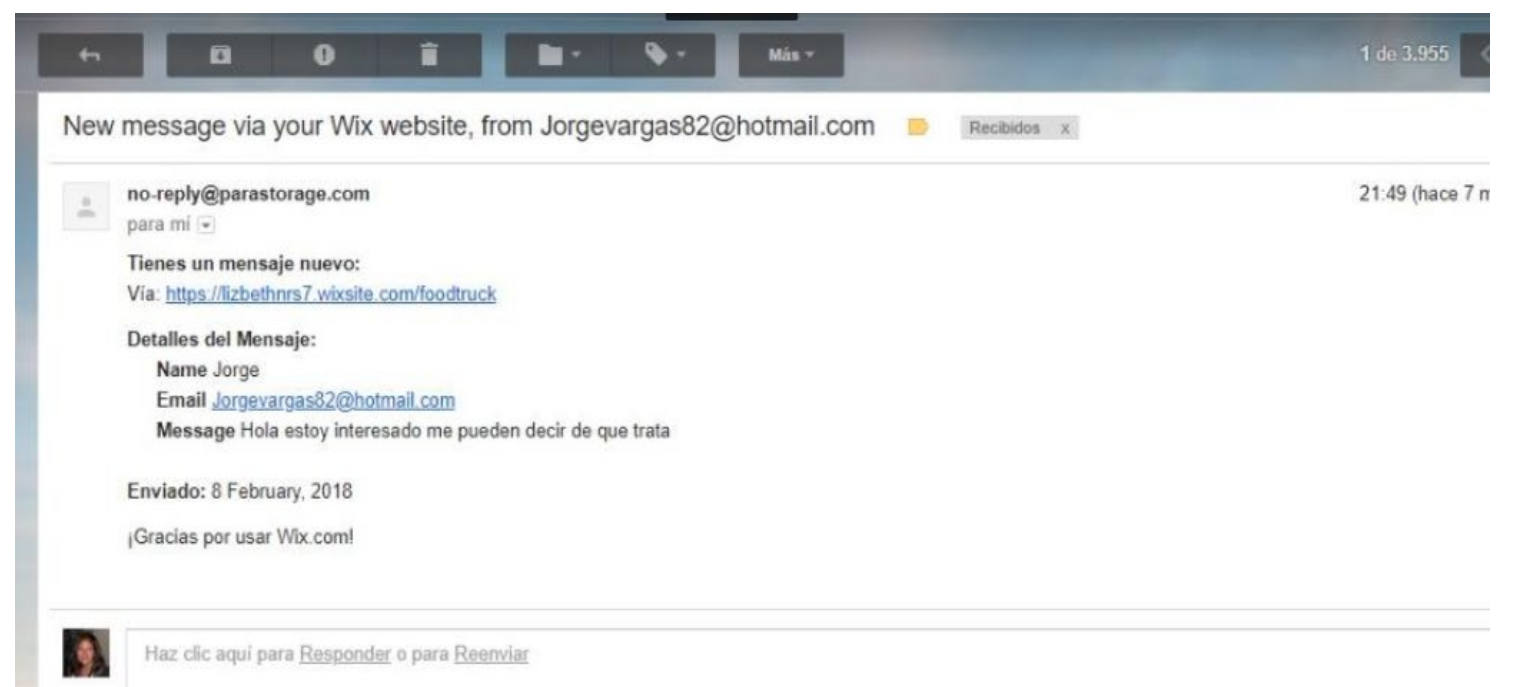

Fuente: Elaboración Propia

\section{CONCLUSIONES:}

- En consumidores de comida rápida hasta el momento, con 2 horas de haber lanzado el landing, se ha pivoteado ya que no hemos alcanzado el porcentaje esperado.

- En Camiones Food trucks, con 2 horas de haber lanzado el landing, se ha tenido una respuesta de un usuario, ello da buena expectativa por lo tanto nos mantenemos perseverando. 
Ilustración 18: Camiones de venta de comida al paso

SEGMENTO 1: en Lima y provincias FoodTrucks

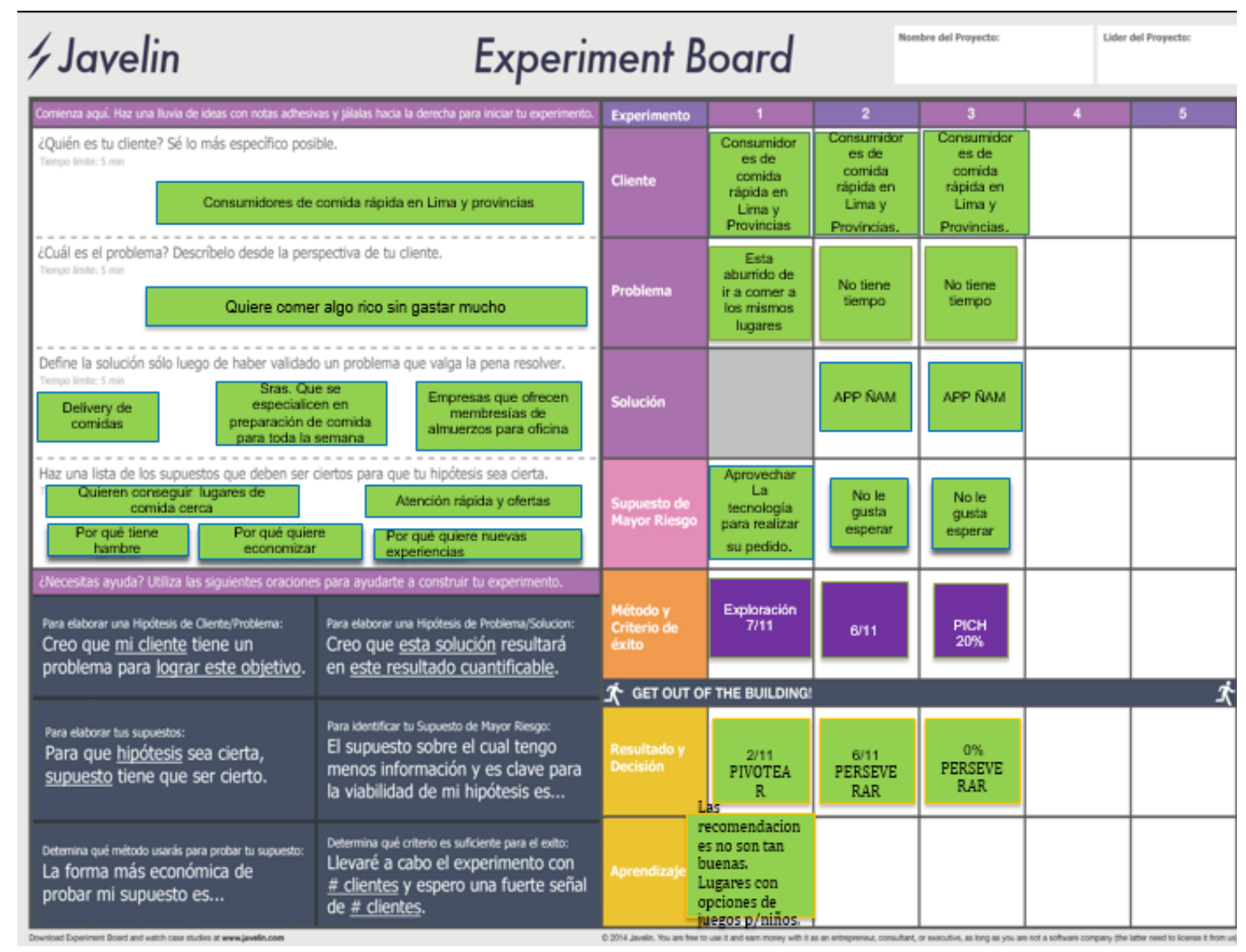

Fuente: Elaboración Propia 
Ilustración 19: Consumidores de comida rápida en Lima y provincias.

Segmento 2

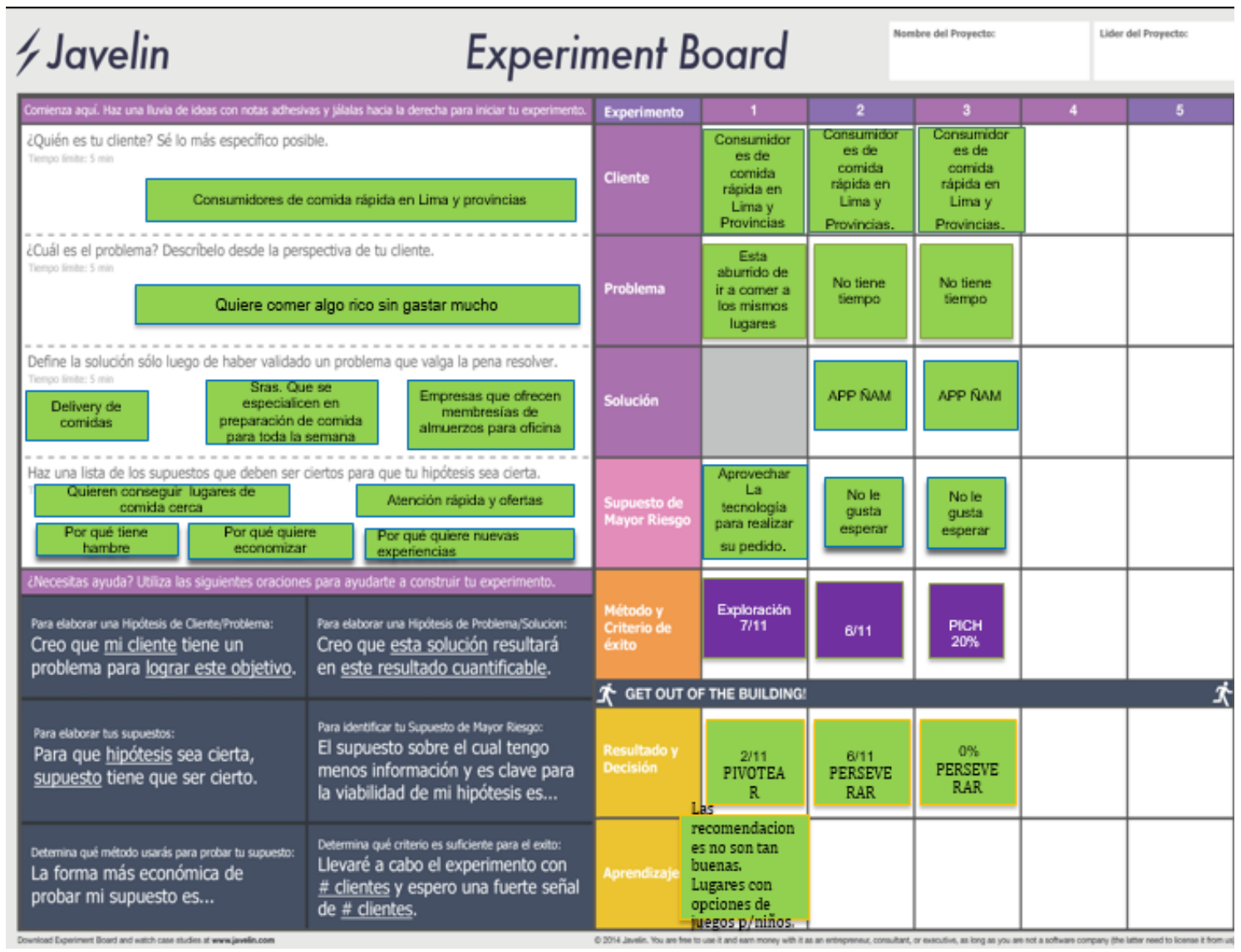

Fuente: Elaboración Propia 


\subsection{INFORME FINAL: ELABORACIÓN DE TENDENCIAS, PATRONES Y CONCLUSIONES}

\section{Conclusiones del Modelo de Negocio}

La empresa ha validado que el primer segmento camiones de venta de comida al paso en Lima y provincias Food trucks, y el segundo segmento de Consumidores de comida rápida en Lima y provincias realmente tienen un problema que los relaciona a ambos, el primero es vender o exhibir sus productos al público consumidor y el segundo es el que busca lugares donde comprar una buena comida y variada, en tal sentido la idea de negocio final es elaborar un aplicativo donde los consumidores puedan encontrar a través del Google maps la ubicación más cercana de un camión food trucks.

Donde podrán visualizar la ubicación de diferentes camiones y revisar la lista de productos que ofrecen, así elegir la comida que más les guste o les provoque en ese momento, también pueden ordenarla a través del aplicativo y pagar a través de tarjeta de crédito o débito.

Esto significa que cuando el consumidor de comida rápida llegue a la ubicación, su pedido ya estará listo o en proceso de atención, por lo tanto, no le demandara mucho tiempo en la espera que era lo que más les disgustaba.

También ellos podrán postear la página del food trucks y calificar su comida, si a ellos les gusto le dará la máxima calificación con 5 estrellas y realizar algún comentario; si la experiencia no fue buena en la atención o el producto no fue de su agrado podrá comentarlo o calificarlo con un dedo hacia abajo. Esto servirá para que los dueños de camiones mejoren su atención y sus productos y para que el público usuario pueda seguir a los más recomendados, ganando así mayores clientes.

Por este servicio del aplicativo, los dueños de camiones de food trucks pagaran un $5 \%$ del volumen de las ventas. 
Ilustración 20: Mapa De Empatía - Food Trucks

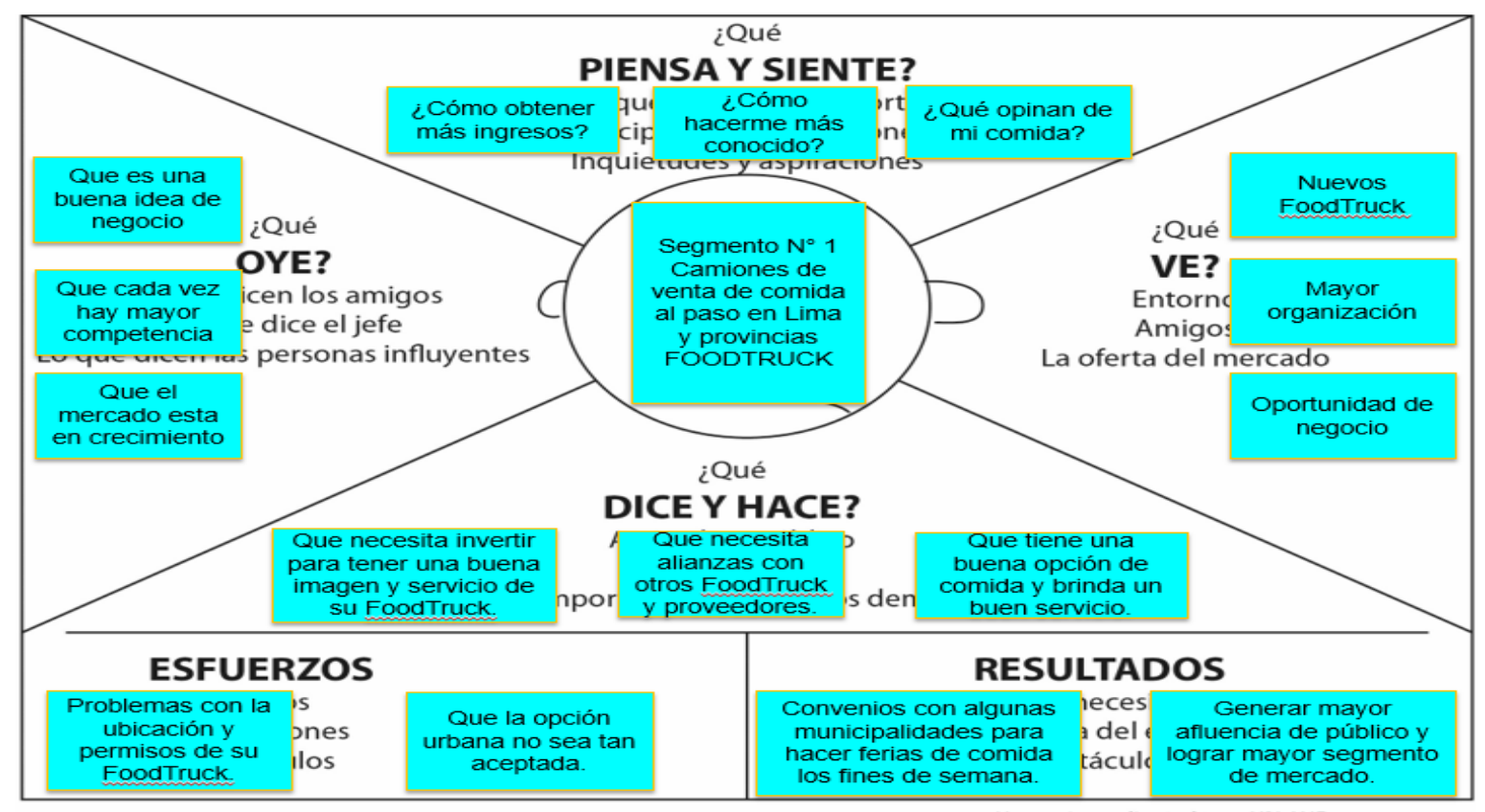

Fuente: Elaboración Propia

Ilustración 21: Mapa De Empatía - Clientes

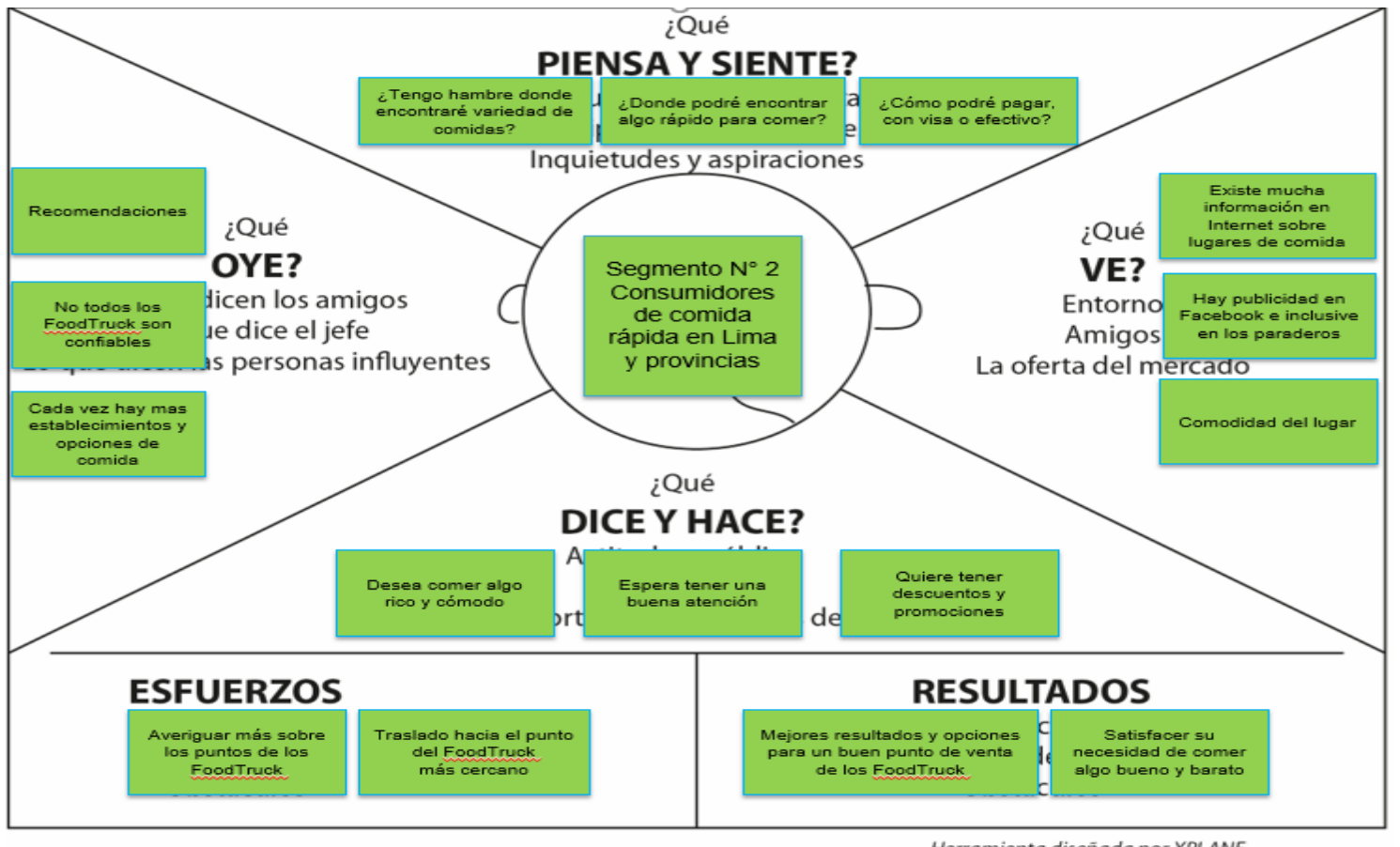

Fuente: Elaboración Propia 
Tabla 3: Encuestas para realizar el TARGET

\begin{tabular}{|c|c|c|c|}
\hline PR & $\begin{array}{l}\text { OYECTO: EMPRESA DE VENTA: } \\
\text { LUGAR: DISTRITO: Lima } \\
\text { /INCIA: Lima }\end{array}$ & DE SERVIC & OS \\
\hline $\begin{array}{l}\text { Núme } \\
\text { ro }\end{array}$ & Pregunta & Respuesta & $\begin{array}{c}\text { Códi } \\
\text { go }\end{array}$ \\
\hline 1 & ¿Consume de manera frecuentemente en los Food & $\mathrm{Si}$ & 1 \\
\hline 1 & & No & 2 \\
\hline & & Diario & 1 \\
\hline 2 & ¿Con que continuidad consume usted en los Food & Semanal & 2 \\
\hline 2 & Trucks? & Mensual & 3 \\
\hline & & Bimensual & 4 \\
\hline & & Miraflores & 1 \\
\hline 3 & ¿Cuál es el distrito donde más consume en un Food & Surco & 2 \\
\hline & Trucks? & San Isidro & 3 \\
\hline & & Otros & 4 \\
\hline & & 10 a 20 soles & 1 \\
\hline 4 & ¿Cuánto invierte aproximadamente en cada & 20 a 30 soles & 2 \\
\hline 4 & oportunidad? & 30 a 40 soles & 3 \\
\hline & & O más... & 4 \\
\hline & & Solo & 1 \\
\hline & & Con Pareja & 2 \\
\hline 5 & ¿Generalmente asiste? & Con Amigos & 3 \\
\hline & & $\begin{array}{c}\text { Con compañeros } \\
\text { de trabajo y/o } \\
\text { estudios }\end{array}$ & 4 \\
\hline & & La cocción & 1 \\
\hline & & Las Salsas & 2 \\
\hline 6 & $\begin{array}{l}\text { ¿Qué característica es más importante para usted para } \\
\text { comprar en un Food Trucks? }\end{array}$ & $\begin{array}{l}\text { La porción del } \\
\text { Producto }\end{array}$ & 3 \\
\hline & & $\begin{array}{l}\text { Variedad de } \\
\text { Productos }\end{array}$ & 4 \\
\hline & & Radio & 1 \\
\hline 7 & ¿Por cuál Medio conociste el Food Truck? & $\begin{array}{l}\text { Revista / } \\
\text { Periódicos } \\
\end{array}$ & 2 \\
\hline & & Redes Sociales & 3 \\
\hline & & Otros & 4 \\
\hline & & Precio & 1 \\
\hline 8 & ¿Eliie el Food Truck por? & Atención & 2 \\
\hline 0 & cenje el roud Iruck pot? & Calidad & 3 \\
\hline & & Todas & 4 \\
\hline
\end{tabular}

Fuente: Elaboración Propia 
Tabla 4: Análisis de los resultados de la encuesta

\begin{tabular}{|c|c|c|c|c|}
\hline \multirow{5}{*}{1} & \multicolumn{4}{|c|}{ ¿Consume de manera frecuentemente en los Food Trucks? } \\
\hline & Respuesta & Código & Frecuencia & Porcentaje \\
\hline & $\mathrm{Si}$ & 1 & 79 & $79 \%$ \\
\hline & No & 2 & 21 & $21 \%$ \\
\hline & Total & & 100 & $100 \%$ \\
\hline
\end{tabular}

\begin{tabular}{|c|c|r|r|r|}
\hline \multirow{4}{*}{2} & \multicolumn{3}{|c|}{ ¿Con que continuidad consume usted en los Food Trucks? } \\
\cline { 2 - 5 } & Respuesta & Código & Frecuencia & \multicolumn{1}{c|}{ Porcentaje } \\
\cline { 2 - 5 } & Diario & 1 & 4 & $4.00 \%$ \\
\cline { 2 - 5 } & Semanal & 2 & 21 & $21.00 \%$ \\
\cline { 2 - 5 } & Mensual & 4 & 38 & $38.00 \%$ \\
\cline { 2 - 5 } & Bimensual & & 37 & $37.00 \%$ \\
\cline { 2 - 5 } & Total & 100 & $100.00 \%$ \\
\hline
\end{tabular}

\begin{tabular}{|l|c|c|c|c|}
\hline \multirow{4}{*}{3} & \multicolumn{4}{|c|}{ ¿Cuál es el distrito donde más consume en un Food Trucks? } \\
\cline { 2 - 5 } & Respuesta & Código & Frecuencia & Porcentaje \\
\cline { 2 - 5 } & Miraflores & 1 & 24 & $24.00 \%$ \\
\cline { 2 - 5 } & Surco & 2 & 31 & $31.00 \%$ \\
\cline { 2 - 5 } & San Isidro & 3 & 19 & $19.00 \%$ \\
\cline { 2 - 5 } & Otros & 4 & 26 & $26.00 \%$ \\
\hline Total & & 100 & $100.00 \%$ \\
\hline
\end{tabular}

\begin{tabular}{|c|c|r|r|r|}
\hline \multirow{4}{*}{} & \multicolumn{4}{|c|}{ ¿Cuánto invierte aproximadamente en cada oportunidad? } \\
\cline { 2 - 5 } & Respuesta & Código & Frecuencia & \multicolumn{1}{c|}{ Porcentaje } \\
\cline { 2 - 5 } & 10 a 20 soles & 1 & 32 & $32.00 \%$ \\
\cline { 2 - 5 } & 20 a 30 soles & 2 & 43 & $43.00 \%$ \\
\cline { 2 - 5 } & 30 a 40 soles & 3 & 18 & $18.00 \%$ \\
\cline { 2 - 5 } & O más... & & 7 & $7.00 \%$ \\
\cline { 2 - 5 } & Total & 100 & $100.00 \%$ \\
\hline
\end{tabular}

\begin{tabular}{|c|c|r|r|r|}
\hline \multirow{4}{*}{} & \multicolumn{3}{|c|}{ ¿'Generalmente asiste? } \\
\cline { 2 - 5 } & Respuesta & Código & Frecuencia & \multicolumn{1}{c|}{ Porcentaje } \\
\cline { 2 - 5 } & Solo & 1 & 12 & $12.00 \%$ \\
\cline { 2 - 5 } & Con Pareja & 2 & 41 & $41.00 \%$ \\
\cline { 2 - 5 } & Con Amigos & 3 & 32 & $32.00 \%$ \\
\cline { 2 - 5 } & & 4 & 15 & $15.00 \%$ \\
\cline { 2 - 5 } & Con compañeros de trabajo y/o estudios & & 100 & $100.00 \%$ \\
\cline { 2 - 5 } & Total & & & \\
& & &
\end{tabular}




\begin{tabular}{|c|c|c|c|c|}
\hline \multirow{8}{*}{6} & \multicolumn{4}{|c|}{ ¿Qué característica es más importante para usted para comprar en un Food Trucks? } \\
\hline & \multicolumn{4}{|c|}{ En ese lugar? } \\
\hline & Respuesta & Código & Frecuencia & Porcentaje \\
\hline & La cocción & 1 & 16 & $16.00 \%$ \\
\hline & Las Salsas & 2 & 15 & $15.00 \%$ \\
\hline & La porción del Producto & 3 & 30 & $30.00 \%$ \\
\hline & Variedad de Productos & 4 & 39 & $39.00 \%$ \\
\hline & Total & & 100 & $100.00 \%$ \\
\hline \multirow{7}{*}{7} & \multicolumn{4}{|c|}{ ¿Por cuál Medio conociste el Food Truck? } \\
\hline & Respuesta & Código & Frecuencia & Porcentaje \\
\hline & Radio & 1 & 1 & $1.00 \%$ \\
\hline & Revista / Periódicos & 2 & 12 & $12.00 \%$ \\
\hline & Redes Sociales & 3 & 63 & $63.00 \%$ \\
\hline & Otros & 4 & 24 & $24.00 \%$ \\
\hline & Total & & 100 & $100.00 \%$ \\
\hline \multirow{7}{*}{8} & \multicolumn{4}{|c|}{ ¿Elije el Food Truck por? } \\
\hline & Respuesta & Código & Frecuencia & Porcentaje \\
\hline & Precio & 1 & 14 & $14.00 \%$ \\
\hline & Atención & 2 & 16 & $16.00 \%$ \\
\hline & Calidad & 3 & 35 & $35.00 \%$ \\
\hline & Todas & 4 & 35 & $35.00 \%$ \\
\hline & Total & & 100 & $100.00 \%$ \\
\hline
\end{tabular}

Fuente: Elaboración Propia 
Entrevistas de profundidad para determinar el plan de ventas y proyección de la demanda.

\section{Entrevista 1}

\section{PREGUNTAS DE INDAGACIÓN}

Tomar en cuenta lo siguiente:

- Escucha al cliente el doble de lo que hablas.

- Muestra un interés sincero en sus respuestas, sin dar signos de impaciencia.

- Haz preguntas pertinentes relacionadas con lo último que ha dicho el cliente.

- Combina las preguntas abiertas para introducir los temas ("¿Qué me dice del presupuesto disponible?" con las cerradas para concretar ("¿Entonces entre mil y dos mil estaría bien?").

- Plantea cada cuestión en el momento oportuno y deja las más delicadas para el final.

- Si ves que el cliente se muestra reacio a responder, reformula la pregunta de otro modo.

- Procura mantener en todo momento el ritmo relajado de una conversación informal.

- Es recomendable que grabes la conversación, para posteriormente analizarla

\section{PREGUNTAS:}

Al inicio comentas que las preguntas son para una investigación de Mercado, y que como estudiantes de la UPC.

\section{1. ¿Hace cuento has iniciado el negocio?}

Hace 1 año he iniciado el negocio.

\section{2. ¿Cuáles son tus metas a corto plazo?}

Corto plazo: Hacerse conocidos en su mercado objetivo que es el mercado de comida saludable.

Largo plazo: Ser los mejores food trucks de comida saludable con insumos peruanos siendo reconocidos a nivel internacional.

\section{3. ¿Cómo evalúan el potencial de nuevos productos o servicios?}


Se realiza pruebas de los productos nuevos con clientes frecuentes y se hacen encuestas para saber su opinión con respecto a la introducción de los productos.

\section{4. ¿Cuáles son tus necesidades y qué tan importantes son?}

La necesidad más importante es lograr que haya una reglamentación para los food trucks para que los derechos y deberes como negocio sean los mismos para todos. Y son importantes para el crecimiento justo y ordenado del negocio.

5. ¿Cuánto han crecido tus ventas de un año a otro? (¿Indicar de manera porcentual o monetario, en caso el Food Trucks recién inicie, confirmar el volumen de ventas?

Recién acaba de cumplir un año en el negocio.

6. ¿Cuántas ventas de sanguches (otros) vendes en promedio?

Es de acuerdo al evento al que se presentan como el día internacional del yoga, Dakar, Camino Inka de acuerdo a la cantidad de asistentes es la venta no especifico un porcentaje.

7. ¿Cuál es el valor agregado que das a tu producto, para que el cliente regrese?

El ser un food trucks con conocimiento de su producto, pudiendo recomendar con conocimiento de causa los productos y brindar al cliente una experiencia diferente compartiendo un momento agradable con un food trucks totalmente equipado y diseñado para brindar una experiencia diferente.

¿Luego explicas el modelo de Negocio que estamos creando y le realizas las siguientes preguntas?

8. ¿Qué te parece si con nuestra aplicación, te pueda unir a más clientes?

Si considero que podría captar más clientes.

9. ¿Estarías dispuesto a pagar un porcentaje, para incrementar tus ventas futuras?

Sí, pero un porcentaje que no afecte mis ingresos.

10. ¿Nuestra aplicación funciona como un Uber o Easy Taxi, que te abonaría las compras realizadas cada quince cada mes, te parece bien?

Preferiría solo mensual.

11. ¿Qué esperarías de nosotros en el presente y en el futuro?

Esperaría que se cree una propuesta de valor mucho más sólida para considerar como opción número 1 el aplicativo y que represente la herramienta para aumentar clientes para mi food trucks que se propone.

\section{ENTREVISTA 2}


Al inicio comentas que las preguntas son para una investigación de Mercado, y que somos estudiantes de la UPC.

1. ¿Hace cuento has iniciado el negocio?

El señor Felipe Rodríguez empezó su negocio de hamburguesas hace 4 años.

2. ¿Cuáles son tus metas a corto plazo? ¿A largo plazo?

Corto plazo: Desea hacerse conocido.

Largo plazo: desea expandirse en otros distritos, adquiriendo otro food trucks.

3. ¿Cuál crees qué es tu mayor fortaleza? ¿Debilidades?

Fortaleza: sabor que cuentan sus hamburguesas. Variadas cremas

Debilidad: no cuenta con permisos de la municipalidad

4. ¿Cómo evalúan el potencial de nuevos productos o servicios?

De acuerdo a la tendencia que exista en la gastronomía. Sr Felipe indica que cuando empezó se guio por lo que más consumen las personas.

5. ¿Cuáles son tus necesidades y qué tan importantes son?

Desean tener mayor facilidad con las municipalidades, para que puedan laborar tranquilamente.

6. ¿Cuánto han crecido tus ventas de un año a otro? ¿Indicar de manera porcentual o monetario, en caso el Food Trucks recién inicie, confirmar el volumen de ventas?

Aumentado en un 20 a $30 \%$.

7. ¿Cuántas ventas de sanguches (otros) vendes en promedio?

De 80 a 100 hamburguesas de lunes a viernes

De 100 a 150 los fines de semana

8. ¿Cuál es el valor agregado que das a tu producto, para que el cliente regrese?

Diferencias de salsas, además tienen distintos variedad de implementos para cada hamburguesa (chorizo, papa, camote, queso, etc.)

¿Luego explicas el modelo de Negocio que estamos creando y le realizas las siguientes preguntas?

9. ¿Qué te parece si con nuestra aplicación, te pueda unir a más clientes?

Muy bueno, ya que así podrá conseguir mayores clientes por el aplicativo.

10. ¿Estarías dispuesto a pagar un porcentaje, para incrementar tus ventas futuras?

Sí, pero va a depender del monto que se cobraría. 
11. ¿Nuestra aplicación funciona como un Uber o Easy Taxi, que te abonaría las compras realizadas cada quince cada mes, te parece bien?

Sí, pero tengo que evaluarlo y saber si se cumpliría con ello, ya que tendría que tener un dinero extra para seguir comprando mis insumos hasta que me abonen ese dinero.

12. ¿Qué esperarías de nosotros en el presente y en el futuro?

La idea me gusta, porque tendría mayores ingresos y la gente me conocería. Pero siempre hay que evaluar cuanto es el monto que se debe pagar y si podría cancelarlo.

\section{ENTREVISTA 3}

Al inicio comentas que las preguntas son para una investigación de Mercado, y que somos estudiantes de la UPC.

1. ¿Hace cuento has iniciado el negocio?

El señor benjamín Bernuy empezó su negocio de venta de tacos hace 2 años.

2. ¿Cuáles son tus metas a corto plazo? ¿A largo plazo?

Corto plazo: Desea hacerse conocido y aumentar sus ventas.

Largo plazo: desea expandirse en otros distritos.

3. ¿Cuál crees qué es tu mayor fortaleza? ¿Debilidades?

Fortaleza: distintos ingredientes para los tacos (pollo, carne, etc.), además que tener cremas.

Debilidad: no cuenta con permisos de la municipalidad

4. ¿Cómo evalúan el potencial de nuevos productos o servicios?

Se guía por sus conocidos en la venta de tacos, además de seguir las tendencias de la gastronomía.

5. ¿Cuáles son tus necesidades y qué tan importantes son?

Desea tener permiso de la municipalidad para que pueda estar en más de 1 distrito.

6. ¿Cuánto han crecido tus ventas de un año a otro? ¿Indicar de manera porcentual o monetario, en caso el Food Trucks recién inicie, confirmar el volumen de ventas?

Aumentado en un $15 \%$.

7. ¿Cuántas ventas de sanguches (otros) vendes en promedio?

100 tacos de lunes a viernes

120 a 150 los fines de semana

8. ¿Cuál es el valor agregado que das a tu producto, para que el cliente regrese? 
Manejada distintas modalidades de ingredientes para los tacos, además de cremas.

¿Luego explicas el modelo de Negocio que estamos creando y le realizas las siguientes preguntas?

9. ¿Qué te parece si con nuestra aplicación, te pueda unir a más clientes?

Bueno, porque se haría conocido.

10. ¿Estarías dispuesto a pagar un porcentaje, para incrementar tus ventas futuras? Sí, pero tiene que analizarlo y saber cuánto es el cobro por el aplicativo.

11. ¿Nuestra aplicación funciona como un Uber o Easy Taxi, que te abonaría las compras realizadas cada quince cada mes, te parece bien?

Sí, pero tengo que evaluarlo porque voy a necesitar mayor capital de trabajo.

12. ¿Qué esperarías de nosotros en el presente y en el futuro?

Que tenga toda la información del aplicativo para que se pueda usar correctamente y nosotros poder explicarles a nuestros clientes. 


\section{CÁPITULO 4: PLAN DE MARKETING}

\subsection{RESULTADOS DE LA INVESTIGACIÓN}

Ilustración 22: Objetivos de Marketing

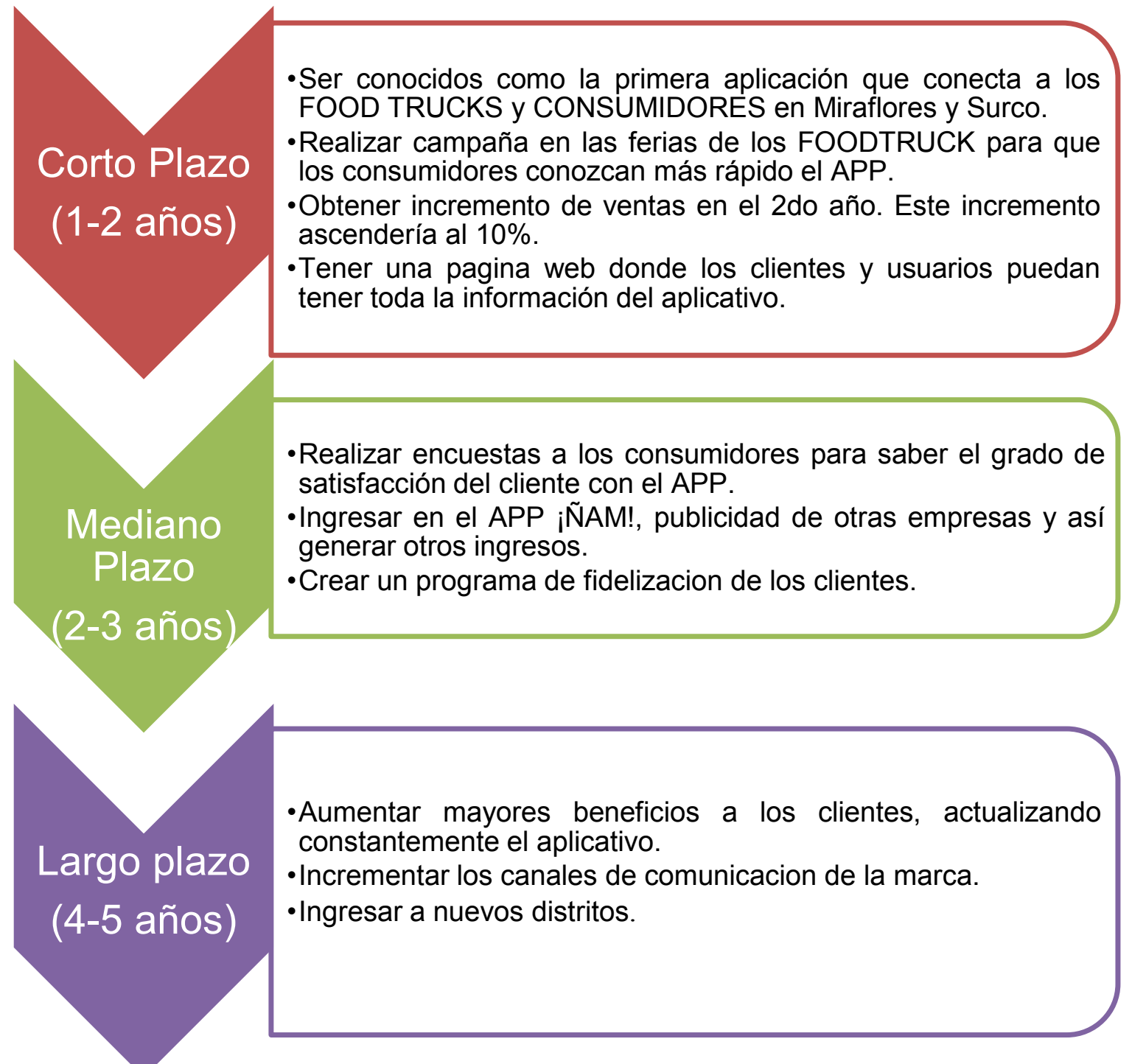

Fuente: Elaboración Propia 


\subsection{ESTRATEGIAS DE MARKETING}

La estrategia que se utilizará será la estrategia por diferenciación de producto (facilidad de pedido, de pago, de entrega y post venta).

\subsubsection{SEGMENTACIÓN}

\section{Variables Socioeconómicas:}

Sexo: hombres y mujeres

Edad: de 20 a 39 años

Hoy en día las personas con un estilo de vida activo, personas que trabajan y estudian que no cuentan con tiempo para realizar actividades de cocina en casa y buscan salir con amigos para socializar saliendo de la rutina de almorzar y cenar en restaurantes o comidas al paso que pueden ubicarse en el rango de estas edades.

Clase Social: A y B

En este análisis se ha identificado que el segmento ideal a atender debe pertenecer a los segmentos A y B, esto principalmente porque el servicio tiene un alto factor diferencial y único, las personas de clase A y B podrían contar con ingresos que les permitan cubrir sus necesidades y tener dinero para estas salidas a comer y para un ritmo de vida social activo.

\section{Variables relacionadas con el servicio:}

El segmento que utilizara este modelo de negocio valora y aprecia las cualidades únicas del servicio. Es un público que puede ser fidelizado y que puede mostrar lealtad a la marca si encuentra los beneficios apropiados.

\section{Variables Psicográficas:}

\section{Personalidad:}

El segmento al que se dirige este servicio se caracteriza por tener personalidad abierta a las nuevas experiencias y tendencias.

\section{Estilo de Vida:}

Según los estilos de vida del Perú propuestos por Rolando Arellano, el segmento del modelo de negocio se encontraría dentro de los estilos de vida LOS SOFISTICADOS este es un segmento mixto con un nivel de ingresos más alto del promedio. Son modernos, 
educados, liberales y cosmopolitas. Son innovadores en el consumo y cazadores de tendencias.

\section{Motivaciones:}

Usando como referencia la teoría de motivación de Maslow, la empresa puede identificar a su segmento meta en la jerarquía de NECESIDADES DE ESTIMA donde se encuentran el logro, el estatus, la fama, la responsabilidad y reputación.

\subsubsection{POSICIONAMIENTO}

La empresa se posicionará como el aplicativo que te brinda el servicio de una forma: Innovadora, confiable, amigable y cercana.

- La navegación en el aplicativo es amigable, brindándole al usuario seguridad y confianza desde el momento de la elección de la compra hasta el recojo del mismo.

- Se conoce la importancia del tiempo en el cliente por ello se da mayor atención en la entrega puntual del pedido, con ello reiteramos la confianza en el aplicativo.

- El primer aplicativo de búsqueda de Food Trucks en Miraflores y Surco, la app brindará la localización de los Food Trucks que se encuentren cercanos al cliente, así como la ruta para llegar al lugar.

\subsection{MERCADO OBJETIVO}

\subsubsection{IDENTIFICACIÓN DEL MERCADO OBJETIVO}

El mercado objetivo de la empresa será identificado luego de hacer una segmentación en base a cada una de las aristas de la investigación del mercado. En primer lugar, la empresa ha definido Mercado el nivel socioeconómico al que la empresa está dirigida, en este caso hombres y mujeres de nivel socioeconómico A y B, entre rangos de edad de 20 a 39 años con un estilo de vida activo (trabajo y estudio). 


\subsubsection{TAMAÑO DE MERCADO}

Tabla 5: Tamaño de Mercado

\begin{tabular}{|c|c|c|}
\hline Datos & Cantidad & Porcentaje \\
\hline Población de Lima & 10982,30 & $100 \%$ \\
\hline Mujeres y Hombres de 25 a 39 años & 2942,30 & $23 \%$ \\
\hline Mujeres y Hombres de NSE A/B & 2698,70 & $25 \%$ \\
\hline Mujeres y Hombres de 25 a 39 años de NSE A/B & 606,80 & $6 \%$ \\
\hline Miraflores y Surco & 443,40 & $4 \%$ \\
\hline
\end{tabular}

Fuente: Elaboración Propia

Ilustración 23 : Población por Edad y Según Nivel Socioeconómico 2017
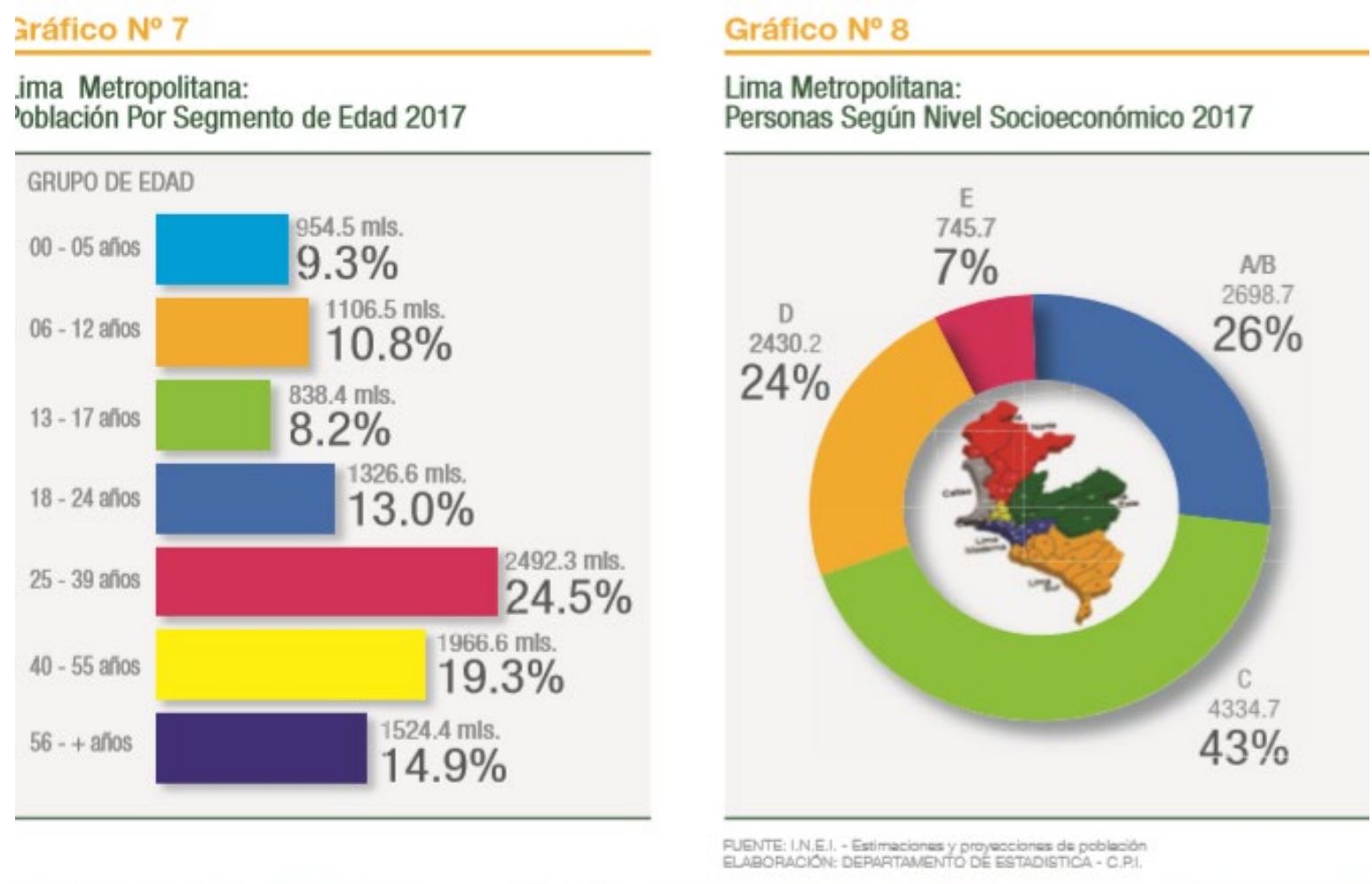

Fuente: INEI 2017

\subsubsection{TAMAÑO DE MERCADO DISPONIBLE}

El tamaño del mercado disponible de la empresa es de 443.40 hombres y mujeres del total de hombres y mujeres del nivel socioeconómico A y B entre los 25 a 39 años de los distritos de Surco y Miraflores. 


\subsubsection{TAMAÑO DE MERCADO OPERATIVO (TARGET)}

Para calcular el tamaño del target se ha calculado los filtros para delimitarlo. Se ha utilizado la población de las zonas de Surco y Miraflores 443.40 miles personas. Aplicamos los siguientes filtros NSE A y B correspondiente al 25\%, variable de edad $23 \%$, consideramos las personas que utilizan redes sociales $63 \%$ y que consumen en un food trucks $79 \%$ con una frecuencia semanal y mensual de 21 y $38 \%$ respectivamente con un promedio de gasto de 20 a 30 soles que representa el $43 \%$.

Tabla 6: Tamaño de Mercado Operativo

\begin{tabular}{|l|r|r|}
\hline \multicolumn{1}{|c|}{ Datos } & Porcentaje & Cantidad \\
\hline Población Miraflores y Surco & & 443400 \\
\hline Población Nivel socioeconómico A/B & $25 \%$ & 1108,50 \\
\hline Población entre 25y 39 años & $23 \%$ & 25496 \\
\hline Usuarios que manejan redes sociales & $63 \%$ & 16062 \\
\hline \% de conversión Landing Page & $20 \%$ & 3212 \\
\hline Consumidores Actuales & $79 \%$ & 2538 \\
\hline
\end{tabular}

Fuente: Elaboración Propia

\subsubsection{POTENCIAL DE CRECIMIENTO DEL MERCADO}

En el Perú, un $42 \%$ de la población utiliza el servicio de internet en su dispositivo (Smartphone) $^{3}$ el cual lo utiliza para servicio de indagación, interacción y entretenimiento. Según estudio de la cámara Peruana de Comercio Electrónico, las

Ilustración 24: Perfil del Comprador Online

\section{Perfil del Comprador online}

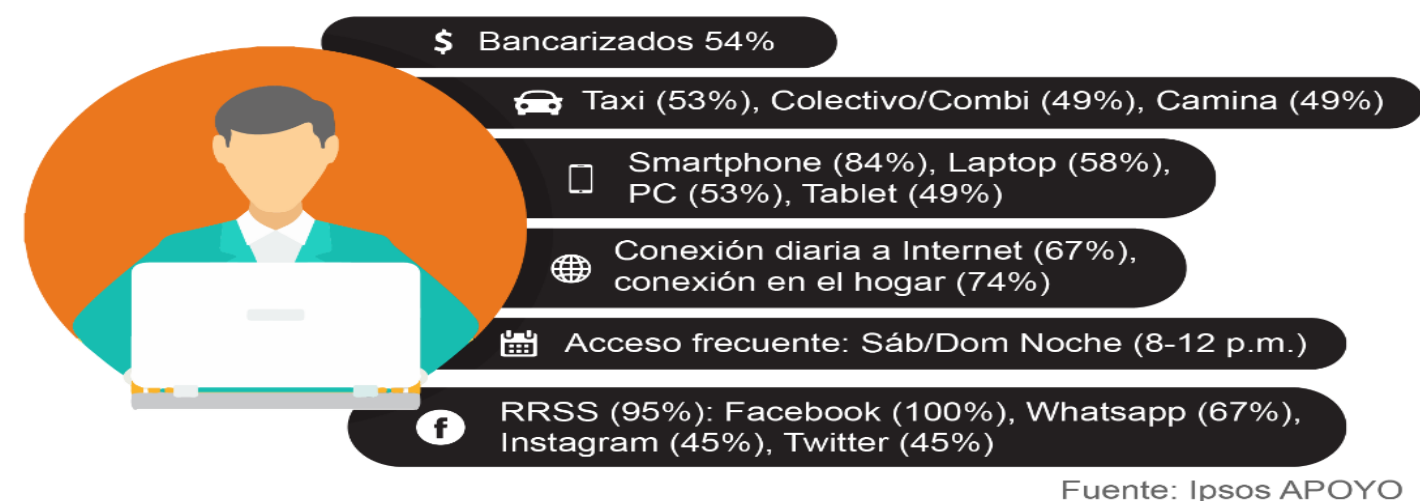

Fuente: Ipsos Apoyo

3 Redactor del Diario Gestion (2017). Casi 2 millones de peruanos realizan sus compras online desde su celular. 04/05/2018. Sitio web : https://gestion.pe/tendencias/2-millones-peruanos-realizan-compras-online-celular-143284 
ventas por internet han alcanzado un total en ventas en el 2016 de US\$ 2,800 millones, lo que ha implicado un crecimiento en los últimos dos años de un 198\%. Además, indica que el E-Commerce está concentrado en la Población A y B (Población a la cual nos dirigimos). Según estudio de Ipsos Perú, el e-commerce crecería un 11\% en el 2017 y un $16 \%$ en el 2018 , lo que significa un crecimiento de S/. 3,600 millones de soles. ${ }^{4}$

¿Por qué compran por internet?

El estudio presentado por GFK presenta dos razones primordiales: las compras en línea ahorran tiempo (29\%) y dinero (27\%).

Ilustración 25: Participación de Servicios del E-Commerce en el 2017

Fuente: Ipsos Apoyo

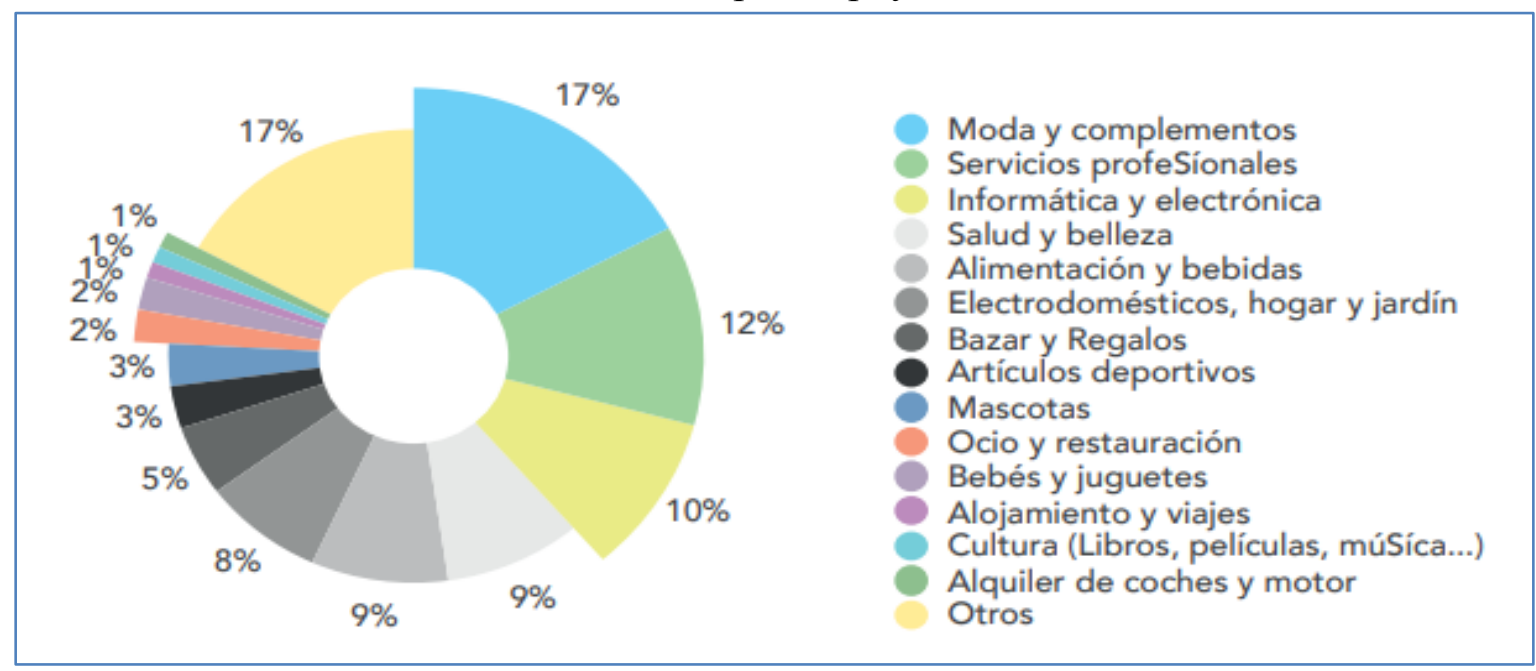

Por lo cual, el sector del negocio corresponde a un 9\% del mercado E-Commerce, el cual para el 2018 sería un importe total de US\$ 324 millones de dólares. ${ }^{5}$

\footnotetext{
4 Entrevista a Javier Alvarez para Peru Retal (2017). El ecommerce en el Perú crecería un 16\% para el 2018. 04/05/2018. Sitio Web: https://www.peru-retail.com/entrevista/ecommerce-peru-creceria-para-2018/

5 Redactora Pamela Flores del Diario El Comercio (2017). "Perú: La evolución del e-commerce". 04.05.2018. Sitio Web :

https://elcomercio.pe/economia/dia-1/peru-evolucion-e-commerce-pamela-flores-noticia-478969
} 


\subsection{DESARROLLO Y ESTRATEGIA DEL MARKETING MIX}

\subsubsection{ESTRATEGIA DEL SERVICIO}

La aplicación ¡Ñam! Buscador de Food Trucks, se ha creado con la finalidad de facilitar la búsqueda de nuevas opciones de comida en el mercado, dirigido para aquellas personas que no cuentan con tiempo suficiente al momento de almorzar o cenar. La estrategia del servicio de acuerdo al ciclo de vida presentado en el gráfico coloca a la empresa en la etapa de introducción.

En esta etapa se experimentará como el servicio es recibido por el mercado.

Ilustración 26: Ciclo de Vida de un producto

\section{CICLO DE VIDA DE UN PRODUCTO}

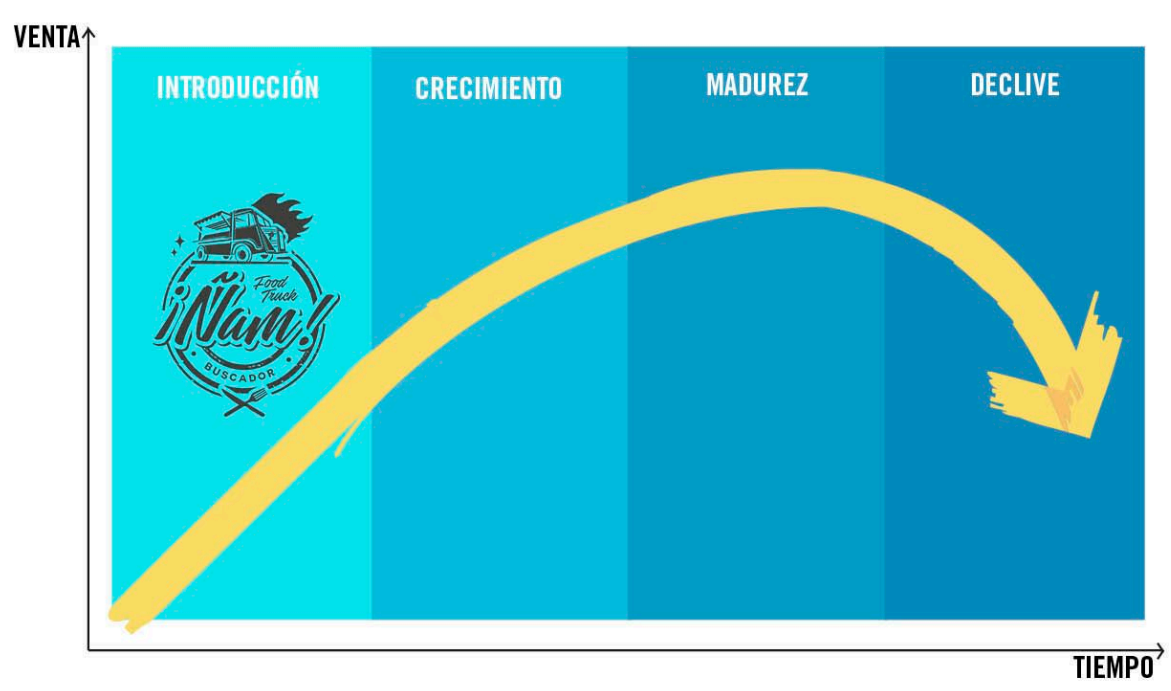

Fuente: Elaboración Propia

De acuerdo a la matriz Ansoff, nos situaremos en la estrategia de diferenciación, ya que nos enfocaremos en atraer clientes potenciales con publicidad y promoción por redes sociales, de igual forma atraer clientes de la competencia presentándoles una marca fresca, diferente, que ofrece una característica distinta, la ubicación de food trucks cercanos a la localización de la persona en la capital. 


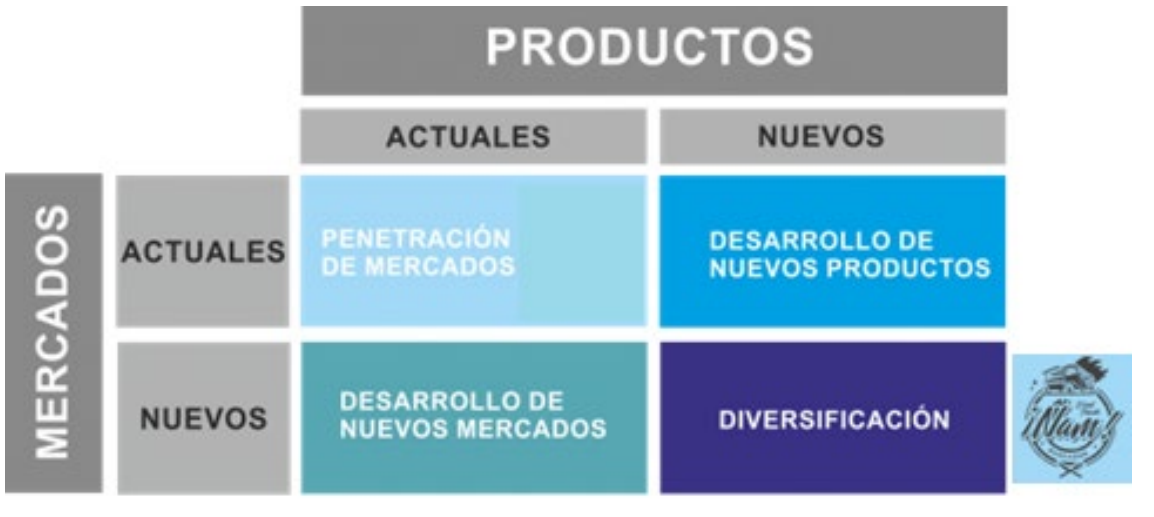

Fuente: Elaboración Propia

\subsubsection{DISEÑO DE PRODUCTO/ SERVICIO}

El diseño del aplicativo será trabajado en formato responsable, ésta característica es básica ya que se podrá visualizar en diferentes plataformas, como pc, Mobile, Tablet, esto permite la facilidad de navegación y uso.

Para la elaboración del diseño del aplicativo se realiza una arquitectura del mismo, para visualizar la navegación correcta; por ello será importante que la navegabilidad haya sido testeada por un User Experience UX; el cual permitirá tener como objetivo principal la satisfacción del usuario al utilizar el aplicativo.

La gráfica del Mobile contará con un diseño amigable e intuitivo. El contenido colocado en el aplicativo depende mucho de los principales pedidos por parte de los usuarios, por ello se realiza una lista de los pedidos más comunes de los consumidores para agregarlos al menú. De la misma forma el aplicativo estará dividido por el tipo de comida que desee consumir el cliente.

El aplicativo te ofrece la facilidad de buscar los food trucks cercanos de tu lugar de ubicación, realizar el pedido, pagarlo y recogerlo en la ruta que indique.

\section{Características claves del aplicativo.}

Confiabilidad: El aplicativo brinda confiabilidad en la navegación y uso. La empresa cuenta con un equipo de programadores certificados que avalan el conocimiento sobre seguridad en internet, de este modo el cliente cuenta con total seguridad al realizar una acción vía online. 
Durable: La actualización de las versiones en el tiempo, conlleva a la durabilidad del aplicativo, pues permite que el aplicativo no quede obsoleto, sino, se mantenga con un alto nivel de calidad.

Nivel de diseño: El diseño presentado en el aplicativo es moderno, sencillo y amigable para complementar la experiencia del usuario.

Ilustración 28: Propuesta Visualización APP - Móvil

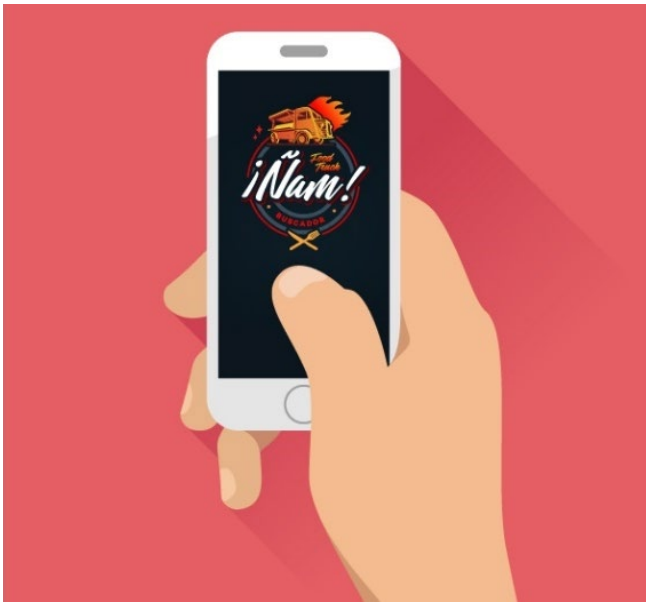

Fuente: Elaboración Propia

Ilustración 29: Página Web - Home

Fuente: Elaboración Propia

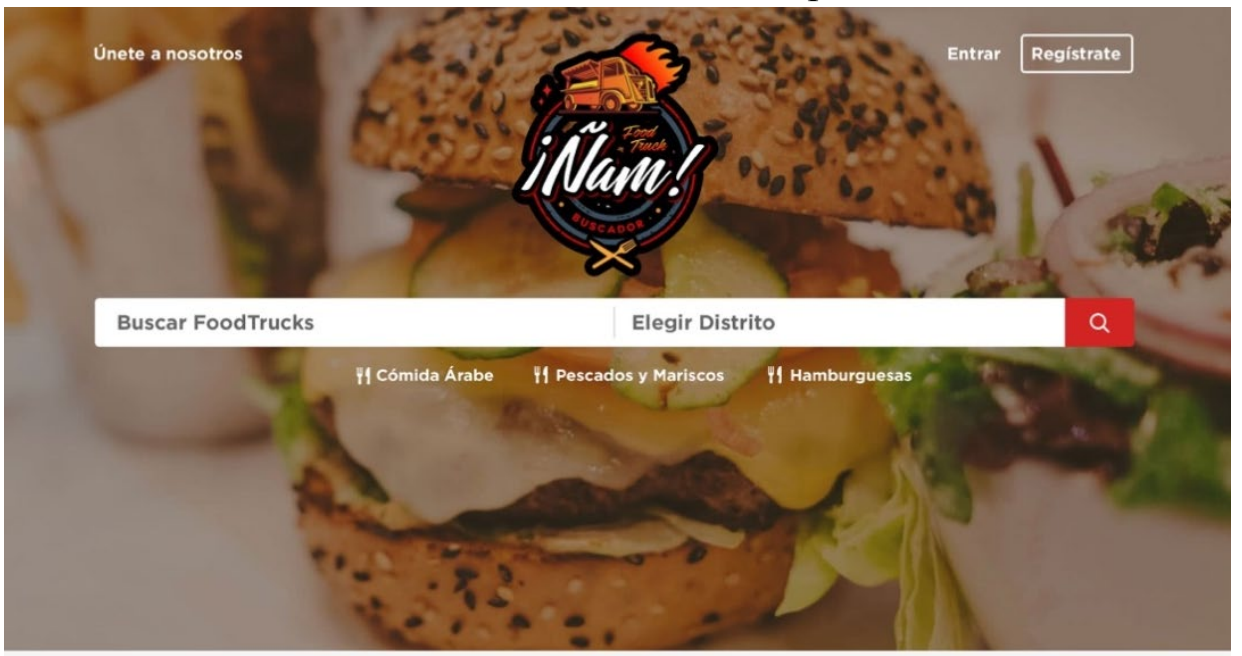

Los Food Trucks más buscados en la ciudad

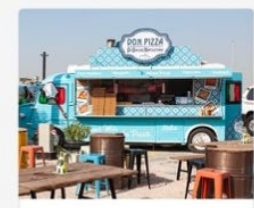

Pizzas

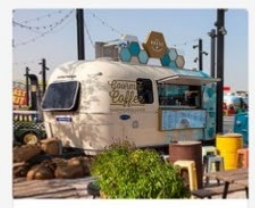

Gourmet Coffee

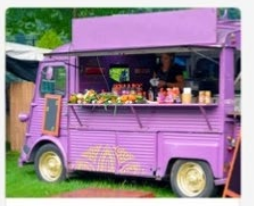

Comida Light

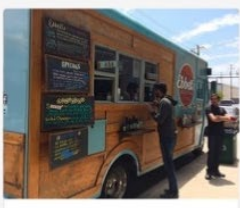

Tacos 
Ilustración 30: Página Web - Interna
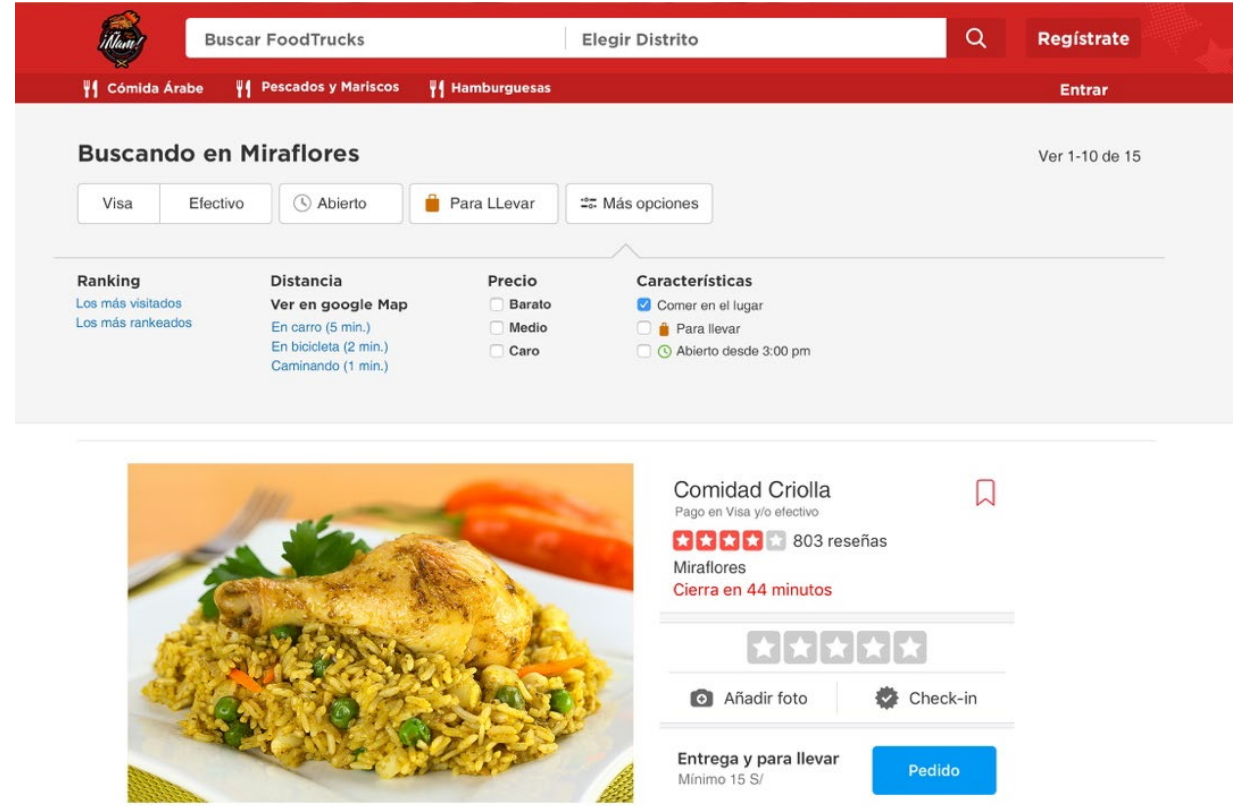

Comidad Criolla
Pago en Visa yo efectivo

ఏ

t大 803 reseñas

Miraflores

Cierra en 44 minutos

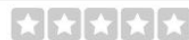

- Añadirfoto Check-in

Entrega y para llevar

Minimo $15 \mathrm{~S}$

Fuente: Elaboración Propia

Ilustración 31: Mobile - Home e Interna
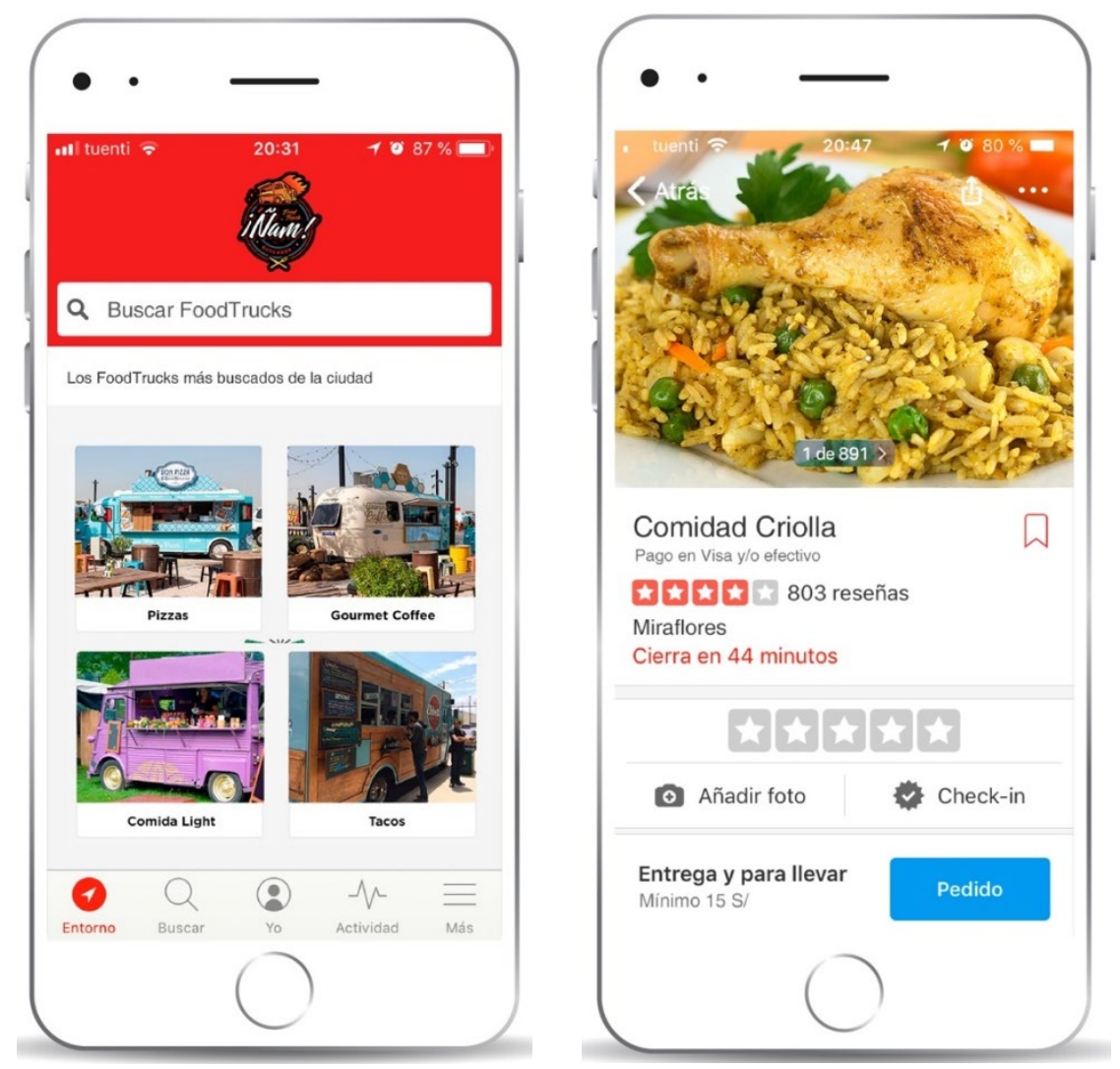

Fuente: Elaboración Propia 


\section{La marca}

El aplicativo se llama ¡Ñam! Buscador de Food Trucks

Se eligió el nombre "Ñam" ya que es la onomatopeya para el sonido que se realiza al comer, indicando a su vez que lo degustado es sabroso, esta palabra es usada en varios países de Latinoamérica, más aún en el léxico peruano, convirtiéndolo así en un nombre fácil de recordar, pronunciar y escribir.

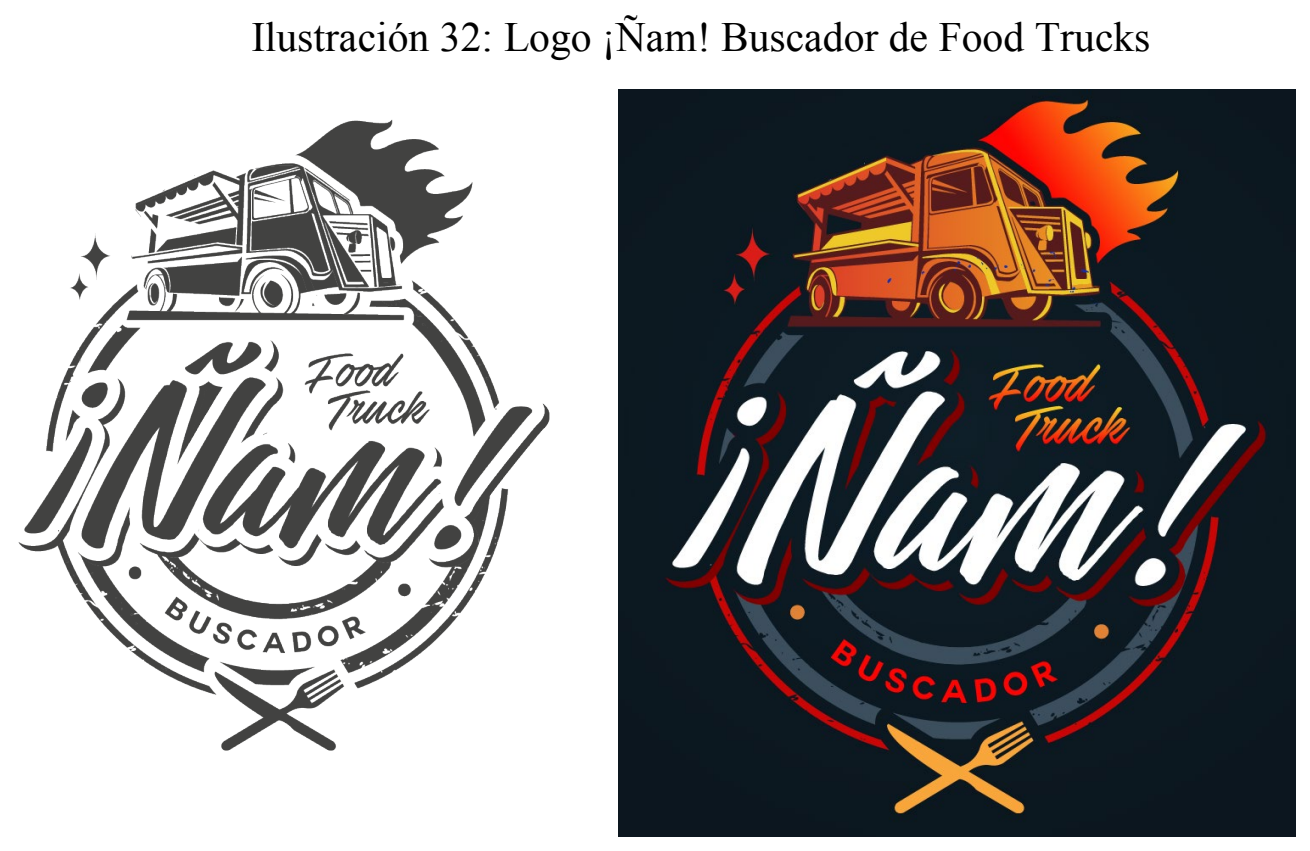

Fuente: Elaboración Propia

El diseño del logotipo está asociado directamente con el servicio que brinda: el buscador de Food Trucks, para complementar la idea en la parte superior se ha colocado una muestra de las diversas formas de camiones de comida existentes, luego se presenta la tipografía "Brush Pen", muy característicos en el entorno peruano; asimismo contiene textos que describe el uso del aplicativo "buscador de Food Trucks", para cerrar la idea se presenta al final del logo 2 cubiertos cruzados cuya referencia es la comida que se encuentra en los lugares. 


\subsubsection{ESTRATEGIA DE PRECIOS}

¡Ñam! Buscador de Food Trucks es un servicio nuevo en el mercado, por lo cual se utilizará la estrategia de Diferenciación de mercado. Sin embargo, debemos tener en cuenta que los clientes son los dueños de Food Trucks, por dos servicios:

1. Costo porcentual por volumen de ventas (5\%)

2. Publicidad mediante la aplicación (Se estima $2 \%$ del 30\% de los clientes registrados). Por tanto, el valor que le damos al cliente es de poder incrementar sus ventas, y al consumidor una mejor ubicación del local y rapidez en la compra de su producto. Por ello, se ha estimado realizar un cobro porcentual por el volumen de ventas que realicen mediante la plataforma.

$\mathrm{Al}$ realizar las entrevistas con los Food Trucks, se ha estimado un nivel de ventas de:

Tabla 7: Estimado de ventas

\begin{tabular}{|l|l|}
\hline ITEMS & NUMERO \\
\hline Ventas de Lunes a viernes (Por Food Trucks) & De 80 a 100 Hamburguesas diarias. \\
\hline Ventas de Sábado a Domingo (Por Food Trucks) & De 120 a 150 Hamburguesas diarias \\
\hline Ventas Semanales & 800 hamburguesas \\
\hline Ventas Mensuales & 3,200 hamburguesas \\
\hline Precio Promedio de los Productos & S/ 15.00 soles \\
\hline $\begin{array}{l}\text { Potencial de Mercado (San Isidro, Miraflores } \\
\text { Surco) }\end{array}$ & 50 Food Trucks \\
\hline Ventas Anuales (Sin considerar Estacionalidad) & $28^{\prime} 800,000$ soles $=(3,200 * 15 * 50 * 12)$ \\
\hline Ventas Anuales Reales (Con Estacionalidad) & \\
\hline
\end{tabular}

Fuente: Elaboración Propia

Por otro lado, se ha determinado que la aplicación será distribuida de manera gratuita.

Porque según estudios realizados por Ipsos sobre el perfil del Smartphonero la gran

${ }^{6}$ Las Ventas Anuales Reales (Con Estacionalidad), es una estimación del porcentaje de ventas de manera mensual que realizan los Food Trucks, ya que todo el año no venden 3,200 de hamburguesas mensuales. 
mayoría de personas acostumbra a descargar aplicaciones que no tengan costo, por ello la descarga tendría que ser gratuita para todos los niveles de usuarios ${ }^{7}$.

\subsubsection{ESTRATEGIA COMUNICACIONAL}

Para llevar la campaña de lanzamiento de la marca al mercado, la empresa utilizará como medio de comunicación las redes sociales, esta será la herramienta principal; debido a que estará dirigida a personas con una fuerte tendencia a la tecnología del internet, el uso del marketing digital, los dispositivos móviles y los medios sociales. Así mismo se utilizará Rollscreen en Patios de Food Trucks, afiches y volantes.

La empresa utilizara la estrategia PUSH que consiste en comunicar al consumidor que adquiere un producto o servicio. Esta estrategia permitirá atraer a los clientes que ya están interesados en el producto previamente. La empresa se enfocará en la herramienta como e-marketing SEO (search engine optimization u optimización para buscadores en español), SEM (publicidad en Google AdWords).

También se utilizará la estrategia PULL a través de los dueños de los food trucks debido a que ellos tendrán un contacto directo con los usuarios y generarán feed back. Así mismo con esta estrategia se mejorará la visibilidad de la empresa en redes sociales.

Empatizar y entender el mercado: Con una comunicación continua y cercana con los usuarios, la empresa utilizara las redes sociales como medio para retroalimentación y dar una respuesta adecuada en el tiempo preciso conociendo así lo que los consumidores desean y necesitan.

Priorizar la calidad del servicio: La empresa brindará información oportuna valiosa para el usuario que le permitirá alternativas de comida (variedad), ahorro de tiempo y satisfacción de su necesidad.

El segmento al que se dirige es el A/B podemos apreciar que ellos son los que se conectan a través de dispositivos móviles.

${ }^{7}$ Redactora Marcela Mendoza del Diario El Comercio (2015). "Las apps de pago no tienen espacio para crecer en el Perú". 20.05.2018. Sitio Web : Fuente: https://elcomercio.pe/economia/peru/apps-pago-espacio-crecer-peru-188099 
Ejemplos de piezas gráficas que se usará para la estrategia comunicacional:

\section{Ilustración 33: Publicidad en redes sociales}

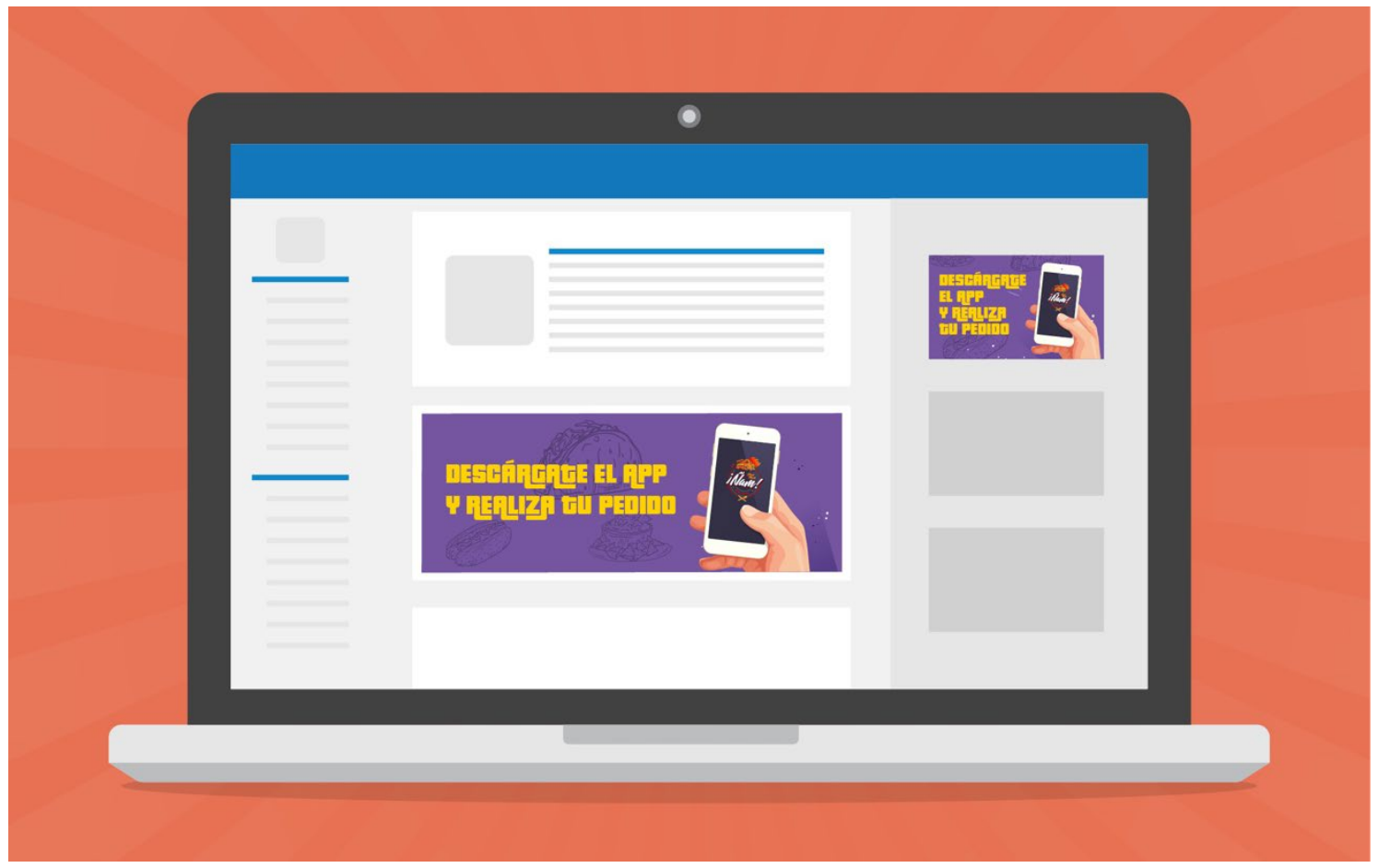

Fuente: Elaboración Propia

Ilustración 34: Rollscreen en patios de Food Trucks

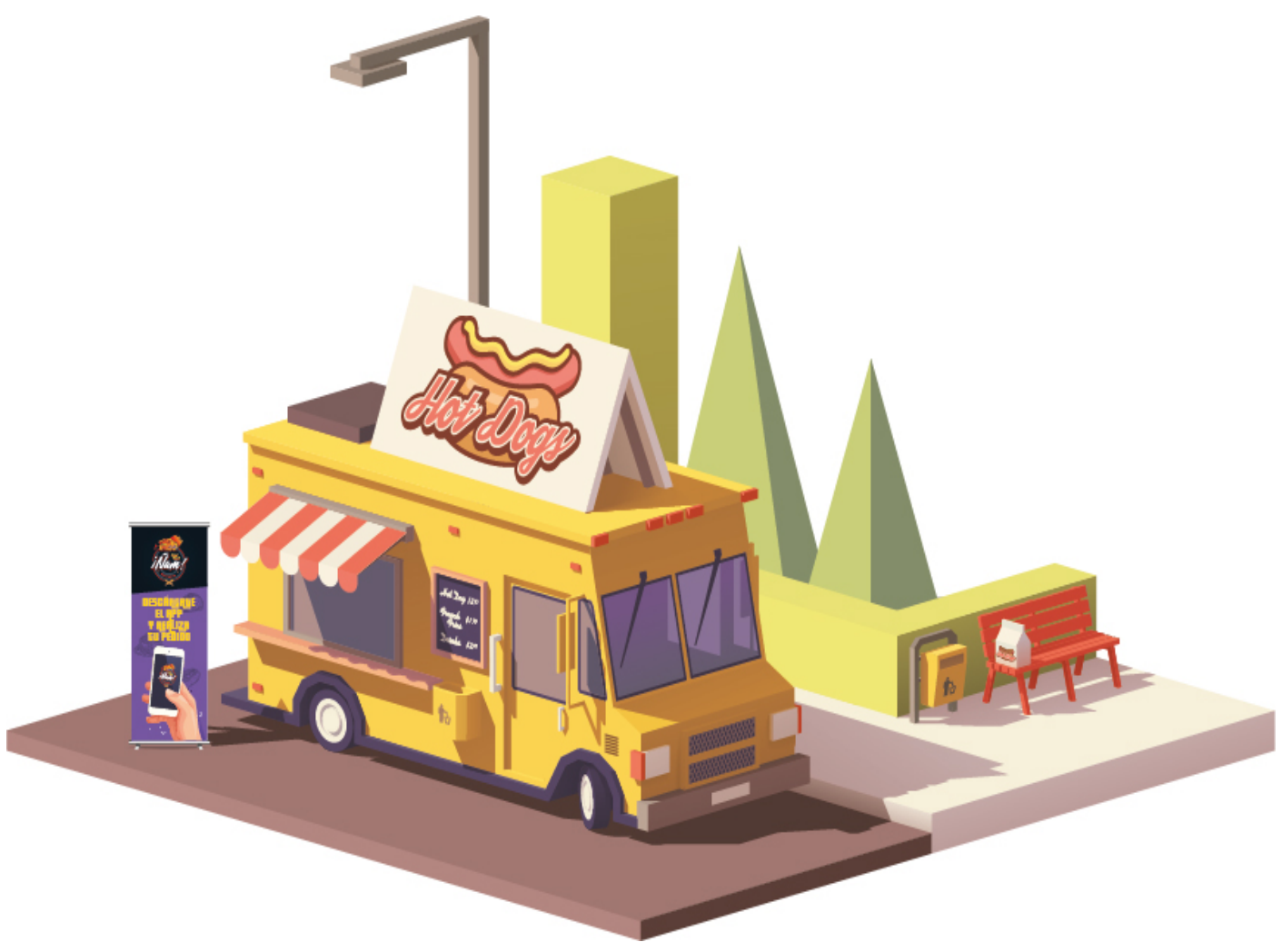

Fuente: Elaboración Propia 
Ilustración 35: Publicidad-afiches y volantes en el patio de comidas Food Trucks
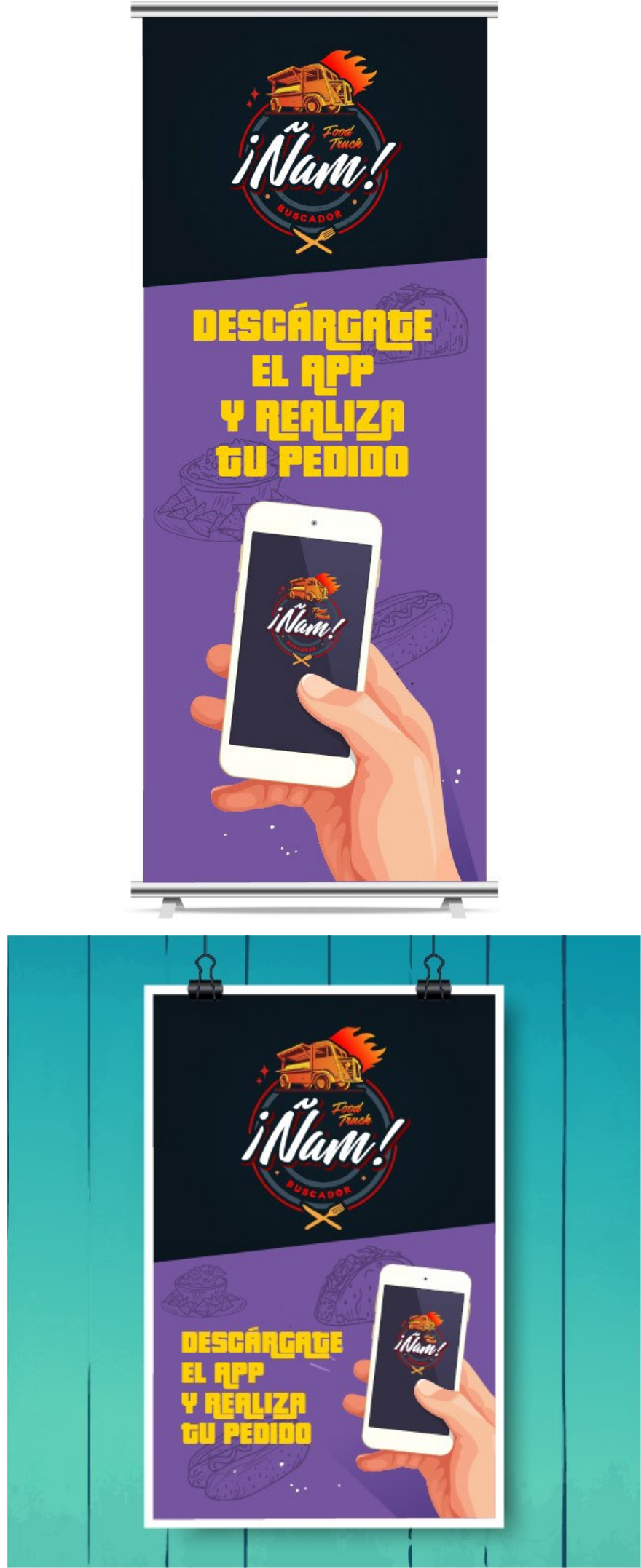

Fuente: Elaboración Propia 


\subsubsection{ESTRATEGIA DE DISTRIBUCIÓN}

¡Ñam! Buscador de Food Trucks contará con una estrategia B2C, atenderá directamente al consumidor por medio del aplicativo móvil. Serán intermediarios en línea, pondrán a los compradores y vendedores juntos sin tener el producto o servicio. El aplicativo tendrá información detallada de todos los FOODTRUCK en Miraflores y Surco, para que el cliente realice su compra por medio de APP.

\subsection{PLAN DE VENTAS Y PROYECCIÓN DE LA DEMANDA}

Por lo conversado con los dueños de los Food Trucks sus ventas diarias son de lunes a viernes unas 100 hamburguesas diarias y los sábados y Domingos son 150 hamburguesas por día (son ventas promedio), por lo cual sus ventas semanales son:

Tabla 8: Cantidad de unidades vendidas.

\begin{tabular}{|c|c|c|c|c|c|c|c|}
\hline $\mathbf{L}$ & $\mathbf{M}$ & $\mathbf{M}$ & $\mathbf{J}$ & $\mathbf{V}$ & $\mathbf{S}$ & $\mathbf{D}$ & TOTAL \\
\hline 100 & 100 & 100 & 100 & 100 & 150 & 150 & 800 \\
\hline
\end{tabular}

Fuente: Elaboración Propia

Los cuales las proyecciones realizadas son:

- Ventas por Mes:

3,200 Productos

- Costo Promedio:

15 Soles

- Ingresos por Mes:

S/. 48,000

- $\quad \mathrm{N}^{\circ}$ De Food Trucks

50 Food Trucks

- Ventas Mensuales Food Trucks S/. 2’ 400,000

- Ventas Anuales Food Trucks

S/. 28’ 800,000 Soles 
Para ello, también analizamos la estacionalidad en ventas y la proyección de clientes:

Tabla 9: Proyección de Ventas

\begin{tabular}{|c|c|c|c|c|c|c|c|c|c|c|c|c|c|c|}
\hline ITEM & Formula & Mes 1 & Mes 2 & Mes 3 & Mes 4 & Mes 5 & Mes 6 & Mes 7 & Mes 8 & Mes 9 & Mes 10 & Mes 11 & Mes 12 & TOTAL \\
\hline $\begin{array}{l}\text { Ventas } \quad \text { Mensuales } \\
\text { FoodTruck (Aprox) }\end{array}$ & A & 3200 & 3200 & 3200 & 3200 & 3200 & 3200 & 3200 & 3200 & 3200 & 3200 & 3200 & 3200 & \\
\hline Precio Promedio (S/.) & $\mathrm{B}$ & 15 & 15 & 15 & 15 & 15 & 15 & 15 & 15 & 15 & 15 & 15 & 15 & \\
\hline Estacionalidad & $\mathrm{C}$ & $70 \%$ & $70 \%$ & $70 \%$ & $90 \%$ & $90 \%$ & $100 \%$ & $100 \%$ & $100 \%$ & $100 \%$ & $100 \%$ & $90 \%$ & $70 \%$ & \\
\hline Número de Afiliados & $\mathrm{D}$ & 10 & 10 & 10 & 20 & 20 & 30 & 30 & 30 & 40 & 40 & 50 & 50 & \\
\hline
\end{tabular}

\begin{tabular}{|c|c|c|c|c|c|c|c|c|c|c|c|c|c|c|}
\hline $\begin{array}{lll}\text { Venta } \quad \text { Mensual } & \text { de } \\
\text { Food Trucks (S/.) } & \end{array}$ & $\begin{array}{c}\mathrm{A} * \mathrm{~B} * \mathrm{C} * \\
\mathrm{D}=\mathrm{E}\end{array}$ & 336,000 & 336,000 & 336,000 & 864,000 & 864,000 & $1,440,000$ & $1,440,000$ & $1,440,000$ & $1,920,000$ & $1,920,000$ & $2,160,000$ & $1,680,000$ & $14,736,000$ \\
\hline $\begin{array}{l}N^{\circ} \text { de Hamburguesas } \\
\text { Vendidas }\end{array}$ & $E / B=F$ & 22,400 & 22,400 & 22,400 & 57,600 & 57,600 & 96,000 & 96,000 & 96,000 & 128,000 & 128,000 & 144,000 & 112,000 & 982,400 \\
\hline
\end{tabular}

\begin{tabular}{|c|c|c|c|c|c|c|c|c|c|c|c|c|c|c|}
\hline $\begin{array}{l}\text { Porcentaje Mediante } \\
\text { el APP }\end{array}$ & $\mathrm{G}$ & $10 \%$ & $10 \%$ & $10 \%$ & $10 \%$ & $20 \%$ & $20 \%$ & $20 \%$ & $20 \%$ & $30 \%$ & $30 \%$ & $30 \%$ & $30 \%$ & \\
\hline Ventas por APP (S/.) & $\begin{array}{c}\mathrm{E} * \mathrm{G}= \\
\mathrm{H}\end{array}$ & 33,600 & 33,600 & 33,600 & 86,400 & 172,800 & 288,000 & 288,000 & 288,000 & 576,000 & 576,000 & 648,000 & 504,000 & $3,528,000$ \\
\hline Ventas $(5 \%)=$ & $\begin{array}{c}\mathrm{H} * 5 \%= \\
\mathrm{I}\end{array}$ & 1,680 & 1,680 & 1,680 & 4,320 & 8,640 & 14,400 & 14,400 & 14,400 & 28,800 & 28,800 & 32,400 & 25,200 & 176,400 \\
\hline $\begin{array}{ll}\text { Ventas } & \text { Publicidad } \\
(2 \%)= & \end{array}$ & $\begin{array}{c}\mathrm{H} * 2 \%= \\
\mathrm{J}\end{array}$ & & & & & 5,184 & 8,640 & 8,640 & 8,640 & 11,520 & 11,520 & 12,960 & 10,080 & 77,184 \\
\hline
\end{tabular}

\begin{tabular}{|c|c|c|c|c|c|c|c|c|c|c|c|c|c|c|}
\hline $\begin{array}{l}\text { Ingresos } \text { Mensuales } \\
\text { (S/.) }\end{array}$ & $\mathrm{I}+\mathrm{J}$ & 1,680 & 1,680 & 1,680 & 4,320 & 13,824 & 23,040 & 23,040 & 23,040 & 40,320 & 40,320 & 45,360 & 35,280 & 253,584 \\
\hline
\end{tabular}

Fuente: Elaboración Propia 
Como pueden apreciar en el cuadro, la empresa ha estimado un porcentaje sobre las ventas totales de sus clientes los cuales lo realizan mediante el APP, un 5\% va dirigido a la empresa. Adicionalmente se está proponiendo un $2 \%$ de ingresos adicionales por la publicidad de sus productos mediante el APP. Los cuales están dando un ingreso anual de S/. 253,584 soles. 


\subsection{PRESUPUESTO DE MARKETING}

El presupuesto de Marketing, se distribuye de la siguiente forma:

Tabla 10: Presupuesto de Marketing

\begin{tabular}{|c|c|c|c|c|c|c|c|c|c|c|c|c|c|c|c|c|}
\hline $\mathbf{N}^{\circ}$ & Ítems & Partida & TIPO & Mes 1 & Mes 2 & Mes 3 & Mes 4 & Mes 5 & Mes 6 & Mes 7 & Mes 8 & Mes 9 & $\begin{array}{c}\text { Mes } \\
10\end{array}$ & $\begin{array}{c}\text { Mes } \\
11\end{array}$ & $\begin{array}{c}\text { Mes } \\
12\end{array}$ & Total \\
\hline $\mathrm{a}$ & $\begin{array}{l}\text { Community } \\
\text { Manager }\end{array}$ & Marketing & Fijo & 1,526 & 1,526 & 1,526 & 1,526 & 1,526 & 1,526 & 1,526 & 1,526 & 1,526 & 1,526 & 1,526 & 1,526 & 18,312 \\
\hline $\mathrm{b}$ & $\begin{array}{l}\text { Inversión en } \\
\text { Facebook }\end{array}$ & Marketing & Variable & 3,000 & & & & & & & & & & & & 3,000 \\
\hline $\mathrm{c}$ & $\begin{array}{l}\text { Diseño de } \\
\text { Aplicativo (web } \\
\text { y mobile) }\end{array}$ & Marketing & Variable & & 6,000 & 2,000 & & & 6,000 & 2,000 & & & & & & 16,000 \\
\hline d & $\begin{array}{l}\text { Actualización del } \\
\text { aplicativo (datos, } \\
\text { diseño y } \\
\text { programación)) }\end{array}$ & Marketing & Variable & & 2,000 & 2,000 & & & 2,000 & 2,000 & & & 2,000 & 2,000 & & 12,000 \\
\hline $\mathrm{e}$ & SEM & Marketing & Variable & 500 & 500 & 500 & 500 & 500 & 500 & 500 & 500 & 500 & 500 & 500 & 500 & 6,000 \\
\hline $\mathrm{f}$ & SEO & Marketing & Variable & 650 & 650 & 650 & 650 & 650 & 650 & 650 & 650 & 650 & 650 & 650 & 650 & 7,800 \\
\hline \multicolumn{4}{|c|}{ Total Social Media } & 5,676 & 10,676 & 6,676 & 2,676 & 2,676 & 10,676 & 6,676 & 2,676 & 2,676 & 4,676 & 4,676 & 2,676 & 63,112 \\
\hline
\end{tabular}

Fuente: Elaboración Propia 
1. Community Manager: Se le pagara un sueldo mensual de S/. 1,400 soles, el cual se ha considerado un $9 \%$ más por los beneficios que asume el empleador (Ley de Pymes ESSALUD); dando un total mensual de S/. 1,526.

2. Inversión en Facebook: Se realizará un gasto para el diseño en Facebook, el cual nos ayudará a recibir las sugerencias de nuestros consumidores y clientes.

3. Diseño de aplicativo: Este es un gasto variable de acuerdo a como se vayan asociando los clientes con nuestro APP. Para ello, tenemos que agregar los nombres de los Food Trucks, que producto ofrecen, precios, etc., con el fin de mantener la plataforma actualizada.

4. Actualización del Aplicativo: Este es un gasto variable de acuerdo a como vayamos generando los ingresos con nuestra app. Está destinado en colocar publicidad de los diferentes productos, incrementar ofertas o promociones para atraer mayores clientes, entre otras ideas.

5. SEM: Es mejorar la publicidad en diferentes páginas web para incrementar el número de seguidores de la app.

6. SEO: Es mejorar la publicidad mediante motores de búsqueda. Con el objetivo de tener un mayor número clientes en la plataforma virtual.

El presupuesto de Marketing representa S/. 63,112 soles. 


\section{CAPÍTULO 5: PLAN DE OPERACIONES}

\subsection{POLITICAS OPERACIONALES}

Las políticas para entregar un producto de calidad son fundamentales. Las normas de operaciones se registrarán para tener control y para que las funciones sean iguales siempre.

La empresa maneja un modelo de negocio dual en el sentido que entrega valor tanto a los usuarios finales como a los clientes.

\subsubsection{CALIDAD}

\section{Políticas de control de calidad}

Debido a que el modelo de negocio se basa en un aplicativo que permita ubicar al food trucks más cercano desde la posición del consumidor y reducir el tiempo de espera por el pedido y pago. Se busca que la aplicación sea descargada de una manera rápida y que no sea pesada para el celular del consumidor, se dará una información precisa del food trucks para lo cual se tendrá un sistema de soporte en coordinación con los dueños de los trucks, la manipulación del aplicativo será sencilla y en pocos pasos se podrá obtener el pedido, los soportes de pago visa y mastercard tendrán un funcionamiento correcto para el pago del pedido con solo mostrar el celular con la orden se hará la entrega del mismo.

Las políticas operacionales se orientan hacia:

\section{Tecnología - Plataforma web y aplicación móvil (user friendly and light weight app)}

La mayor parte de la inversión se destinará al desarrollo e interacción de la plataforma y aplicación web, lo que reafirma el compromiso de lograr los más altos estándares de calidad.

La tecnología se basa en conectar a los consumidores de food trucks con los dueños con esto se desea hacer conocidos a los food trucks y lograr el crecimiento de esta tendencia de comida.

La tecnología de la plataforma y de la aplicación está orientada a ser amigable con el usuario. Atender sus necesidades enfocándose en facilitar el uso del servicio como parte de sus atributos pretende ganarse la lealtad del usuario.

\section{Precio}


El precio es muy importante $\mathrm{y}$ es un factor clave de distinción con respecto a la competencia. La estrategia de la empresa es de Diferenciación debido a que se desea obtener más clientes, generar más ingresos y hacerse más conocidos. Los food trucks tienen un monto promedio del costo de cada plato y las personas que utilizaran lo saben, el ingreso por el aplicativo se dará por parte del food trucks, el cual representa el 5\% del volumen de ventas. La descarga del aplicativo para los usuarios seria gratuita.

\section{Protocolo de servicio}

Se ha diseñado un protocolo de servicio para asegurar la calidad de la atención por parte de la empresa. El protocolo de servicio se extiende a las interacciones desde el momento del ingreso del aplicativo hasta el recojo del pedido pudiendo después de realizar la compra el calificar el servicio al igual se usa la página web para poder realizar algún comentario del mismo, así como alguna queja o problema que se haya tenido para que el personal correspondiente en la empresa puede darle seguimiento y solución al tema.

\section{Seguridad}

Las transacciones realizadas mediante el aplicativo mediante las tarjetas de crédito o débito son seguras. Se usa Pay Pal.

\section{Soporte Técnico}

La empresa incluye en sus features un canal de asistencia para soporte técnico online y vía online.

\subsubsection{PROCESOS}

Para comprender de manera integral los procesos de la empresa, se ha diseñado un flujograma para una mejor comprensión visual.

Los procesos de la empresa se orientan en generar valor, satisfaciendo la necesidad del cliente y minimizando los tiempos de espera para lograr la atención esperada.

Para obtener eficiencia y eficacia la empresa se necesita concentrar los esfuerzos de todo el equipo de trabajo hacia la satisfacción del usuario, al reconocer el rol de cada miembro del equipo estos se alinean en torno a metas comunes. 


\subsubsection{PLANIFICACIÓN}

La planificación es fundamental para lograr el éxito en una empresa, permitiendo reducir la incertidumbre y minimizar riesgos.

Para la empresa el tener un soporte para cualquier problema del sistema, el permitir realizar el pago de una manera segura, el tener la geolocalización funcionando de la manera más efectiva, el tener las opciones de comida de preferencias del consumidor dentro de la gama de productos a elegir en base a una investigación de mercado. El contar con un software que permite la descarga y uso de la aplicación de una manera eficiente. Permite brindar el servicio para el cual la aplicación ha sido creada.

\subsubsection{INVENTARIO}

En el caso de la empresa no se aplica. 


\subsection{DISEÑO DE INSTALACIONES}

\subsubsection{LOCALIZACIÓN DE LAS INSTALACIONES}

¡Ñam! Buscador de Food Trucks contará con una oficina en el departamento de uno de los integrantes del equipo, está ubicado en el distrito de Surquillo, en la Calle eucalipto 122 departamento 501 - Surquillo. Se eligió dicho distrito, ya que ¡Ñam! Buscador de Food Trucks contara con clientes en Miraflores y Surco. Se eligió esta ubicación ya que es céntrico para los clientes y los trabajadores de la empresa. El alquiler pactado es de S/600.00 soles.

Ilustración 36: Ubicación de oficina

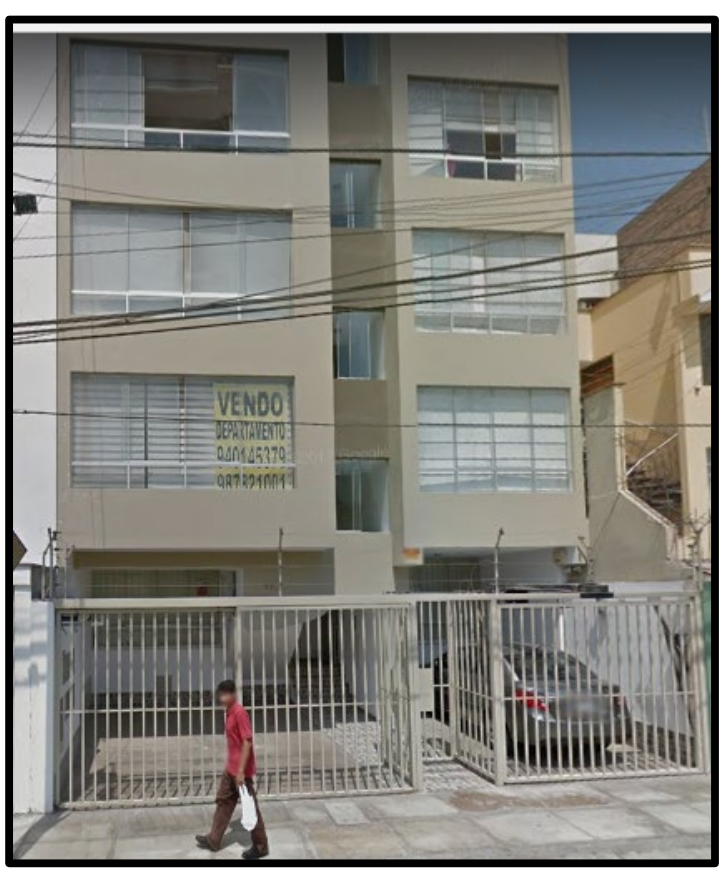

Fuente: Elaboración Propia 
Ilustración 37: Ubicación geográfica de la oficina

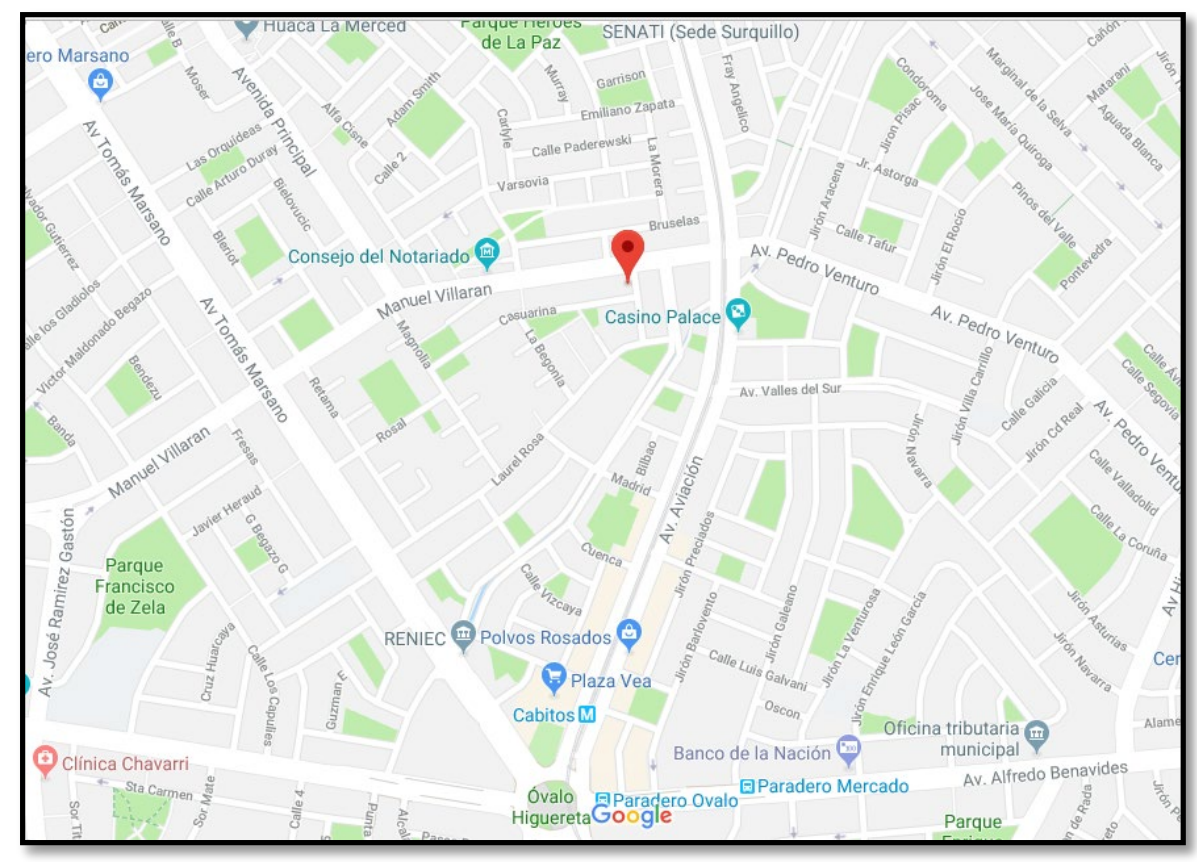

Fuente: Google Maps

\subsubsection{CAPACIDAD DE LAS INSTALACIONES}

La oficina contara con un área de $7.7 \mathrm{~m} 2$ con un aforo de 9 personas de los cuales están destinados para el área de atención al cliente, área administrativa, área operativa y servicios higiénicos.

La oficina tendrá horario de atención de:

- Lunes a Viernes de $2 \mathrm{pm}$ a $11 \mathrm{pm}$.

- Sábados y domingos de $6 \mathrm{pm}$ a $10 \mathrm{pm}$. 


\subsubsection{DISTRIBUCIÓN DE LAS INSTALACIONES}

Nuestra oficina cuenta con área de atención para los clientes, área administrativa, área operativa y servicios higiénicos.

Ilustración 38: Plano de distribución oficina

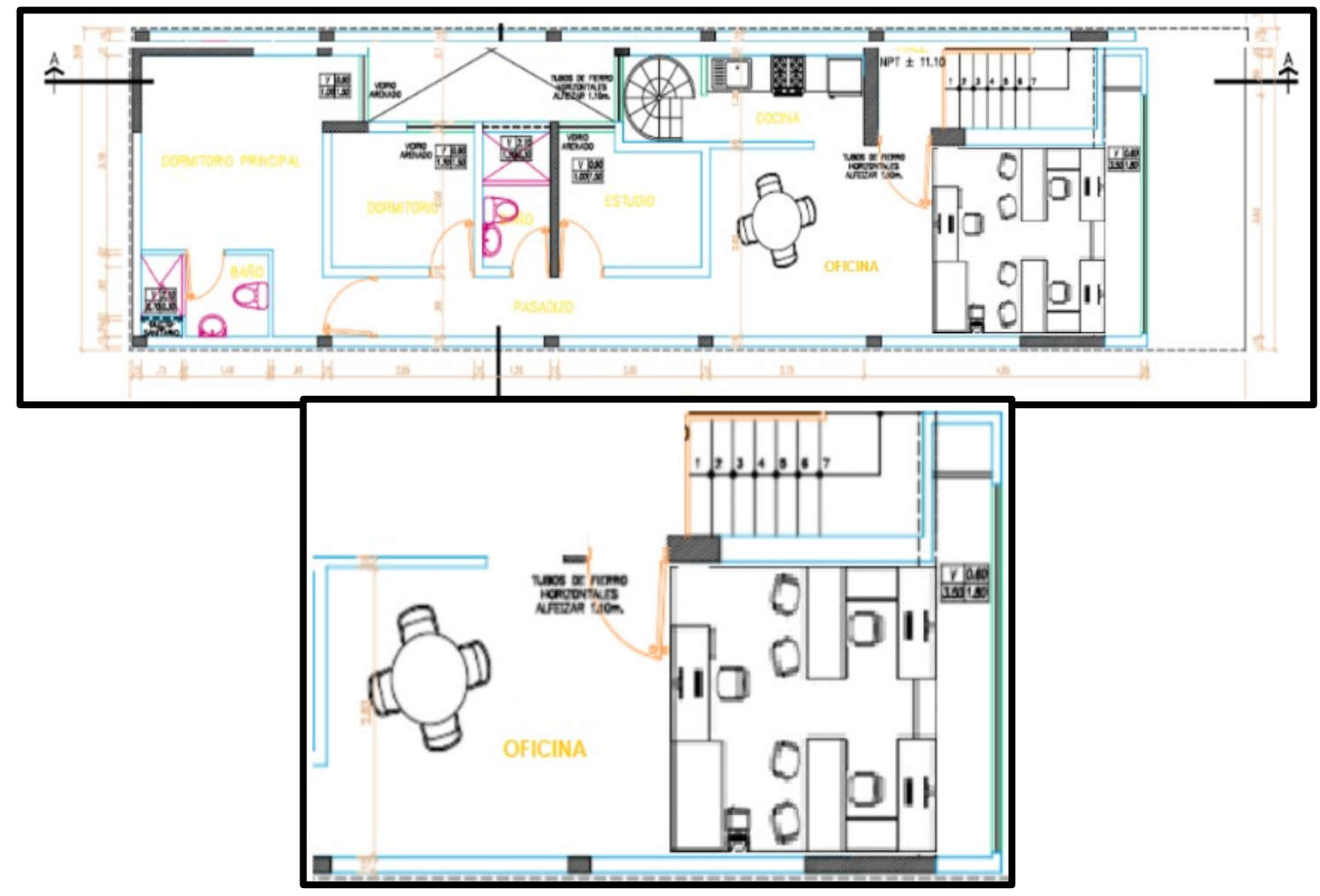

Fuente: Elaboración Propia

\subsection{ESPECIFICACIONES DEL SERVICIO TÉCNICO}

Vendedor: Food Trucks ÑAM S.A.C

Tamaño: $138,8 \mathrm{Mb}$

Categoría: Comida

Compatibilidad: Compatible iOS10.0 o posterior y Android.

Ubicación: Esta app utiliza tu ubicación, aunque no esté abierta de modo que puede reducir la duración de la batería del dispositivo.

Idiomas: español, inglés.

Edad: De 12 años a más

\section{Características Generales}

- Plataforma Multidioma, Accesibilidad múltiple: Multiplataforma PC, Smartphone, 
- Tablet.

- Área Privada - Espacio exclusivo para los usuarios registrados.

- Web Auto gestionable - Permite de forma autónoma gestionar todos los contenidos y menús de la web.

- Buscador de Productos personalizado - Buscador de productos adaptado a las necesidades del usuario.

- Paquete de Configuración SEO - Permite de forma fácil y rápida optimizar la indexación de la página web. Incluye la generación automática de parámetros SEO.

- Integración con el programa de email marketing

- Integración con Redes Sociales - Facebook, Twitter, Addis, Google Plus, YouTube, Vimeo, LinkedIn, entre otras.

- Integración con Google Maps y Waze.

- Integración con Google Analytics.

- Integración con Plataforma de Pago.

\section{Características Online}

- Permite visualizar los precios de los productos con distintas tarifas.

- Configuración de las distintas formas de pago.

- Permite realizar descuentos automáticos (según importe de compra, según cliente).

- Generación automática y mantenimiento de cupones de descuento o regalo. 


\subsection{MAPA DE PROCESOS Y PERT}

Se presenta la navegación del usuario en la aplicación, la navegación pretende ser amigable e intuitivo.

Ilustración 39: Navegación del usuario en la aplicación.

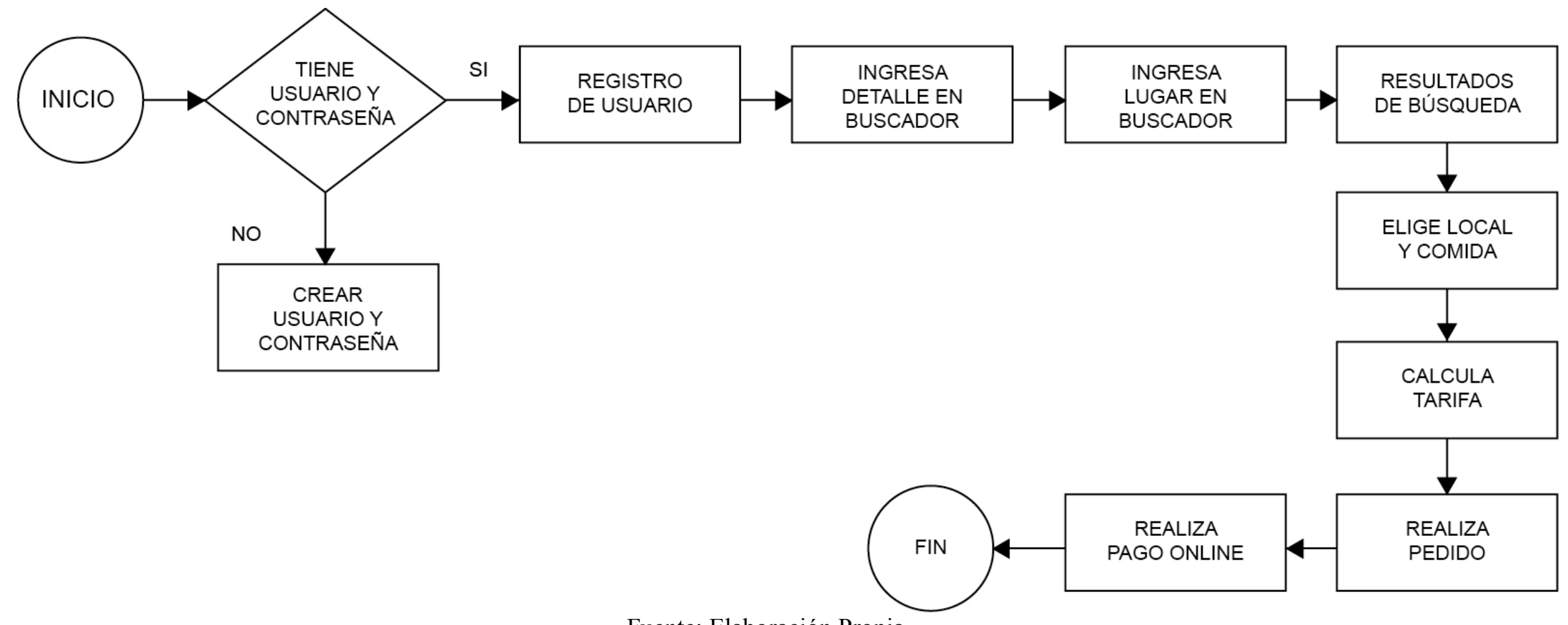

Fuente: Elaboración Propia 
Ilustración 40: Flujograma Cliente (Recoge pedido)

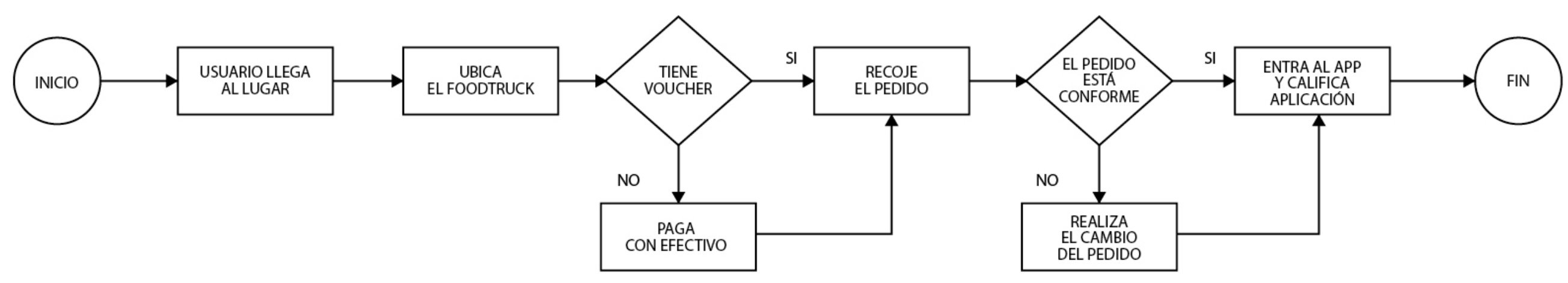

Fuente: Elaboración Propia 
Tabla 11: Actividades del Proyecto para el Diagrama PERT

\begin{tabular}{|c|c|c|c|}
\hline Clave & Actividad & Predecesora & Tiempo de ejecución \\
\hline A & Creación de aplicación & No aplica & 60 días \\
\hline B & Planificación y Proyección & $\mathrm{A}$ & 30 días \\
\hline C & Instalación de oficina & $\mathrm{A}$ & 5 días \\
\hline D & Instalación de sistemas y redes & $\mathrm{C}$ & 25 días \\
\hline E & Instalación de plataforma de pago & $\mathrm{C}$ & 25 días \\
\hline F & Trámite de licencia de funcionamiento & $\mathrm{D}, \mathrm{E}$ & 5 días \\
\hline G & Reclutamiento & $\mathrm{F}$ & 10 días \\
\hline H & Inicio Plan de marketing en redes & $\mathrm{G}$ & 15 días \\
\hline I & Período de prueba & $\mathrm{H}$ & 15 días \\
\hline
\end{tabular}

Fuente: Elaboración Propia

Ilustración 41: Diagrama PERT

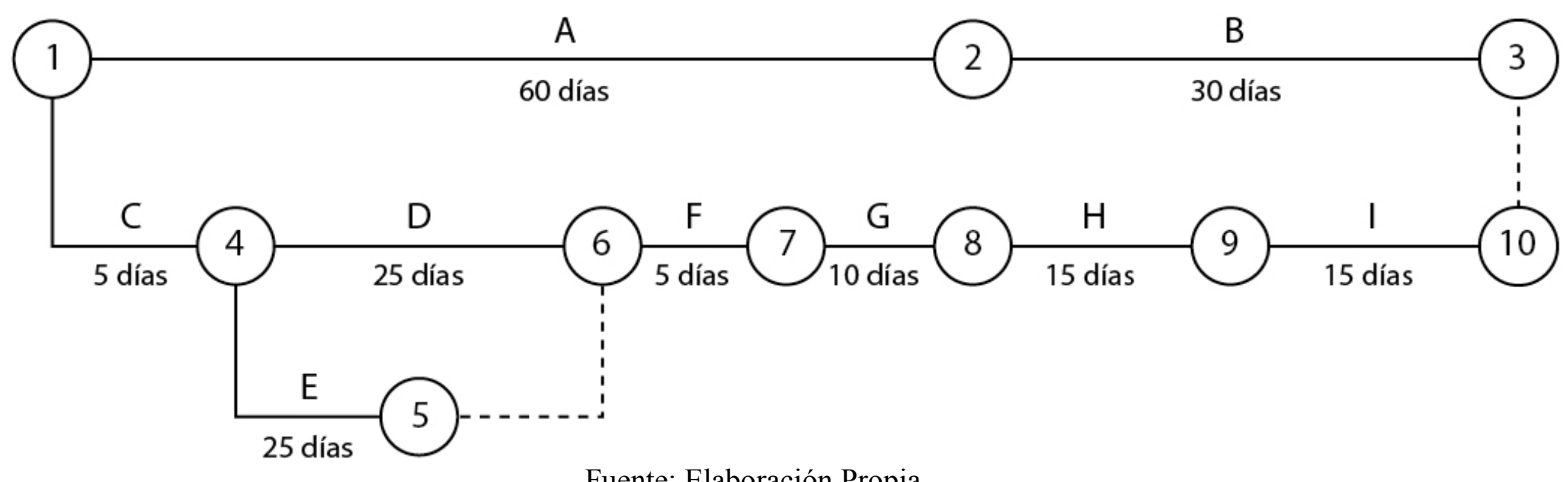

Fuente: Elaboración Propia

Duración total de nuestro proyecto: 3 meses. 


\section{Wireframe de navegación en el APP ¡ÑAM!}

Ilustración 42: Paso 1 Registro Usuario y Contraseña

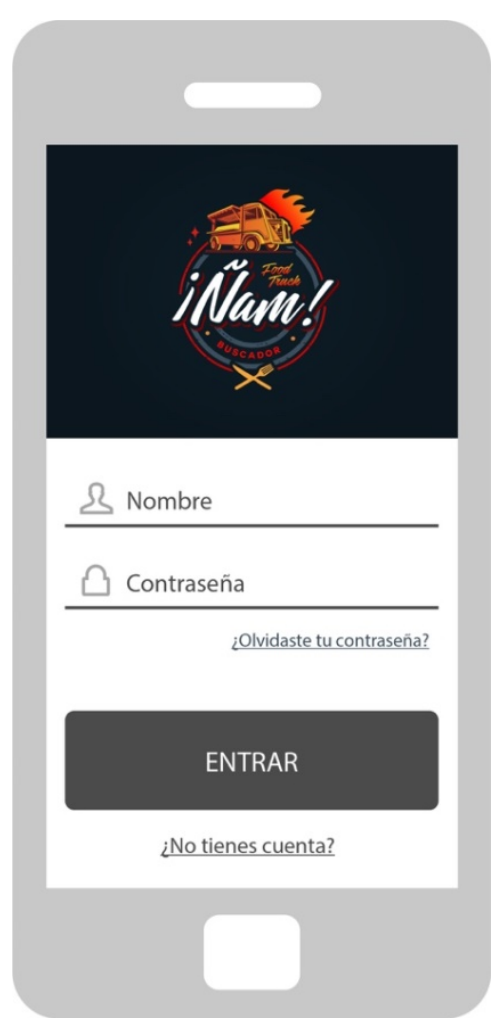

Fuente: Elaboración Propia
Ilustración 43: Paso 2 Ingresa detalle y lugar de la búsqueda

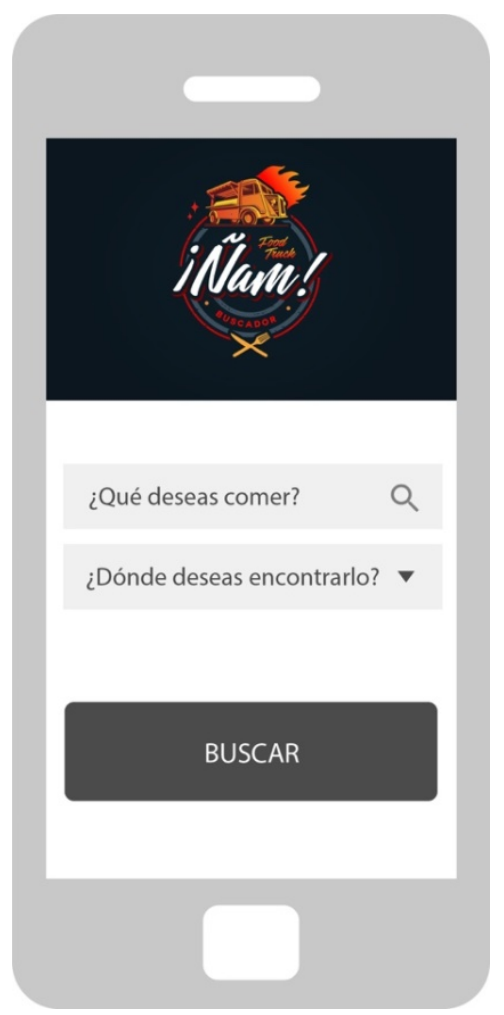

Fuente: Elaboración Propia
Ilustración 44: Paso 3 Resultado de búsqueda y elección de local

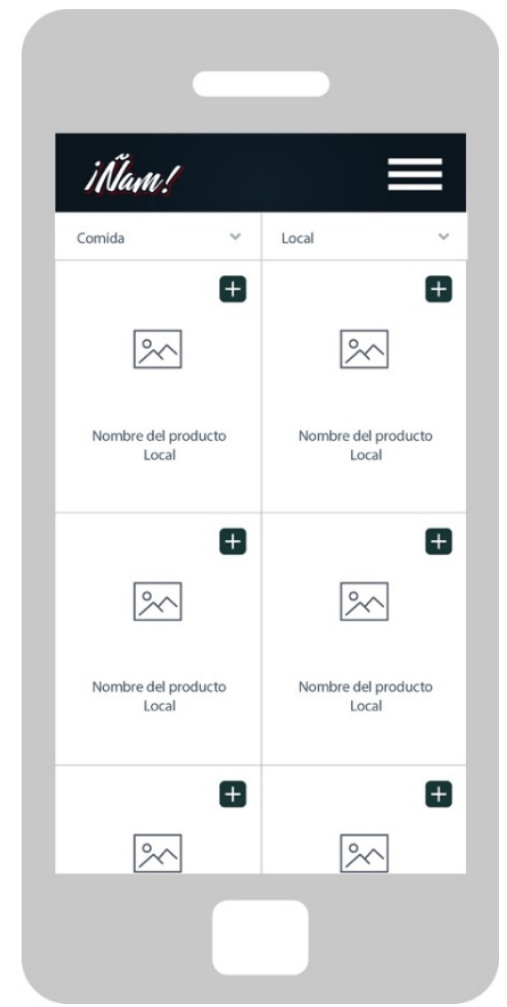

Fuente: Elaboración Propia 
Ilustración 45: Paso 4 Información del Producto y confirmación del pedido

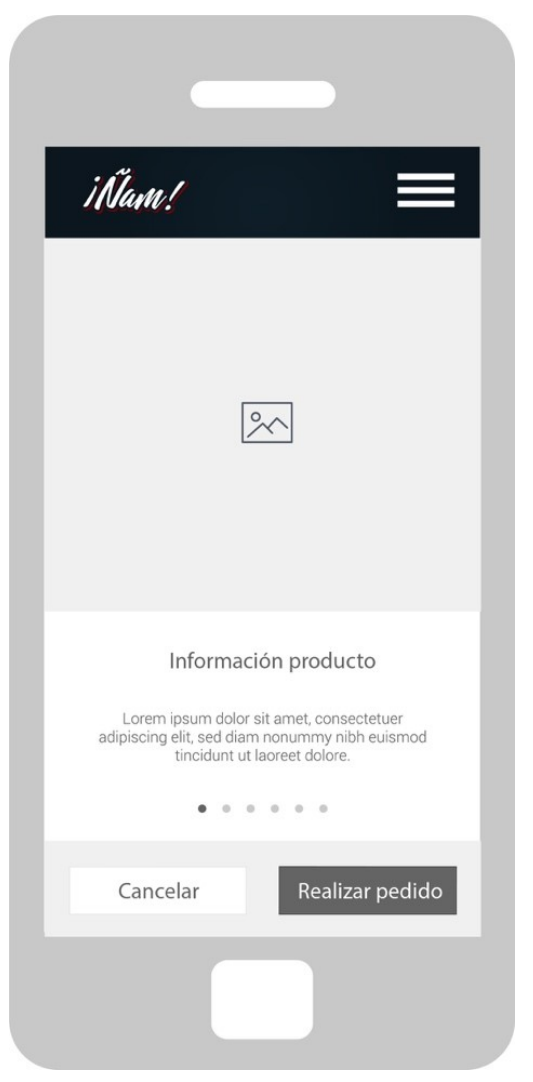

Fuente: Elaboración Propia
Ilustración 46: Paso 5 Solicitud de tarjeta, cálculo de tarifa y pago.

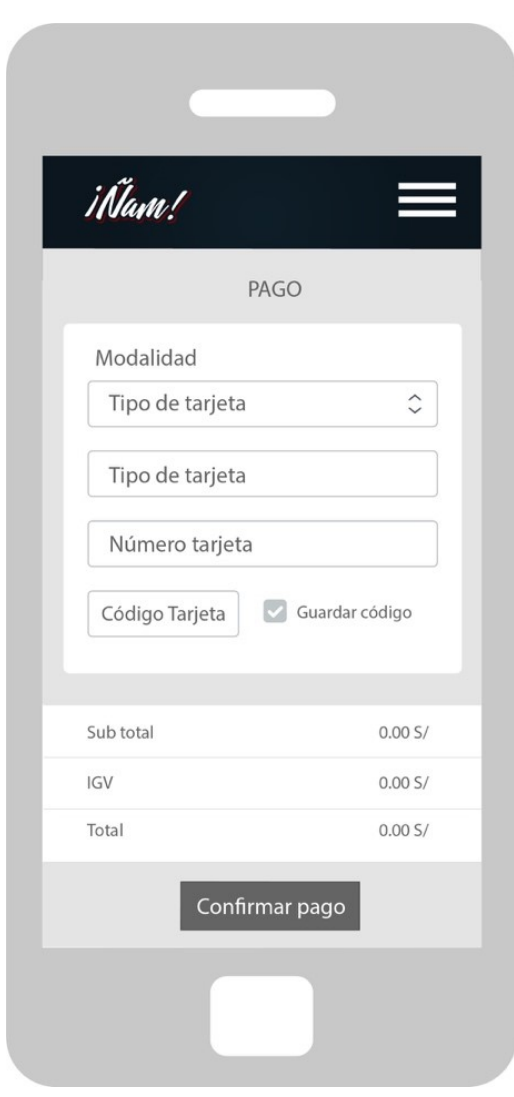

Fuente: Elaboración Propia 


\subsection{PLANEAMiENTO DE LA PRODUCCIÓN}

\subsubsection{GESTIÓN DE COMPRAS Y STOCK}

(No aplica)

\subsubsection{GESTIÓN DE CALIDAD}

\section{Seguridad en la Transacción:}

El servicio será brindado vía un APP, por lo cual se debe mantener la seguridad de los datos de los clientes. Por ello, se va trabajar con PayPal para mantener la información y las transacciones de los usuarios, ellos cobran una comisión por porcentaje de las ventas, pero garantizan la seguridad de los clientes.

\section{Protocolo de Servicio:}

Se ha diseñado métodos de calidad del servicio que la empresa ofrece, para ello se ha diseñado: Puntuación mediante el APP respecto al nivel de Servicio, encuestas vía redes sociales, encuestas vía e-mail y finalmente se realizaran entrevistas de indagación tanto como para clientes y consumidores del nivel de servicios que ofrece.

\section{Seguridad en los Pedidos:}

Con el fin de garantizar los pedidos de los clientes, se actualizarán de manera continua los productos que ofrecen los clientes en el APP. Para ello, de manera quincenal se reunirán los clientes con el fin de garantizar la originalidad del producto y revisar los comentarios dejados por los consumidores con el fin de garantizar la calidad del producto.

\section{Canal de Reclamos:}

La empresa implementara el Libro de Reclamaciones, para medir el nivel de Satisfacción de los clientes y las sugerencias brindadas por la experiencia del Servicio. Por ello, ese medio se implementará vía Web y mediante al APP.

\section{Soporte Técnico:}


La empresa cuenta con personal altamente calificado para brindar un soporte adecuado en caso el APP tenga un problema técnico ya sea online o telefónica.

\section{Medio Ambiente:}

La empresa realizara campañas de No Contaminación mediante la app, de cómo: evitar el consumo de papel (transacciones de pago) y de cómo eliminar los residuos (materiales para la elaboración de las hamburguesas). 


\subsection{INVERSIÓN DE ACTIVOS FIJOS VINCULADOS AL PROCESO PRODUCTIVO}

Tabla 12: Inversión en Activos Fijos vinculados al Costo

\begin{tabular}{|c|c|c|c|c|c|c|c|}
\hline \multicolumn{6}{|c|}{ Máquinas y Equipos } & \multicolumn{2}{|c|}{ DEPRECIACION } \\
\hline ITEM & $\begin{array}{l}\text { Cant } \\
\text { idad }\end{array}$ & $\begin{array}{l}\text { P.U. } \\
\text { (IGV) }\end{array}$ & \begin{tabular}{|c|} 
Unidad \\
de \\
Medida \\
\end{tabular} & $\begin{array}{l}\text { Precio Sin } \\
\text { Igv (S/.) }\end{array}$ & $\begin{array}{c}\text { Precio Total } \\
(\mathrm{S} / .)\end{array}$ & $\begin{array}{c}\text { Año } \\
\text { s }\end{array}$ & Importe (S/.) \\
\hline Impresora HP & 1 & 800.00 & Unidades & 677.97 & 800.00 & 5.00 & 160.00 \\
\hline Teléfono & 1 & 150.00 & Unidades & 127.12 & 150.00 & & \\
\hline \multicolumn{4}{|c|}{ IMPORTE TOTAL } & 805.08 & 950.00 & & 160.00 \\
\hline
\end{tabular}

\begin{tabular}{|c|c|c|c|c|c|c|c|}
\hline \multicolumn{6}{|c|}{ Computadoras } & \multicolumn{2}{|c|}{ DEPRECIACION } \\
\hline ITEM & $\begin{array}{l}\text { Cant } \\
\text { idad }\end{array}$ & $\begin{array}{l}\text { P.U. } \\
\text { (IGV) }\end{array}$ & \begin{tabular}{|c|} 
Unidad \\
de \\
Medida \\
\end{tabular} & $\begin{array}{c}\text { Precio Sin } \\
\text { Igv (S/.) }\end{array}$ & $\begin{array}{c}\text { Precio Total } \\
(\mathrm{S} / .)\end{array}$ & $\begin{array}{c}\text { Año } \\
\mathbf{S}\end{array}$ & Importe (S/.) \\
\hline Laptop I5 HP & 1 & 2100.00 & Unidades & $1,779.66$ & $2,100.00$ & 4.00 & 525.00 \\
\hline & & & & & 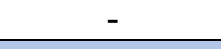 & & \\
\hline \multicolumn{4}{|c|}{ IMPORTE TOTAL } & $1,779.66$ & $2,100.00$ & & 525.00 \\
\hline
\end{tabular}

\begin{tabular}{|c|c|c|c|c|c|c|c|}
\hline \multicolumn{6}{|c|}{ Muebles y Equipos de Oficina } & \multicolumn{2}{|c|}{ DEPRECIACION } \\
\hline ITEM & $\begin{array}{l}\text { Cant } \\
\text { idad }\end{array}$ & $\begin{array}{l}\text { P.U. } \\
\text { (IGV) }\end{array}$ & $\begin{array}{c}\text { Unidad } \\
\text { de } \\
\text { Medida } \\
\end{array}$ & $\begin{array}{c}\text { Precio Sin } \\
\operatorname{Igv}(\mathrm{S} / .)\end{array}$ & $\begin{array}{c}\text { Precio Total } \\
(\mathrm{S} / .)\end{array}$ & $\begin{array}{c}\text { Año } \\
\text { s }\end{array}$ & Importe (S/.) \\
\hline Silla & 1 & 150.00 & Unidades & 127.12 & 150.00 & 5.00 & 30.00 \\
\hline $\begin{array}{c}\text { Mueble } \\
\text { Archivador }\end{array}$ & 1 & 180.00 & Unidades & 152.54 & 180.00 & 5.00 & 36.00 \\
\hline $\begin{array}{l}\text { Mesa Grande } \\
\text { (Escritorio) }\end{array}$ & 1 & 400.00 & Unidades & 338.98 & 400.00 & 5.00 & 80.00 \\
\hline \multirow[t]{2}{*}{ Cajoneros } & 1 & 80.00 & Unidades & 67.80 & 80.00 & 5.00 & 16.00 \\
\hline & & & & - & - & & \\
\hline \multicolumn{4}{|c|}{ IMPORTE TOTAL } & 686.44 & 810.00 & & 162.00 \\
\hline
\end{tabular}

INVERSIÓN TOTAL EN ACTIVO FIJO PARA EL PROCESO PRODUCTIVO

S/ $\quad 3,860.00$

S/

847.00

Fuente: Elaboración Propia

La empresa ¡Ñam! Buscador de Food Trucks, por ser una empresa de servicio, la única inversión dirigida al proceso productivo, serán los considerados por los del Gerente de Operaciones, los cuales los hemos dividido en:

Para calcular la depreciación de cada activo, lo hemos considerado el Reglamento de la Ley del Impuesto a la Renta, aprobado por el Decreto Supremo N. ${ }^{\circ} 122-94-E F$, publicado el 21.9.1994 y normas modificatorias (en adelante Reglamento del Impuesto a la Renta). 


\subsection{ESTRUCTURA DE COSTOS Y GASTOS OPERATIVOS}

La empresa ¡Ñam! Buscador de Food Trucks ha considerados los siguientes costos:

- Planilla: Se ha considerado el servicio por Recibos por Honorarios del Gerente de Operaciones, el cual tendrá un sueldo de S/ 2,000 (dos mil soles).

- Gastos Pre Operativos: Gastos relacionados antes del inicio de ejecución de las actividades de la empresa. Como: Elaboración del Proyecto, Constitución de la Empresa, entre otros.

- Gastos Operativos: Gastos fijos para el funcionamiento de la operación, como: Agua, Luz, Teléfono, Internet y alquiler de oficina.

- Software: Se está colocando los gastos de la creación del APP y de la Página Web, además de un servicio de Servidor Cloud en la nube para tener a nuestros clientes y consumidor con un buen servicio de conectividad.

- Útiles de Oficina: Materiales o insumos para mantener un orden en los documentos.

Tabla 13: Gastos vinculados al Costo y Gastos Operativos

\begin{tabular}{|c|c|c|c|c|c|}
\hline \multicolumn{7}{|c|}{ Planilla } \\
\hline ITEM & Cantidad & $\begin{array}{c}\text { P.U. } \\
\text { (IGV) }\end{array}$ & $\begin{array}{c}\text { Unidad de } \\
\text { Medida }\end{array}$ & $\begin{array}{c}\text { Precio Sin } \\
\text { Igv (S/.) }\end{array}$ & $\begin{array}{c}\text { Precio } \\
\text { Total (S/.) }\end{array}$ \\
\hline Gerente de Operaciones & 1 & $2,000.00$ & Unidades & & $2,000.00$ \\
\hline & & & & & \\
\hline \multicolumn{3}{|l|}{ IMPORTE TOTAL } & - & $2,000.00$ \\
\hline
\end{tabular}

\begin{tabular}{|c|c|c|c|c|c|}
\hline \multicolumn{7}{|c|}{ Gastos Pre Operativos } \\
\hline ITEM & Cantidad & $\begin{array}{c}\text { P.U. } \\
\text { (IGV) }\end{array}$ & $\begin{array}{c}\text { Unidad de } \\
\text { Medida }\end{array}$ & $\begin{array}{c}\text { Precio Sin } \\
\text { Igv (S/.) }\end{array}$ & $\begin{array}{c}\text { Precio } \\
\text { Total (S/.) }\end{array}$ \\
\hline Elaboración del Proyecto & 1 & 1800.00 & Unidad & $1,525.42$ & $1,800.00$ \\
\hline Constitución Empresa & 1 & 1200.00 & Unidad & $1,016.95$ & $1,200.00$ \\
\hline Registro Indecopi Marca & 1 & 534.99 & Unidad & 453.38 & 534.99 \\
\hline $\begin{array}{c}\text { Inscripción en Cámara de } \\
\text { Comercio }\end{array}$ & 1 & 95.00 & Unidad & 80.51 & 95.00 \\
\hline Adelanto de Alquiler (2 Meses) & 2 & 600.00 & Unidad & $1,016.95$ & $1,200.00$ \\
\hline Gastos de Instalacion & 1 & 800.00 & Unidad & 677.97 & 800.00 \\
\hline \multicolumn{7}{|l|}{ IMPORTE TOTAL } & & & \\
\hline & & & & $2,228.81$ & $5,629.99$ \\
\hline
\end{tabular}




\begin{tabular}{|c|c|c|c|c|c|}
\hline ITEM & Cantidad & $\begin{array}{c}\text { P.U. } \\
(\text { IGV) }\end{array}$ & $\begin{array}{c}\text { Unidad de } \\
\text { Medida }\end{array}$ & $\begin{array}{c}\text { Precio Sin Igv } \\
\text { (S/.) }\end{array}$ & $\begin{array}{c}\text { Precio Total } \\
\text { (S/.) }\end{array}$ \\
\hline Alquiler de Oficina & 1 & 600.00 & Unidad & 508.47 & 600.00 \\
\hline Agua & 1 & 15.00 & Unidad & 12.71 & 15.00 \\
\hline Luz & 1 & 30.00 & Unidad & 25.42 & 30.00 \\
\hline Teléfono / Internet & 1 & 60.00 & Unidad & 50.85 & 60.00 \\
\hline \multicolumn{7}{|c|}{ IMPORTE TOTAL } & & 705.00 \\
\hline
\end{tabular}

\begin{tabular}{|c|c|c|c|c|c|}
\hline \multicolumn{6}{|c|}{ Software } \\
\hline ITEM & Cantidad & $\begin{array}{l}\text { P.U. } \\
\text { (IGV) }\end{array}$ & $\begin{array}{c}\text { Unidad de } \\
\text { Medida }\end{array}$ & $\begin{array}{c}\text { Precio Sin Igv } \\
(\mathrm{S} / .)\end{array}$ & $\begin{array}{l}\text { Precio Total } \\
\text { (S/.) }\end{array}$ \\
\hline $\begin{array}{c}\text { Desarrollo de APP y } \\
\text { Pagina Web }\end{array}$ & 1 & $65,000.00$ & Unidades & $55,084.75$ & $65,000.00$ \\
\hline \multirow[t]{2}{*}{ Servidor Cloud } & 1 & $18,000.00$ & Unidades & $15,254.24$ & $18,000.00$ \\
\hline & & & & & - \\
\hline \multicolumn{4}{|c|}{ IMPORTE TOTAL } & $70,338.98$ & $83,000.00$ \\
\hline
\end{tabular}

\begin{tabular}{|c|c|c|c|c|c|}
\hline \multicolumn{7}{|c|}{ Útiles de Oficina } \\
\hline ITEM & Cantidad & $\begin{array}{c}\text { P.U. } \\
(\text { IGV) }\end{array}$ & $\begin{array}{c}\text { Unidad de } \\
\text { Medida }\end{array}$ & $\begin{array}{c}\text { Precio Sin Igv } \\
\text { (S/.) }\end{array}$ & $\begin{array}{c}\text { Precio Total } \\
\text { (S/.) }\end{array}$ \\
\hline Lapiceros & 2 & 1.00 & Unidades & 1.69 & 2.00 \\
\hline Lápices & 2 & 1.00 & Unidades & 1.69 & 2.00 \\
\hline Folder & 0.5 & 50.00 & Ciento & 21.19 & 25.00 \\
\hline Sobres & 0.5 & 40.00 & Ciento & 16.95 & 20.00 \\
\hline Hojas Bond & 1 & 17.90 & Ciento & 15.17 & 17.90 \\
\hline Cd & 0.5 & 60.00 & Ciento & 25.42 & 30.00 \\
\hline Engrapador & 1 & 15 & Unidades & 12.71 & 15.00 \\
\hline Perforador & 1 & 8 & Unidades & 6.78 & 8.00 \\
\hline \multicolumn{7}{|l|}{ IMPORTE TOTAL } & & 77.03 & 119.90 \\
\hline
\end{tabular}

Fuente: Elaboración Propia 


\section{CAPÍTULO 6: ESTRUCTURA \\ ORGANIZACIONAL Y RECURSOS HUMANOS}

\subsection{OBJETIVOS ORGANIZACIONALES}

Los objetivos organizacionales se encuentran alineados con la Visión de:

"Ser el aplicativo de búsqueda de comida de food trucks más utilizado en Lima y expandirse a todo el Perú." y con la Misión: Cambiar la forma de solicitar comida por aplicación, al reducir el tiempo de espera en los food trucks.

Conectar a los usuarios con los Food trucks por medio de la aplicación. Agilizar la ubicación de los locales de food trucks, para aumentar la demanda del servicio de food trucks en Lima Metropolitana.

Los objetivos organizacionales también están alineados con los objetivos

Estratégicos:

- Formar parte de la asociación de Food Trucks en Lima, ya que con ellos se le permitirá a la empresa tener una mejor red de contactos, a los que se les podrá ofrecer el producto.

- Desarrollar un App de fácil acceso, que permita a los usuarios identificar donde se ubican los Food Trucks, los diferentes tipos de food trucks y los precios de sus productos.

- Tener un personal altamente calificado, que permita resolver cualquier inconveniente de manera rápida y eficiente y además ser innovadores en crear nuevas formas de incrementar los usuarios.

- Contar con la tecnología más moderna, amigable y eficiente del mercado.

- Crear programa de fidelización para los clientes.

- Mantener la estrategia de segmentación orientada a la diferenciación lo que permitirá a la empresa generar un LOVEMARK.

- Incrementar los canales de comunicación de la marca. 
En líneas generales, la empresa busca permanecer en el tiempo, obteniendo rentabilidad y generando crecimiento en ventas y utilidades.

\subsection{NATURALEZA DE LA ORGANIZACIÓN}

¡ÑAM! es una micro empresa con fines de lucro que cuenta con 7 colaboradores, cuyo capital está repartido en participaciones sociales aportados por los socios. La organización es de formato horizontal, el aporte es colaborativo, con ello se crea un ambiente de compromiso por parte de sus integrantes

\subsubsection{ORGANIGRAMA}

Ilustración 47: Organigrama ¡ÑAM! Buscador de Food Trucks

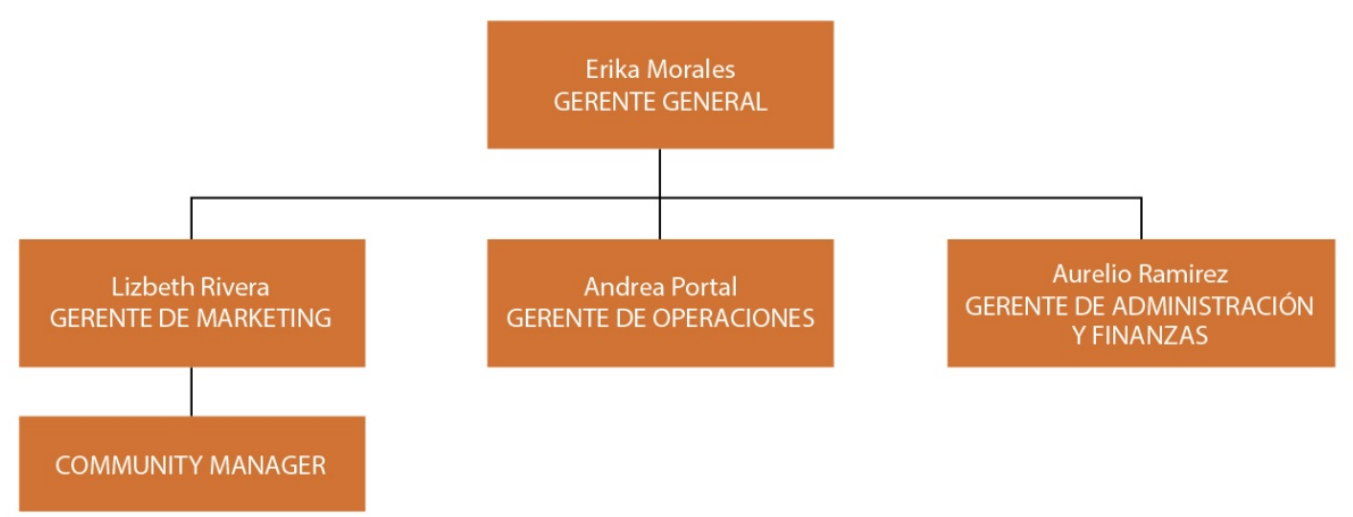

Fuente: Elaboración Propia 


\section{Gerencia General:}

- Celebrar y firmar contratos a nombre de la persona jurídica.

- Representar a la empresa ante entes públicos y privados.

- Definir las funciones y metas de cada área.

- Realizar evaluaciones periódicas del funcionamiento de cada área.

- Planificar las metas de corto y largo plazo.

- Evaluar el cumplimiento de la meta de satisfacción del personal.

\section{Gerencia de Marketing:}

- Supervisar labor del Community Manager, Diseñador y Programador.

- Elaborar estrategias para el incremento de las ventas.

- Supervisar el presupuesto destinado al área.

\section{Gerencia de Operaciones:}

- Coordinar horarios laborales y cumplimiento del mismo.

- Supervisar el correcto funcionamiento de los sistemas.

- Establecer matrices de riesgo de las operaciones de la empresa.

- Lograr los niveles deseados de eficiencia productiva.

\section{Gerencia de Administración y Finanzas:}

- Llevar la contabilidad de la empresa.

- Encargado de la medición de ventas y cumplimiento de metas.

- Administración de personal.

\section{Community Manager:}

- Encargado de la promoción de la empresa a través de redes sociales. 


\subsubsection{DISEÑO DE PUESTOS Y FUNCIONES}

\section{Perfil de Puesto: Gerente General}

Área: Administración

Supervisa: Gerencia

Responsabilidades principales del puesto:

- Dirigir las decisiones de la empresa de manera colaborativa con el resto de gerentes.

- Administrar los recursos de la empresa de la manera más eficiente posible.

\section{Funciones específica del puesto:}

- Firmar contratos a nombre de la persona jurídica.

- Representar a la empresa ante entes públicos y privados.

- Definir las funciones y metas de cada área.

- Realizar evaluaciones periódicas del funcionamiento de cada área.

- Planificar de las metas de corto y largo plazo.

- Evaluar el cumplimiento de la meta de satisfacción del personal.

Perfil de Puesto: Gerente de Marketing Área: Marketing

Supervisa: Community Manager

Responsabilidades principales del puesto:

- Desarrollar la marca y posicionarla en el mercado.

- Realizar estrategias de publicidad para el rendimiento de ventas.

Funciones específicas del puesto:

- Diseñar e implementar el Plan de Marketing de la organización.

- Definir las estrategias de marketing.

- Planificar, elaborar y gestionar el presupuesto del departamento, bajo unos estándares de eficiencia y optimización de recursos. 
- Analizar las acciones del departamento y evaluar y controlar los resultados de las mismas.

- Dirigir y liderar el equipo de trabajo.

Perfil de Puesto: Gerente de Operaciones

Área: Operaciones

Responsabilidades principales del puesto:

- Asegurar la operación logística.

- Administrar los recursos de manera eficiente.

- Planificar y diseñar políticas sustentado en procesos de mejora continua.

Funciones específicas del puesto:

- Supervisar el proceso del servicio.

- Coordinar horarios laborales y cumplimiento del mismo.

- Supervisar el correcto funcionamiento de los sistemas.

- Establecer matrices de riesgo de las operaciones de la empresa.

- Lograr los niveles deseados de eficiencia productiva.

Perfil de Puesto: Gerente de Administración y Finanzas

Área: Administración y Finanzas

Responsabilidades principales del puesto:

- Velar por la salud financiera de la empresa.

- Programar los pagos del personal.

- Procesar pagos por servicio.

Funciones específicas del puesto:

- Llevar la contabilidad de la empresa

- Encargado de la medición de ventas y cumplimiento de metas.

- Administración personal. 


\section{Perfil de Puesto: Community Manager \\ Área: Marketing}

\section{Responsabilidades principales del puesto:}

- Creación y gestión de contenidos.

- Analítica. Monitorización de todos los parámetros: engagement, crecimiento comunidad, ROI, trafico web social.

- Comunicación con la comunidad. Establecer diálogos bidireccionales, crear audiencias, humanizar la marca y generar valor.

- Planificación de acciones de marketing digital.

- Funciones específicas del puesto:

- Decidir estrategias de publicación de contenido.

- Monitorizar todas las publicaciones y novedades del sector de su empresa, así como de sus propias publicaciones.

- Conocerá a su público objetivo y crear relaciones estables y duraderas con los fans de las redes sociales.

\subsection{POLÍTICAS ORGANIZACIONALES}

- Las políticas organizacionales de la empresa se basan en 3 factores: supervivencia, rentabilidad y crecimiento. Con estos 3 factores se espera que la empresa tenga durabilidad en el tiempo.

- Mantener relaciones de cordialidad entre el equipo de trabajo.

- Adaptación a los cambios si el mercado lo requiere.

- Respetar la privacidad de los colaboradores.

- Crear un sistema de remuneración justo y de acuerdo a la experiencia y conocimiento del colaborador.

- Establecer normas aplicables para la selección y reclutamiento que permitan la elección de los colaboradores idóneos. 
- La empresa debe enfocarse en el servicio, dar importancia al feedback, ser flexibles y proactivos.

- La empresa debe enfocarse en la tecnología, en como los avances en este aspecto pueden afectar el negocio si la empresa no va de la mano con estos avances.

- La empresa debe estar alerta a la competencia para poder aplicar las estrategias adecuadas para mantener su servicio como una necesidad para los usuarios.

\subsection{GESTION HUMANA}

\subsubsection{RECLUTAMIENTO}

La empresa para el personal que se encontrara en la oficina administrativa buscara profesionales con 2 años de experiencia en sus rubros de preferencia en aplicaciones móviles. Los medios a utilizar para la publicación de oportunidades laborales se harán mediante referencias de personas conocidas así también la empresa usara las redes sociales.

\subsubsection{SELECCIÓN, CONTRATACIÓN E INDUCCIÓN}

\section{La Selección:}

- Revisión de Curriculum vitae, estos deberán estar alineados con el perfil que se requiere según puesto a ocupar.

- Luego se realizará entrevistas personales del personal.

- La empresa exigirá la entrega de referencias personales y de antecedentes penales y policiales.

- Luego de esto se realizará la decisión final.

\section{La Contratación:}

La contratación de personal será realizada por el área administrativa.

- Los postulantes que reúnan los requisitos establecidos por la Empresa y aprueben el proceso de selección, presentarán a la Administración los documentos expuestos anteriormente, los cuales serán revisados para corroborar la veracidad de los mismos.

- Si los documentos son fraudulentos o contienen información falsa, La Empresa tiene derecho de separar al colaborador de la empresa. En primera instancia la contratación se hará por un periodo de 3 meses (periodo de prueba) luego de este tiempo, la 
administración generará un contrato fijo de trabajo renovable cada año brindando al colaborador los beneficios de ley.

\section{La Inducción:}

- La empresa brindara la información necesaria al nuevo integrante sobre los ejes principales de la misma, como la visión, misión y valores. Además, se entregará el reglamento interno de trabajo y sus funciones a desempeñar según el puesto a ocupar. La etapa de inducción estará a cargo de la administración.

\subsubsection{CAPACITACIONES. DESEMPEÑO Y EVALUACIÓN DE DESEMPEÑO}

\section{Capacitación}

- La capacitación es un requisito fundamental para que la empresa pueda operar en óptimas condiciones. Por ello se brindará a los trabajadores capacitaciones presenciales, los cuales se basarán en atención al cliente y manejo del aplicativo. Las capacitaciones se realizarán cada 4 meses.

\section{Desempeño}

- Para los colaboradores que se encuentren estudiando se les dará facilidades para que culminen sus estudios correctamente, otorgando permisos y manejando diferentes horarios sin afectar su trabajo en la empresa. Con ello podrán desarrollarse profesionalmente y poder asumir nuevos puestos en la empresa.

\section{Evaluación de desempeño}

- Se realizará una evaluación de desempeño cada 6 meses a cada integrante de la empresa, para determinar las competencias de cada trabajador y por ende indicarles en que debe mejorar cada uno. 
Tabla 14: Ficha de evaluación de desempeño

\begin{tabular}{|c|c|c|c|c|c|c|}
\hline $\begin{array}{c}\mathbf{N} \\
\circ\end{array}$ & $\begin{array}{l}\text { COMPET } \\
\text { ENCIA }\end{array}$ & CONDUCTA OBSERVADA & $\begin{array}{l}\text { Casi } \\
\text { siempre } \\
\text { (9 de } 10 \\
\text { veces) }\end{array}$ & $\begin{array}{l}\text { Frecuent } \\
\text { emente } \\
\text { ( } 7 \text { de } 10 \\
\text { veces) }\end{array}$ & $\begin{array}{c}\text { Pocas } \\
\text { veces } \\
(5 \text { de } \\
10 \\
\text { veces } \\
\text { ) }\end{array}$ & $\begin{array}{l}\text { Nunca } \\
\text { (meno } \\
\text { s de } 2 \\
\text { de } 10 \\
\text { veces) }\end{array}$ \\
\hline \multirow{3}{*}{1} & \multirow{3}{*}{$\begin{array}{l}\text { ORIENTA } \\
\text { CION AL } \\
\text { LOGRO } \\
\text { DE }\end{array}$} & $\begin{array}{l}\text { 1. Planifica su propio tiempo para la } \\
\text { realización de las actividades previstas y } \\
\text { cumplir los objetivos. }\end{array}$ & & & & \\
\hline & & $\begin{array}{l}\text { 2. Orienta sus acciones hacia la consecución } \\
\text { de los objetivos que le han asignado. }\end{array}$ & & & & \\
\hline & & $\begin{array}{l}\text { 3. Toma de decisiones o hace } \\
\text { recomendaciones oportunas cuando es } \\
\text { necesaria una respuesta rápida ante un cliente } \\
\text { interno o externo. }\end{array}$ & & & & \\
\hline \multirow{4}{*}{2} & \multirow{4}{*}{$\begin{array}{l}\text { TRABAJO } \\
\text { EN } \\
\text { EQUIPO }\end{array}$} & $\begin{array}{l}\text { 1. Participa en las reuniones de coordinación } \\
\text { de su área de manera activa aportando ideas y } \\
\text { datos importantes. }\end{array}$ & & & & \\
\hline & & $\begin{array}{l}\text { 2, Mantiene relaciones interpersonales } \\
\text { positivas con las diferentes personas de la } \\
\text { institución. }\end{array}$ & & & & \\
\hline & & $\begin{array}{l}\text { 3. Colabora de acuerdo a sus funciones con } \\
\text { sus compañeros y las demás áreas para que las } \\
\text { cosas se hagan de manera rápida y coordinada. }\end{array}$ & & & & \\
\hline & & $\begin{array}{l}\text { 4. Ayuda a las personas de su área para que } \\
\text { realicen sus trabajos cumplan sus objetivos } \\
\text { con calidad. }\end{array}$ & & & & \\
\hline \multirow{3}{*}{3} & \multirow{3}{*}{$\begin{array}{l}\text { COMPRO } \\
\text { MISO } \\
\text { CON EL } \\
\text { IMPACT } \\
\text { O DEL }\end{array}$} & $\begin{array}{l}\text { 1. Se preocupa por estar cada vez mejor } \\
\text { capacitado para servir en el cumplimiento de } \\
\text { los objetivos de su área y de la institución. }\end{array}$ & & & & \\
\hline & & $\begin{array}{l}\text { 2. Mantiene en reserva información } \\
\text { confidencial de la Empresa, Clientes, } \\
\text { proveedores, entre otros. }\end{array}$ & & & & \\
\hline & & $\begin{array}{l}\text { 3. Se involucra con todas aquellas áreas y } \\
\text { actividades en donde pueda agregar valor. }\end{array}$ & & & & \\
\hline \multirow{4}{*}{4} & \multirow{4}{*}{$\begin{array}{l}\text { INICIATI } \\
\text { VA Y } \\
\text { PROACTI } \\
\text { VIDAD }\end{array}$} & $\begin{array}{l}\text { 1. Propone cambios, mejoras y soluciones } \\
\text { sobre el trabajo de su área. }\end{array}$ & & & & \\
\hline & & $\begin{array}{l}\text { 2. Es perseverante en la búsqueda de } \\
\text { soluciones o mejores, no se queda con la } \\
\text { primera alternativa. }\end{array}$ & & & & \\
\hline & & $\begin{array}{l}\text { 3. Esta constantemente buscando información } \\
\text { e investigando sobre el mercado, la } \\
\text { competencia, productos, entre otros. }\end{array}$ & & & & \\
\hline & & $\begin{array}{l}\text { 4. Se anticipa a las situaciones problemáticas } \\
\text { que podrían surgir en el corto plazo en sus } \\
\text { funciones o área. }\end{array}$ & & & & \\
\hline \multirow{3}{*}{5} & \multirow{3}{*}{$\begin{array}{c}\text { ENFOQU } \\
\text { E AL } \\
\text { CLIENTE } \\
\text { INTERNO } \\
\text { Y }\end{array}$} & $\begin{array}{l}\text { 1. Entiende adecuadamente los requerimientos } \\
\text { de sus clientes y busca la solución más } \\
\text { apropiada para ellos. }\end{array}$ & & & & \\
\hline & & $\begin{array}{l}\text { 2. Es capaz de generar credibilidad y una } \\
\text { relación de confianza con el cliente. }\end{array}$ & & & & \\
\hline & & $\begin{array}{l}\text { 3. Denota permanente disposición para atender } \\
\text { cordialmente a los clientes internos y externos. }\end{array}$ & & & & \\
\hline
\end{tabular}

Fuente: Elaboración Propia 


\subsubsection{MOTIVACIÓN}

Para mantener un buen clima laboral en la empresa se está determinando tener las siguientes motivaciones para el personal que trabaja en la empresa:

- Otorgar reconocimientos por los logros obtenidos alcanzados.

- Realizar reuniones semanales para conocernos como equipo de trabajo.

- Por su cumpleaños se dará día libre.

- Se aceptarán ideas innovadoras para que la empresa mejore.

- Se tomarán en cuenta las sugerencias del personal.

- Se dará feedback a cada trabajador para que refuerce sus competencias.

\subsubsection{SISTEMA DE REMUNERACIÓN}

La empresa ¡Ñam! Buscador de Food Trucks está dentro del grupo de la constitución de micro empresa (Mypes), ya que cumple con todas las características de una. Por ejemplo, en el sistema Tributario las microempresas deben seguir los siguientes parámetros:

Tabla 15: Sistema Tributario Microempresas

\begin{tabular}{|l|l|}
\hline \multicolumn{2}{|c|}{ MICROEMPRESA } \\
\hline Número de colaboradores & $\begin{array}{l}\text { De uno (1) hasta diez (10) trabajadores } \\
\text { inclusive }\end{array}$ \\
\hline Venta Anual & $\begin{array}{l}\text { Hasta el monto máximo de } 150 \\
\text { Unidades Impositivas Tributarias (UIT) }\end{array}$ \\
\hline
\end{tabular}

Fuente: Elaboración Propia

Por lo cual la UIT para el 2018 es de S/ 4,150 de acuerdo el Decreto Supremo No 3802017-EF, el cual me permite tener unas Ventas Anuales de S/ 622,500.

Por ello, la empresa tiene una estructura de:

Tabla 16: Estructura de la empresa 


\begin{tabular}{|l|l|}
\hline $\begin{array}{l}\text { Venta Anual } \\
\text { (Proyectada) }\end{array}$ & S/ 253,584 soles. \\
\hline $\begin{array}{l}\text { Recibos por } \\
\text { Honorario }\end{array}$ & $\begin{array}{l}\text { (3) Gerente de Administración Finanzas, Gerente de Ventas } \\
\text { y Gerente de Operaciones }\end{array}$ \\
\hline Planilla & \begin{tabular}{l} 
(2) Gerente General y Community Manager \\
\hline
\end{tabular} \\
\hline
\end{tabular}

Fuente: Elaboración Propia

Por lo cual, el Régimen Laboral para una Micro Empresa es:

Tabla 17: Régimen Laboral para una Microempresa

\begin{tabular}{|l|l|}
\hline \multicolumn{1}{|c|}{ INDICADOR / REGIMEN } & \multicolumn{1}{|c|}{ MICRO EMPRESA } \\
\hline Beneficios sociales & $\begin{array}{l}\text { Remuneración Mínima Vital } \\
\text { Jornada máxima } \\
\text { Descanso semanal } \\
\text { Trabajo en sobretiempo } \\
\text { Feriados } \\
\text { Vacaciones: 15 días. Posibilidad de reducción de } \\
15 \text { a 7 días calendario. }\end{array}$ \\
\hline Indemnización por & $\begin{array}{l}\text { Equivalente a 10 remuneraciones diarias por cada } \\
\text { año completo de servicios. Tope máximo de 90 } \\
\text { remuneraciones diarias. Las fracciones de año se } \\
\text { abonan por dozavos }\end{array}$ \\
\hline Seguro complementario & $\begin{array}{l}\text { No arbitrario } \\
\text { de trabajo de riesgo }\end{array}$
\end{tabular}

Periodicidad de pago: Quincenal

Rango de remuneración mensual por áreas: como política de remuneración define: 
Tabla 18: Rango de remuneración mensual

\begin{tabular}{|l|l|c|}
\hline \multicolumn{1}{|c|}{ Área } & \multicolumn{1}{|c|}{ Modalidad } & Rango en Nuevos Soles (S/) \\
\hline Gerente General & Planilla & $1,500-3,000$ \\
\hline Gerente de Operaciones & $\begin{array}{l}\text { Recibo por } \\
\text { honorario }\end{array}$ & $1,500-3,000$ \\
\hline $\begin{array}{l}\text { Gerente de Administración y } \\
\text { Finanzas }\end{array}$ & $\begin{array}{l}\text { Recibo por } \\
\text { honorario }\end{array}$ & $1,500-2,000$ \\
\hline Gerente de Ventas & $\begin{array}{l}\text { Recibo por } \\
\text { honorario }\end{array}$ & $1,500-2,000$ \\
\hline Community Manager & Planilla & $1,000-2,000$ \\
\hline
\end{tabular}

Fuente: Elaboración Propia

Adicionalmente contara con servicios de terceros como (01) Diseñador Gráfico, (01) Contador, (01) Programador. 


\subsection{ESTRUCTURA DE GASTOS DE RECURSOS HUMANOS}

Tabla 19: Planilla Correspondiente Al Primer Año

\begin{tabular}{|c|c|c|c|c|c|c|c|}
\hline DESCRIPCIÓN & Modalidad & Cantidad & $\begin{array}{c}\text { Sueldo } \\
\text { Promedio }\end{array}$ & $\begin{array}{l}\text { MESES } \\
\text { /AÑ̃ }\end{array}$ & $\begin{array}{l}\text { REMUNERA } \\
\text { CIÓN } \\
\text { ANUAL }\end{array}$ & $\begin{array}{c}\text { LEYES } \\
\text { LABORAL } \\
\text { ES } \\
\text { ESSALUD } \\
(1) \\
\end{array}$ & $\begin{array}{l}\text { REMUNERACI } \\
\text { ÓN TOTAL }\end{array}$ \\
\hline \multicolumn{8}{|c|}{ MANO DE OBRA DIRECTA } \\
\hline Gerente de Operaciones & $\begin{array}{l}\text { Recibo por } \\
\text { Honorario }\end{array}$ & 1 & $\mathrm{~S} / .2,000$ & 12 & $\mathrm{~S} / .24,000$ & $\mathrm{~S} / .0$ & $\mathrm{~S} / .24,000$ \\
\hline TOTAL & & 1 & \multicolumn{2}{|c|}{ S/. } & $\mathrm{S} / . \mathbf{2 4 , 0 0 0}$ & $\mathrm{S} / .0$ & $\mathrm{~S} / . \mathbf{2 4 , 0 0 0}$ \\
\hline \multicolumn{8}{|c|}{ PERSONAL ADMINISTRATIVO } \\
\hline Gerente General & Planilla & 1 & $\mathrm{~S} / .2,000$ & 12 & $\mathrm{~S} / .24,000$ & $\mathrm{~S} / .2,160$ & S/. 26,160 \\
\hline $\begin{array}{l}\text { Gerente de } \\
\text { Administración y } \\
\text { Finanzas }\end{array}$ & $\begin{array}{l}\text { Recibo por } \\
\text { Honorario }\end{array}$ & 1 & $\mathrm{~S} / .1,000$ & 12 & $\mathrm{~S} / .12,000$ & $\mathrm{~S} / .0$ & $\mathrm{~S} / .12,000$ \\
\hline TOTAL & & 2 & \multicolumn{2}{|c|}{$\mathrm{S} /}$. & $\mathrm{S} / . \mathbf{3 6 , 0 0 0}$ & $\mathrm{S} / .2,160$ & $\mathrm{~S} / . \mathbf{3 8 , 1 6 0}$ \\
\hline \multicolumn{8}{|c|}{ PERSONAL DE VENTAS } \\
\hline Gerente de Ventas & $\begin{array}{l}\text { Recibo por } \\
\text { Honorario }\end{array}$ & 1 & $\mathrm{~S} / .2,000$ & 12 & $\mathrm{~S} / .24,000$ & $\mathrm{~S} / .0$ & $\mathrm{~S} / .24,000$ \\
\hline Community Manager & Planilla & 1 & $\mathrm{~S} / .1,400$ & 12 & $\mathrm{~S} / .16,800$ & $\mathrm{~S} / .1,512$ & $\mathrm{~S} / .18,312$ \\
\hline TOTAL & & 2 & \multicolumn{2}{|c|}{$\mathrm{S} /}$. & $\mathrm{S} / . \mathbf{4 0 , 8 0 0}$ & $\mathrm{S} / . \mathbf{1 , 5 1 2}$ & $\mathrm{S} / . \mathbf{4 2 , 3 1 2}$ \\
\hline
\end{tabular}

TOTAL PLANILLA

$\mathrm{S} / . \mathbf{1 0 4 , 4 7 2}$

(1) SE CALCULA EN BASE AL TOTAL DE INGRESOS PERCIBIDOS

\begin{tabular}{|c|c|c|c|c|}
\hline \multicolumn{5}{|c|}{ OTROS GASTOS DE RRHH } \\
\hline DESCRIPCIÓN & Cantidad & Importe & $\begin{array}{c}\text { MESES } \\
\text { /AÑ̃ }\end{array}$ & $\begin{array}{l}\text { COSTO } \\
\text { ANUAL }\end{array}$ \\
\hline Proceso de Selección & 5 & $\mathrm{~S} / .400$ & 1 & $\mathrm{~S} / .2,000$ \\
\hline $\begin{array}{l}\text { Capacitacion y } \\
\text { Desarrollo }\end{array}$ & 1 & $\mathrm{~S} / .500$ & 2 & $\mathrm{~S} / .1,000$ \\
\hline Proceso de Inducción & 1 & $\mathrm{~S} / .300$ & 1 & $\mathrm{~S} / .300$ \\
\hline Aguinaldos & 5 & $\mathrm{~S} / .200$ & 1 & $\mathrm{~S} / .1,000$ \\
\hline TOTAL & 12 & $\mathrm{~S} /$. & & $\mathrm{S} / . \mathbf{4 , 3 0 0}$ \\
\hline
\end{tabular}

Fuente: Elaboración Propia 


\section{CAPÍTULO 7: PLAN ECONÓMICO - FINANCIERO}

\subsection{SUPUESTOS}

- Todos los montos están expresando en Nuevos Soles.

- Los equipos e insumos serán comprados en el mercado local.

- CAPEX comprende inversión en implementación en las oficinas administrativas.

- Tasa I.G.V.: $18 \%$

- Impuesto a la renta aplicable a partir del 2017: $29.5 \%$

- Los plazos de depreciación de los activos fijos se plantean de acuerdo a su naturaleza, 5 años para herramientas y 10 años para muebles y enseres.

- Tasa de distribución de utilidades: 8\% (empresas de servicios).

- Mix de ventas: 5\% de las ventas de los Food Trucks y se estima un 2\% por ventas de publicidad en la app.

- Se considera un Capital propio de S/. 40,000 (Cuarenta mil soles), el cual es aportado S/ 10,000 (diez mil soles) por cada socio (4).

- Las ventas para los Años 3, 4 y 5 tienen un crecimiento Proyectado del 8\%, 12\% y $15 \%$.

- Se considera una Garantía de Alquiler de 2 meses por adelantado.

- Para el Año 2, tenemos un $100 \%$ de operatividad de nuestro servicio, ya que el Año 1 recién estamos captando clientes

- Se considera un incremento del sueldo del 3\% a partir del Año 2 por inflación hacia adelante para personal en Planillas.

- Se considera un incremento del sueldo del 5\% a partir del Año 2 por inflación hacia adelante para personal en Recibo por Honorarios.

- Se considera un incremento del 10\% en el alquiler a partir del Año 2 hacia adelante. 
- Se considera un incremento del 5\% en el incremento de los Servicios y materiales de oficina a partir del Año 2.

- Incremento anual de precio venta de 5\% a partir del año 3

- En la Planilla se considera 2 personal en planilla y 3 por Recibos por Honorarios.

- Se considera en el costo de ventas el 5\% de PayPal, el cual nos da la seguridad de los pagos de los clientes.

- El alquiler del local se considera al $100 \%$ en el costo de ventas. Los servicios como Agua, Luz e Internet, se reportes en Costo y Gasto.

- Tasa de financiamiento: Se establece una tasa de $7.51 \%$, la cual contiene un premium de 100 bps sobre el promedio de bonos peruanos del sector privado con plazos entre 3-5 años por la naturaleza de riesgo del proyecto

- Crecimiento de ventas de acuerdo a objetivos estratégicos.

- WACC: Se determina una WAAC de $6.68 \%$ considerando una estructura de capital/financiamiento de 28/72. 


\subsection{INVERSIÓN EN ACTIVOS (FIJOS E INTANGIBLE) Y DEPRECIACIÓN}

Tabla 20: Inversión en Activos Fijos Vinculados al Costo

\begin{tabular}{|l|r|c|c|c|c|c|c|}
\hline \multicolumn{7}{|c|}{ Máquinas y Equipos } & \multicolumn{2}{c|}{ DEPRECIACION } \\
\hline ITEM & $\begin{array}{c}\text { Canti } \\
\text { dad }\end{array}$ & $\begin{array}{c}\text { P.U. } \\
\text { (IGV) }\end{array}$ & $\begin{array}{c}\text { Unidad de } \\
\text { Medida }\end{array}$ & $\begin{array}{c}\text { Precio Sin } \\
\text { Igv (S/.) }\end{array}$ & $\begin{array}{c}\text { Precio } \\
\text { Total (S/.) }\end{array}$ & Años & $\begin{array}{c}\text { Importe } \\
\text { (S/.) }\end{array}$ \\
\hline Impresora HP & 1 & 800.00 & Unidades & 677.97 & 800.00 & 5.00 & 160.00 \\
\hline Teléfono & 1 & 150.00 & Unidades & 127.12 & 150.00 & & \\
\hline \multicolumn{7}{|c|}{} \\
\hline
\end{tabular}

\begin{tabular}{|c|c|c|c|c|c|c|c|}
\hline \multicolumn{7}{|c|}{ Computadoras } & \multicolumn{2}{c|}{ DEPRECIACION } \\
\hline ITEM & $\begin{array}{c}\text { Canti } \\
\text { dad }\end{array}$ & $\begin{array}{c}\text { P.U. } \\
\text { (IGV) }\end{array}$ & $\begin{array}{c}\text { Unidad de } \\
\text { Medida }\end{array}$ & $\begin{array}{c}\text { Precio Sin } \\
\text { Igv (S/.) }\end{array}$ & $\begin{array}{c}\text { Precio } \\
\text { Total (S/.) }\end{array}$ & Años & $\begin{array}{c}\text { Importe } \\
\text { (S/.) }\end{array}$ \\
\hline Laptop I5 HP & 1 & 2100.00 & Unidades & $1,779.66$ & $2,100.00$ & 4.00 & 525.00 \\
\hline & & & & & - & & \\
\hline \multicolumn{3}{|c|}{ IMPORTE TOTAL } & $1,779.66$ & $2,100.00$ & & 525.00 \\
\hline
\end{tabular}

\begin{tabular}{|c|c|c|c|c|c|c|c|}
\hline \multicolumn{6}{|c|}{ Muebles y Equipos de Oficina } & \multicolumn{2}{|c|}{ DEPRECIACION } \\
\hline ITEM & $\begin{array}{l}\text { Cant } \\
\text { idad }\end{array}$ & $\begin{array}{l}\text { P.U. } \\
\text { (IGV) }\end{array}$ & $\begin{array}{l}\text { Unidad de } \\
\text { Medida }\end{array}$ & $\begin{array}{l}\text { Precio Sin } \\
\text { Igv (S/.) }\end{array}$ & $\begin{array}{c}\text { Precio } \\
\text { Total }(\mathrm{S} / .)\end{array}$ & Años & $\begin{array}{c}\text { Importe } \\
(\mathrm{S} / .)\end{array}$ \\
\hline Silla & 1 & 150.00 & Unidades & 127.12 & 150.00 & 5.00 & 30.00 \\
\hline $\begin{array}{l}\text { Mueble } \\
\text { Archivador }\end{array}$ & 1 & 180.00 & Unidades & 152.54 & 180.00 & 5.00 & 36.00 \\
\hline $\begin{array}{l}\text { Mesa Grande } \\
\text { (Escritorio) }\end{array}$ & 1 & 400.00 & Unidades & 338.98 & 400.00 & 5.00 & 80.00 \\
\hline Cajoneros & 1 & 80.00 & Unidades & 67.80 & 80.00 & 5.00 & 16.00 \\
\hline & & & & - & - & & \\
\hline \multicolumn{4}{|c|}{ IMPORTE TOTAL } & 686.44 & 810.00 & & 162.00 \\
\hline \multicolumn{5}{|c|}{$\begin{array}{l}\text { INVERSIÓN TOTAL EN ACTIVO FIJO PARA EL } \\
\text { PROCESO PRODUCTIVO }\end{array}$} & $\begin{array}{c}\mathrm{S} / \\
\mathbf{3 , 8 6 0 . 0 0}\end{array}$ & & $\begin{array}{c}\text { S/ } \\
847.00\end{array}$ \\
\hline
\end{tabular}

Fuente: Elaboración Propia 
Tabla 21: Inversión en Activos Fijos vinculados

Gastos Administrativos y de Ventas

\begin{tabular}{|l|c|c|c|c|c|c|c|}
\hline \multicolumn{7}{|c|}{ Máquinas y Equipos } & \multicolumn{2}{c|}{ DEPRECIACION } \\
\hline \multicolumn{1}{|c|}{ ITEM } & $\begin{array}{c}\text { Canti } \\
\text { dad }\end{array}$ & $\begin{array}{c}\text { P.U. } \\
(\mathbf{I G V})\end{array}$ & $\begin{array}{c}\text { Unidad de } \\
\text { Medida }\end{array}$ & $\begin{array}{c}\text { Precio Sin } \\
\text { Igv (S/.) }\end{array}$ & $\begin{array}{c}\text { Precio } \\
\text { Total (S/.) }\end{array}$ & Años & $\begin{array}{c}\text { Importe } \\
\text { (S/.) }\end{array}$ \\
\hline $\begin{array}{l}\text { Horno } \\
\text { Microondas }\end{array}$ & 1 & 289.00 & Unidades & 244.92 & 289.00 & 5.00 & 57.80 \\
\hline Refrigeradora & 1 & 800.00 & Unidades & 677.97 & 800.00 & 5.00 & 160.00 \\
\hline $\begin{array}{l}\text { Proyector con } \\
\text { Scram }\end{array}$ & 1 & 1700.00 & Unidades & 1440.68 & 1700.00 & 5.00 & 340.00 \\
\hline Impresora HP & 1 & 800.00 & Unidades & 677.97 & 800.00 & 5.00 & 160.00 \\
\hline Teléfono & 1 & 150.00 & Unidades & 127.12 & 150.00 & & \\
\hline \multicolumn{7}{|l|}{} \\
\hline
\end{tabular}

\begin{tabular}{|c|c|c|c|c|c|c|c|}
\hline \multicolumn{7}{|c|}{ Computadoras } & \multicolumn{2}{c|}{ DEPRECIACION } \\
\hline ITEM & $\begin{array}{c}\text { Canti } \\
\text { dad }\end{array}$ & $\begin{array}{c}\text { P.U. } \\
\text { (IGV) }\end{array}$ & $\begin{array}{c}\text { Unidad de } \\
\text { Medida }\end{array}$ & $\begin{array}{c}\text { Precio Sin } \\
\text { Igv (S/.) }\end{array}$ & $\begin{array}{c}\text { Precio } \\
\text { Total (S/.) }\end{array}$ & Años & $\begin{array}{c}\text { Importe } \\
\text { (S/.) }\end{array}$ \\
\hline Laptop I5 HP & 4 & 2100.00 & Unidades & $7,118.64$ & $8,400.00$ & 4.00 & $2,100.00$ \\
\hline & & & & & - & & \\
\cline { 1 - 1 } & & & $7,118.64$ & $8,400.00$ & & $2,100.00$ \\
\hline
\end{tabular}

\begin{tabular}{|c|c|c|c|c|c|c|c|}
\hline \multicolumn{6}{|c|}{ Muebles y Equipos de Oficina } & \multicolumn{2}{|c|}{ DEPRECIACION } \\
\hline ITEM & $\begin{array}{c}\text { Canti } \\
\text { dad }\end{array}$ & $\begin{array}{l}\text { P.U. } \\
\text { (IGV) }\end{array}$ & $\begin{array}{l}\text { Unidad de } \\
\text { Medida }\end{array}$ & $\begin{array}{l}\text { Precio Sin } \\
\text { Igv (S/.) }\end{array}$ & $\begin{array}{c}\text { Precio } \\
\text { Total }(\mathrm{S} / .)\end{array}$ & Años & $\begin{array}{c}\text { Importe } \\
(\mathrm{S} / .)\end{array}$ \\
\hline Sillas & 4 & 150.00 & Unidades & 508.47 & 600.00 & 5.00 & 120.00 \\
\hline $\begin{array}{l}\text { Mueble } \\
\text { Archivador }\end{array}$ & 1 & 180.00 & Unidades & 152.54 & 180.00 & 5.00 & 36.00 \\
\hline $\begin{array}{l}\text { Mesa Grande } \\
\text { (Escritorio) }\end{array}$ & 1 & 800.00 & Unidades & 677.97 & 800.00 & 5.00 & 160.00 \\
\hline Cajoneros & 4 & 80.00 & Unidades & 271.19 & 320.00 & 5.00 & 64.00 \\
\hline $\begin{array}{l}\text { Mueble para } \\
\text { Bidón de } \\
\text { Agua }\end{array}$ & 1 & 70.00 & Unidades & 59.32 & 70.00 & 5.00 & 14.00 \\
\hline & & & & - & - & & \\
\hline \multicolumn{4}{|c|}{ IMPORTE TOTAL } & $1,669.49$ & $1,970.00$ & & 394.00 \\
\hline \multicolumn{5}{|c|}{$\begin{array}{l}\text { Inversión Total en Activos Fijos vinculados a los Gastos } \\
\text { Administrativos y de Ventas }\end{array}$} & $\begin{array}{c}\mathrm{S} / \\
17,969.00\end{array}$ & & $\begin{array}{c}\mathrm{S} / \\
4,058.80\end{array}$ \\
\hline
\end{tabular}

Fuente: Elaboración Propia 


\subsection{PROYECCIÓN EN VENTAS}

Tabla 22: Proyección de ventas

\begin{tabular}{|l|l|l|l|l|l|l|l|l|l|l|l|l|l|l|l|l|l|l|}
\hline ITEM & Formula & Mes 1 & Mes 2 & Mes 3 & Mes 4 & Mes 5 & Mes 6 & Mes 7 & Mes 8 & Mes 9 & Mes 10 & Mes 11 & Mes 12 & AÑ̃ 1 & AÑ் 2 & AÑ̃ 3 & AÑ் 4 & AÑ̃ 5 \\
\hline
\end{tabular}

\begin{tabular}{|c|c|c|c|c|c|c|c|c|c|c|c|c|c|c|c|c|c|c|}
\hline \multicolumn{19}{|c|}{ VENTAS DE LOS FOOD TRUCKS } \\
\hline $\begin{array}{l}\begin{array}{l}\text { Ventas Mensuales FoodTruck } \\
\text { (Aprox) }\end{array} \\
\end{array}$ & A & 3200 & 3200 & 3200 & 3200 & 3200 & 3200 & 3200 & 3200 & 3200 & 3200 & 3200 & 3200 & & & & & \\
\hline Precio Promedio (S/.) & B & 15 & 15 & 15 & 15 & 15 & 15 & 15 & 15 & 15 & 15 & 15 & 15 & & & & & \\
\hline Estacionalidad & $\mathrm{C}$ & $70 \%$ & $70 \%$ & $70 \%$ & $90 \%$ & $90 \%$ & $100 \%$ & $100 \%$ & $100 \%$ & $100 \%$ & $100 \%$ & $90 \%$ & $70 \%$ & & & & & \\
\hline Número de Afiliados & $\mathrm{D}$ & 10 & 10 & 10 & 20 & 20 & 30 & 30 & 30 & 40 & 40 & 50 & 50 & & & & & \\
\hline $\begin{array}{l}\begin{array}{l}\text { Venta Mensual de Food Trucks } \\
(\mathrm{S} / .)\end{array} \\
\end{array}$ & $\begin{array}{c}\mathrm{A}^{*} \mathrm{~B}^{*} \mathrm{C} \mathrm{C}^{*} \mathrm{D}= \\
\mathrm{E}\end{array}$ & 336,000 & 336,000 & 336,000 & 864,000 & 864,000 & $1,440,000$ & $1,440,000$ & $1,440,000$ & $1,920,000$ & $1,920,000$ & $2,160,000$ & $1,680,000$ & $\begin{array}{c}14,736,00 \\
0\end{array}$ & \begin{tabular}{|c|}
$20,208,00$ \\
0
\end{tabular} & $\begin{array}{c}21,824,64 \\
0\end{array}$ & \begin{tabular}{|c|}
$24,443,59$ \\
7
\end{tabular} & $28,110,136$ \\
\hline $\mathrm{N}^{\circ}$ de Hamburguesas Vendidas & $E / B=F$ & 22,400 & 22,400 & 22,400 & 57,600 & 57,600 & 96,000 & 96,000 & 96,000 & 128,000 & 128,000 & 144,000 & 112,000 & 982,400 & $1,347,200$ & $1,454,976$ & $1,629,573$ & $1,874,009$ \\
\hline
\end{tabular}

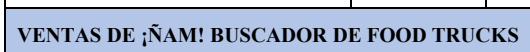

\begin{tabular}{|c|c|c|c|c|c|c|c|c|c|c|c|c|c|c|c|c|c|c|}
\hline Porcentaje Mediante el APP & G & $10 \%$ & $10 \%$ & $10 \%$ & $10 \%$ & $20 \%$ & $20 \%$ & $20 \%$ & $20 \%$ & $30 \%$ & $30 \%$ & $30 \%$ & $30 \%$ & & & & & \\
\hline Ventas por APP (S/.) & $\mathrm{E} * \mathrm{G}=\mathrm{H}$ & 33,600 & 33,600 & 33,600 & 86,400 & 172,800 & 288,000 & 288,000 & 288,000 & 576,000 & 576,000 & 648,000 & 504,000 & $3,528,000$ & $5,256,000$ & $5,676,480$ & $6,357,658$ & $7,311,306$ \\
\hline Ventas $(5 \%)=$ & $H * 5 \%=I$ & 1,680 & 1,680 & 1,680 & 4,320 & 8,640 & 14,400 & 14,400 & 14,400 & 28,800 & 28,800 & 32,400 & 25,200 & 176,400 & 262,800 & 283,824 & 317,883 & 365,565 \\
\hline Ventas Publicidad $(2 \%)=$ & $H * 2 \%=J$ & & & & & 5,184 & 8,640 & 8,640 & 8,640 & 11,520 & 11,520 & 12,960 & 10,080 & 77,184 & 40,416 & 43,649 & 48,887 & 56,220 \\
\hline INGRESOS MENSUALES (S/.) & $\mathrm{I}+\mathrm{J}$ & 1,680 & 1,680 & 1,680 & 4,320 & 13,824 & 23,040 & 23,040 & 23,040 & 40,320 & 40,320 & 45,360 & 35,280 & 253,584 & 303,216 & 327,473 & 366,770 & 421,786 \\
\hline Acumulados & & 1,680 & 3,360 & 5,040 & 9,360 & 23,184 & 46,224 & 69,264 & 92,304 & 132,624 & 172,944 & 218,304 & 253,584 & 253,584 & 556,800 & 884,273 & $1,251,043$ & $1,672,829$ \\
\hline
\end{tabular}




\begin{tabular}{|c|c|c|c|c|c|c|c|c|c|c|c|c|c|c|c|c|c|c|}
\hline \multicolumn{19}{|c|}{ 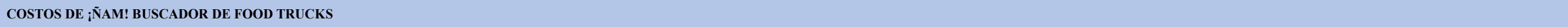 } \\
\hline Gerente de Operaciones & & $2,000.00$ & $2,000.00$ & $2,000.00$ & $2,000.00$ & $2,000.00$ & $2,000.00$ & $2,000.00$ & $2,000.00$ & $2,000.00$ & $2,000.00$ & 2,000.00 & $2,000.00$ & $24,000.00$ & $25,200.00$ & $26,460.00$ & $27,783.00$ & $29,172.15$ \\
\hline Costos de Servicios & & 705.00 & 705.00 & 705.00 & 705.00 & 705.00 & 705.00 & 705.00 & 705.00 & 705.00 & 705.00 & 705.00 & 705.00 & $8,460.00$ & $9,243.00$ & $10,101.15$ & $11,041.81$ & $12,073.06$ \\
\hline Alquiler de Oficina & & 600.00 & 600.00 & 600.00 & 600.00 & 600.00 & 600.00 & 600.00 & 600.00 & 600.00 & 600.00 & 600.00 & 600.00 & $7,200.00$ & $7,920.00$ & $8,712.00$ & $9,583.20$ & $10,541.52$ \\
\hline Agua & & 15.00 & 15.00 & 15.00 & 15.00 & 15.00 & 15.00 & 15.00 & 15.00 & 15.00 & 15.00 & 15.00 & 15.00 & 180.00 & 189.00 & 198.45 & 208.37 & 218.79 \\
\hline Luz & & 30.00 & 30.00 & 30.00 & 30.00 & 30.00 & 30.00 & 30.00 & 30.00 & 30.00 & 30.00 & 30.00 & 30.00 & 360.00 & 378.00 & 396.90 & 416.75 & 437.58 \\
\hline Teléfono / Internet & & 60.00 & 60.00 & 60.00 & 60.00 & 60.00 & 60.00 & 60.00 & 60.00 & 60.00 & 60.00 & 60.00 & 60.00 & 720.00 & 756.00 & 793.80 & 833.49 & 875.16 \\
\hline Materiales & & 119.90 & & & & & 119.90 & & & & 119.90 & & & 359.70 & 377.69 & 396.57 & 416.40 & 437.22 \\
\hline Servicio Cloud & & $18,000.00$ & & & & & & & & & & & & $18,000.00$ & $18,900.00$ & $19,845.00$ & $20,837.25$ & $21,879.11$ \\
\hline Comisión de PayPal (5\%) & $5 \%$ & 84.00 & 84.00 & 84.00 & 216.00 & 691.2 & $1,152.00$ & $1,152.00$ & $1,152.00$ & $2,016.00$ & $2,016.00$ & $2,268.00$ & $1,764.00$ & $12,679.20$ & $15,160.80$ & $16,373.66$ & $18,338.50$ & $21,089.28$ \\
\hline TOTAL COSTO DE VENTAS & & $20,908.90$ & $2,789.00$ & $2,789.00$ & $2,921.00$ & $3,396.20$ & $3,976.90$ & $3,857.00$ & $3,857.00$ & $4,721.00$ & $4,840.90$ & $4,973.00$ & $4,469.00$ & $63,498.90$ & $68,881.49$ & 73,176.38 & $78,416.96$ & $84,650.82$ \\
\hline Acumulados & & 20,909 & 23,698 & 26,487 & 29,408 & 32,804 & 36,781 & 40,638 & 44,495 & 49,216 & 54,057 & 59,030 & 63,499 & \begin{tabular}{|l|}
$63,498.90$ \\
\end{tabular} & \begin{tabular}{|c|}
$132,380.3$ \\
9
\end{tabular} & \begin{tabular}{|c|}
$205,556.7$ \\
7
\end{tabular} & \begin{tabular}{|c|}
$283,973.7$ \\
3
\end{tabular} & $368,624.54$ \\
\hline
\end{tabular}

\begin{tabular}{|c|c|c|c|c|c|c|c|c|c|c|c|c|c|c|c|c|c|}
\hline \multicolumn{18}{|l|}{ UTILIDAD BRUTA } \\
\hline UTILIDAD BRUTA & $19,228.90$ & $1,109.00$ & $1,109.00$ & $1,399.00$ & $10,427.80$ & $19,063.10$ & $19,183.00$ & $19,183.00$ & $35,599.00$ & $35,479.10$ & $40,387.00$ & $30,811.00$ & \begin{tabular}{|c|}
$190,085.1$ \\
0
\end{tabular} & $\begin{array}{c}234,334.5 \\
2\end{array}$ & $\begin{array}{c}254,296.9 \\
0\end{array}$ & \begin{tabular}{|c|}
$288,353.1$ \\
1
\end{tabular} & $337,134.77$ \\
\hline Acumulados & $19,228.90$ & $20,337.90$ & $21,446.90$ & $20,047.90$ & $9,620.10$ & $9,443.00$ & $28,626.00$ & $47,809.00$ & $83,408.00$ & $\begin{array}{c}118,887.1 \\
0\end{array}$ & $\begin{array}{c}159,274.1 \\
0\end{array}$ & $\begin{array}{c}190,085.1 \\
0\end{array}$ & $\begin{array}{c}190,085.1 \\
0\end{array}$ & $\begin{array}{c}424,419.6 \\
2\end{array}$ & $\begin{array}{c}678,716.5 \\
1\end{array}$ & $\begin{array}{c}967,069.6 \\
3\end{array}$ & $\begin{array}{c}1,304,204 . \\
39\end{array}$ \\
\hline
\end{tabular}




\begin{tabular}{|c|c|c|c|c|c|c|c|c|c|c|c|c|c|c|c|c|c|c|}
\hline \multicolumn{19}{|c|}{ GASTOS DE ADMINISTRACION } \\
\hline Gerente General & Planilla & $2,160.00$ & $2,160.00$ & $2,160.00$ & $2,160.00$ & $2,160.00$ & $2,160.00$ & $2,160.00$ & $2,160.00$ & $2,160.00$ & $2,160.00$ & $2,160.00$ & $2,160.00$ & $25,920.00$ & $26,697.60$ & $27,498.53$ & $28,323.48$ & $29,173.19$ \\
\hline Gerente de Adm y Finanzas & RRHH & $1,000.00$ & $1,000.00$ & $1,000.00$ & $1,000.00$ & $1,000.00$ & $1,000.00$ & $1,000.00$ & $1,000.00$ & $1,000.00$ & $1,000.00$ & $1,000.00$ & $1,000.00$ & $12,000.00$ & $12,600.00$ & $13,230.00$ & $13,891.50$ & $14,586.08$ \\
\hline Costos de Servicios & & 270.00 & 270.00 & 270.00 & 270.00 & 270.00 & 270.00 & 270.00 & 270.00 & 270.00 & 270.00 & 270.00 & 270.00 & $3,240.00$ & $3,402.00$ & $3,572.10$ & $3,750.71$ & $3,938.24$ \\
\hline Agua & & 50.00 & 50 & 50 & 50 & 50 & 50 & 50 & 50 & 50 & 50 & 50 & 50 & 600 & 630 & 661.50 & 694.58 & 729.30 \\
\hline Luz & & 100.00 & 100 & 100 & 100 & 100 & 100 & 100 & 100 & 100 & 100 & 100 & 100 & 1200 & 1260 & $1,323.00$ & $1,389.15$ & $1,458.61$ \\
\hline Teléfono / Internet & & 120.00 & 120 & 120 & 120 & 120 & 120 & 120 & 120 & 120 & 120 & 120 & 120 & 1440 & 1512 & $1,587.60$ & $1,666.98$ & $1,750.33$ \\
\hline Imprevisto & & 200.00 & 200.00 & 200.00 & 200.00 & 200.00 & 200.00 & 200.00 & 200.00 & 200.00 & 200.00 & 200.00 & 200.00 & $2,400.00$ & $2,520.00$ & $2,646.00$ & $2,778.30$ & $2,917.22$ \\
\hline Gastos de RRHH & & $1,200.00$ & - & - & - & - & - & 500.00 & - & & - & - & $1,000.00$ & $2,700.00$ & $2,450.00$ & $2,450.00$ & $2,450.00$ & $2,572.50$ \\
\hline Proceso de Selección & & 400.00 & & & & & & & & & & & & 400.00 & - & - & - & - \\
\hline Capacitacion y Desarrollo & & 500.00 & & & & & & 500.00 & & & & & & $1,000.00$ & $1,200.00$ & $1,200.00$ & $1,200.00$ & $1,200.00$ \\
\hline Proceso de Inducción & & 300.00 & & & & & & & & & & & & 300.00 & - & - & - & - \\
\hline Aguinaldos & & & & & & & & & & & & & $1,000.00$ & $1,000.00$ & $1,250.00$ & $1,250.00$ & $1,250.00$ & $1,250.00$ \\
\hline
\end{tabular}

\begin{tabular}{|c|c|c|c|c|c|c|c|c|c|c|c|c|c|c|c|c|c|}
\hline $\begin{array}{l}\text { TOTAL GASTOS } \\
\text { ADMINISTRACION } \\
\end{array}$ & $4,830.00$ & $3,630.00$ & $3,630.00$ & $3,630.00$ & $3,630.00$ & $3,630.00$ & $4,130.00$ & $3,630.00$ & $3,630.00$ & 3,630.00 & $3,630.00$ & $4,630.00$ & $46,260.00$ & $47,669.60$ & $49,396.63$ & $51,193.99$ & $53,187.22$ \\
\hline Acumulados & $4,830.00$ & $8,460.00$ & $12,090.00$ & $15,720.00$ & $19,350.00$ & $22,980.00$ & $27,110.00$ & $30,740.00$ & $34,370.00$ & $38,000.00$ & $41,630.00$ & $46,260.00$ & $46,260.00$ & $93,929.60$ & $\begin{array}{l}143,326.2 \\
3\end{array}$ & $\begin{array}{l}194,520.2 \\
2\end{array}$ & $247,707.44$ \\
\hline
\end{tabular}

\begin{tabular}{|c|c|c|c|c|c|c|c|c|c|c|c|c|c|c|c|c|c|}
\hline \multicolumn{18}{|l|}{ GASTOS DE VENTAS } \\
\hline Gerente de Ventas & $2,000.00$ & $2,000.00$ & $2,000.00$ & $2,000.00$ & $2,000.00$ & $2,000.00$ & $2,000.00$ & $2,000.00$ & $2,000.00$ & $2,000.00$ & $2,000.00$ & $2,000.00$ & $24,000.00$ & $24,720.00$ & $25,461.60$ & $26,225.45$ & $27,012.21$ \\
\hline Community Manager & $1,512.00$ & $1,512.00$ & $1,512.00$ & $1,512.00$ & $1,512.00$ & $1,512.00$ & $1,512.00$ & $1,512.00$ & $1,512.00$ & $1,512.00$ & $1,512.00$ & $1,512.00$ & $18,144.00$ & $19,051.20$ & $20,003.76$ & $21,003.95$ & $22,054.15$ \\
\hline Gastos de Marketing & $4,150.00$ & $9,150.00$ & $5,150.00$ & $1,150.00$ & $1,150.00$ & $9,150.00$ & $5,150.00$ & $1,150.00$ & $1,150.00$ & $3,150.00$ & $3,150.00$ & $1,150.00$ & $44,800.00$ & $49,280.00$ & $54,208.00$ & $59,628.80$ & $65,591.68$ \\
\hline Gastos en Facebook & $3,000.00$ & - & - & - & - & - & - & - & - & - & - & - & $3,000.00$ & $3,300.00$ & $3,630.00$ & 3,993.00 & $4,392.30$ \\
\hline Diseño de Aplicativo (web y mobile) & - & $6,000.00$ & $2,000.00$ & - & - & $6,000.00$ & $2,000.00$ & - & - & - & - & - & $16,000.00$ & $17,600.00$ & $19,360.00$ & $21,296.00$ & $23,425.60$ \\
\hline Actualización del aplicativo & - & $2,000.00$ & $2,000.00$ & - & - & $2,000.00$ & $2,000.00$ & - & - & $2,000.00$ & $2,000.00$ & - & $12,000.00$ & $13,200.00$ & $14,520.00$ & $15,972.00$ & $17,569.20$ \\
\hline SEM & 500.00 & 500.00 & 500.00 & 500.00 & 500.00 & 500.00 & 500.00 & 500.00 & 500.00 & 500.00 & 500.00 & 500.00 & $6,000.00$ & $\mid 6,600.00$ & $7,260.00$ & $7,986.00$ & $8,784.60$ \\
\hline SEO & 650.00 & 650.00 & 650.00 & 650.00 & 650.00 & 650.00 & 650.00 & 650.00 & 650.00 & 650.00 & 650.00 & 650.00 & $7,800.00$ & $8,580.00$ & $9,438.00$ & $10,381.80$ & $11,419.98$ \\
\hline
\end{tabular}




\begin{tabular}{|c|c|c|c|c|c|c|c|c|c|c|c|c|c|c|c|c|c|}
\hline \begin{tabular}{|l} 
TOTAL GASTOS \\
ADMINISTRACION
\end{tabular} & $7,662.00$ & $12,662.00$ & $8,662.00$ & $4,662.00$ & $4,662.00$ & $12,662.00$ & $8,662.00$ & $4,662.00$ & $4,662.00$ & $6,662.00$ & $6,662.00$ & $4,662.00$ & $86,944.00$ & $93,051.20$ & $99,673.36$ & $\begin{array}{c}106,858.2 \\
0\end{array}$ & $114,658.04$ \\
\hline Acumulados & $7,662.00$ & $20,324.00$ & $28,986.00$ & $33,648.00$ & $38,310.00$ & $50,972.00$ & $59,634.00$ & $64,296.00$ & $68,958.00$ & $75,620.00$ & $82,282.00$ & $86,944.00$ & $86,944.00$ & $\begin{array}{c}179,995.2 \\
0 \\
\end{array}$ & $\begin{array}{c}279,668.5 \\
6 \\
\end{array}$ & $\begin{array}{c}386,526.7 \\
6 \\
\end{array}$ & $501,184.79$ \\
\hline
\end{tabular}

\begin{tabular}{|c|c|c|c|c|c|c|c|c|c|c|c|c|c|c|c|c|c|}
\hline UTLIDAD OPERATIVA & $31,720.90$ & $17,401.00$ & $13,401.00$ & $6,893.00$ & $2,135.80$ & $2,771.10$ & $6,391.00$ & $10,891.00$ & $27,307.00$ & $25,187.10$ & $30,095.00$ & $21,519.00$ & $56,881.10$ & $93,613.72$ & $\begin{array}{c}105,226.9 \\
1\end{array}$ & $\begin{array}{c}130,300.9 \\
3\end{array}$ & $169,289.51$ \\
\hline Acumulados & $31,720.90$ & $49,121.90$ & $\begin{array}{c}-52.90 \\
62,52.9\end{array}$ & $\begin{array}{c}- \\
69,415.90\end{array}$ & $67,280.10$ & $64,509.00$ & $58,118.00$ & $47,227.00$ & $19,920.00$ & $5,267.10$ & $35,362.10$ & $56,881.10$ & $56,881.10$ & $\begin{array}{c}150,494.8 \\
2\end{array}$ & $\begin{array}{c}255,721.7 \\
2\end{array}$ & $\begin{array}{c}386,022.6 \\
5\end{array}$ & 17 \\
\hline
\end{tabular}

Fuente: Elaboración Propia 
- El primer año se muestra pocas ventas, ya que recien estamos captando clientes, a partir del Año 2 tenemos un crecimiento en ventas del 37\%, porque estamos en un $100 \%$ de operación.

\subsection{CÁLCULO DEL CAPITAL DE TRABAJO}

Según el diagrama de Pert presentado, para iniciar operaciones nos va a tomar un total de tres meses. Para ello, se ha realizado un flujo en donde indica el calendario tentativo de Inversión, el cual es:

Tabla 23: Capital de Trabajo

\begin{tabular}{|c|c|c|c|c|c|c|c|}
\hline DESCRIPCIÓN & QUINC 1 & QUINC 2 & QUINC 3 & QUINC 4 & QUINC 5 & QUINC 6 & TOTAL \\
\hline $\begin{array}{l}\text { Estudios del } \\
\text { proyecto }\end{array}$ & 500.00 & & 500.00 & & 800.00 & & $1,800.00$ \\
\hline $\begin{array}{l}\text { Gastos de } \\
\text { Constitución }\end{array}$ & 500.00 & & 500.00 & & & & $1,000.00$ \\
\hline $\begin{array}{l}\text { Gastos de } \\
\text { Instalación }\end{array}$ & & 400.00 & & 400.00 & & & 800.00 \\
\hline $\begin{array}{l}\text { Maquinaria y } \\
\text { Equipos }\end{array}$ & $15,189.00$ & & & & & & $15,189.00$ \\
\hline Vehículos & & & & & & & - \\
\hline Muebles y Enseres & $2,780.00$ & & & & & & $2,780.00$ \\
\hline $\begin{array}{l}\text { Herramientas de } \\
\text { trabajo }\end{array}$ & & 119.90 & & 119.90 & & & 239.80 \\
\hline $\begin{array}{l}\text { Alquileres PRE } \\
\text { Operativos }\end{array}$ & 600.00 & & 600.00 & & 600.00 & & $1,800.00$ \\
\hline $\begin{array}{l}\text { Publicidad PRE } \\
\text { Operativa }\end{array}$ & & & & $3,000.00$ & $10,300.00$ & & $13,300.00$ \\
\hline Gastos de Pruebas & 300.00 & & 300.00 & & & & 600.00 \\
\hline $\begin{array}{l}\text { Selección y } \\
\text { Entrenam. de } \\
\text { Personal }\end{array}$ & $1,300.00$ & & & & $1,000.00$ & & $2,300.00$ \\
\hline $\begin{array}{l}\text { Adquisición de } \\
\text { Marcas y Patentes }\end{array}$ & & & 629.99 & & & & 629.99 \\
\hline $\begin{array}{l}\text { Gastos de } \\
\text { inauguración }\end{array}$ & & & & & & & - \\
\hline Garantía de Alquiler & $1,200.00$ & & & & & & $1,200.00$ \\
\hline Póliza de Seguro & & & & & & & - \\
\hline $\begin{array}{l}\text { Capital de trabajo } \\
\text { disponible }\end{array}$ & & & & & & $10,000.00$ & $10,000.00$ \\
\hline Desarrollo de APP & $32,500.00$ & & & $32,500.00$ & & & $65,000.00$ \\
\hline $\begin{array}{l}\text { Materiales Directos } \\
\text { e Indirectos }\end{array}$ & & & & $18,000.00$ & & & $18,000.00$ \\
\hline $\begin{array}{l}\text { Suministros } \\
\text { Diversos }\end{array}$ & 375.00 & & 375.00 & 199.32 & 375.00 & & $1,324.32$ \\
\hline SUB TOTAL & $55,244.00$ & 519.90 & $2,904.99$ & $54,219.22$ & $13,075.00$ & $10,000.00$ & $135,963.11$ \\
\hline IMPREVISTOS & $2,762.20$ & 26.00 & 145.25 & $2,710.96$ & 653.75 & 500.00 & $6,798.16$ \\
\hline $\begin{array}{l}\text { INVERSIÓN } \\
\text { TOTAL }\end{array}$ & $58,006.20$ & 545.90 & $3,050.24$ & $56,930.18$ & $13,728.75$ & $10,500.00$ & $142,761.27$ \\
\hline
\end{tabular}

Fuente: Elaboración Propia 
Por lo cual, la estructura de inversión inicial es:

Tabla 24: Inversión Inicial

\begin{tabular}{|l|c|c|c|c|}
\hline DESCRIPCIÓN & & & $\%$ \\
\hline I.- INVERSIÓN FIJA & $18,208.80$ & & $28.33 \%$ \\
\hline 1.1 TANGIBLE & $22,229.99$ & & $12.75 \%$ & \\
\hline 1.2 INTANGIBLE & & $102,322.48$ & $15.57 \%$ & \\
\hline II.- CAPITAL DE TRABAJO & $16,798.16$ & & $11.77 \%$ & $71.67 \%$ \\
\hline 2.1 DISPONIBLE & $1,200.00$ & & $0.84 \%$ & \\
\hline 2.2 EXIGIBLE & $84,324.32$ & & $59.07 \%$ & \\
\hline 2.3 REALIZABLE & & $142,761.27$ & $100.00 \%$ & $100.00 \%$ \\
\hline INVERSIÓN TOTAL & & & & \\
\hline
\end{tabular}

Fuente: Elaboración Propia

\subsection{ESTRUCTURA DE FINANCIAMIENTO:}

Se determina una estructura de financiamiento con $28 \%$ de capital social propio (S/. 40,000 a ser aportado por los 4 socios) y el saldo será financiado mediante un instrumento de renta fija (bono a largo plazo):

Tabla 25: Estructura de Financiamiento

\begin{tabular}{|c|c|c|c|c|c|}
\hline \multicolumn{6}{|c|}{ INVERSION PROPIA Y EXTERNA } \\
\hline Fuente & Inversión (\%) & Monto (miles) & Costo & impuesto & WACC \\
\hline Banco & $0 \%$ & - & $22.99 \%$ & $70.50 \%$ & $0.00 \%$ \\
\hline Bono & $72 \%$ & 102,761 & $7.51 \%$ & $70.50 \%$ & $3.81 \%$ \\
\hline Capital Social & $28 \%$ & 40,000 & $10.23 \%$ & & $2.87 \%$ \\
\hline Total & $100 \%$ & 142,761 & & & $6.68 \%$ \\
\hline
\end{tabular}

$$
\text { Fuente: Elaboración Propia }
$$

Calendario del bono corporativo: Se considera un premium de $100 \mathrm{bps}$ sobre el promedio de bonos peruanos del sector privado con plazos entre 3-5 años por la naturaleza de riesgo del proyecto:

Tabla 26: Calendario del bono corporativo

\begin{tabular}{|c|c|c|c|c|c|}
\hline Financiamiento & \multicolumn{1}{|l}{$\mathbf{1 0 2 , 7 6 1}$} & \multicolumn{3}{l}{} \\
\cline { 1 - 2 } TEA & $\mathbf{7 . 5 1 \%}$ & & Interés & Cuota & E.F. \\
\hline Plazo & $\mathbf{5}$ & Cupón & 7,722 & 7,722 & 2,278 \\
\hline $\mathbf{n}$ & Deuda & - & 7,722 & 7,722 & 2,278 \\
\hline $\mathbf{1}$ & 102,761 & - & 7,722 & 38,550 & 2,278 \\
\hline $\mathbf{2}$ & 102,761 & 30,828 & 5,405 & 36,234 & 1,595 \\
\hline $\mathbf{3}$ & 102,761 & 30,828 & 3,089 & 44,193 & 911.16 \\
\hline $\mathbf{4}$ & 71,933 & 41,105 & & &
\end{tabular}

Fuente: Elaboración Propia 


\subsection{ESTADOS FINANCIEROS}

Tabla 27: Estados Financieros Anuales (En nuevos soles)

\begin{tabular}{|c|c|c|c|c|c|}
\hline \multicolumn{6}{|c|}{ FOOD TRUCK ÑAM S.A.C. } \\
\hline ESTADO DE RESULTADOS & Año 1 & Año 2 & Año 3 & Año 4 & Año 5 \\
\hline Ingresos por Ventas & 253,584 & 303,216 & 327,473 & 366,770 & 421,786 \\
\hline Costo de Ventas & $-63,499$ & $-68,881$ & $-73,176$ & $-78,417$ & $-84,651$ \\
\hline Ganancia (Pérdida) Bruta & 190,085 & 234,335 & 254,297 & 288,353 & 337,135 \\
\hline Gastos de Ventas y Distribución & $-86,944$ & $-93,051$ & $-99,673$ & $-106,858$ & $-114,658$ \\
\hline Gerente de Ventas & $-24,000$ & $-24,720$ & $-25,462$ & $-26,225$ & $-27,012$ \\
\hline Community Manager & $-18,144$ & $-19,051$ & $-20,004$ & $-21,004$ & $-22,054$ \\
\hline Gastos de Marketing & $-44,800$ & $-49,280$ & $-54,208$ & $-59,629$ & $-65,592$ \\
\hline Otros gastos de Ventas & 0 & 0 & 0 & 0 & 0 \\
\hline Gastos de Administración & $-51,634$ & $-53,044$ & $-54,771$ & $-56,568$ & $-58,562$ \\
\hline Gerente General & $-25,920$ & $-26,698$ & $-27,499$ & $-28,323$ & $-29,173$ \\
\hline Gerente de Adm y Finanzas & $-12,000$ & $-12,600$ & $-13,230$ & $-13,892$ & $-14,586$ \\
\hline Costos de Servicios & $-3,240$ & $-3,402$ & $-3,572$ & $-3,751$ & $-3,938$ \\
\hline Imprevisto & $-2,400$ & $-2,520$ & $-2,646$ & $-2,778$ & $-2,917$ \\
\hline Gastos de RRHH & $-2,700$ & $-2,450$ & $-2,450$ & $-2,450$ & $-2,573$ \\
\hline Depreciación & $-5,374$ & $-5,374$ & $-5,374$ & $-5,374$ & $-5,374$ \\
\hline $\begin{array}{l}\text { Ganancia (Pérdida) por actividades de } \\
\text { operación }\end{array}$ & 51,507 & 88,239 & 99,853 & 124,927 & 163,915 \\
\hline Ingresos Financieros & 0 & 0 & 0 & 0 & 0 \\
\hline Gastos Financieros & $-7,722$ & $-7,722$ & $-7,722$ & $-5,405$ & $-3,089$ \\
\hline Resultado antes de Impuesto a las Ganancias & 43,785 & 80,518 & 92,131 & 119,521 & 160,826 \\
\hline Utilidades al personal & 3,503 & $6,441^{-}$ & 7,370 & 9,562 & $12,866^{-}$ \\
\hline Impuesto a la renta & 12,917 & 23,753 & 27,179 & 35,259 & 47,444 \\
\hline Ganancia (Pérdida) Neta del Ejercicio & 27,366 & 50,323 & 57,582 & 74,701 & 100,517 \\
\hline
\end{tabular}

Fuente: Elaboración Propia 
Tabla 28: Estado de Situación Financiera

Estados Financieros Anuales (En nuevos soles)

FOOD TRUCK ÑAM S.A.C.

\begin{tabular}{|c|c|c|c|c|c|}
\hline $\begin{array}{l}\text { ESTADO DE SITUACIÓN } \\
\text { FINANCIERA }\end{array}$ & Año 1 & Año 2 & Año 3 & Año 4 & Año 5 \\
\hline \multicolumn{6}{|l|}{ Activos } \\
\hline \multicolumn{6}{|l|}{ Activos Corrientes } \\
\hline Efectivo y Equivalentes al Efectivo & 23,799 & 40,321 & 88,298 & 109,421 & 142,566 \\
\hline $\begin{array}{l}\text { Cuentas por cobrar comerciales por } \\
\text { cobrar }\end{array}$ & 253,584 & 303,216 & 327,473 & 366,770 & 421,786 \\
\hline Inventarios & - & - & - & - & - \\
\hline Total Activos Corrientes & 277,383 & 343,537 & 415,771 & 476,191 & 564,351 \\
\hline \multicolumn{6}{|l|}{ Activos No Corrientes } \\
\hline Propiedades de Inversión & 40,199 & 40,199 & 40,199 & 40,199 & 40,199 \\
\hline Propiedades, Planta y Equipo (neto) & 34,825 & 29,450 & 24,076 & 18,701 & 13,327 \\
\hline Total Activos No Corrientes & 34,825 & 29,450 & 24,076 & 18,701 & 13,327 \\
\hline TOTAL DE ACTIVOS & 312,208 & 372,987 & 439,847 & 494,893 & 577,678 \\
\hline \multicolumn{6}{|l|}{ Pasivos y Patrimonio } \\
\hline \multicolumn{6}{|l|}{ Pasivos Corrientes } \\
\hline \multicolumn{6}{|l|}{ Obligaciones financieras } \\
\hline Cuentas por Pagar Comerciales & 138,578 & 146,095 & 154,444 & 163,427 & 173,220 \\
\hline \multicolumn{6}{|l|}{ Otras Cuentas por Pagar } \\
\hline Parte Corriente Deuda LP & - & - & 30,828 & 30,828 & 41,105 \\
\hline $\begin{array}{l}\text { Provisión por Beneficios a los } \\
\text { Empleados }\end{array}$ & 3,503 & 6,441 & 7,370 & 9,562 & 12,866 \\
\hline Total Pasivos Corrientes & 142,081 & 152,537 & 192,643 & 203,817 & 227,190 \\
\hline \multicolumn{6}{|l|}{ Pasivos No Corrientes } \\
\hline Obligaciones Financieras & 102,761 & 102,761 & 71,933 & 41,105 & - \\
\hline \multicolumn{6}{|l|}{ IR Diferido } \\
\hline Total Pasivos No Corrientes & 102,761 & 102,761 & 71,933 & 41,105 & - \\
\hline Total Pasivos & 244,842 & 255,298 & 264,576 & 244,921 & 227,190 \\
\hline \multicolumn{6}{|l|}{ Patrimonio } \\
\hline Capital Emitido & 40,000 & 40,000 & 40,000 & 40,000 & 40,000 \\
\hline Resultados Acumulados & 27,366 & 77,689 & 135,271 & 209,972 & 310,488 \\
\hline Total Patrimonio & 67,366 & 117,689 & 175,271 & 249,972 & 350,488 \\
\hline TOTAL PASIVO Y PATRIMONIO & 312,208 & 372,987 & 439,847 & 494,893 & 577,678 \\
\hline
\end{tabular}

Fuente: Elaboración Propia 


\subsection{FLUJO FINANCIERO}

Se proyecta el estado de resultados a 5 años a fin de realizar un flujo financiero por el mismo período:

Tabla 29: Flujo de Caja

\begin{tabular}{|c|c|c|c|c|c|c|}
\hline & Año 0 & Año 1 & Año 2 & Año 3 & Año 4 & Año 5 \\
\hline VENTAS & & 253,584 & 303,216 & 327,473 & 366,770 & 421,786 \\
\hline Incremento de Ventas & & & $20 \%$ & $8 \%$ & $12 \%$ & $15 \%$ \\
\hline COSTOS DE VENTAS & & $-63,499$ & $-68,881$ & $-73,176$ & $-78,417$ & $-84,651$ \\
\hline Incremento de Costos & & & $8 \%$ & $6 \%$ & $7 \%$ & $8 \%$ \\
\hline GASTOS OPERATIVOS & & $-138,578$ & $-146,095$ & $-154,444$ & $-163,427$ & $-173,220$ \\
\hline Crecimiento de Gastos Operativos & & & $5 \%$ & $6 \%$ & $6 \%$ & $6 \%$ \\
\hline Margen bruto & & $75 \%$ & $77 \%$ & $78 \%$ & $79 \%$ & $80 \%$ \\
\hline Margen operativo & & $20 \%$ & $29 \%$ & $30 \%$ & $34 \%$ & $39 \%$ \\
\hline
\end{tabular}

Fuente: Elaboración Propia

Calculo de la depreciación anual:

Tabla 30: Depreciación anual

\begin{tabular}{|l|c|c|c|}
\hline \multicolumn{1}{|c|}{ Activos de inversión } & Inversión & Inversión (sin IGV) & Vida útil (Años) \\
\hline Equipos & 4,689 & 3,974 & 5 \\
\hline Equipos Tecnológicos & 10,500 & 8,898 & 4 \\
\hline Muebles & 2,780 & 2,356 & 5 \\
\hline Intangibles & 22,230 & 18,839 & 10 \\
\hline Otros varios & 0 & 0 & n.a. \\
\hline Total Inversión & 40,199 & 34,067 & \\
\hline \multicolumn{2}{|c|}{ Fuente: Elaboración Propia }
\end{tabular}


Flujo proyectado a 5 años:

Tabla 31: Flujo proyectado a 5 años

\begin{tabular}{|c|c|c|c|c|c|c|}
\hline & Año 0 & Año 1 & Año 2 & Año 3 & Año 4 & Año 5 \\
\hline Ingresos & & 253,584 & 303,216 & 327,473 & 366,770 & 421,786 \\
\hline Costos directos de fabricación & & $-63,499$ & $-68,881$ & $-73,176$ & $-78,417$ & $-84,651$ \\
\hline Costos Fijos & & $-138,578$ & $-146,095$ & $-154,444$ & $-163,427$ & $-173,220$ \\
\hline Depreciación & & $-5,374$ & $-5,374$ & $-5,374$ & $-5,374$ & $-5,374$ \\
\hline EBIT & & $\mathbf{5 1 , 5 0 7}$ & 88,239 & 99,853 & 124,927 & 163,915 \\
\hline Impuestos (-) & & $-12,917$ & $-23,753$ & $-27,179$ & $-35,259$ & $-47,444$ \\
\hline Depreciación (+) & & 5,374 & 5,374 & 5,374 & 5,374 & 5,374 \\
\hline FEO & & 43,965 & 69,861 & 78,048 & 95,042 & 121,846 \\
\hline Activo Fijos & $-40,199$ & & & & & \\
\hline $\mathrm{CTN}$ & $-102,322$ & & & & & \\
\hline FCLD & $-142,521$ & 43,965 & 69,861 & 78,048 & 95,042 & 121,846 \\
\hline Financiamiento & 102,761 & & & & & \\
\hline Cupón & & 0 & 0 & $-30,828$ & $-30,828$ & $-41,105$ \\
\hline Intereses & & $-7,722$ & $-7,722$ & $-7,722$ & $-5,405$ & $-3,089$ \\
\hline Escudo fiscal de los intereses & & 2,278 & 2,278 & 2,278 & 1,595 & 911 \\
\hline FCNI & $-39,760$ & 38,521 & 64,417 & 41,776 & 60,403 & 78,564 \\
\hline
\end{tabular}

\begin{tabular}{|l|c|}
\hline VPN(FCLD) con WACC $(6.68 \%)$ en S/. & $185,945.85$ \\
\hline IR con WACC en \% & 2.30 \\
\hline VPN(FCNI) con COK (10.23\%) en S/. & $\mathbf{1 6 8 , 6 0 6 . 7 5}$ \\
\hline IR con COK en \% & $\mathbf{2 . 1 8}$ \\
\hline
\end{tabular}

\begin{tabular}{|l|l|}
\hline Recupero & 1.02 \\
\hline
\end{tabular} 
- Cálculo del valor presente y retorno en base al WACC de $6.68 \%$ y COK de $10.23 \%$. En ambos casos los resultados del proyecto son satisfactorios y se recomienda inversión ya que son superiores al WACC y al COK.

- El recupero de la inversión es al año y dos meses de operaciones.

\subsection{TASA DE DESCUENTO ACCIONISTA Y WACC}

Cálculo del COK (10.23\%)

Tabla 32: Calculo del COK

\begin{tabular}{|c|c|c|c|}
\hline \multicolumn{4}{|c|}{ Modelo CAPM para países emergentes } \\
\hline Datos: & Valor & Descripción & Fuente \\
\hline $\mathrm{rf}$ & 0.0291 & $\begin{array}{l}\text { Long term rate treasury us Bonds ( }>10 \text { years) } \\
\qquad \text { as per } 20 / 04 / 2017\end{array}$ & $\begin{array}{l}\frac{\text { https://www.treasury.gov/resou }}{\text { rce-center/data-chart- }} \\
\underline{\text { center/interest- }} \\
\underline{\text { rates/Pages/TextView.aspx?dat }} \\
\underline{\mathrm{a}=\text { longtermrate }}\end{array}$ \\
\hline ßu & 0.97 & $\begin{array}{c}\text { beta unleveraged (Business \& Consumer } \\
\text { Services) }\end{array}$ & $\frac{\frac{\text { http://pages.stern.nyu.edu/ ada }}{\text { modar/New_Home_Page/dataf }}}{\underline{\text { ile/Betas.html }}}$ \\
\hline$\beta 1$ & 2.73 & beta leveraged & \\
\hline $\mathrm{Rm}$ & 0.0516 & $\begin{array}{l}\text { Rendimiento últimos } 10 \text { años al } 21.04 .17 \text { del } \\
\text { sector industrial, NYSE MKT Composite }\end{array}$ & $\begin{array}{l}\text { https://www.nyse.com/publicd } \\
\text { ocs/nyse/indices/NYSE Globa } \\
\text { IIndex_Group Monthly Perf } \\
\text { ormance_Report 20170331.pd } \\
\underline{\mathrm{f}}\end{array}$ \\
\hline $\begin{array}{l}\text { Riesgo } \\
\text { país }\end{array}$ & 0.0118 & Riesgo país Perú - EMBI+ JP Morgan & $\frac{\text { https://elcomercio.pe/economia }}{\frac{\text { /peru/riesgo-pais-peru-region- }}{\underline{\text { noticia-512673 }}}}$ \\
\hline COK & $10.23 \%$ & & \\
\hline
\end{tabular}

Fuente: Elaboración Propia

Tabla 33: Estructura de Financiamiento

\begin{tabular}{|c|c|c|c|c|c|}
\hline \multicolumn{6}{|c|}{ INVERSION PROPIA Y EXTERNA } \\
\hline Fuente & Inversión (\%) & Monto (miles) & Costo & impuesto & WACC \\
\hline Banco & $0 \%$ & - & $22.99 \%$ & $70.50 \%$ & $0.00 \%$ \\
\hline Bono & $72 \%$ & 102,761 & $7.51 \%$ & $70.50 \%$ & $3.81 \%$ \\
\hline Capital Social & $28 \%$ & 40,000 & $10.23 \%$ & & $2.87 \%$ \\
\hline Total & $100 \%$ & 142,761 & & & $6.68 \%$ \\
\hline
\end{tabular}

Fuente: Elaboración Propia

De acuerdo a la estructura de financiamiento $(72 / 28)$ se determina que la WACC es de $6.68 \%$.

Para estimar la tasa de bono a ofrecer, se realizó un promedio de las tasas de interés de bonos corporativos de 3-5 años emitidos en Perú los últimos 9 trimestres. A este promedio 
se le adicionó un premium de 100 bps por la naturaleza de riesgo del proyecto (nueva empresa):

Tabla 34: Tasas Interés Bonos

\begin{tabular}{|c|c|}
\hline \multicolumn{2}{|c|}{ Tasas Interés Bonos* } \\
\hline Banco & TEA \\
\hline 1Q15 & $5.79 \%$ \\
\hline 2Q15 & $7.51 \%$ \\
\hline 3Q15 & $6.46 \%$ \\
\hline 4Q15 & n.a. \\
\hline 1Q16 & $6.30 \%$ \\
\hline 2Q16 & n.a. \\
\hline 3Q16 & n.a. \\
\hline 4Q16 & n.a. \\
\hline 1Q17 & n.a. \\
\hline Promedio & $\mathbf{6 . 5 1 \%}$ \\
\hline
\end{tabular}

Fuente: *Tasas interés bonos 3-5 años (Fuente: BCRP)

Se descarta el financiamiento bancario por tener un costo superior:

Tabla 35: Tasas referenciales SBS

\begin{tabular}{|c|c|}
\hline \multicolumn{2}{|c|}{ Tasas referenciales SBS* } \\
\hline Banco & TEA \\
\hline 1Q15 & $22.77 \%$ \\
\hline 2Q15 & $22.49 \%$ \\
\hline 3Q15 & $22.47 \%$ \\
\hline 4Q15 & $22.61 \%$ \\
\hline 1Q16 & $22.64 \%$ \\
\hline 2Q16 & $23.12 \%$ \\
\hline 3Q16 & $23.23 \%$ \\
\hline 4Q16 & $23.51 \%$ \\
\hline 1Q17 & $24.06 \%$ \\
\hline Promedio & $\mathbf{2 2 . 9 9 \%}$ \\
\hline
\end{tabular}

Fuente: *Tasas referenciales a pequeñas empresas más de 360 días (Fuente SBS) 


\subsection{INDICADORES DE RENTABILIDAD}

Tabla 36: Análisis Vertical

\begin{tabular}{|c|c|c|c|c|c|}
\hline \multicolumn{6}{|c|}{ Análisis Vertical } \\
\hline ESTADO DE RESULTADOS & Año 1 & Año 2 & Año 3 & Año 4 & Año 5 \\
\hline Ingresos por Ventas & $100 \%$ & $100 \%$ & $100 \%$ & $100 \%$ & $100 \%$ \\
\hline Costo de Ventas & $-25 \%$ & $-23 \%$ & $-22 \%$ & $-21 \%$ & $-20 \%$ \\
\hline Ganancia (Pérdida) Bruta & $75 \%$ & $77 \%$ & $78 \%$ & $79 \%$ & $80 \%$ \\
\hline Gastos de Ventas y Distribución & $-34 \%$ & $-31 \%$ & $-30 \%$ & $-29 \%$ & $-27 \%$ \\
\hline Gerente de Ventas & $-9 \%$ & $-8 \%$ & $-8 \%$ & $-7 \%$ & $-6 \%$ \\
\hline Community Manager & $-7 \%$ & $-6 \%$ & $-6 \%$ & $-6 \%$ & $-5 \%$ \\
\hline Gastos de Marketing & $-18 \%$ & $-16 \%$ & $-17 \%$ & $-16 \%$ & $-16 \%$ \\
\hline Otros gastos de Ventas & $0 \%$ & $0 \%$ & $0 \%$ & $0 \%$ & $0 \%$ \\
\hline Gastos de Administración & $-20 \%$ & $-17 \%$ & $-17 \%$ & $-15 \%$ & $-14 \%$ \\
\hline Gerente General & $-10 \%$ & $-9 \%$ & $-8 \%$ & $-8 \%$ & $-7 \%$ \\
\hline Gerente de Adm y Finanzas & $-5 \%$ & $-4 \%$ & $-4 \%$ & $-4 \%$ & $-3 \%$ \\
\hline Costos de Servicios & $-1 \%$ & $-1 \%$ & $-1 \%$ & $-1 \%$ & $-1 \%$ \\
\hline Imprevisto & $-1 \%$ & $-1 \%$ & $-1 \%$ & $-1 \%$ & $-1 \%$ \\
\hline Gastos de RRHH & $-1 \%$ & $-1 \%$ & $-1 \%$ & $-1 \%$ & $-1 \%$ \\
\hline Depreciación & $-2 \%$ & $-2 \%$ & $-2 \%$ & $-1 \%$ & $-1 \%$ \\
\hline $\begin{array}{l}\text { Ganancia (Pérdida) por actividades } \\
\text { de operación }\end{array}$ & $20 \%$ & $29 \%$ & $30 \%$ & $34 \%$ & $39 \%$ \\
\hline Ingresos Financieros & $0 \%$ & $0 \%$ & $0 \%$ & $0 \%$ & $0 \%$ \\
\hline Gastos Financieros & $-3 \%$ & $-3 \%$ & $-2 \%$ & $-1 \%$ & $-1 \%$ \\
\hline $\begin{array}{l}\text { Resultado antes de Impuesto a las } \\
\text { Ganancias }\end{array}$ & $17 \%$ & $27 \%$ & $28 \%$ & $33 \%$ & $38 \%$ \\
\hline Utilidades al personal & $-1 \%$ & $-2 \%$ & $-2 \%$ & $-3 \%$ & $-3 \%$ \\
\hline Impuesto a la renta & $-5 \%$ & $-8 \%$ & $-8 \%$ & $-10 \%$ & $-11 \%$ \\
\hline $\begin{array}{l}\text { Ganancia (Pérdida) Neta del } \\
\text { Ejercicio }\end{array}$ & $11 \%$ & $17 \%$ & $18 \%$ & $20 \%$ & $24 \%$ \\
\hline
\end{tabular}

Fuente: Elaboración Propia

El análisis vertical muestra que nuestro costo representa un $25 \%$ de las ventas y con tendencia a disminuir, ya que la tecnología de nuestro servicio hace que nuestros costos sean mínimos. Por lo cual, cada año vamos a estar innovando con el fin de ir mejorar los costos y ahorrando en la medida que fuera posible a fin de invertir en nuestro APP y de adquirir más afiliados.

Los costos fijos se muestran relativamente estables en el tiempo y de diluyen a medida que se incrementa el nivel de ventas.

Los gastos financieros no son significativos y se observa un resultado positivo a partir del primer año de operaciones. 
Tabla 37: Análisis Horizontal

\begin{tabular}{|c|c|c|c|c|}
\hline \multicolumn{5}{|c|}{ Análisis Horizontal } \\
\hline ESTADO DE RESULTADOS & Año 2 & Año 3 & Año 4 & Año 5 \\
\hline Ingresos por Ventas & $20 \%$ & $8 \%$ & $12 \%$ & $15 \%$ \\
\hline Costo de Ventas & $8 \%$ & $6 \%$ & $7 \%$ & $8 \%$ \\
\hline Ganancia (Pérdida) Bruta & $23 \%$ & $9 \%$ & $13 \%$ & $17 \%$ \\
\hline $\begin{array}{l}\text { Gastos de Ventas y } \\
\text { Distribución }\end{array}$ & $7 \%$ & $7 \%$ & $7 \%$ & $7 \%$ \\
\hline Gerente de Ventas & $3 \%$ & $3 \%$ & $3 \%$ & $3 \%$ \\
\hline Community Manager & $5 \%$ & $5 \%$ & $5 \%$ & $5 \%$ \\
\hline Gastos de Marketing & $10 \%$ & $10 \%$ & $10 \%$ & $10 \%$ \\
\hline Otros gastos de Ventas & $0 \%$ & $0 \%$ & $0 \%$ & $0 \%$ \\
\hline Gastos de Administración & $3 \%$ & $3 \%$ & $3 \%$ & $4 \%$ \\
\hline Gerente General & $3 \%$ & $3 \%$ & $3 \%$ & $3 \%$ \\
\hline Gerente de Adm y Finanzas & $5 \%$ & $5 \%$ & $5 \%$ & $5 \%$ \\
\hline Costos de Servicios & $5 \%$ & $5 \%$ & $5 \%$ & $5 \%$ \\
\hline Imprevisto & $5 \%$ & $5 \%$ & $5 \%$ & $5 \%$ \\
\hline Gastos de RRHH & $-9 \%$ & $0 \%$ & $0 \%$ & $5 \%$ \\
\hline Depreciación & $0 \%$ & $0 \%$ & $0 \%$ & $0 \%$ \\
\hline $\begin{array}{l}\text { Ganancia (Pérdida) por actividades } \\
\text { de operación }\end{array}$ & $71 \%$ & $13 \%$ & $25 \%$ & $31 \%$ \\
\hline Ingresos Financieros & $0 \%$ & $0 \%$ & $0 \%$ & $0 \%$ \\
\hline Gastos Financieros & $0 \%$ & $0 \%$ & $-30 \%$ & $-43 \%$ \\
\hline $\begin{array}{l}\text { Resultado antes de Impuesto a las } \\
\text { Ganancias }\end{array}$ & $84 \%$ & $14 \%$ & $30 \%$ & $35 \%$ \\
\hline Utilidades al personal & $84 \%$ & $14 \%$ & $30 \%$ & $35 \%$ \\
\hline Impuesto a la renta & $84 \%$ & $14 \%$ & $30 \%$ & $35 \%$ \\
\hline $\begin{array}{l}\text { Ganancia (Pérdida) Neta del } \\
\text { Ejercicio }\end{array}$ & $84 \%$ & $14 \%$ & $30 \%$ & $35 \%$ \\
\hline
\end{tabular}

Fuente: Elaboración Propia

En análisis horizontal muestra que al año 2 un crecimiento importante, y es porque tenemos 100\% operación y mayor captación de clientes. Luego en el año 3 y 4 mantiene un crecimiento saludable.

Los gastos fijos muestran un incremento razonable en el tiempo, el cual están ajustados al nivel de ventas de la empresa. 
Tabla 38: Cálculo del EBITDA

Fuente: Elaboración Propia

\begin{tabular}{|lccccc|}
\hline & Año 1 & Año 2 & Año 3 & Año 4 & Año 5 \\
Ratio de liquidez & & & & & \\
Ratio corriente & 1.95 & 2.25 & 2.16 & 2.34 & 2.48 \\
Prueba ácida & 2.0 & 2.3 & 2.2 & 2.3 & 2.5 \\
Ratio de solvencia & & & & & \\
Ratio de patrimonio & $22 \%$ & $32 \%$ & $40 \%$ & $51 \%$ & $61 \%$ \\
Ratios de rentabilidad & $-41 \%$ & $-43 \%$ & $33 \%$ & $30 \%$ & $29 \%$ \\
ROE & $9 \%$ & $13 \%$ & $13 \%$ & $15 \%$ & $17 \%$ \\
ROA & 1.47 & 0.88 & 0.78 & 0.43 & 0.19 \\
Ratio de endeudamiento & & & & & \\
Deuda / EBITDA & & & & & \\
\hline
\end{tabular}

La empresa mantiene ratios de liquidez aceptable $(>1.9 \mathrm{x})$ e incluso en la prueba ácida se mantiene sobre $2 \mathrm{x}$. Por lo cual, muestra que tenemos solvencia frente para cubrir los pagos a nuestros proveedores.

La solvencia patrimonial es estable desde el primer año, y en crecimiento. Este se da por la buena estructura en costos y gastos que se han propuesto en el proyecto, con fin de generar una buena rentabilidad.

Los indicadores de rentabilidad son positivos a partir del tercer año, luego de superar el punto de equilibrio y obtener resultados financieros positivos.

El nivel de endeudamiento respecto al EBITDA es positivo, ya que los niveles de endeudamiento son considerados para nuestra empresa, ya que la emisión de bonos nos un financiamiento bajo, el cual nos permite mostrar a nuestros accionistas una rentabilidad saludable para la empresa.

\subsection{ANÁLISIS DE RIESGO}

\subsubsection{ANÁLISIS DE SENSIBILIDAD}

En el análisis de sensibilidad, se toman diversos factores que pueden influir en el desempeño económico de la empresa debido a la significativa relación que tiene con:

1. Indicadores macroeconómicos (crecimiento del PBI, inflación, tipo de cambio).

2. Desempeño de los sectores alimentario.

3. Crecimiento del sistema financiero (las entidades bancarias están colocando mayores préstamos para las pymes). 
Por lo tanto, se plantean 2 escenarios que reflejan las variables antes mencionadas:

\section{Escenario 1: Escenario pesimista}

- Disminución de los ingresos por ventas de $10 \%$.

- Disminución de los costos de ventas de $10 \%$.

- Sin variación respecto a gastos operativos.

- Sin variación respecto a gastos financieros.

El PBI del Perú se ha desacelerado en los últimos años, pero muestra un crecimiento sostenido a través del tiempo. Similar comportamiento se muestra en el sector Alimentario, el cual ha mantenido un crecimiento estable en los últimos años, excepto en el año 2014 cuando experimentó por primera vez un decrecimiento de 3.25\%:

Tabla 39: Pbi y Sector Alimentos: Valor Agregado Bruto Por Años

\begin{tabular}{|c|c|c|c|c|c|c|c|c|c|}
\hline ACTIVIDADES & 2010 & 2011 & 2012 & 2013 & 2014 & 2015 & 2016 & 2017 & ABRIL/2018 \\
\hline PBI ALIMENTOS & 127.73 & 129.77 & 130.89 & 140.40 & 135.83 & 140.31 & 141.61 & 142.22 & 147.89 \\
\hline CRECIMIENTO ANUAL & & 1.59 & 0.86 & 7.27 & -3.25 & 3.30 & 0.92 & 0.43 & 3.99 \\
\hline PBI TOTAL & $1,420.11$ & $1,492.23$ & $1,567.89$ & $1,583.37$ & $1,612.10$ & $1,612.83$ & $1,610.71$ & $1,631.46$ & 536.42 \\
\hline CRECIMIENTO ANUAL & & 5.08 & 5.07 & 0.99 & 1.81 & 0.05 & -0.13 & 1.29 & -67.12 \\
\hline
\end{tabular}

Fuente: Elaboración Propia

De la misma forma, el sector financiero muestra una fuerte aceleración de la colocación de créditos, por la estabilidad política y economía que estamos teniendo actualmente, ya que el año 2017, el sector financiero se encontraba en estado de incertidumbre, el cual nadie quería arriesgar su dinero. Hoy en día el Sector Alimentos, se encuentra en crecimiento, y es esto se ve reflejado por el incremento de Food Trucks que existe actualmente.

\section{Escenario 2: Escenario optimista}

- Incremento de los ingresos por ventas de $10 \%$.

- Incremento de los costos de ventas de $10 \%$.

- Sin variación respecto a gastos operativos.

- Sin variación respecto a gastos financieros.

Este escenario propone reflejar resultados reales del factor PBI Alimentos acumulado de $10 \%$ en los últimos 5 años. 


\subsubsection{ANALISIS POR ESCENARIOS (POR VARIABLES)}

Tabla 40: Escenario Pesimista:

$-10 \%$ ingresos/costos de ventas, no incremento en gastos operativos

\begin{tabular}{|c|c|c|c|c|c|c|}
\hline \multicolumn{7}{|c|}{ ESTADO DE RESULTADOS - ESCENARIO PESIMISTA } \\
\hline & Año 0 & Año 1 & Año 2 & Año 3 & Año 4 & Año 5 \\
\hline INGRESOS & & 253,584 & 303,216 & 327,473 & 366,770 & 421,786 \\
\hline Alteración Escenario & & 0.90 & 0.90 & 0.90 & 0.90 & 0.90 \\
\hline Incremento de Ventas & & & $19.57 \%$ & $8.00 \%$ & $12.00 \%$ & $15.00 \%$ \\
\hline VENTAS & & 228,226 & 272,894 & 294,726 & 330,093 & $\mathbf{3 7 9 , 6 0 7}$ \\
\hline COSTOS DE VENTAS & & $-57,149.01$ & $-61,993.34$ & $-65,858.74$ & $-70,575.26$ & $-76,185.74$ \\
\hline Incremento de Costos & & & $8.48 \%$ & $6.24 \%$ & $7.16 \%$ & $7.95 \%$ \\
\hline GASTOS OPERATIVOS & & $-138,578.41$ & $-146,095.21$ & $-154,444.39$ & $-163,426.59$ & $-173,219.66$ \\
\hline Crecimiento de Gastos Operativos & & & $5.42 \%$ & $5.71 \%$ & $5.82 \%$ & $5.99 \%$ \\
\hline Margen bruto & & $75 \%$ & $123 \%$ & $122 \%$ & $121 \%$ & $120 \%$ \\
\hline Margen operativo & & $14 \%$ & $24 \%$ & $25 \%$ & $29 \%$ & $34 \%$ \\
\hline \multicolumn{7}{|c|}{ FLUJO DE CAJA - ESCENARIO PESIMISTA } \\
\hline & Año 0 & Año 1 & Año 2 & Año 3 & Año 4 & Año 5 \\
\hline Ingresos & & 228,226 & 272,894 & 294,726 & 330,093 & 379,607 \\
\hline Costos directos de fabricación & & $-57,149$ & $-61,993$ & $-65,859$ & $-70,575$ & $-76,186$ \\
\hline Costos Fijos & & $-138,578$ & $-146,095$ & $-154,444$ & $-163,427$ & $-173,220$ \\
\hline Depreciación & & $-5,374$ & $-5,374$ & $-5,374$ & $-5,374$ & $-5,374$ \\
\hline EBIT & & 32,498 & 64,806 & $\mathbf{7 4 , 4 2 3}$ & 96,091 & 130,202 \\
\hline Impuestos (-) & & & & $-19,677$ & $-26,752$ & $-37,498$ \\
\hline Depreciación $(+)$ & & 5,374 & 5,374 & 5,374 & 5,374 & 5,374 \\
\hline FEO & & 37,873 & 70,180 & 60,120 & 74,713 & 98,078 \\
\hline Activo Fijos & $-40,199$ & & & & & \\
\hline $\mathrm{CTN}$ & $-102,322$ & & & & & \\
\hline FCLD & $-142,521$ & 37,873 & 70,180 & 60,120 & $\mathbf{7 4 , 7 1 3}$ & 98,078 \\
\hline Financiamiento & 102,761 & & & & & \\
\hline Amortización & & 0 & 0 & $-30,828$ & $-30,828$ & $-41,105$ \\
\hline Intereses & & $-7,722$ & $-7,722$ & $-7,722$ & $-5,405$ & $-3,089$ \\
\hline Escudo fiscal de los intereses & & 2,278 & 2,278 & 2,278 & 1,595 & 911 \\
\hline FCNI & $-39,760$ & 32,429 & 64,736 & 23,848 & 40,074 & 54,796 \\
\hline
\end{tabular}

\begin{tabular}{|l|c|}
\hline VPN (FCLD) con WACC & $132,848$. \\
$(6.68 \%)$ en S/. & 33 \\
\hline IR con WACC en $\%$ & 1.93 \\
\hline VPN (FCNI) con COK & $121,576$. \\
$(10.23 \%)$ en S/. & 13 \\
\hline IR con COK en $\%$ & 1.85 \\
\hline
\end{tabular}

Fuente: Elaboración Propia

En el escenario pesimista el VPN es positivo y el retorno calculado es superior al WACC y COK respectivamente.

Incluso bajo un escenario pesimista, la inversión es viable.

Tabla 41: Escenario Optimista:

$+10 \%$ ingresos/costos de ventas, no incremento en gastos operativos 


\begin{tabular}{|c|c|c|c|c|c|c|}
\hline \multicolumn{7}{|c|}{ ESTADO DE RESULTADOS - ESCENARIO OPTIMISTA } \\
\hline & Año 0 & Año 1 & Año 2 & Año 3 & Año 4 & Año 5 \\
\hline INGRESOS & & 253,584 & 303,216 & 327,473 & 366,770 & 421,786 \\
\hline Alteración Escenario & & 1.1 & 1.1 & 1.1 & 1.1 & 1.1 \\
\hline Incremento de Ventas & & & $19.57 \%$ & $8.00 \%$ & $12.00 \%$ & $15.00 \%$ \\
\hline VENTAS & & 278,942 & $\mathbf{3 3 3 , 5 3 8}$ & 360,221 & $\mathbf{4 0 3 , 4 4 7}$ & 463,964 \\
\hline COSTOS DE VENTAS & & $-69,848.79$ & $-75,769.63$ & $-80,494.02$ & $-86,258.65$ & $-93,115.90$ \\
\hline Incremento de Costos & & & $8.48 \%$ & $6.24 \%$ & $7.16 \%$ & $7.95 \%$ \\
\hline GASTOS OPERATIVOS & & $-138,578.41$ & $-146,095.21$ & $-154,444.39$ & $-163,426.59$ & $-173,219.66$ \\
\hline Crecimiento de Gastos Operativos & & & $5.42 \%$ & $5.71 \%$ & $5.82 \%$ & $5.99 \%$ \\
\hline Margen bruto & & $75 \%$ & $123 \%$ & $122 \%$ & $121 \%$ & $120 \%$ \\
\hline Margen operativo & & $25 \%$ & $33 \%$ & $35 \%$ & $38 \%$ & $43 \%$ \\
\hline \multicolumn{7}{|c|}{ FLUJO DE CAJA - ESCENARIO OPTIMISTA } \\
\hline & Año 0 & Año 1 & Año 2 & Año 3 & Año 4 & Año 5 \\
\hline Ingresos & & 278,942 & 333,538 & 360,221 & 403,447 & 463,964 \\
\hline Costos directos de fabricación & & $-69,849$ & $-75,770$ & $-80,494$ & $-86,259$ & $-93,116$ \\
\hline Costos Fijos & & $-138,578$ & $-146,095$ & $-154,444$ & $-163,427$ & $-173,220$ \\
\hline Depreciación & & $-5,374$ & $-5,374$ & $-5,374$ & $-5,374$ & $-5,374$ \\
\hline EBIT & & 70,515 & 111,673 & 125,282 & 153,762 & 197,629 \\
\hline Impuestos (-) & & & $-30,666$ & $-34,680$ & $-43,765$ & $-57,389$ \\
\hline Depreciación $(+)$ & & 5,374 & 5,374 & 5,374 & 5,374 & 5,374 \\
\hline FEO & & 75,890 & 86,382 & 95,976 & 115,371 & 145,614 \\
\hline Activo Fijos & $-40,199$ & & & & & \\
\hline CTN & $-102,322$ & & & & & \\
\hline FCLD & $-142,521$ & 75,890 & 86,382 & 95,976 & 115,371 & 145,614 \\
\hline Financiamiento & 102,761 & & & & & \\
\hline Amortización & & 0 & 0 & $-30,828$ & $-30,828$ & $-41,105$ \\
\hline Intereses & & $-7,722$ & $-7,722$ & $-7,722$ & $-5,405$ & $-3,089$ \\
\hline Escudo fiscal de los intereses & & 2,278 & 2,278 & 2,278 & 1,595 & 911 \\
\hline FCNI & $-39,760$ & 70,446 & 80,938 & 59,704 & 80,732 & 102,332 \\
\hline
\end{tabular}

\begin{tabular}{|l|c|}
\hline VPN (FCLD) con WACC & $278,056$. \\
$(6.68 \%)$ en S/. & 71 \\
\hline IR con WACC en \% & 2.95 \\
\hline VPN (FCNI) con COK & $252,934$. \\
$(10.23 \%)$ en S/. & 36 \\
\hline IR con COK en $\%$ & 2.77 \\
\hline
\end{tabular}

Fuente: Elaboración Propia

En el escenario optimista el VPN es positivo y el retorno calculado es significativamente superior al WACC y COK respectivamente.

\subsubsection{ANALISIS DE PUNTO DE EQUILIBRIO}


Tabla 42: Punto de equilibrio

\section{ANÁLISIS PUNTO DE EQUILIBRIO}

\begin{tabular}{|c|c|c|c|c|c|}
\hline ESTADO DE RESULTADOS & Año 1 & Año 2 & Año 3 & Año 4 & Año 5 \\
\hline Ingresos por Ventas & 195,172 & 199,031 & 208,831 & 214,745 & 220,577 \\
\hline Costo de Ventas & $-48,872$ & $-45,214$ & $-46,665$ & $-45,913$ & $-44,269$ \\
\hline Ganancia (Pérdida) Bruta & 146,300 & 153,817 & 162,166 & 168,832 & 176,308 \\
\hline Gastos de Ventas y Distribución & $-86,944$ & $-93,051$ & $-99,673$ & 106,858 & 114,658 \\
\hline Gerente de Ventas & $-24,000$ & $-24,720$ & $-25,462$ & $-26,225$ & $-27,012$ \\
\hline Community Manager & $-18,144$ & $-19,051$ & $-20,004$ & $-21,004$ & $-22,054$ \\
\hline Gastos de Marketing & $-44,800$ & $-49,280$ & $-54,208$ & $-59,629$ & $-65,592$ \\
\hline Otros gastos de Ventas & 0 & 0 & 0 & 0 & 0 \\
\hline Gastos de Administración & $-51,634$ & $-53,044$ & $-54,771$ & $-56,568$ & $-58,562$ \\
\hline Gerente General & $-25,920$ & $-26,698$ & $-27,499$ & $-28,323$ & $-29,173$ \\
\hline Gerente de Adm y Finanzas & $-12,000$ & $-12,600$ & $-13,230$ & $-13,892$ & $-14,586$ \\
\hline Costos de Servicios & $-3,240$ & $-3,402$ & $-3,572$ & $-3,751$ & $-3,938$ \\
\hline Imprevisto & $-2,400$ & $-2,520$ & $-2,646$ & $-2,778$ & $-2,917$ \\
\hline Gastos de RRHH & $-2,700$ & $-2,450$ & $-2,450$ & $-2,450$ & $-2,573$ \\
\hline Depreciación & $-5,374$ & $-5,374$ & $-5,374$ & $-5,374$ & $-5,374$ \\
\hline $\begin{array}{l}\text { Ganancia (Pérdida) por actividades } \\
\text { de operación }\end{array}$ & 7,722 & 7,722 & 7,722 & 5,405 & 3,088 \\
\hline Ingresos Financieros & 0 & 0 & 0 & 0 & 0 \\
\hline Gastos Financieros & $-7,722$ & $-7,722$ & $-7,722$ & $-5,405$ & $-3,089$ \\
\hline $\begin{array}{l}\text { Resultado antes de Impuesto a las } \\
\text { Ganancias }\end{array}$ & 0 & 0 & 0 & 0 & 0 \\
\hline Utilidades al personal & - & & & & - \\
\hline Impuesto a la renta & - & - & - & - & - \\
\hline $\begin{array}{l}\text { Ganancia (Pérdida) Neta del } \\
\text { Ejercicio }\end{array}$ & 0 & 0 & 0 & 0 & 0 \\
\hline
\end{tabular}

Fuente: Elaboración Propia

Dado que el gran componente de la estructura de costos es variable (costo de ventas), el punto de equilibrio para la empresa para los primeros cinco años es un promedio de ventas anuales de S/. 207,671 soles. Hay que tener en cuenta que nuestras proyecciones de ventas son optimistas. 


\subsubsection{PRINCIPALES RIESGOS DEL PROYECTO (CUALITATIVOS)}

Los principales riesgos del proyecto se clasifican según su naturaleza:

\section{Riesgo de mercado (medio):}

- A inicios del 2018 se indicaba un crecimiento del $4 \%$ a $4.5 \%$ de crecimiento. Hoy en día se espera un crecimiento del $3.5 \%$ con tendencia a bajar, si: 1 . Se incrementa el ruido político, 2. se produce una sub-ejecución en la inversión pública destinada en la reconstrucción del Niño Costero o 3. Si se genera una abrupta reversión de los flujos de capitales hacia economías emergentes.

- Hoy existe un consumidor con una nueva tendencia de consumo y de liquidez para adquirir nuevos servicios. El cual, el tener un APP innovador que una Los Food Trucks, son una estrategia de venta de alimentos, el cual reduce el tiempo de espera y un buen servicio.

\section{Riesgo financiero (bajo)}

- Existe apetito de financiamiento en la plaza local.

- Financiamiento e ingresos en la misma moneda (sin riesgo de tipo de cambio).

- Financiamiento a tasa fija (sin riesgo de tasa de interés).

- Proyecciones financieras de manera mensual, trimestral y anual. Con el fin de asegurar la proyección de ventas propuesta en el Plan Financiero.

\section{Riesgo de liquidez (bajo)}

- El modelo de negocio permite asegurar el dinero por el producto comprado por el cliente, ya que al comprar el producto tiene que pagarlo mediante la aplicación, el cual permite asegurar nuestra comisión por la venta realizada mediante nuestra app. Para ello, tenemos un socio estratégico que es PayPal, el cual permite dar la seguridad a nuestros clientes.

\section{Riesgo operativo (bajo)}

- Estructura de presupuesto bien asignado, con el fin de ejecutar los recursos necesarios en el año.

- Tercerización de servicios especializados a fin de mantener un bajo nivel de costos fijos. Por ejemplo, el servicio Cloud nos permite tener servidores en la nude, el cual 
nos da el aseguramiento del funcionamiento del APP en un $100 \%$, sin tener que depreciar ningún servidor físico, el cual genera costo en: Planilla, mantenimiento y renovación.

\section{Riesgo reputacional/socio-ambiental (bajo)}

- Nos estamos acogiendo a ley MyPE y registrados con Sunat, con el fin de asegurar a nuestros empleados y socios, que somos una empresa seria en el mercado y con mucho potencial de crecimiento, por ser un servicio innovador.

- La naturaleza del negocio y su propuesta de valor promueven una imagen de responsabilidad con el medio ambiente, ya que vamos a promover que los dueños de los Food Truck utilicen productos biodegradables como: empaques, bolsas, cubiertos, tachos con clasificación de basura, entre otros. 


\section{CONCLUSIONES}

En la actualidad el consumidor peruano busca mayor comodidad y ahorro de tiempo, es por ello que realizan compras a través de la web lo que genera una oportunidad para ¡Ñam! Buscador de Food Trucks este aplicativo ofrece una forma eficiente y practica de localizar el Food Truck con la comida deseada, ahorrar tiempo en su ubicación, pago y recojo del producto que desea.

¡Ñam! Buscador de Food Trucks es un aplicativo que permitirá cubrir la necesidad de sus clientes de hacerse conocidos y aumentar su rentabilidad.

Para elegir el tipo de negocio esperado se debe analizar el mercado, cuáles son las necesidades insatisfechas del público objetivo al que se desea dirigir el producto o servicio nuevo, realizar la proyección de ventas del mismo para estimar si el modelo de negocio es rentable o no.

Dentro del modelo de negocio al que la empresa se ha dirigido no tienen un competidor directo, pero si puede darse una competencia indirecta de los servicios de delivery si es que el usuario considera que esta modalidad satisface su necesidad en lugar del aplicativo.

El proyecto está dirigido a hombres y mujeres de 20 a 35 años de nivel socioeconómico A/B que pertenecen a los distritos de surco, Miraflores y surquillo con un ritmo de vida social activo que valora y aprecia las cualidades únicas del servicio, este público puede ser fidelizado y con la entrega de los beneficios adecuados se conseguiría la lealtad a la marca.

La elección de estrategia comunicacional es muy importante para el modelo de negocio que se desea impulsar y promocionar es por esto que ¡Ñam! Buscador de Food Trucks eligió como medio de comunicación las redes sociales por la fuente tendencia tecnológica hoy en día así mismo también el uso de rollscreen, afiches y volantes en los patios de 
Food Trucks. El uso de la tecnología más la ayuda visual que se brindara para el conocimiento del servicio serán las herramientas que se utilizaran para llegar al público objetivo y que aseguraran el conocimiento de la marca y el deseo del usuario por conocer más de la misma.

La inversión que se necesita para realizar las operaciones del proyecto, tiene un porcentaje adecuado, ya que el Capital Propio es de 28\% y el Financiado es del 72\%, el cual que permite ratios de retorno bastante atractivos para los inversionistas, así como de obtener una tasa de interés atractiva para poder llevar a cabo el proyecto.

Tener en cuenta que el proyecto comienza el Año 1 con un solo $70 \%$ de operaciones, ya que los primeros meses estamos comenzando con la captación de clientes. Es por ello, que en Año 2, tienen un crecimiento del considerable del 37.14\%, ya que comenzaron con un buen número de afiliados, gracias a las alianzas estratégicas con los gremios de Food Trucks.

Los gastos de Planillas siempre son los más costosos dentro una organización. Por ello, hemos priorizado que personal estará con contrato y cuál de ellos, estará por recibo por honorario. Con el fin de ahorrar en las planillas y evitar el sobrecosto del 9\% por Essalud según lo indicado por la Ley MyPE.

Para la proyección de la demanda hemos utilizado unas ventas promedio del mercado, según lo manifestado por los dueños de Food Trucks durante las entrevistas. Por ello, es importante indicar que las ventas podrían ir incrementarse, ya que hemos utilizado un precio promedio del producto (S/.15, 00 soles), el cual mayor precio del producto, mayor comisión tiene la empresa.

Los activos fijos que vamos a adquirir son de alta calidad, el cual va a permitir trabajar de una manera más eficiente y rápida, con el fin de minimizar los errores durante la ejecución del Proyecto. 
Según los análisis verticales y horizontales realizados, ha demostrado que nuestra estructura de costos y gastos, son las que utiliza hoy en el día las empresas con un buen control de gasto, ya que está respetando el 70/30, es decir, solo un $70 \%$ de lo que ingresa en la empresa, se destina para el gasto y el $30 \%$ es para cubrir mis obligaciones financieras, impuesto y márgenes para los accionistas. En caso se tuviera un porcentaje menor, la empresa no podría cubrir sus obligaciones.

La evaluación económica del proyecto, así como los escenarios propuestos en el plan, han demostrado que el proyecto es altamente viable, dado la tiene un costo de oportunidad del COK $(10,23 \%)$ y que la empresa deberá de exigir una tasa de rentabilidad mínima del (WACC de $(6.68 \%)$ ) sobre todas sus inversiones, y que con dicha tasa no presentaría ningún riesgo.

El análisis a diez años, respecto al retorno de la inversión ha demostrado flujos positivos con retorno sobre la inversión superior al costo del capital y del financiamiento.

Al efectuar el análisis de valor presente de los flujos estimados, se determina un recupero de la inversión se ejecuta a partir del año 2, el cual es un resultado es bastante positivo y atractivo para los inversionistas, ya que pueden invertir su capital con un rápido retorno.

El análisis de ratios financiero no identifica ninguna situación crítica en la empresa, el cual muestra que podemos tener flujos de efectivos acordes sin perjudicar la operación de la empresa.

Tanto para los escenarios pesimista y optimista, demuestra que el proyecto es viable. Por la nueva tendencia de consumo en el mercado, el cual permite asegurar las proyecciones de ingresos, gastos y márgenes indicados en el proyecto.

Tanto las bases cuantitativas como cualitativas del proyecto ¡Ñam! Buscador de Food Trucks, demuestran que es un proyecto innovador en el mercado y con una viabilidad financiera acorde. 


\section{REFERENCIAS BIBLIOGRAFICAS}

Porter, M. E. (1980) Estrategia competitiva: Técnicas para el análisis de la empresa y sus competidores. New York, 1980.

HERSEY, P., BLANCHARD, K. y JOHNSON, D. (1988) Administración del Comportamiento Organizacional - Liderazgo Situacional. Séptima Edición. México: Prentice.

Chiavenato (2011) Admisnitracion de Recurso Humanos. España, McGraw-Hill Interamericana de España, 2011.

Kotler, P., Armstrong, G. (2003) Fundamentos de marketing. México: Pearson Educación, 2003.

Kotler, P., Kartajaya, H. (2010). Marketing 3.0. LID Editorial, 2010.

GOODSTEIN, Leonard. NOLAN, Timothy. PFEIFFER, William J. Planeación Estratégica Aplicada. Editorial Mc Graw Hill. Bogotá D.C. 2005.

MINTZBEG, Henry. La caída y ascenso de la Planeación Estratégica. Harvard Bussiness Review, Canadá. 2005.

PORTER, Michael. Ser Competitivo. Ediciones Deusto. Barcelona 2009.

SERNA, Gómez, Humberto. Gerencia Estratégica. 3R Editores. Séptima Edición. Bogotá D.C. 2000.

Sallenave, Paul Jean. Gerencia y Planeación Estratégica. Editorial Norma 2004.

Guía de los Fundamentos para la Dirección de Proyectos (Guía del PMBOK -4ta Edición), UPC, Lima 2010.

Álvarez Torres, Martin. Manual de Planeación Estratégica. Panorama Editorial. México 2006.

David, F. R. Conceptos de Administración Estratégica, 9a edición. México,Pearson Educación, 2003.

Redactora Marcela Mendoza del Diario El Comercio (2015). "Las apps de pago no tienen espacio para crecer en el Perú". 20.05.2018. Sitio Web : Fuente:

https://elcomercio.pe/economia/peru/apps-pago-espacio-crecer-peru-188099

Redactor del Diario Gestion (2018). Una tendencia que crece sobre ruedas. 04/04/2018.

Sitio web : https://gestion.pe/especial/50-ideas-de-negocios/noticias/food-truckstendencia-sobre-ruedas-noticia-1992335 
Redactora de la BBC Lucy Burton (2012). Food trucks rev-up fast food. 04/04/2018. Sitio web: http://www.bbc.com/news/av/business-20094042/food-trucks-rev-up-fastfood

Redactor del Diario Gestion (2017). Casi 2 millones de peruanos realizan sus compras online desde su celular. 04/05/2018. Sitio web : https://gestion.pe/tendencias/2millones-peruanos-realizan-compras-online-celular-143284

Redactor del Diario Gestión (2017). BCP recorta estimado de crecimiento económico en Perú desde 4.2\% hasta 3.5\% para el 2018. 04/05/2018. Sitio Web:

https://gestion.pe/economia/bcp-recorta-estimado-crecimiento-economico-peru-4-2hasta-3-5-2018-226008

Redactora Catherine Contreras del Diario El Comercio (2017). Balance gastronómico 2017: Alimentar el 'post-boom'. 04/05/2018. Sitio Web:

https://elcomercio.pe/gastronomia/peruana/ano-2017-gastronomia-balance-gastronomianoticia-485102

Redactor del Diario Perú 21 (2018). El desempleo en Lima se incrementa en 7.3\%. 04/05/2018. Sitio Web: https://peru21.pe/economia/desempleo-lima-tasa-sube-7-3enero-2018-395983

Redactor del Tele Sur (2017). Situación económica y social de Perú a un año del Gobierno de Kuczynski. 04/05/2018. Sitio Web:

https://www.telesurtv.net/news/Situacion-economica-y-social-de-Peru-a-un-ano-deKuczynski-20170727-0066.html

Redactor del INEI (2015). El 33\% del gasto en alimentos de los peruanos son realizados fuera del hogar. 04/05/2018. Sitio Web: https://www.inei.gob.pe/prensa/noticias/el-33del-gasto-en-alimentos-de-los-peruanos-son-realizados-fuera-del-hogar-8539/

Redactor del Diario El Comercio (2015). San Isidro: vecinos protestan contra Food Trucks. 04/05/2018. Sitio Web: https://elcomercio.pe/whatsapp/sucesos/san-isidrovecinos-protestan-food-trucks-fotos-389217

Redactor del Diario La República (2017). Tendencias del mercado de lo natural. 04/05/2018. Sitio Web: http://larepublica.pe/marketing/860310-tendencias-delmercado-de-lo-natural

Redactor del Diario Gestión (2018). Penetración de smartphones en Perú casi se triplicó en últimos cuatro años. 04/05/2018. Sitio Web:

https://gestion.pe/economia/empresas/penetracion-smartphones-peru-triplico-ultimoscuatro-anos-225607

Boletín del Sistema de Naciones Unidas en el Perú (2014). LA ONU Y LA COP 20. 04/05/2018. Sitio Web: http://onu.org.pe/wpcontent/uploads/2014/04/Bolet\%C3\%ADn-COP20.pdf 
Redactor del Diario El Comercio (2016). La planta de reciclaje más grande del país abrió sus puertas. 04/05/2018. Sitio Web: https://elcomercio.pe/lima/planta-reciclajegrande-pais-abrio-puertas-239732

Entrevista a Javier Alvarez para Peru Retal (2017). El ecommerce en el Perú crecería un 16\% para el 2018. 04/05/2018. Sitio Web : https://www.peruretail.com/entrevista/ecommerce-peru-creceria-para-2018/

Redactora Pamela Flores del Diario El Comercio (2017). "Perú: La evolución del ecommerce". 04/05/2018. Sitio Web : https://elcomercio.pe/economia/dia-1/peruevolucion-e-commerce-pamela-flores-noticia-478969

Redactora Marcela Mendoza del Diario El Comercio (2015). "Las apps de pago no tienen espacio para crecer en el Perú". 20/05/2018. Sitio Web :

https://elcomercio.pe/economia/peru/apps-pago-espacio-crecer-peru-188099

Redactor del Diario La República (2017). "COCINAS SOBRE RUEDAS: EL BOOM DE LOS FOOD TRUCKS EN LIMA”. 10/05/2018 Sitio Web:

https://larepublica.pe/marketing/848679-cocinas-sobre-ruedas-el-boom-de-los-foodtrucks-en-lima

Arellano Marketing Investigación y Consultoría (2017) 10/05/2017. Sitio Web: http://www.arellanomarketing.com/inicio/

Redactor del Diario La República (2015). El negocio y apuesta de los food trucks en Mistura 2015. 10/05/2018 Sitio Web: https://larepublica.pe/sociedad/700028-elnegocio-y-apuesta-de-los-food-trucks-en-mistura-2015

Diario el Comercio. Riesgo País (2018) 06/06/2018. Sitio Web:

https://elcomercio.pe/economia/peru/riesgo-pais-peru-region-noticia-512673

Como hallar el Long term rate treasury us Bonds (>10years), (sf). 06/06/2018. Sitio Web: https://www.treasury.gov/resource-center/data-chartcenter/interestrates/Pages/TextView.aspx?data=longtermrate

Sunat, Importe de UIT actual (2018), 06/06/2018. Sitio Web: http://www.sunat.gob.pe/indicestasas/uit.html 


\section{ANEXOS}

\section{ENCUESTAS REALIZADAS}
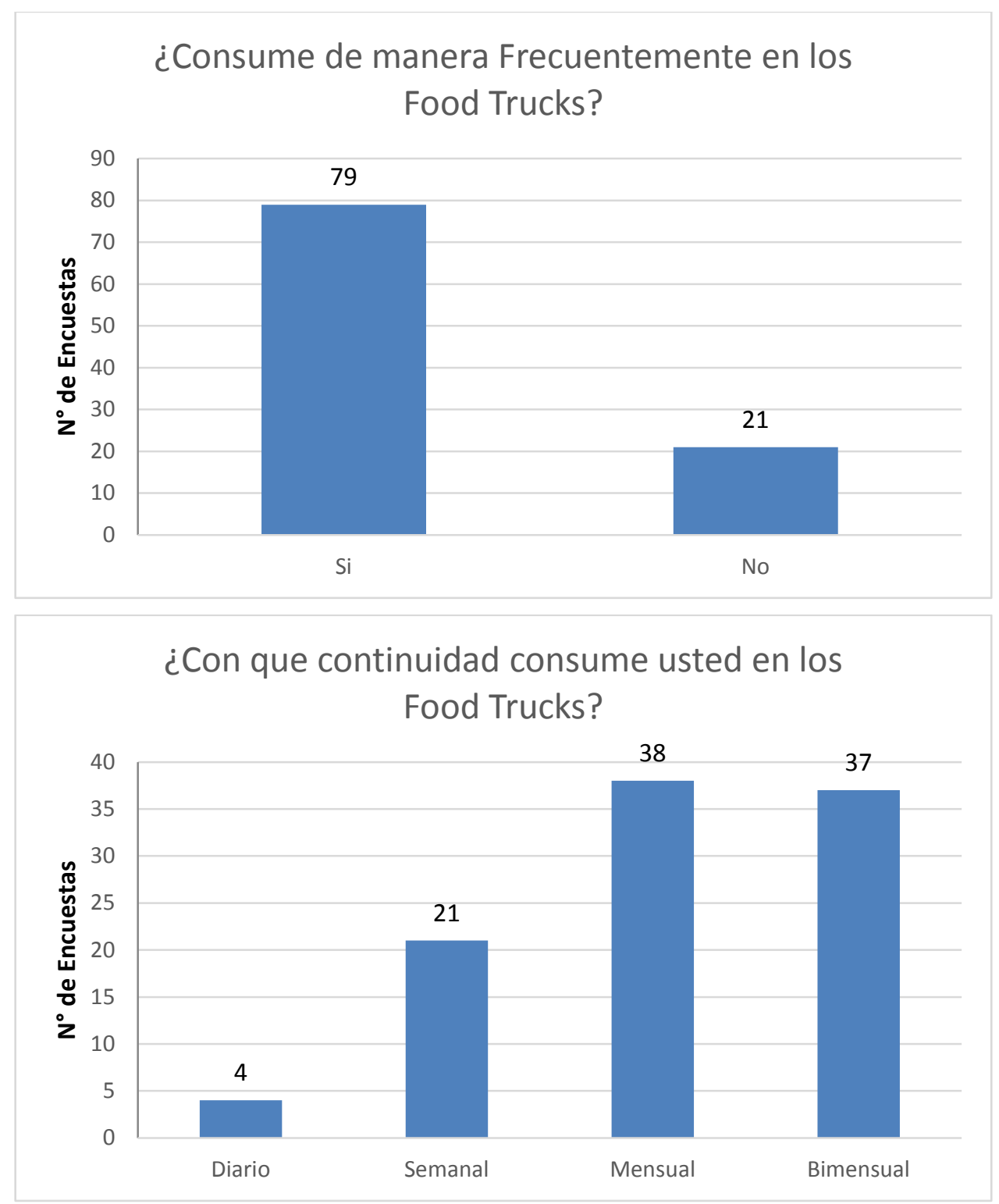
¿Cuál es el distrito donde mas consume en un Food Trucks?
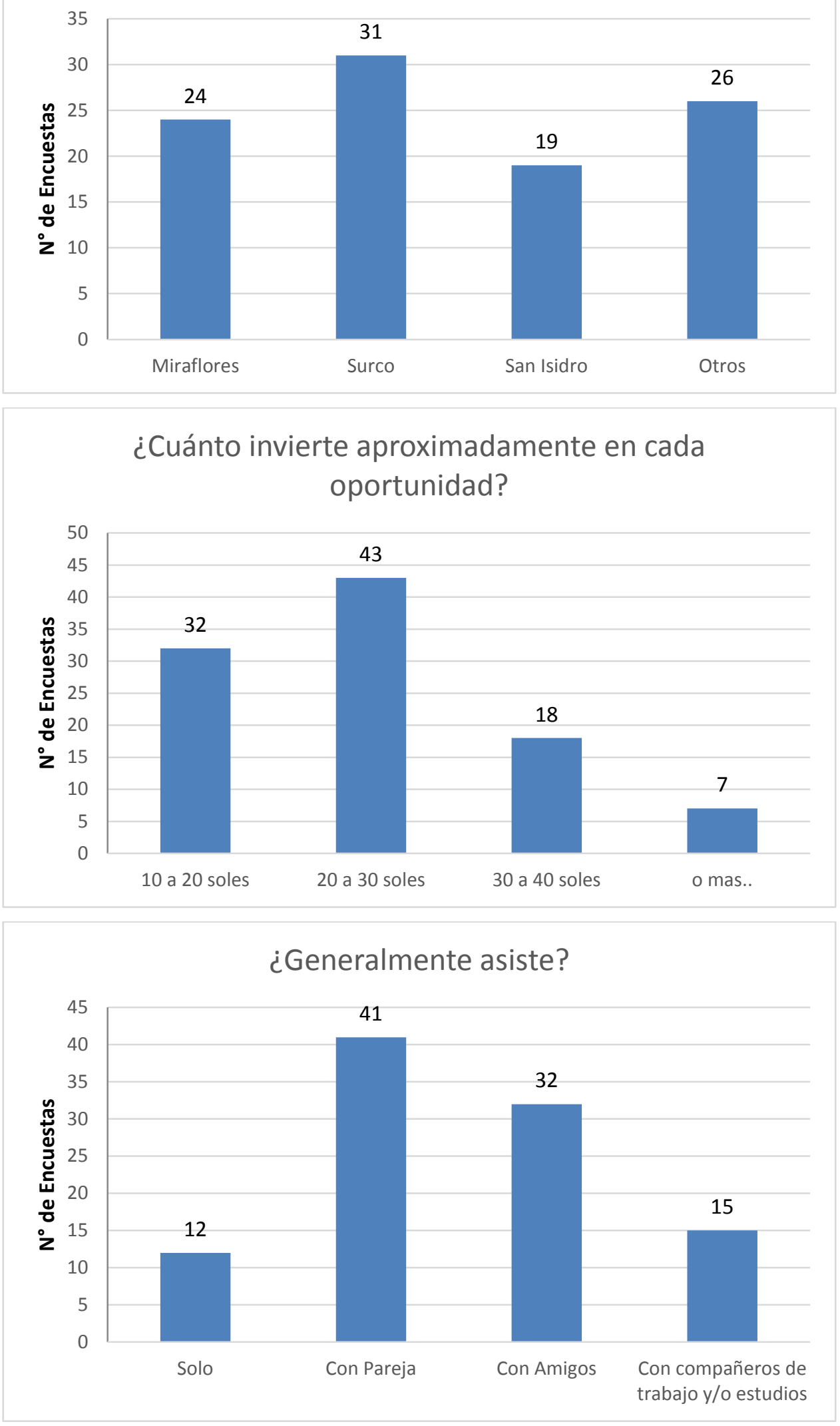
¿Qué característica es más importante para usted para comprar en un Food Trucks?
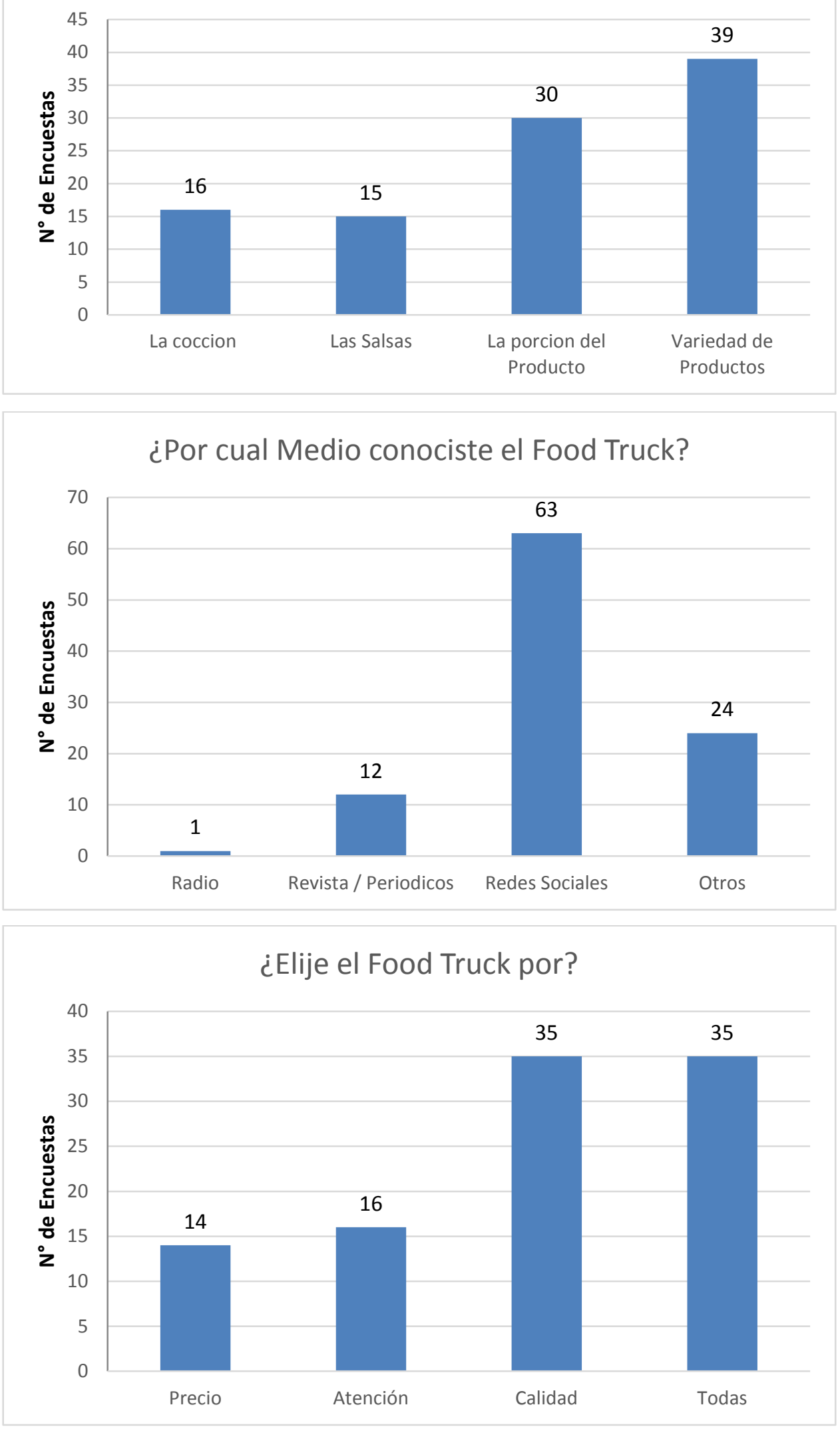